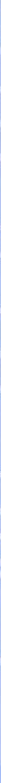

Routledge Advances in Sociology

\title{
INTERGENERATIONAL FAMILY RELATIONS
}

\section{AN EVOLUTIONARY SOCIAL SCIENCE APPROACH}

Antti O. Tanskanen and Mirkka Danielsbacka

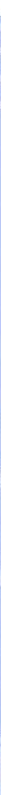




\section{Intergenerational Family Relations}

This book offers a synthesis of social science and evolutionary approaches to the study of intergenerational relations, using biological, psychological and sociological factors to develop a single framework for understanding why kin help one another across generations. With attention to both biological family relations and in-law and step-relations, it provides an overview of existing studies centred on intergenerational relations - particularly grandparenting - that incorporate social science and evolutionary family theories. This evolutionary social science approach to intergenerational family relations goes well beyond the traditional nature versus nurture distinction. As such, it will appeal to scholars across a range of disciplines with interests in relations of kinship, the lifecourse and the sociology of the family.

Antti O. Tanskanen is Senior Researcher in the Department of Social Research at the University of Turku, Finland.

Mirkka Danielsbacka is Senior Researcher in the Department of Social Research at the University of Turku, Finland. 
"This book is of interest to all family scholars but in particular those scientists seeking to understand better the complexities of intergenerational relations. The real pleasure in reading this book is that it challenges one's traditional thinking about intergenerational relations. I strongly recommend it to all family scholars but particularly those seeking new ideas."

- Ann Buchanan, Professor Emeritus, Department of Social Policy and Intervention, University of Oxford, UK

"In a rapidly ageing world, the contributions that grandparents make to children, and the pleasures that they derive from making those contributions, are hot topics of research and discussion in the social sciences. In this timely review and synthesis of what anthropologists, demographers, evolutionary biologists, historians, psychologists and sociologists have separately discovered about grandparents, Tanskanen and Danielsbacka provide an invaluable resource for workers in all these fields, as well as for those struggling to bring evidence-based practice to social work and other applied areas."

- Martin Daly, Professor Emeritus, Department of Psychology, Neuroscience and Behaviour, McMaster University, Canada

"It is only fitting that social scientists from the homeland of Westermarck should be the first to blend biological and social science approaches to the study of intergenerational relations and the family. Tanskanen and Danielsbacka show how theories from social science and biology are complementary and can be seamlessly blended together to organize and explain findings from the study of intergenerational relations, plus generate new hypotheses for further studies. A must read for anyone with an interest in the study of intergenerational relations and the family."

- Rosemary L. Hopcroft, Professor, Department of Sociology, University of North Carolina, USA

"This ambitious book provides an inclusive synthesis concerning studies on intergenerational relations among humans. Reading this book will strongly benefit all biologists and social scientists working with family relations."

- Virpi Lummaa, Professor, Department of Biology,

University of Turku, Finland 


\section{Routledge Advances in Sociology}

For a full list of titles in this series, please visit www.routledge.com/series/SE0511

\section{Social Generativity}

A Relational Paradigm for Social Change

Edited by Mauro Magatti

The Live Art of Sociology

Cath Lambert

\section{Video Games as Culture}

Considering the Role and Importance of Video Games in Contemporary Society

Daniel Muriel and Garry Crawford

The Sociology of Central Asian Youth

Choice, Constraint, Risk

Mohd. Aslam Bhat

\section{Indigenous Knowledge Production}

Navigating Humanity within a Western World

Marcus Woolombi Waters

Time and Temporality in Transitional and Post-Conflict Societies

Edited by Natascha Mueller-Hirth, Sandra Rios Oyola

\section{Practicing Art/Science}

Experiments in an Emerging Field

Edited by Philippe Sormani, Guelfo Carbone and Priska Gisler

The Dark Side of Podemos?

Carl Schmitt's Shadow in Progressive Populism

Josh Booth and Patrick Baert

Intergenerational Family Relations

An Evolutionary Social Science Approach

Antti O. Tanskanen and Mirkka Danielsbacka

Performing Fantasy and Reality in Contemporary Culture

Anastasia Seregina 


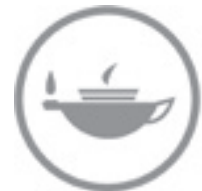
Taylor \& Francis Taylor \& Francis Group http://taylorandfrancis.com 


\title{
Intergenerational Family Relations
}

An Evolutionary Social Science Approach

\author{
Antti O. Tanskanen and \\ Mirkka Danielsbacka
}

(2) $\begin{aligned} & \text { Routledge } \\ & \text { Taylor \& Francis Group } \\ & \text { LONDON AND NEW YORK }\end{aligned}$ 
First published 2019

by Routledge

2 Park Square, Milton Park, Abingdon, Oxon OX14 4RN

and by Routledge

711 Third Avenue, New York, NY 10017

Routledge is an imprint of the Taylor \& Francis Group, an informa business

(C) 2019 Antti O. Tanskanen and Mirkka Danielsbacka

The right of Antti O. Tanskanen and Mirkka Danielsbacka to be identified as authors of this work has been asserted by them in accordance with sections 77 and 78 of the Copyright, Designs and Patents Act 1988.

The Open Access version of this book, available at www.taylorfrancis.com, has been made available under a Creative Commons Attribution-Non Commercial-No Derivatives 4.0 license.

Trademark notice: Product or corporate names may be trademarks or registered trademarks, and are used only for identification and explanation without intent to infringe.

British Library Cataloguing-in-Publication Data

A catalogue record for this book is available from the British Library

Library of Congress Cataloging-in-Publication Data

A catalog record has been requested for this book

ISBN: 978-1-138-09187-0 (hbk)

ISBN: 978-1-315-10780-6 (ebk)

Typeset in Times New Roman

by Deanta Global Publishing Services, Chennai, India 


\section{Contents}

List of figures viii

List of tables $\quad$ ix

List of boxes $\quad x$

Foreword xi

Preface xiv

1 Cooperative breeding species 1

2 Theories on intergenerational relations $\quad 12$

3 Structure of intergenerational relations 49

$4 \quad$ Factors related to intergenerational relations 63

$5 \quad$ Grandparents and parental childbearing $\quad 87$

6 Grandparents and child wellbeing $\quad 100$

$\begin{array}{lll}7 & \text { Grandparent wellbeing } & 120\end{array}$

$\begin{array}{lll}8 & \text { What about aunts and uncles? } & 135\end{array}$

$\begin{array}{lll}9 & \text { An evolutionary social science approach } & 147\end{array}$

$\begin{array}{lr}\text { Index } & 159\end{array}$ 


\section{Figures}

3.1 Life expectancy in selected countries 52

3.2 Child-parent-grandparent relationships from the child's perspective 54

3.3 Grandparent-child-grandchild relationships from grandparents' perspective 55

3.4 Biological and non-biological intergenerational family relationships 56

3.5 (a) Family types in which mothers have children with different partners. (b) Family types in which fathers have children with different partners

3.6 Family types when mothers have a stepparent (example in the figure considers maternal grandfather's step-relatedness to a grandchild)

3.7 Family types when mothers have foster or adoptive parents (example in the figure considers maternal grandparents' relatedness to a grandchild)

3.8 Family types when children have foster or adoptive parents $\quad 60$

8.1 Relatedness among aunts, uncles, parents and niece/nephew $\quad 136$

8.2 Relatedness among aunt, uncle, parents and niece/nephew when maternal aunt and paternal uncle are monozygotic twins to mother and father

8.3 Relatedness among aunts, uncles, parents and niece/nephew when aunts and uncles are half-siblings to mother and father 


\section{Tables}

2.1 Degree of genetic relatedness between the self and kin 19

2.2 Key evolutionary predictions for biased grandparental investment 22

2.3 Key social science predictions for biased intergenerational relations 28 


\section{Boxes}

1.1 Intergenerational relations 2

1.2 Grandparental investment 4

$\begin{array}{lll}1.3 & \text { Naturalistic fallacy } & 6\end{array}$

2.1 Ultimate reasons and proximate mechanisms 13

2.2 Conscious and unconscious motives behind $\begin{array}{ll}\text { human behaviour } & 15\end{array}$

$\begin{array}{ll}2.3 & \text { Inclusive fitness theory } \\ & 18\end{array}$

2.4 Parental investment theory 20

2.5 Grandparental endowment 35 


\section{Foreword}

Intergenerational family relations: An evolutionary social science approach covers a gambit of hot topics across the social and natural sciences that have direct implications for understanding family function, relationships and outcomes. In recent decades, dramatic demographic changes have pushed the issues of intergenerational exchange and intergenerational relations to centre stage in policy, service and academic debate. Increased shared lifespans between generations, reduced birth rate, and increased individual wealth and investment per child mean that generations have more opportunities to influence each other than ever before in human history. Simultaneously, recent reductions in state investment, increased rates of divorce and gender biases in rates of remarriage mean families are increasingly diverse. These times of change have seen the value of families and their relationships increase. Intergenerational family relations makes a valuable contribution to this burgeoning field of enquiry.

Crucial to a comprehensive view of the myriad factors that impact on and are consequences of family relations is a multi-level, interdisciplinary approach. Intergenerational family relations successfully achieves this by introducing the reader to an interdisciplinary perspective that takes them from broad population, historical and evolutionary level analyses to detailed differences in dyadic relationships between family members. This enables the authors to critically explore questions related to why grandparenting exists, and the health impact grandparenting may or may not have on family members, parental birth rates and grandchild development, the influence of the welfare state, and the roles of aunts and uncles.

It is a privilege for me to write this foreword as I have known Mirkka and Antti personally for the last five years and have followed their research closely. I had the honour of examining Mirkka's Doctoral thesis and have been lucky enough to host Mirkka and Antti at Edith Cowan University as Visiting Research Fellows on two occasions. Although relatively early in their careers, they have published extensively, exploring intergenerational relations and grandparents in particular. They have two distinct aspects to their research that I admire and are clearly on display in this book. First, as I will expand on below, they synthesise theoretical concepts across disciplines to improve our understanding of the family. Second, they continuously utilise large, where possible longitudinal, nationally representative, population data sources to produce high-quality empirical investigations. 
Indeed, in line with the current momentum in the field, there are sections in this book where the data and analyses are strong enough to critically evaluate causal pathways in the extant literature. Together these skills place them in an ideal position to write Intergenerational family relations.

Over the last 15 years my research has promoted the development of interdisciplinary perspectives on intergenerational relations, with a particular focus on the different roles grandparents play and how they impact family functioning, grandchild development and the health of the grandparents themselves. This interdisciplinary perspective has brought together empirical and theoretical work across the disciplines of sociology, evolutionary ecology, psychology and economics. Therefore, it is not surprising that I personally found the theoretical work in this book to be one of its more outstanding features. Throughout most chapters, and particularly in Chapters 2 and 9, both the social science and evolutionary perspectives have been extended and synthesised. The evolution theory that has been reviewed previously has been extended to include kin detection, resource competition and reproductive conflict. Moreover, the extensive treatment of theoretical perspectives from the social sciences, which have often been neglected in the interdisciplinary literature, gives them a clearer voice.

At the broadest level, Intergenerational family relations advances the work of bringing together two traditionally disparate disciplines: social sciences and evolutionary perspectives. It must be noted that interdisciplinary research is not a job for the faint-hearted. It requires the constructive synthesis of disciplines that often see the world from fundamentally different perspectives. On the one hand there are important methodological and theoretical differences between the disciplines that should be preserved. These differences give the disciplines the unique vision and identity that made them attractive to researchers. What needs to be addressed are the barriers between these disciplines and recognition that these views are operating at different, ultimately compatible, levels of explanation. Through a more detailed treatment of the diverse social science perspectives on intergenerational relations, a clearer understanding should facilitate more equitable synthesis across disciplines. Therefore, the second aim of this book, namely to synthesise research and theory across social science and evolutionary fields, is up to date, and crucially expands the representation and inclusion of social science. Chapter 9 caps this endeavour by developing testable hypotheses that expressly combine social science and evolutionary perspectives that will be valuable for both current and future scholars.

Grandparents are things of folklore and wonder for grandchildren. For many people, even as adults, their most salient early memories were spent with their grandparents and other family members. Throughout time human families and societies have depended on the intergenerational transfer of knowledge, help and affection. In most societies, elders, and specifically grandparents, hold those resources and transmit them to future generations. Through this pivotal role, grandparents have ensured their families and communities have thrived for millennia. Intergenerational family relations: An evolutionary social science approach provides a critical, contemporary update and extension of this research 
programme, culminating in a research guide for those brave souls who want to pursue interdisciplinary family research.

- David A. Coall, Senior Lecturer, School of Medical and Health Sciences, Edith Cowan University,

Western Australia.

\section{Latest publication}

Coall, D. A., Hilbrand, S., Sear, R., \& Hertwig, R. (2018). Interdisciplinary perspectives on grandparental investment: A journey towards causality. Contemporary Social Science, 13. https://doi.org/10.1080/21582041.2018.1433317 


\section{Preface}

Our careers as intergenerational and family relations scholars began almost accidentally around a decade ago. At that time, we were both postgraduate students preparing our PhDs on very different topics: Antti was working on employment relationships and Mirkka on war history. The reason for beginning to study family and intergenerational relations was the opportunity to work on the Generational Transmissions in Finland project, examining social relations among Finnish Baby Boomers (born between 1945 and 1950) and their adult children. We are extremely thankful to the project leader at the time, J. P. Roos, as well as Elina Haavio-Mannila and Anna Rotkirch, who warmly welcomed us into the project. After all these years, the project is still running, and we are currently (in February 2018) preparing the third round of data collection.

From the very beginning, one of the unique aspects of the Generational Transmissions in Finland project has been its interdisciplinary nature, meaning that knowledge from different fields of study is combined. The human family is approached as a context-sensitive biosocial institution based on kin relationships extending beyond the nuclear family. In this sense, social science and evolutionary approaches are seen as complementary rather than mutually exclusive. This is also the approach adopted in this book, which combines theories and findings from different fields, including anthropology, biology, demography, economics, psychology and sociology.

Several people have influenced this book. We would like to thank the intergenerational relations scholars from different disciplines whose work has made it possible to write the current synthesis. Several colleagues have contributed to this volume by reading and commenting on earlier manuscript drafts. They are Venla Berg, Ann Buchanan, Simon N. Chapman, David A. Coall, Jani Erola, Mirkka Lahdenperä, Jenni E. Pettay, Anna Rotkirch and Heikki Sarmaja. We are deeply grateful for their effort, which has helped us to substantially improve the book. However, it goes without saying that we are responsible for all the flaws and mistakes present in the book. It would have been impossible to write this book without funding. We gratefully acknowledge the financial support provided by the Kone Foundation and Sociology Unit at the University of Turku. Additional funding was provided by the Association of Finnish Non-fiction Writers. 
In addition, we are much obliged to Markus Jokela and Anna Rotkirch, who have co-authored several articles related to family and intergenerational relations with us during the years. Their support and guidance have been indispensable.

Finally, we wish to dedicate this book to the memory of our beloved paternal grandmothers, Ruth Tanskanen and Eeva Danielsbacka, who were always there for us during our childhood.

Antti O. Tanskanen and Mirkka Danielsbacka 


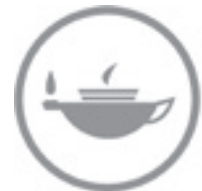
Taylor \& Francis Taylor \& Francis Group http://taylorandfrancis.com 


\section{Cooperative breeding species}

The idea that several people in a community participate in childrearing was popularised by Hillary Clinton in her bestselling book, It Takes a Village and Other Lessons Children Teach Us (1996). The phrase "It takes a village to raise a child" captures one key aspect of human family life. Humans are a cooperative breeding species, meaning that individuals other than the biological mother tend to be involved in childrearing (Hrdy, 1999, 2009). In biology, these others are called "allomothers", and depending on the living conditions and environment, they may include several different types of relatives, friends, neighbours or formal child care providers (Daly \& Perry, 2017; Perry \& Daly, 2017). Cooperative breeding is a species-typical means of childrearing in humans as well as certain other animals. Based on current knowledge, approximately 3 per cent of mammals (e.g., African wild dogs, Kalahari meerkats, naked mole-rats), less than 10 per cent of birds, and some fish are cooperative breeders (e.g., Desjardins et al., 2007; Jennions \& Macdonald, 1994; Jetz \& Rubenstein, 2011). Humans are an exception compared to other great apes; for instance, among chimpanzees, gorillas and orangutans, our closest living relatives, the mother alone is almost always responsible for childrearing (Hrdy, 2007).

Why does cooperative breeding exist in the human species? Studies from huntergatherer populations may provide one answer to this question if we assume that these populations follow fairly similar ways of life as populations that have lived in the human environment of evolutionary adaptedness. According to evidence from three contemporary hunter-gatherer populations, human children consume 13 million calories more than they produce until they reach adulthood (Kaplan, 1994). The extra calories are needed because large brains take a long time and require considerable energy to develop, which leads to long childhood dependency. According to evolutionary anthropologists, cooperative breeding systems may have enabled human children to enlarge their brain size at great cost (Hrdy, 2007). In practice, large brains and cooperative breeding have likely co-evolved.

In the animal kingdom, larger brain size is typically associated not only with an increased length of childhood dependency but also with longer birth intervals among females (Isler \& van Schaik, 2012). When a previous descendant is dependent on constant maternal care, the possibility of having another child is substantially decreased. Thus, one can assume that human females should have 


\section{Cooperative breeding species}

extremely long birth intervals. Interestingly, and in contrast to this prediction, evidence shows that human females tend to have quite low birth intervals compared with other great apes. Using data from hunter-gatherer populations, evolutionary anthropologists have found that in natural fertility populations, human females tend to give birth approximately every three years, whereas among orangutans, the birth interval is approximately eight years, and among chimpanzees, it is from five to six years (Kaplan et al., 2000). Cooperative breeding systems may provide a solution to the puzzle of how to increase brain size without excessively decreasing fertility (Isler \& van Schaik, 2012).

Although there are several common features in the family life of humans and other species, human life histories have at least four distinctive characteristics compared to other primates and mammals: 1) an exceptionally long lifespan, 2) an extended period of dependent childhood, 3) support of reproduction by older post-reproductive females and 4) male investment in their descendants (Kaplan et al., 2000). These aspects of human family life are all considered in the current book. We began our interdisciplinary examination of intergenerational relations (Box 1.1) on the species-typical childrearing system, cooperative breeding, and its meaning for human family formation. We now present the key institutional changes in recent decades that have influenced intergenerational relations.

\section{Box 1.1 Intergenerational relations}

In this book, intergenerational relations mean relations between family generations. The three family generations studied are grandparents, parents and children. Intergenerational relations between family generations may denote a direct relationship and interaction between two generations or a more complex relationship in which, for instance, the middle generation (parents) mediates the relationship between the grandparents and grandchildren. When other intergenerational relations are considered, the obvious focus is aunts and uncles, who are considered later in this book.

\section{Grandparents: More important than ever?}

One of the most important trends in the Western world after the Second World War has been the shift in which welfare responsibilities have been transferred from family members to the state (Esping-Andersen, 1990, 2009). After this change, the wellbeing of individuals was no longer as crucially dependent on family support. Some social scientists have argued that because of the processes of modernisation and individualisation, the meaning of family relations has substantially diminished or become meaningless (e.g., Beck, 1992; Giddens, 1991). 
However, empirical studies have shown that this is not the case. Although the societal meaning of the family has diminished in welfare states as public support providers have taken on tasks that formerly belonged to kin, people still develop close and significant family relations, and there is no evidence that the emotional importance of these ties has substantially diminished (Salmon \& Shackelford, 2011).

As populations in the Western world age rapidly, intergenerational family relations may become even more important. Due to increased life expectancy in Western societies, the proportion of elderly adults and the total number of grandparents (or potential grandparents) are rising. Currently, grandparents and grandchildren have more shared years of life than ever before. Due to decreased fertility rates in modern Western countries, grandparents today have fewer grandchildren, which means that they may be able to invest more resources in any particular grandchild. Thus, grandparents have a great opportunity to influence the lives of their adult children and grandchildren. The growing possibilities for interaction among different family generations in current societies also mean that these relations tend to have a great deal of policy relevance.

Despite this situation, Western social and family policies typically consider the family a nuclear family that includes a mother, a father and a child or children. The normative nuclear family model ignores the fact that human family structures are flexible and include people outside the nuclear family who are highly committed to improving the wellbeing of dependent children. Thus, when planning social and family policies, it is worthwhile to consider that humans have a predisposition to raise children in cooperative networks. In these networks, grandparents are often the ones who tend to invest a high amount of time and resources in their descendants. For instance, based on a multinational European survey, 58 per cent of grandmothers and 49 per cent of grandfathers with grandchildren younger than 14 years old provide child care to them at least occasionally (Hank \& Buber, 2009). According to the UK evidence, 44 per cent of toddlers are looked after by their grandparents on a weekly basis or more often (Fergusson et al., 2008).

Grandparental investment (Box 1.2) includes not only child care but the many different types of support that grandparents channel towards their descendants. Obviously, it is not only the quantity but also the quality of the investment that matters. Kin arrangements are known to provide more stable foster care places for children than non-kin arrangements, and grandparents tend to have the most important role as foster carers (Perry et al., 2014). However, in public policies, the investment by extended kin is not always recognised. In several countries, grandparents have few, if any, legal rights in relation to their grandchildren (Buchanan, 2017; Rotkirch \& Buchanan, 2016). For instance, the lack of visiting rights is a common feature in Western countries, meaning that after parental divorce, grandparents may completely lose contact with their grandchildren. This phenomenon may have negative implications for both grandchildren and grandparents, who may highly value close relations with one another. 


\section{Box 1.2 Grandparental investment}

"Grandparental investment" is used here as a general term for all conscious and unconscious investments grandparents make in their grandchildren, directly or indirectly via the grandchildren's parents. These investments may include being in contact and spending time with grandchildren as well as giving them money, emotional support, care and practical help. Thus, although the term investment sounds like an economic term, it refers to a much wider range of forms of support, not merely the financial support that grandparents may allocate to their descendants. In social science studies, the term "grandparental involvement" is often used to refer to active grandparenting. In practice, studies using the terms "grandparental involvement" and "grandparental investment" have often used the same measurements for these two concepts (e.g., grandparental child care, contact frequency, emotional closeness and financial transfers). Thus, the concepts of grandparental involvement and grandparental investment can be defined to mean basically the same phenomenon.

\section{The problem of intradisciplinarity}

When we examine the previous research on intergenerational family relations, a clear trend becomes apparent: these studies are surprisingly often intradisciplinary in nature, meaning that scholars tend to work within only one specific discipline. Here, the term "intradisciplinary" specifically refers to the fact that evolutionary scientists often tend to ignore social science studies and vice versa. Coall and Hertwig (2011) conducted an intensive literature review of grandparental investment studies and investigated how often sociologists and evolutionary researchers cite one another's works. By the year 2009, the most frequently cited sociology article was written by Bengtson and Roberts (1991), which was cited a total of 132 times; however, only three of these citations were by evolutionary scholars. The most frequently cited evolutionary article was a paper by Hawkes and colleagues (1998), which was cited a total of 216 times but only four times among sociologists.

Our starting point for this book is that intergenerational relations research should be interdisciplinary, meaning that knowledge, terminology and methodologies from different disciplines are integrated. Interdisciplinarity is needed because the lack of dialogue between disciplines has had detrimental effects on the cumulative progress of the study of family relations (Coall \& Hertwig, 2010).

\section{Social science and evolutionary approaches}

This book brings together research from several different disciplines, namely, anthropology, biology, demography, economics, psychology and sociology. We separate these different disciplines beneath two "umbrellas": evolutionary 
and social sciences. Evolutionary science here refers to all studies that explicitly consider humans as products of natural selection. These studies are most often conducted in the fields of evolutionary anthropology, biology and psychology. Social science research, by contrast, includes studies typically conducted in the fields of social anthropology, demography, economy, (mainstream) psychology and sociology. Obviously, the division between evolutionary and social science studies is not completely rigid. Furthermore, there may be substantial differences in content within the two groups. In the case of evolutionary studies, for instance, evolutionary psychologists may concentrate on different issues than evolutionary demographers. With regard to social science research, sociologists often study somewhat different issues than psychologists, who in turn investigate different issues than those studied by anthropologists. However, in this book, the most important division exists between studies that adopt an evolutionary approach and those that do not. For this reason, we use the abovementioned division between the study fields.

The present book continues the fruitful discussion and interaction between the evolutionary and social science disciplines that has been gradually developing in recent years (e.g., Coall \& Hertwig, 2010; Hopcroft, 2010; Rotkirch, 2018; Turner et al., 2015) by erasing the division between disciplines and promoting the cumulative progress of the science of human behaviour. These approaches have been given several names, including "biosociology", "evolutionary sociology" and "evolutionary family sociology" (e.g., Hopcroft, 2016a; Walsh, 2014). In the current book, we have decided to use the term "evolutionary social science" because of its broader range (see also Turner et. al., 2015). Our reason for not using terms such as "biosociology" or "evolutionary sociology" is that the social sciences include not only sociology but also anthropology, demography, psychology and economics; thus, it would be misleading to use only the term sociology. The term "evolutionary social science" refers to the fact that, in this book, the results of several social science disciplines are taken into consideration. The purpose is to present an interdisciplinary view of intergenerational family relations.

\section{Why were prior studies intradisciplinary?}

Evolutionary scientists have often ignored social science studies and vice versa, as discussed above. One important reason for the lack of dialogue between social and evolutionary scientists is the lack of a common language. The terminology used among scholars from different disciplines tends to reflect the prevailing paradigms in different fields, and individuals have a general tendency to evaluate new information according to how it fits with their current knowledge (i.e., the dominant paradigm) (Pronin, 2007). Because only a limited number of scholars have sufficient knowledge of both social science and evolutionary research, it has been difficult to bridge the gap between these approaches.

Evolutionary scholars may avoid or ignore social science research because they may consider social science studies to be complex and multidimensional by nature, and they may have difficulty identifying clear hypotheses and results in these studies. At first glance, it may seem that social science studies do not provide any 
added value for evolutionary scholars when social scientists provide, for instance, different conceptualisations of the forms of relationships among individuals from different family generations. However, this is not the case. Social scientists have, for instance, wide knowledge of the socioeconomic and institutional factors that may be related to the quality and quantity of intergenerational relations. For instance, welfare state arrangements as well as individuals' health and wealth are important factors that can be associated with the intergenerational transfers that are often investigated in the social science research. Moreover, in many cases, largescale social science data could substantially improve the investigations conducted by evolutionary scholars. Thus, we believe that evolutionary scholars could benefit by paying attention to social science studies much more than they may believe.

The reasons why evolutionary findings are often ignored in social science studies have been documented in several publications by scholars whose own academic roots are in sociology (e.g., Barkow, 2006; Hopcroft, 2016b; Sanderson, 2007; Segerstråle, 2000). According to these scholars, at least three common reasons for ignoring evolutionary findings can be identified: 1) a legacy of pseudo-biological views makes evolutionary theory unattractive (although these views have nothing to do with current evolutionary science); 2) the misconception that if something is natural it is also morally acceptable is apt to lead to the avoidance of evolutionary studies (although among evolutionary scientists, it is self-evident that although a certain behaviour has evolutionary roots, this does not mean that such behaviour is morally acceptable or should be encouraged; see Box 1.3 for the naturalistic fallacy); and 3) the belief that evolutionary science is deterministic leads some scholars to avoid it (although evolutionary researchers widely agree that biological evolution is a complex, dynamic and context-dependent historical process that produces a large amount of diversity).

\section{Box 1.3 Naturalistic fallacy}

The naturalistic fallacy refers to the assumption that if something is natural, it is also morally acceptable. This is a fallacy because regardless of whether a certain behaviour has evolutionary roots, it does not mean that the behaviour should be encouraged. For instance, it is widely accepted that humans have predispositions to nepotism; however, whether this tendency is seen as morally good or bad is related to the context and the way in which nepotistic efforts become apparent. Many people may think that when nepotistic efforts manifest as an investment in kin and help to keep small children alive, they can be morally supported. In contrast, when a company manager hires an incompetent relative rather than highly competent non-kin, people are likely to think this is morally unsustainable. Thus, it is important to understand that the question of whether a certain behaviour has evolutionary roots has nothing to do with its moral acceptability. If someone represents the opposite claim, she or he has posited a naturalistic fallacy. 
It is worth mentioning that the problem of ignoring studies from other fields does not exist only for evolutionary and social science scholars. Such disregard can even occur in studies that represent the same discipline, often because the division of fields of study has become increasingly nuanced. This does not mean that different fields or branches of study do not benefit from one another but rather that it is possible to publish research without taking into account the findings from closely related fields. For instance, there has been a division of intergenerational relations studies between family and stratification sociologists; family sociologists have analysed the factors related to grandparental involvement (e.g., Hank \& Buber, 2009), whereas stratification sociologists have been interested in whether the socioeconomic resources of grandparents benefit grandchildren in the long term (e.g., Mare, 2011). However, the factors that may increase or decrease grandparental involvement should be acknowledged by stratification scholars because grandparental involvement is a mechanism by which grandparents can transmit resources to their descendants. In addition, family sociologists can benefit from the results related to the outcomes of grandparental involvement that show whether grandparental involvement actually makes a difference. Thus, divisions within sociology may prevent the progress of intergenerational relations studies.

It is fair to say that the avoidance of studies from other disciplines is often based on misunderstandings, misconceptions and a lack of knowledge of the premises of the "other side". Whatever the reasons for evolutionary scholars to ignore studies by social scientists and vice versa, this disregard is scientifically unfruitful and prevents the development of knowledge about human behaviour. Despite the problem of intradisciplinarity, in recent years, there has been increasing discussion between the social science and evolutionary disciplines (e.g., Coall \& Hertwig, 2010; Sear, 2015). Thus, signs indicate progress towards interdisciplinarity in the research on intergenerational relations. We hope that in the future, the mutual neglect between social science and evolutionary studies, as described by Coall and Hertwig (2011), will be considered an odd part of history by researchers from both "sides".

\section{The aim of the book}

This book has three aims that are closely related to one another. First, the book provides answers to several theoretical and empirical questions, including the following: Why does caring grandparenthood exist among humans? Why do the four categories of grandparents (i.e., maternal grandmothers and grandfathers as well as paternal grandmothers and grandfathers) differ in their investment in their grandchildren? Why and how does genetic relatedness tend to shape intergenerational relations? How do socio-economic factors relate to kin support? Do grandparents provide more support in stronger than in weaker welfare states, or vice versa, and why? Does active grandparenting improve grandchildren's development, parental fertility or the wellbeing of grandparents themselves?

The second aim of this book is to provide a comprehensive synthesis of intergenerational family relations studies by combining theories and findings from 
social science and evolutionary studies. We hope that this synthesis helps to lower the boundaries between social and evolutionary scientists by showing how different perspectives can benefit one another. Third, combining the social science and evolutionary perspectives, we apply the evolutionary social science approach to intergenerational family relations and provide examples of how to form evolutionary social science hypotheses that can be used in future studies.

In this book, we mainly examine the intergenerational relationships among three family generations - grandparents, parents and children - and we mostly concentrate on the downward investments in Western societies. It is well known that older generations provide more support to younger ones than vice versa (e.g., Kohli et al., 2010), and existing studies more often measure downward than upward investment, especially in the case of grandparents and grandchildren (but see, e.g., Hoff, 2007). Hence, it is relevant to pay particular attention to downward investment. In addition, the focus is on studies conducted in Western societies. However, we have acknowledged studies investigating non-Western societies because they provide important reference points and help to put Western societies into perspective.

\section{A reader's guide to Intergenerational family relations}

This book is organised into nine chapters. As a whole, the book provides cumulative knowledge on intergenerational family relations, culminating in the final chapter, which introduces the evolutionary social science approach, which can be applied in future studies. The individual chapters are also independent entities and can be read as such or sequentially, depending on one's interests. In Chapter 1, we have provided the background for the book by presenting the cooperative breeding system, considering the key demographic changes related to intergenerational family relations, discussing the problem of intradisciplinarity in intergenerational relations research and introducing the aim of the book. Next, we briefly present the main content of the forthcoming chapters.

Chapter 2 considers the key theories and approaches related to intergenerational relations. First, we present the evolutionary theories behind kin altruism, namely, the inclusive fitness and parental investment theories. Then, we turn to the key evolutionary theories that seek to explain grandparental investment behaviour: reproductive value, paternity uncertainty, sex-specific reproductive strategies, sex-chromosome relatedness and resource competition. Second, we introduce the most important social science approaches to intergenerational relations and present models of intergenerational solidarity and intergenerational ambivalence, as well as the lifecourse approach. In this section, we present predictions derived from the kin keeper, parents as gatekeepers, same-sex dyad, intergenerational stake, and need and opportunity models. Finally, we discuss the similarities and differences between the evolutionary and social science approaches.

Chapter 3 focuses on the structure of intergenerational family ties. In this chapter, different family constellations and the historical changes related to them are discussed. Moreover, the demography of grandparenting is presented, with 
attention to both longer-term and more recent demographic changes. Family ties among grandparents, parents and children, which include relationships between biological and non-biological kin, are introduced. With regard to non-biological kin relations, in-law, step- and adoptive relations are considered. Finally, potential future changes in intergenerational relations are presented.

Chapter 4 introduces the empirical findings from studies related to intergenerational kin investments. First, the findings related to the biased investment of grandparents based on genetic relatedness, sex and lineage are considered. Next, we turn to socioeconomic and demographic factors, such as geographical proximity, health and wealth, which are shown to be associated with intergenerational kin investments. Finally, the role of welfare state institutions in shaping intergenerational relations is considered.

Chapter 5 focuses on the association between grandparental investment and fertility. The findings from traditional and historical populations and contemporary affluent societies are introduced. The findings are discussed with reference to evolutionary and social science theories that predict the effects grandparents may have on fertility.

Chapter 6 considers whether grandparents can improve children's wellbeing. First, studies that have been conducted in traditional and historical populations in which grandparents may have helped to keep small children alive are introduced. Second, studies that identify the correlation between grandparental investment and children's wellbeing in contemporary societies are reviewed. The chapter ends with a discussion of the limitations of the existing studies.

Chapter 7 considers whether grandparental investment is related to the wellbeing of grandparents themselves. First, the chapter evaluates whether grandparenthood (i.e., being a grandparent) is associated with the wellbeing of grandparents. Second, the potential outcomes of active grandparenting are considered among grandparents who are primary carers for their grandchildren, among grandparents living in three-generational households and among grandparents living separately from their grandchildren. The findings are discussed in terms of the potential evolutionary importance of the grandparental outcomes.

Chapter 8 concentrates on aunts and uncles, who share approximately the same amount of genes with their nieces and nephews as grandparents share with their grandchildren. In present-day Western societies, aunts and uncles do not usually live with one another (as opposed to grandparents), meaning that the investment of aunts and uncles towards their nieces and nephews is more independent of one another than the investment of grandmothers and grandfathers from the same lineage. This means that several kin investment hypotheses can be tested among aunts and uncles more reliably than among grandmothers and grandfathers. The factors associated with investments made by aunts and uncles (i.e., genetic relatedness, sex and lineage, as well as socio-economic and demographic characteristics) are introduced. Finally, the findings from social stratification studies are discussed.

Chapter 9 summarises the key findings related to the intergenerational relations that were reviewed in the earlier chapters. The pros and cons of these studies are discussed, with special attention to methodological issues. Most importantly, the 
evolutionary social science approach to intergenerational relations is formulated, and several hypotheses are provided. Thus, new avenues for intergenerational relations studies are developed.

\section{References}

Barkow, J. H. (2006). Introduction: Sometimes the bus does wait. In J. H. Barkow (Ed.), Missing the revolution: Darwinism for social scientists (pp. 3-60). Oxford: Oxford University Press.

Beck, U. (1992). The risk society. London: Sage.

Bengtson, V. L., \& Roberts, R. E. (1991). Intergenerational solidarity in aging families: An example of formal theory construction. Journal of Marriage and Family, 53, 856-870.

Buchanan, A. (2017). Changing roles of grandparents in the UK. In D. W. Shwalb \& Z. Hossain (Eds.), Grandparents in cultural context. London: Routledge.

Clinton, H. (1996). It takes a village and other lessons children teach us. New York: Simon \& Schuster.

Coall, D. A., \& Hertwig, R. (2010). Grandparental investment: Past, present, and future. Behavioral and Brain Sciences, 33, 1-59.

Coall, D. A., \& Hertwig, R. (2011). Grandparental investment: A relic of the past or a resource for the future? Current Directions in Psychological Science, 20, 93-98.

Daly, M., \& Perry, G. (2017). Matrilateral bias in human grandmothering. Frontiers in Sociology, 2. https://doi.org/10.3389/fsoc.2017.00011

Desjardins, J. K., Stiver, K. A., Fitzpatrick, J. L., Milligan, N., Van Der Kraak, G. J., \& Balshine, S. (2007). Sex and status in a cooperative breeding fish: Behavior and androgens. Behavioral Ecology and Sociobiology, 62, 785-794.

Esping-Andersen, G. (1990). The three worlds of welfare capitalism. Princeton, NJ: Princeton University Press.

Esping-Andersen, G. (2009). Incomplete revolution: Adapting welfare states to women's new roles. Cambridge: Polity Press.

Fergusson, E., Maughan, B., \& Golding, J. (2008). Which children receive grandparental care and what effect does it have? Journal of Child Psychology and Psychiatry, 49, 161-169.

Giddens, A. (1991). Modernity and self identity. Cambridge: Polity Press.

Hank, K., \& Buber, I. (2009). Grandparents caring for their grandchildren: Findings from the 2004 Survey of Health, Ageing, and Retirement in Europe. Journal of Family Issues, 30, 53-73.

Hawkes, K., O’Connell, J.F., Blurton Jones, N. G., Alvarez, H., \& Charnov, E. L. (1998). Grandmothering, menopause and the evolution of human life histories. Proceedings of the National Academy of Sciences, 95, 1336-1339.

Hoff, A. (2007). Patterns of intergenerational support in grandparent-grandchild and parent-child relationships in Germany. Ageing \& Society, 27, 643-665.

Hopcroft, R. L. (2010). Sociology: A biosocial introduction. London: Paradigm.

Hopcroft, R. L. (2016a). Grand challenges in evolutionary sociology and biosociology. Frontiers in Sociology, 1. https://doi.org/10.3389/fsoc.2016.00002

Hopcroft, R. L. (2016b). Evolution and gender: Why it matters for contemporary life. New York: Routledge.

Hrdy, S. B. (1999). Mother nature: A history of mothers, infants and natural selection. New York: Pantheon. 
Hrdy, S. B. (2007). Evolutionary context of human development: The cooperative breeding model. In C.A. Salmon \& T. K. Shackelford (Eds.), Family relationships: An evolutionary perspective (pp. 39-68). New York: Oxford University Press.

Hrdy, S. B. (2009). Mothers and others: The evolutionary origins of mutual understanding. Cambridge, MA: Harvard University Press.

Isler, K., \& Van Schaik, C. P. (2012). How our ancestors broke through the gray ceiling: Comparative evidence for cooperative breeding in early homo. Current Anthropology, 53, S453-S465.

Jennions, M., \& Macdonald, D. (1994). Cooperative breeding in mammals. Trends in Ecology and Evolution, 9, 89-93.

Jetz, W., \& Rubenstein, D. R. (2011). Environmental uncertainty and the global biogeography of cooperative breeding in birds. Current Biology, 21, 72-78.

Kaplan, H. (1994). Evolutionary and wealth flows theories of fertility: Empirical tests and new models. Population and Development Review, 20, 753-791.

Kaplan, H., Hill, K., Lancaster, J., \& Hurtado, A. M. (2000). A theory of human life history evolution: Diet, intelligence, and longevity. Evolutionary Anthropology, 9, 156-185.

Kohli, M., Albertini, M., \& Künemund, H. (2010). Linkages among adult family generations: Evidence from comparative survey research. In P. Heady \& M. Kohli (Eds.), Family, kinship and state in contemporary Europe: Perspectives on theory and policy (pp. 225-248). Frankfurt: Campus.

Mare, R. D. (2011). A multigenerational view of inequality. Demography, 48, 1-23.

Perry, G., \& Daly, M. (2017). A model explaining the matrilateral bias in alloparental investment. Proceedings of the National Academy of Sciences, 114, 9290-9295.

Perry, G., Daly, M., \& Macfarlan, S. (2014). Maternal foster families provide more stable placements than paternal families. Children and Youth Services Review, 46, 155-159.

Pronin, E. (2007). Perception and misperception of bias in human judgment. Trends in Cognitive Sciences, 11, 37-43.

Rotkirch, A. (2018). Evolutionary family sociology. In R. L. Hopcroft (Ed.), Oxford handbook of evolution, biology, and society (pp. 451-478). Oxford: Oxford University Press.

Rotkirch, A., \& Buchanan A. (2016). Conclusions: What have we learnt? In A. Buchanan \& A. Rotkirch (Eds.), Grandfathers: Global perspectives (pp. 285-309). London: Palgrave Macmillan.

Salmon, C. A., \& Shackelford, T. K. (Eds.) (2011). The Oxford handbook on evolutionary family psychology. New York: Oxford University Press.

Sanderson, S. K. (2007). Evolutionism and its critics: Deconstructing and reconstructing an evolutionary interpretation of human society. London: Paradigm.

Sear, R. (2015). Evolutionary contributions to the study of human fertility. Population Studies, 69, S39-S55.

Segerstråle, U. (2000). Defenders of the truth: The battle for science in the sociobiology debate and beyond. Oxford: Oxford University Press.

Turner, J. H., Machalek, R., \& Maryanski, A. (Eds.) (2015). Handbook on evolution and society: Toward an evolutionary social science. New York: Routledge.

Walsh, A. (2014). Biosociology: Bridging the biology-sociology divide. London: Transaction Publishers. 


\section{Theories on intergenerational relations}

[T] he methodological rigor of sociology is likely to benefit evolutionary investigations, and the theoretical framework of evolutionary theory may widen the scope of hypotheses examined by sociologists. It is time to stop pointing fingers, and to start benefiting from each other.

(Coall \& Hertwig, 2010, p. 42)

The humble wish of cooperation between disciplines Coall and Hertwig (2010) presented in their extensive review of grandparent studies is also one we want to emphasise. The aim of the current chapter is to introduce the most important social science and evolutionary theories on intergenerational relations. To begin with, it is important to define what the term "theory" actually means. Perhaps the most common answer to the question, "What is theory?" is, "It depends on whom you ask". The word "theory" tends to have a different meaning for lay people compared to scientists, for instance. For lay people, theory often refers to an apprehension or a hint regarding a specific everyday life issue. In contrast, among scientists, the term is typically defined to mean a broad concept that can explain a wide amount of phenomena. For instance, the theory of evolution by natural selection is one of the most widely accepted and influential scientific theories and has great capacity to explain different phenomena.

The usefulness of any given theory can be summarised in five criteria: 1) logical coherence, 2) empirical success, 3) parsimony, 4) relative explanatory power and 5) productivity (Sanderson, 2012). Logical coherence means that the theory must be logically consistent, clearly formulated and able to be tested empirically. Empirical success simply means that the theory should receive support when it is tested empirically. Empirical success can be defined as the most important criterion for a useful theory because when the theory is not empirically supported, it must be either abandoned or reformulated. According to parsimony, a criterion for a good theory is that it should be economical or cost effective in explaining as many phenomena as possible. Relative explanatory power means that the most useful theory is the one that receives the most empirical evidence. The best theory is simply the one that has the greatest explanatory power compared to rival theories. Finally, productivity refers to the capacity of a theory to produce new views and hypotheses over time. 
Perhaps one of the most important aspects of scientific theories is that they are general by nature. It could be argued that scientific theories have two main purposes. First, they should help us to understand what is happening in the world and why. Second, theories should help us to predict what may happen in the future. In this book, we are studying intergenerational family relations, meaning that the most relevant theories to our purpose are those that can help us to better understand or make predictions about human behaviour.

Theories can be divided into different hierarchical positions according to their level of abstractness. Here, we classify three sets of theories from lowest generality to highest: 1) conceptualisation, 2) proximate mechanisms and 3) ultimate reasons (see Box 2.1). Conceptualisation, which makes it possible to name (or re-name) phenomena or to give a common concept to related phenomena, can be defined as the lowest level of theoretical approach. Although conceptualisation presents the simplest form of theory, it is important to note that when building more complicated theories, groups of concepts are always needed. This means that concepts and higher-level theories cannot be completely separated from one another.

\section{Box 2.1 Ultimate reasons and proximate mechanisms}

Ultimate reasons involve the possible evolutionary function of a behaviour and why natural selection might have favoured a certain trait. Ultimate explanations ask why a behaviour exists in the species. With regard to intergenerational relations, ultimate explanations focus on why kin help each other across generations. One may ask why caring grandparenthood exists in the first place and why close relatives tend to help each other more than distant or non-related individuals. Proximate explanations, in turn, describe the mechanisms that trigger and enable the behaviour and are interested in how certain behaviour is expressed and what contextual factors are related to it. Proximate questions may consider how different socio-ecological factors (e.g., geographical distance, socioeconomic factors or welfare state institutions) facilitate intergenerational helping behaviour. Evolutionary researchers tend to focus more on the ultimate explanations for certain results and often pay less attention to proximate mechanisms, whereas social scientists pay attention to proximate mechanisms but tend to ignore or even deny the existence of ultimate explanations.

Proximate explanations can be defined as medium-level theories. They describe the mechanisms that trigger and enable behaviour and are interested in how certain behaviour is expressed and what contextual factors are related to it. Among sociologists, proximate mechanisms are also called "middle-range theories" (Merton, 1968). 
A wide range of sociologists have adopted a view that the most important aim of sociology is to study these middle-range theories because they can provide explanations from mechanisms leading to a certain outcome. In the case of intergenerational relations, for instance, sociologists have asked what the mechanism is that explains similarity between the socioeconomic status of grandparents and grandchildren (Mare, 2011).

Theories with the highest generality focus on the ultimate reasons and present macro-level theories. Ultimate reasons may concern, for instance, the possible evolutionary function of a behaviour - that is, why natural selection might have favoured a certain trait. In the case of intergenerational family relations, an ultimate question could be why caring grandparenthood exists in the species. Whether researchers are willing to identify only proximate mechanisms or continue to detect ultimate reasons could be dependent on several factors, which vary from one situation to another. Typically, researchers stop when they think they are intellectually satisfied, or "feel they have understood something adequately and thus have no need to go any further" (Sanderson, 2012, pp. xii).

To date, there has been a division between disciplines, in that evolutionary researchers have focused more on ultimate explanations. Nevertheless, it is important to note that this division of labour is not exhaustive. Several evolutionary scholars investigating intergenerational relations have paid attention to proximate factors, such as differences based on socioeconomic status (e.g., Sear, 2015). Moreover, an increasing amount of social scientists are interested in not only proximate mechanisms but also ultimate reasons (e.g., Hopcroft, 2010). In this book, we combine theories and findings related to both ultimate reasons and proximate mechanisms and consider them complementary to each other.

\section{Evolutionary theories on intergenerational relations}

Evolutionary theory on human behaviour is based on Darwin's (1859) theory of natural selection, which showed how beneficial heritable traits are passed on to the next generations through selective survival and reproduction; individuals with these beneficial traits produce more descendants to the next generations than individuals without these traits. The process of natural selection requires three basic features. First, genetic variation must exist in a population. Second, reproductive success and survival must vary between the members of a population. Third, factors related to reproductive success and survival must be at least partly heritable so that they can be genetically transmitted from parents to children. Selection pressure can focus various dimensions, such as the physical body, emotional reactions or behavioural dispositions. Thus, in evolutionary research, the central idea is that natural selection has shaped not only individuals' physical traits but also psychological and behavioural predispositions.

However, all behavioural traits are not evolutionary adaptations, and evolutionary scientists have debated how evolutionary adaptations can actually be recognised. Atran (2001) has summarised the general discussion of adaptations into the following key points: a trait is likely to have an evolutionary basis if it can be 
assumed to be a response to some general challenge during our evolutionary history, is present in all known human populations, develops spontaneously in most healthy individuals, makes an appearance in a certain stage of life and includes changes that are hormonal or psycho-physical. Obviously, the evolutionary adaptations should be genetic. Additional features of evolutionary traits are that the emotions they produce are easy to actuate but difficult to suppress. Investment in close kin can be defined as a behavioural predisposition that has an evolutionary function.

When one considers kin investment from an evolutionary point of view, it is important to note that these investments are often made without conscious decisions (Box 2.2). This book frequently uses terms such as "investments" and "strategies", but we do not use them to refer to necessarily conscious behaviour. For instance, investments, despite requiring an action, can refer to conscious stakes as well as to the unconscious investments parents or grandparents make in their descendants without acknowledging them (Euler \& Michalski, 2008; Trivers, 2002). The unconscious nature of parental or grandparental behaviour is important because in the majority of cases, people most likely do not "choose", for instance, a particular child or grandchild to favour. Thus, unconscious favouring tends to be a natural aspect of social relations (Euler, 2011).

\section{Box 2.2 Conscious and unconscious motives behind human behaviour}

In social science research, humans are often seen as rational actors who make conscious choices. In contrast, evolutionary scientists typically consider also the unconscious motives behind human behaviour. The main point is that individuals do not typically behave as they do because they are consciously attempting to increase their fitness (i.e., reproductive success and survival); rather, they are following specific emotions and cues that lead to a certain behaviour. The different stance between evolutionary and social scientists with regard to conscious and unconscious motives for human behaviour also provides a good example of the problem related to the lack of common language producing misunderstandings between scholars representing different disciplines.

Evolutionary theory seeks the fundamental reasons for kin investments and emotional ties between relatives. The starting point for evolutionary family studies is to understand the human family as a reproductive system characterised by cooperative breeding and allomothering (Hrdy, 1999, 2009), as described at the beginning of this book (Chapter 1). Partly due to cooperative breeding, human families are very flexible by nature, meaning that several individuals outside the nuclear family participate in childrearing (Sear, 2016). Related to cooperative breeding 
and allomothering, humans have predisposition to a certain repertoire of emotions, namely maternal and paternal care, love between a couple, sexual jealousy, grandparental love, love between siblings and incest aversion (Westermarck, 1921).

One of the main explanatory powers of an evolutionary approach is that it seeks to understand what motivates individuals to be supportive and the reasons why positive emotions towards close kin develop. The idea that there is some biological core of intergenerational relations gains strong support from analyses and reviews of pre-modern, traditional and contemporary human societies (e.g., Sear \& Coall, 2011; Sear \& Mace, 2008). For instance, the fact that researchers have found the occurrence of caring grandparenthood in other species further highlights the possible evolutionary meaning of intergenerational support. The appearance of caring grandparenthood among other species indicates that it may have existed long before our species (Homo sapiens).

Indeed, grandparental care, which is a central part of intergenerational relations in humans, is not a uniquely human phenomenon. Occasional caring grandmotherhood has been found among several primates, such as wild chimpanzees and baboons (Collins et al., 1984; Nakamichi et al., 2004; Paul, 2005; Wroblewski, 2008) and elephants (Lahdenperä et al., 2016; Lee, 1987), as well as dolphins (Norris \& Pryor, 1991), killer whales (e.g., Brent et al., 2015; Foster et al., 2012) and some birds (Richardson et al., 2007). Previously, it has been argued that compared to other species, human grandparenting has three unique features: the regularity of caring grandparents, the existence of a caring paternal grandfather and the comparatively long postmenopausal lifespan of women (Euler, 2011). The most recent evidence, however, indicates that killer whales and short-finned pilot whales also go through a menopause and live long after that (Croft et al., 2017).

\section{Life history theory}

Life history theory, a branch of evolutionary theory that is devoted to the study of life cycles, is a widely used analytical tool, especially among evolutionary biologists and ecologists. Models developed from the principles of life history theory aim to understand individual variability in growth, survival, development and reproduction in response to varying environmental conditions within an evolutionary framework (e.g., Stearns 1992). Within evolutionary biology and developmental psychology, the life history theory has been developed to conceptualise the timing of important life course transitions in organisms. Life history theory posits that all individuals have a limited amount of resources, which they need to allocate to different life-important functions such as individual growth, development, mating, reproduction and parenting. The allocation of resources requires certain trade-offs between different functions. Therefore, life history theory expects selection to favour phenotypic mechanisms that allocate finite resources between competing alternatives in a manner that ultimately results in greater fitness (e.g., Hill \& Kaplan, 1999; Low, 1978). These phenotypic mechanisms may be, for instance, molecular, developmental, physiological, psychological or behavioural. 
Life history theory is concerned with how individuals manage (consciously or unconsciously) the trade-offs between investing resources in varying life domains. For instance, a trade-off between the growth and maintenance of body functions on the one hand and mating and reproduction on the other is visible in the fact that many species stop growing with sexual maturation (Stearns, 1992). Another typical trade-off is between descendant quantity and quality, meaning the allocation of reproductive effort to increasing the number of descendants (quantity) or to increasing the fitness of descendants (quality) (Hill \& Kaplan, 1999). In subsistence societies, descendant quality has typically been indicated by the capability to survive during the dangerous childhood period, whereas in contemporary societies, it can be interpreted to mean different factors related to children's wellbeing (see Chapter 6).

Life history theory emphasises that "optimal" evolutionary behaviour is context-dependent and varies depending on the costs and benefits imposed by the environment. In other words, various aspects of human physiology and behaviours are subject to flexibility as a response to environmental conditions. This means that the tempo of family trajectories is related to the opportunities and challenges (i.e., trade-offs) available to the individuals (Miller et al., 2015). For example, speeding up childbearing in harsh conditions provides a greater chance of achieving childbearing goals (Chisholm, 1999; Chisholm et al., 2005).

One trade-off (a central one to this book) is the trade-off between investing in one's own reproduction versus supporting the reproduction of closely related kin. The grandmother hypothesis assumes that, compared to most other animals, human females stop reproducing early in relation to their long lifespan because they can gain more fitness benefits by investing in their existing descendants than by reproducing in old age (Hawkes, 2003; Hawkes \& Blurton-Jones, 2005; Lahdenperä, 2010). Thus, according to the grandmother hypothesis, the long postmenopausal lifespan of human females is an evolved adaptation that allows postreproductive older women to provide support to their descendants, contributing to the fertility of daughters and daughters-in-law and the survival of grandchildren.

In recent years, there has been heated debate regarding the evolution of caring grandmotherhood and its connection to menopause and human females' long post-reproductive lifespans (e.g., see Coall \& Hertwig, 2010, and Strassmann \& Garrard, 2011, for discussion; see Kachel et al., 2011, and Kim et al., 2012, for mathematical simulations). Although several results have been favourable towards the grandmother hypothesis, others have not. Opponents of the grandmother hypothesis have argued, for instance, that caring grandmotherhood and a long infecund lifespan might be by-products of evolution, meaning that the long post-reproductive lifespan may have evolved first, with caring grandmotherhood evolving later (e.g., Broadfield, 2010; Peccei, 2001; see also Marlowe, 2000, for patriarch hypothesis). Thus, the grandmother hypothesis remains debatable.

\section{Inclusive fitness and parental investment theories}

The evolutionary theories behind intergenerational family relations are rooted in Hamilton's (1964) inclusive fitness theory and Trivers' (1972) parental 
investment theory. Inclusive fitness theory (Box 2.3) predicts that the closer the actual kin relationship is (i.e., the more people have reason to recognise that they are genetically related), the more people will provide altruistic help. Since the 1960s, Hamilton's rule has been widely studied and utilised within several disciplines, and its predictions have proven to be advantageous in understanding a wide range of behavioural phenomena among humans and non-human animals (Abbot et al., 2011).

\section{Box 2.3 Inclusive fitness theory}

Hamilton's (1964) inclusive fitness theory, also known as kin selection theory and Hamilton's rule, is used to explain the behaviour of several species in addition to humans, including eusocial insects, birds and primates. Inclusive fitness theory can be condensed to the formula $\mathrm{B}^{*} \mathrm{r}>\mathrm{C}$, where $\mathrm{B}$ means benefit to the recipient, $r$ is the degree of relatedness between the recipient and contributor and $\mathrm{C}$ is the cost to the contributor. This means that in terms of one's inclusive fitness, it is beneficial to help close relatives even if the costs are high because the relatedness is also high but helping more distant relatives with high costs is less beneficial. The theory argues that by helping genetically related kin, especially in the descending line, it is possible to increase the probability that one's own genes will spread to future generations. An individual can enhance his or her inclusive fitness by supporting his or her close relatives' reproductive success (indirect fitness) at the expense of his or her own direct fitness.

People share 50 per cent same genes with their children and have, on average, a 25 per cent chance of having the same genes as their grandchildren. In addition, due to the assessment of the need of help and reproductive value of the receiver, investments are predicted to go towards the younger generation (Hughes, 1988). Inclusive fitness theory argues that natural selection has favoured investment in close kin, meaning that "all other factors being equal", individuals should invest more in their close relatives than in more distant relatives or non-relatives. Genetic relations between family members (assuming that spouses are not related) are presented in Table 2.1.

In its original form, however, inclusive fitness theory ignores affines (or in-laws). In-laws, who are genetically non-related family members, are thus often considered by evolutionary researchers to be similar to any other non-related friend or acquaintance (Burton-Chellew \& Dunbar, 2011). Hughes (1988) was the first to argue that as an extension of inclusive fitness theory, kin investment should also vary by in-laws, who are usually not closely genetically related but become "inversely" genetically related to each other through common descendants 


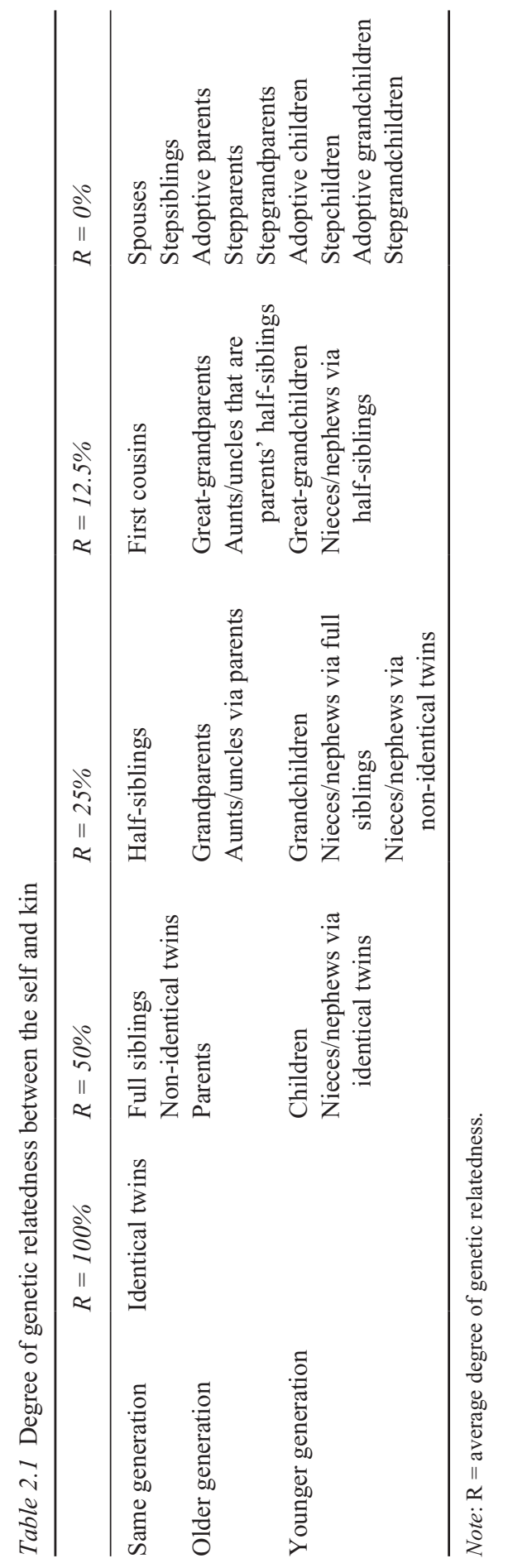


(Danielsbacka et al., 2015; 2017). Thus, the shared genetic interest that may have influenced evolved psychological predispositions is not limited to genetic kin but may also involve in-laws. This inverse genetic relatedness predicts that the relationship between in-laws should particularly be affected by the existence of a descendant who ties two formerly non-related kin together.

In his classic article, Trivers (1972) applied Hamilton's general rule to parental behaviour. Trivers' theory of parental investment (Box 2.4) takes into account the investments that parents make in their descendants, acknowledging the difference between maternal and paternal investment (i.e., mothers typically invest more than fathers do). Parental investment can be easily extended to grandparental investment (see Chapter 1: Box 1.1).

\section{Box 2.4 Parental investment theory}

Trivers' (1972) parental investment theory is based on the idea that in species for which descendant survival and reproducing is dependent on parental care, such as humans, evolution has favoured parents who are willing to make costly investments. Parents can invest, for instance, time, energy and resources in their descendants. The theory acknowledges that the investments made in one descendant may diminish investments in other descendants at the same time or in the future. By investing in their descendants, parents can enhance their inclusive fitness. Moreover, there is a difference between the sexes regarding the amount and cost of the investment. Due to pregnancy and lactation, mammal females have a greater obligatory investment in each reproductive event than males do. In addition, because of paternity uncertainty males tend to invest less, on average, in their descendants than females do.

In addition, children compete with their siblings for parental resources, which may produce differences in the allocation of parental investments (Trivers, 1974). Due to the socio-ecological context and available resources, parents may allocate their investments to certain children only, such as those who are the most promising or those who need the most assistance. In addition, the Trivers-Willard hypothesis suggests that female mammals may have a way of adjusting descendant sex ratio in response to their maternal condition (Trivers \& Willard, 1973). It may be preferable to have female descendants if the conditions are expected to be poor and male descendants if the conditions are expected to be good. This hypothesis, applied to humans, may also predict greater parental investment in daughters in harsh conditions and greater parental investment in sons when good conditions prevail (Hopcroft, 2005; 2015). Studies testing the Trivers-Willard hypothesis have provided mixed results (Rotkirch, 2018). 


\section{Theories of biased grandparental investments}

One of the most common findings in grandparental investment studies is that the descending order of grandparental investment seems to adhere to the following pattern: the maternal grandmother invests the most, followed by the maternal grandfather and paternal grandmother, whereas the paternal grandfather usually invests the least (see Coall \& Hertwig, 2010, and Euler, 2011, for reviews). This biased grandparental investment pattern has been confirmed in several studies and with a wide range of investment variables (e.g., care provided during childhood, emotional closeness, financial support and contact frequencies). Among evolutionary researchers, the reasons for the investment bias between grandparent types have been approached through several theories, namely, inclusive fitness, reproductive value, sex-specific reproductive strategies, paternity uncertainty and sex-chromosome relatedness (Table 2.2). These approaches are complementary rather than mutually exclusive.

According to inclusive fitness theory (Hamilton, 1964), all else being equal, individuals are more inclined to help their kin than their non-kin. Thus, one may assume that biological grandparents should invest more in their grandchildren compared to non-biological grandparents (Coall et al., 2014, 2016). In the case of biological versus non-biological grandparents, it should be noted that grandparents may have several ways of having non-biological grandchildren, and all of these may affect the amount of investments they channel towards their descendants.

Although it may surprise some who are unfamiliar with evolutionary theory, investments in biological and adoptive grandchildren may not differ substantially. This is because psychological parental and grandparental attachment processes tend to be quite similar between biological and adoptive children, at least when compared to those with stepchildren or stepgrandchildren (Rotkirch, 2018; Tanskanen et al., 2014). According to the mating effort hypothesis, stepgrandparents (who are the new spouses of the biological grandparents) may invest in their stepgrandchildren because they are willing to behave as good spouses (Pashos et al., 2016). The incidental exposure hypothesis, alternatively, predicts that when biological grandparents invest in their grandchildren, their new spouses (i.e., stepgrandparents) become "incidentally exposed" to the grandchildren as well, which can explain the "investment" by stepgrandparents (Euler, 2011). The common feature of both the mating effort and the incidental exposure hypotheses is that they assume that stepgrandparents are not necessarily highly involved in stepgrandchildren entirely voluntarily.

Biological grandparents share approximately 25 per cent of their genes with their grandchildren. However, the relatedness varies, on average, between 23 and 27 per cent due to the asymmetric impact of X and Y chromosome inheritance, which may affect the bias in grandparental investment. With respect to autosome chromosomes, grandparents are equally related to grandchildren, but not with respect to sex chromosomes. With respect to sex chromosomes, paternal grandfathers are always related to their grandsons (paternal grandfathers and grandsons share the same Y chromosome), but never related to their granddaughters 


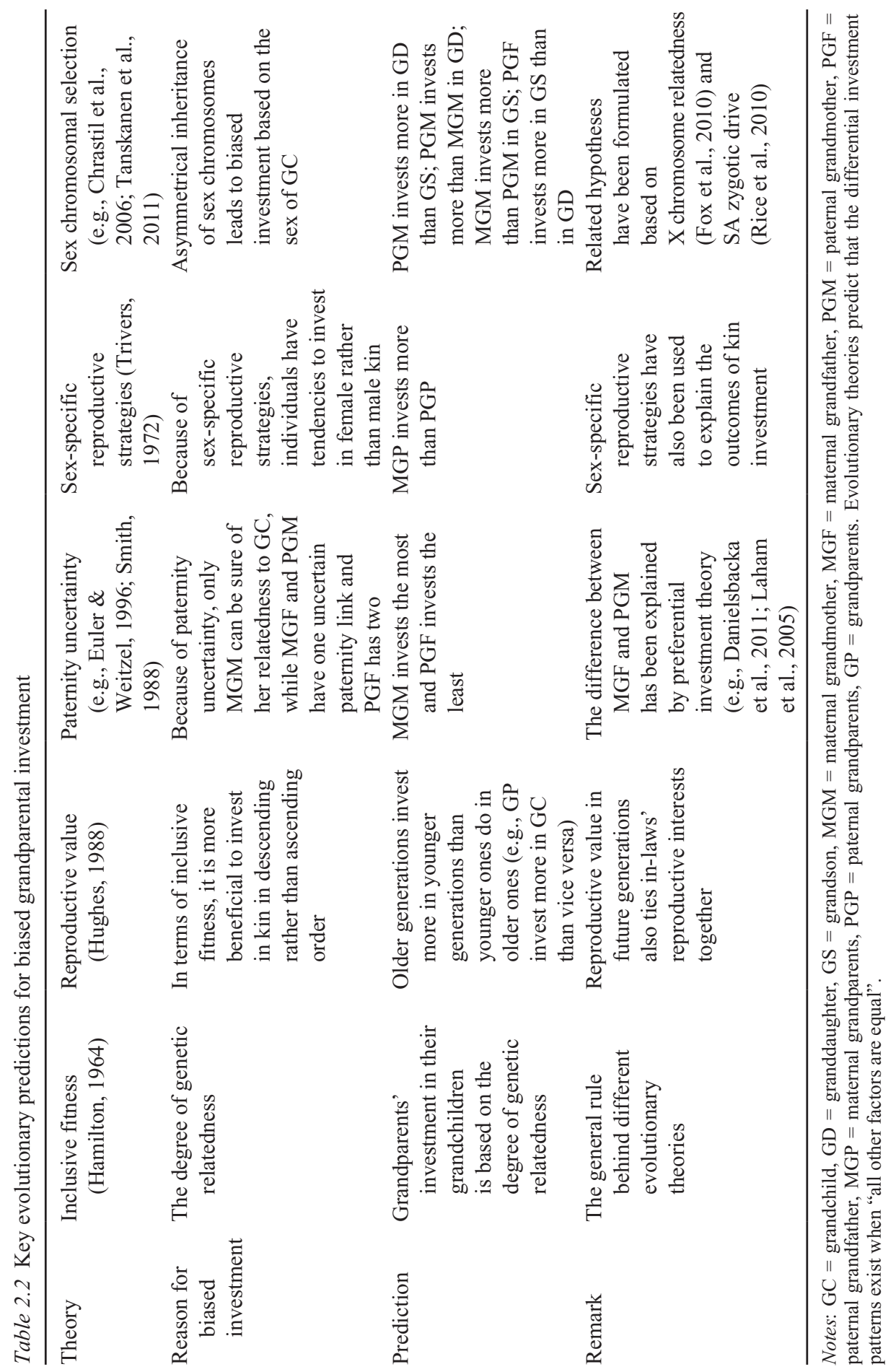


(the paternal $\mathrm{X}$ chromosome for the granddaughter comes from the paternal grandmother). Paternal grandmothers, on the contrary, are always related to their granddaughters and never related to their grandsons in terms of sex chromosomes. Maternal grandparents, in turn, have an equal chance to be related to both grandsons and granddaugters (grandchildren inherit one X chromosome from either the maternal grandfather or the grandmother). Following the logic of the inclusive fitness theory (Hamilton, 1964), when the genetic relatedness between individuals increases, the potential investment also increases. Thus, according to predictions derived from sex-chromosome relatedness, maternal grandmothers and grandfathers should invest equally in granddaughters and grandsons, whereas paternal grandmothers should invest more in granddaughters than in grandsons and paternal grandfathers should invest more in grandsons than in granddaughters (e.g., Chrastil et al., 2006; Fox et al., 2010; Rice et al., 2010; Tanskanen et al., 2011).

Genetic relatedness as well as sex and lineage are important factors with regard to biased grandparental investment. A single descendant is more costly for women (due to pregnancy and lactation) than for men (Trivers, 1972). Maternal investment is also more obligatory, whereas paternal investment can be more facultative. This has been shown, for instance, in the finding that losing a mother is more detrimental to a child than losing a father (Sear \& Mace, 2008). Thus, in the ancestral past, females could have improved their inclusive fitness by maximising their maternal care (Campbell, 2013). Sex-specific reproductive strategies appear to be reflected in several evolved psychological dispositions, for instance, making women, on average, more empathetic and caring towards their kin and towards young children (Rotkirch \& Janhunen, 2010).

Sex-specific reproductive strategies are also used to explain the potentially different effects of maternal and paternal kin on fertility and child outcomes. Because of lower obligatory levels of paternal than maternal investment, men can theoretically increase their fitness more than women by mating with several partners (but see Kokko \& Jennions, 2003), meaning that when other factors are equal, men can be assumed to invest more in descendant quantity (i.e., number of children) and women in descendant quality (i.e., child wellbeing). These sexspecific reproductive strategies may lead to different reproductive interests not only between women and men but also between maternal and paternal relatives (Euler, 2011).

The best reproductive strategy for a woman and her kin is often not to maximise the number of children born, at least when the wellbeing of the woman and existing children is not guaranteed. Having many children with short birth intervals can have detrimental outcomes for women and their already born children (Euler, 2011). For men, the potential cost of having several children within a short period is smaller than it is for women. In addition, maternal grandparents are related to women, whereas paternal grandparents are not. As daughters are always irreplaceable, daughters-in-law could be replaceable, at least in circumstances where men can be predicted to find a new partner. This argument suggests that it is more important for maternal than paternal kin to protect the health and wellbeing of women and their children, leading maternal kin to favour quality 
over quantity. In contrast, from the perspective of paternal grandparents' fitness, it may be more beneficial to boost quantity over quality (Mace \& Sear, 2005). In some situations, this may even lead to exploiting the fertility of daughters-in-law at the expense of the health and wellbeing of these women and their children. Thus, according to sex-specific reproductive strategies, paternal grandparents (or grandparents-to-be) are predicted to invest more in the increased fertility of adult sons, whereas maternal grandparents are assumed to invest more in increased grandchild wellbeing.

Paternity uncertainty (also called relationship uncertainty) means that whereas women can be sure that the children to whom they gave birth are biologically related to them, men can never be 100 per cent certain that the children are actually theirs. We will not consider here the modern possibility of surrogacy or modern gene tests that can confirm paternity at 99.9 per cent certainty, because most evolutionary traits of parental and grandparental behaviour were shaped long before modern medicine. In the case of grandparents, paternity uncertainty means that only the maternal grandmothers have no relationship uncertainty since they can be certain that their daughters and their daughters' children are genetically related to them. Maternal grandfathers (via themselves and their daughters) and paternal grandmothers (via their sons and their sons' children) have one kinship link with paternity uncertainty, whereas paternal grandfathers have two. Based on predictions derived from paternity uncertainty, all else being equal, grandparents should typically unconsciously bias their investment in grandchildren following the differences in genetic certainty. Therefore, according to paternity uncertainty, it is assumed that maternal grandmothers invest in their grandchildren the most, followed by maternal grandfathers and paternal grandmothers, whereas paternal grandfathers should invest the least (Euler \& Weitzel, 1996; Smith, 1988).

Paternity uncertainty does not directly explain the frequently documented difference between maternal grandfathers and paternal grandmothers (e.g., Danielsbacka et al., 2011; Laham et al., 2005). In contemporary societies maternal grandfathers are commonly found to invest more in their grandchildren than paternal grandmothers do, although both have the same genetic certainty regarding descendants. This phenomenon is often explained by incidental exposure, meaning that maternal grandfathers increase their reported involvement due to their spouse, the maternal grandmother, who invests the most (e.g., McBurney et al., 2002; Pollet et al., 2006).

Another theoretical explanation was first presented by Laham and colleagues (2005), who argued that the difference between maternal grandfathers and paternal grandmothers can be explained by preferential investment in more certain kin. The preferential investment hypothesis predicts that grandparental investment changes according to the degree of genetic relatedness and according to the availability of other investment options as represented by the existence of grandchildren via sons or daughters. If parents have children and grandchildren of both sexes, they are expected to invest more in their daughter's children (uterine grandchildren) than in their son's children (agnatic grandchildren). In the absence of grandchildren via a daughter, both sexes are expected to invest more in their 
son's children. Thus, in a typical case, maternal grandfathers would invest more because paternal grandmothers commonly have a more certain investment option available through a grandchild via a daughter. If more certain options are unavailable, similar investment levels by both the maternal grandfather and paternal grandmother are predicted.

\section{Kin detection}

Above, we have discussed the importance of genetic relatedness for kin investment. To invest in kin, one must first detect a person as kin. With the exception of a mother's relatedness to her child, all human relatedness is more or less uncertain and must be inferred. Even a child has to infer its relationship to his/her mother (and siblings). To recognise kin members, humans need cues indicative of relatedness. These cues can be direct or indirect (Antfolk, 2014; Bressan \& Kramer, 2015). Direct cues may be physical or psychological, such as facial or personality resemblance, and they may be other-referent or self-referent (Krupp et al., 2011). Other-referent cues are based on information from already recognised kin (e.g., mother or father), against which an alleged relative (e.g., grandparent) is compared, and self-referent cues are based on information about oneself against which an alleged relative is compared.

Kin detection is important not only for kin investments but also to avoid inbreeding. Incest aversion (also called Westermarck effect) develops towards those family members with whom people are in close contact during childhood (Westermarck, 1921). Hence, childhood proximity and coresidence are also kin detection cues for humans.

The mother's and the maternal grandmother's relationship to a child to whom she (or her daughter) has given birth is certain, and a particular kin detection mechanism between the mother (and the mother's mother) and a child is unnecessary. For the most part, however, humans must rely on indirect environmental cues (Lieberman et al., 2007). For instance, a father and his relatives cannot be 100 per cent certain of his relatedness to a child; thus, for fathers, cues of relatedness are necessary. One central mechanism could be that the man knows the mother of the child has been with him, loves him and has no other lovers, meaning that the relationship with the mother is the most important. Facial resemblance is also suggested to be one important imprinting mechanism for fathers and their side of kin. Studies support this prediction as newborn babies are most often said to resemble their father (Daly \& Wilson, 1982; McLain et al., 2000), and parental investment seems to be more affected by paternal than maternal resemblance (Alvergne et al., 2009; Platek et al., 2002; but see DeBruine, 2004).

However, there is a lack of studies on how children actually detect their parents (but see DeBruine, 2005; Marcinkowska \& Rantala, 2012). Especially father recognition has been understudied, although it is likely that human children recognise their father as the adult male who coresided and associated with their mother during childhood (Haig, 2011). In particular, three childhood kinship cues seem to be associated with kin-directed behaviour towards parents in adulthood: the 
reported amount of parental support, phenotypic similarity and behavioural similarity (Antfolk et al., 2014). Parental detection is, of course, also important in the case of grandparental recognition. From grandchildren's perspective it might be important to detect a grandparent to ensure the continuity of the investment they receive. From grandparents' perspective the kin detection can help to channel the investment towards genetically related grandchildren.

Because paternity uncertainty tends to shape fathers' (or putative fathers') investment in their children (Alvergne et al., 2009; Platek et al., 2002), it is worthwhile to assume that in the case of grandparental investment, the effect of grandparent-grandchild resemblance should also vary according to paternity uncertainty (Euler, 2011). According to this view, the investment of paternal grandfathers should be the most dependent on grandparent-grandchild resemblance, whereas the investment of maternal grandmothers should be least dependent of all grandparent types. Among maternal grandfathers and paternal grandmothers, the effect of resemblance should be less important compared to paternal grandfathers and more important compared to maternal grandmothers.

\section{Resource competition and reproductive conflict}

So far, we have mainly concentrated on theories related to kin support and closeness. However, human family relations include not only help and emotional closeness but also conflicts and competition. Next, we present models of local resource competion and reproductive conflict.

Although there are several reasons to predict that grandparents have high tendencies to invest time and resources in their grandchildren, in some cases, competition for limited resources may exist between grandparents and grandchildren. In particular, in low-resource environments, grandparents may actually have a detrimental effect on grandchildren because grandparents who live in the same household with grandchildren may compete with them for the same resources, such as food or maintenance (Strassmann, 2011; Strassmann \& Garrard, 2011). This competition may have been extremely harsh in subsistence societies and presents a trade-off between grandparents' own survival and their investment in grandchildren.

According to the local resource competition model, in three-generational families (where grandparents live in the same household as their adult children and grandchildren), older grandparents may cease to be net producers, thereby competing for resources with their grandchildren (Strassmann \& Garrard, 2011). The resource competition between grandparents and grandchildren may involve food or maintenance (in subsistence societies) or parental time and involvement (in contemporary societies) (Tanskanen et al., 2016). The competition may have detrimental effects not only for grandchildren but also for grandparents themselves, in that grandparents may not receive as much support from their adult children as they may need.

Reproductive conflict can occur between simultaneously reproducing females. From an evolutionary ecology perspective, reproducing at the same time may 
have had detrimental effects for child survival, especially in harsh environments. For that reason, it may have been avoided. In addition, the severity of the conflict may be related to the degree of relatedness between the two females. For instance, the possibility for reproductive conflict occurs between a mother-in-law and a daughter-in-law if these unrelated females from different generations reproduce simultaneously (Lahdenperä et al., 2012). Intergenerational reproductive overlap applies to daughters and mothers as well, but simultaneous reproduction between them does not produce as much motive for conflict as does simultaneous reproduction between mothers-in-law and daughters-in-law. Mothers and daughters are typically equally related to the descendants of the elder-generation mother ( 50 per cent), but in the case of mothers-in-law and daughters-in-law, the latter will be unrelated to the descendants of mothers-in-law ( 50 per cent to their own descendants vs. 0 per cent to the mother-in-law's descendants). Thus, reproductive conflict is more likely to occur between unrelated females (Cant \& Johnstone 2008). Equal asymmetry exists between mothers(-in-law) and daughters(-in-law), as the women from the elder generation will be only half as related to the younger generation's descendants as their own (50 per cent vs. 25 per cent) (Lahdenperä et al., 2012). Similarly (although not exactly the same), reproductive conflict can occur if two closely living females from the same generation reproduce simultaneously. The disadvantages may be especially severe if these two females are unrelated, such as sisters-in-law, and if they reproduce at the same time (Pettay et al., 2016).

As stated above, the long postmenopausal lifespan of human females might have evolved because post-reproductive older women can provide support to their descendants, contributing to the fertility of daughters and daughters-in-law and the survival of grandchildren (the grandmother hypothesis). In addition to this "positive" selection pressure, there may be a "negative" selection pressure that has played a role in the evolution of menopause. Reproductive conflict may have served as this kind of negative selection pressure because reproducing simultaneously with one's own descendants may have reduced the survival of both generations' descendants (Lahdenperä et al., 2012).

\section{Social science theories on intergenerational relations}

Intergenerational relations have been important topics not only in evolutionary but also in social science research (e.g., Arber \& Timonen, 2012; Szydlik, 2016). For the purpose of this book, the most relevant approaches to intergenerational relations are intergenerational solidarity and intergenerational ambivalence models, the life course approach and the model of opportunity, need, family and cultural-contextual factors. In addition, the kin keeper theory, the theory of parents as gatekeepers and the rational grandparent model are introduced (Table 2.3). There are other conceptualisations, such as studies related to grandparental roles (e.g., Baydar \& Brooks-Gunn, 1998; Mueller \& Litwin, 2011), which are not considered because of their limited ability to provide added value to the empirical research programme developed in this book, that is, the evolutionary social science approach. 


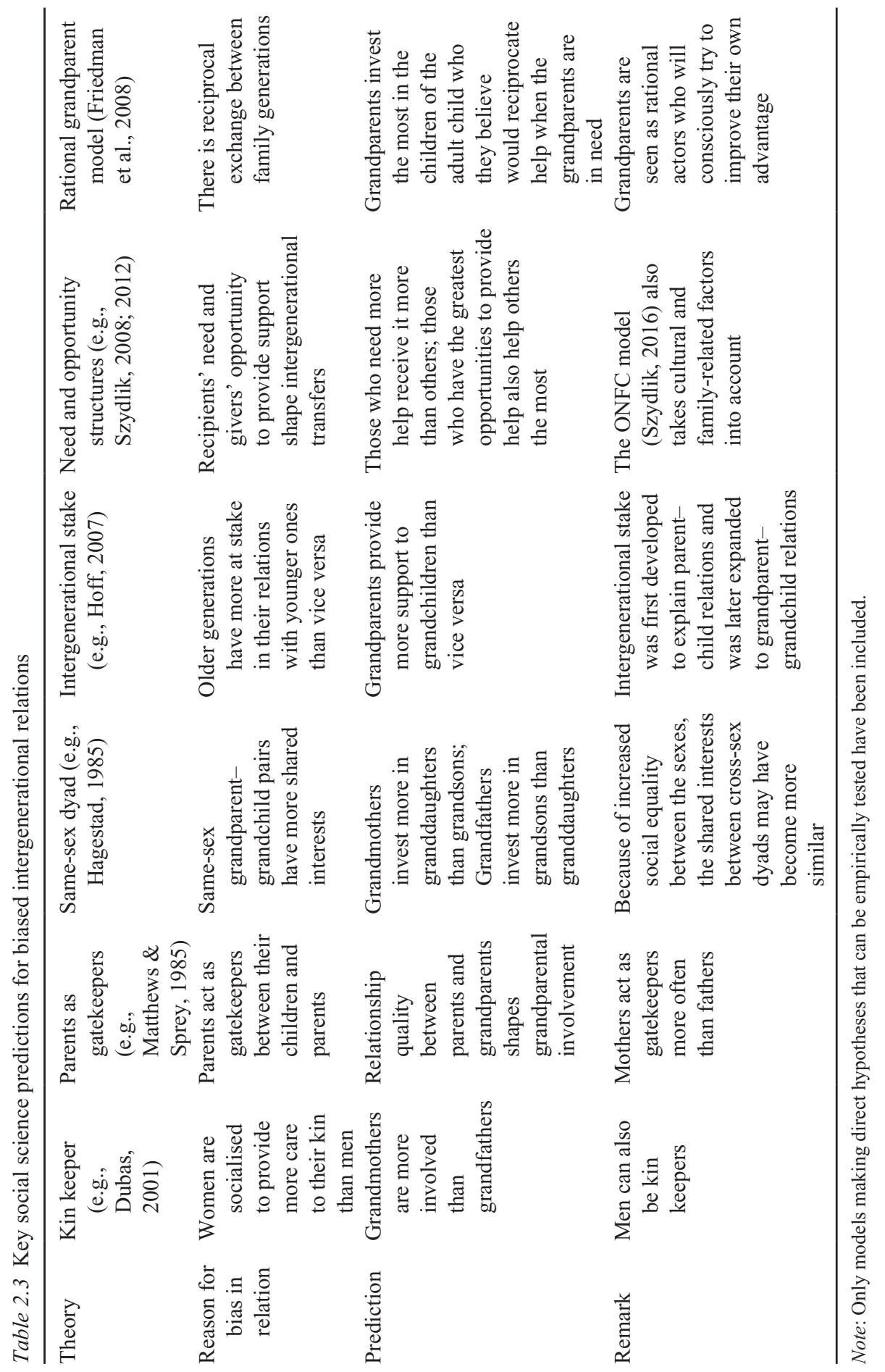




\section{Kin keepers and gatekeepers}

Evolutionary researchers have often examined the biased grandparental investment between maternal and paternal grandparents, as well as between grandmothers and grandfathers. Social scientists have examined this issue as well, although they have typically used the term "grandparental involvement" instead of "investment". The main social science theories that aim to explain biased grandparental involvement are the kin keeper theory and the theory of parents as gatekeepers. The kin keeper theory emphasises the difference between grandmothers' and grandfathers' involvement, whereas the notion of parents as gatekeepers (or mediators) between grandparents and grandchildren takes into consideration the quality of the relationship between the parental and grandparental generations.

In social science studies, grandparent types are not always separated from each other. Nevertheless, many family social scientists acknowledge the importance of biological variables such as sex and lineage (e.g., Chan \& Elder, 2000; Giarrusso et al., 1995). One of the main explanations for the different investments between grandmothers and grandfathers is the kin keeper theory. This theory assumes that social norms encourage or even force women to behave in a more caring way than men; consequently, women are socialised as kin keepers who manage and maintain relationship ties within families (Bracke et al., 2008; Dubas, 2001; Willson et al., 2003). The kin keeper theory predicts that due to this socialisation, women are more prone than men to maintain contact with, provide support to and take care of their relatives. Thus, the kin keeper theory provides similar predictions as sex-specific reproductive strategies that also state that investing in their descendants is more obligatory for women than for men. The difference between the kin keeper theory and sex-specific reproductive strategies is that the former understands kin relations mainly as a product of socialisation and the latter as an evolved predisposition.

The social science focus on the emotional relations between parental and grandparental generations has raised the question of parents' role as gatekeepers between grandparents and grandchildren (Robertson, 1975; Thompson \& Walker, 1987), which can be seen as closely related to the linked lives perspective (King \& Elder, 1995). The gatekeeping role of parents can emerge especially in cases of young children who cannot yet decide for themselves which grandparent they wish to spend time with (Matthews \& Sprey, 1985; Sprey \& Matthews, 1982). When parents guard access to a grandchild, they act as gatekeepers. This gatekeeping role of the middle generation also highlights the importance of the quality of the dyadic parent-grandparent relationship, which is why it is argued that the perception of relationship quality should be studied especially from the parental perspective (Thompson \& Walker, 1987). Moreover, based on the kin keeper theory, mothers are assumed to take care of children more than fathers do, so it can be assumed that mothers may also decide who will have closer access to the child (Bracke et al., 2008). This person is often the maternal grandmother because the daughtermother bond tends to be the strongest of all adult child-parent dyads (e.g., Fischer, 1986; Hagestad, 1986; Rossi \& Rossi, 1990). It is easy to see the similarity with the evolutionarily-rooted parental investment theory (Trivers, 1972), indicating 
that investing in descendants is more obligatory for women than for men, which is one reason why ties between mothers and daughters have evolved to be so strong. However, unlike the evolutionary view, the parents as gatekeepers hypothesis takes into account that grandparents cannot take for granted the acceptance of their investment, which may be partly or wholly rejected by the parents of the grandchildren.

Finally, social science studies have consistently acknowledged that the sex of not only parents and grandparents but also of grandchildren can influence intergenerational relations. Perhaps the most common prediction is that same-sex grandparent-grandchild dyads are closer to one another compared to mixed-sex dyads (Dubas, 2001; Hagestad, 1985). This may be because same-sex pairs may have more shared interests and similar hobbies and feel more connected, whereas mixed-sex dyads may have a weaker connection. Based on this view, grandmothers should invest more in granddaughters than in grandsons, whereas grandfathers should invest more in grandsons than in granddaughters.

\section{Intergenerational solidarity}

The intergenerational solidarity model formulated by Bengtson and colleagues (e.g., Bengtson, 1975; 2001) was intended to represent different aspects of the bonds that tie family members of different generations together. It was first developed to describe relations between parents and children but was later expanded to describe grandparent-grandchild relations (Silverstein et al., 1998). The original intergenerational solidarity model included three dimensions, namely, normative, functional and structural solidarity (Bengtson, 1975). However, this original intergenerational solidarity model was highly criticised for its narrowness and the fact that it did not specify the interrelationships between the dimensions of normative, functional and structural solidarity (e.g., Atkinson et al., 1986). As a result, a taxonomy for intergenerational solidarity was formulated that included six dimensions (Roberts et al., 1991): affectual solidarity (e.g., sentiments between family members), associational solidarity (e.g., contact frequency), consensual solidarity (e.g., agreement on values), functional solidarity (e.g., assistance), normative solidarity (e.g., filial and parental obligations) and structural solidarity (e.g., geographical distance). In addition, Bengtson and Roberts (1991) showed that the different dimensions tend to relate to each other.

In the early 1970s, Bengtson and Kuypers (1971) formulated the intergenerational stake hypothesis to explain why parents tend to invest more in their children than children invest in their parents. This hypothesis was first formulated to describe parent-child relations and only later expanded to grandparentgrandchild relations (Hoff, 2007). According to this hypothesis, parents have more at "stake" in their relations towards descending kin because parents want to ensure that the joint family values are transferred from older generations to younger ones. Thus, the intergenerational stake hypothesis assumes that generations invest in interaction differently because parents and grandparents are more concerned than children and grandchildren are with the continuity of the family, whereas children are more interested in gaining independence and autonomy. It is 
not difficult to see the resemblance between the intergenerational stake hypothesis and the evolutionary notion of the receivers' reproductive value (Hughes, 1988), which both predict that the net flow of the investment would be directed towards the younger generation. One of the differences between evolutionary and social science approaches is that the evolutionary theory of reproductive value states that individuals typically have a spontaneous tendency to invest in those family members who have the highest current or future reproductive value, whereas the intergenerational stake hypothesis emphasises that parents and grandparents consciously attempt to transfer family values to their descendants.

The intergenerational solidarity model also highlights the role of the cultural-contextual structures within which intergenerational family relations take place. There are stronger and weaker welfare states, and an important question is whether the type of welfare state influences intergenerational relations. In the previous literature, two mutually exclusive assumptions, namely, the crowdingout and crowding-in hypotheses, have been presented (e.g., Künemund \& Rein, 1999). The crowding-out hypothesis predicts that advantageous public support and services "crowd out" informal support. This perspective assumes that intergenerational family support is mainly a result of poor public services. In contrast, the crowding-in hypothesis states that extensive welfare state support can help individuals provide more informal support to each other. It is hypothesised that by taking care of several tasks, strong welfare states may "crowd in" intergenerational support and even strengthen family relations.

In recent decades, the intergenerational solidarity model has been widely utilised in intergenerational relations studies. One of the most obvious limitations of this model is its limited ability to formulate testable hypotheses. This limitation is based on the descriptive nature of the model. Recently, Szydlik (2016) attempted to respond to this problem by formulating a model based on proximate factors related to opportunity, need and family, as well as cultural-contextual variables (the ONFC model). The ONFC model can be defined as an extension of the traditional intergenerational solidarity model. The ONFC model notes that the recipient's need for support, the potential giver's opportunity to provide support, the family structure and the cultural context are all related to intergenerational relations. For instance, the ONFC model assumes that those who have more money provide more financial support to their relatives. Moreover, those who need more help receive more help from kin. Finally, individuals are predicted to provide more financial support to their relatives in stronger than in weaker welfare states, because formal support received from the state diminishes the financial burden of families leaving money for informal financial transfers, and enabling relatives to help one another. The ONFC model can be considered useful because it provides testable hypotheses on intergenerational relations.

\section{Intergenerational ambivalence}

The intergenerational solidarity model and related models described above can be criticised for ignoring the ambivalent nature of kin relations. According to the 
concept of intergenerational ambivalence, conflicting and emotionally close relationships are not two alternative sides of intergenerational relations; instead, it is argued that intergenerational relations generate both solidarity and conflict at the same time. In practice, this means that individuals may simultaneously (or within a short period of time) have both positive and negative feelings towards their kin.

Intergenerational ambivalence has long been an understudied topic among social scientists. However, after a special section published in the Journal of Marriage and Family in 2002, this situation has gradually changed; scholars have increasingly paid attention to intergenerational ambivalence in family relations (e.g., Lüscher 2002; Pillemer et al., 2007; Willson et al., 2003). Although the intergenerational ambivalence model can be used to study relations not only between adult children and parents but also between grandchildren and grandparents (Lüscher \& Hoff, 2013), to date, studies concerning the former type of relations have dominated the field.

Rather than a theory, the intergenerational ambivalence model can be defined as a descriptive construction that may help scholars draw attention to seemingly contradictory forces that shape family relations (Connidis, 2015). In the existing literature, intergenerational ambivalence has been divided into two groups, psychological and sociological ambivalence. The term psychological ambivalence has been used by scholars to refer to mixed emotions and behaviours between family members (e.g., Lüscher \& Pillemer, 1998). For instance, psychological ambivalence can be studied by investigating the degree of affection one feels towards a family member even if one is annoyed with that person. Sociological ambivalence, in turn, refers to contradictory expectations towards institutional requirements, such as social status, norms and roles. Sociological ambivalence can exist, for instance, when individuals have contradictory or opposing role expectations.

Intergenerational ambivalence can be detected by using either direct or indirect measures of ambivalence (Lendon et al., 2014). Direct measures of intergenerational ambivalence refer to questions that indicate conflicted or mixed feelings the respondents have towards the same object (e.g., parent or adult child). In these cases, both positive and negative dimensions are measured via a single question. These questions can measure, for instance, how often parents and adult children feel great affection towards each other even if they are angry with each other, how often they have feelings of regard towards each other and how often they have mixed feelings towards each other (Pillemer et al., 2007). Indirect ambivalence can be investigated by using different measures of kin support, emotional closeness and conflict. Although these factors indicate both positive and negative feelings or behaviours, the different aspects of ambivalence are measured via separate questions rather than via one question measuring both negative and positive feelings. Indirect measures of ambivalence can include, for instance, questions about how often parents and adult children meet each other, how often they provide support to each other, how emotionally close they feel towards each other and how often they have disagreements with each other. The scale for indirect ambivalence can be then calculated by combining these different aspects of ambivalence into one factor. Although direct and indirect measures of ambivalence tend to be 
different constructs, they have been shown to correlate relatively strongly with one another (e.g., Lendon et al., 2014).

\section{Life course approach}

In addition to the intergenerational solidarity and intergenerational ambivalence models, another commonly used perspective among social scientists is the life course approach (e.g., Elder \& Johnson, 2003). The life course approach is very descriptive by nature and is often utilised in the same studies as the intergenerational solidarity model. Perhaps the main difference between the intergenerational solidarity and life course models is that the implementations of the life course approach tend to be wider compared to the intergenerational solidarity model (Mortimer \& Shanahan, 2007). In this sense, the life course approach can be considered an "umbrella model" that covers different aspects of human life.

In recent decades, scholars have defined several general aspects that can be considered the main features of the life course approach (Elder et al., 2003; Mayer, 2009). First, the approach notes that the growth and development of any individual is a lifelong process that does not end, for instance, when an individual reaches maturity (e.g., lifelong learning). Second, individuals are seen as active agents who make choices that are available to them and thus construct their own life course careers. Third, the life courses of individuals are related to the historical time and geographical place in which they live. Fourth, according to the life course approach, the age and life course stage at which key life course events occur is important. Finally, life course scholars emphasise that the lives of family members are linked together, meaning that a life course event that one family member experiences influences other social relations among the family members.

The life course perspective emphasises that intergenerational relations are bound to the place and time in which people live (Elder et al., 2003; Settersten, 2003); thus, intergenerational relations may not have been similar in traditional and historical populations compared to contemporary affluent societies. In addition, the approach can describe, although it does not explain, the cultural variation of matri- and patrilocal kin systems. The life course approach also notes that the relations between any family members, including grandparents, parents and children, are always influenced by all other social connections in the family (Cox \& Paley, 1997). This linked lives perspective indicates that a life course transition that a child (e.g., transition from childhood to adulthood), a parent (e.g., having another child) or a grandparent (e.g., leaving the working life behind) experiences should influence others in the same social circle (Crosnoe \& Elder, 2002). Furthermore, the age and the phase of life of a person should affect his or her family relations (Elder, 1994). For instance, when grandparents retire, they may have more time to look after their grandchildren, and when grandchildren are younger, they are more likely to need grandparental child care. Finally, the life course perspective also notes, as does the ONFC model (Szydlik, 2016), that kin support is connected to the receiver's needs and the giver's possibilities. For instance, national family policies shape parents' demand for kin help with child care (Leitner, 2003). 
With its emphasis on age and life stage, the life course perspective comes close to biological life history theory (Lummaa, 2007), which also states that age, life stage and environmental factors are important determinants of, for instance, the reproductive behaviour of humans. One of the main differences between the life course approach and life history theory is that the former is descriptive by nature and does not provide clear testable predictions, whereas the latter does.

\section{Rational grandparents}

Grandparents have also been presented as rational investors based on rational choice theory (Friedman et al., 2008). The rational grandparent model is an extension of the rational parent model (Friedman et al., 1994). According to the theory of grandparents as rational investors, grandparents may allocate their investments in those grandchildren whose parents they believe will support the grandparents when they are older. According to this theory, grandparents can act as rational investors who expect their investment to be reciprocated at some point. One of the key challenges of the rational grandparent model is that testing the hypotheses created by this theory would require longitudinal datasets constructed in a very complex manner.

Although the predictions of the rational grandparent model may not gain support from empirical research in Western countries (Coall \& Hertwig, 2010), reciprocity could be an important issue in non-Western countries such as China or other Asian countries where filial obligations are strong and elderly parents need the assistance from their adult children (e.g., Sheng \& Settles, 2006). Hence, the predictions of the rational grandparent model should be tested within different societies and ideally compare Western societies to non-Western ones.

\section{Outcomes of grandparental involvement}

In recent decades, an increasing number of social science studies have noted that grandparental involvement may have either positive or negative outcomes for children, parents and grandparents themselves. Although evolutionary scholars have often tried to explain the potential kin effects by ultimate reasons, namely, by sex-specific reproductive strategies, the grandmother hypothesis and sexchromosome relatedness, the social science models have concentrated on proximate mechanisms that are often related to need and opportunity structures. It is worth mentioning that in the theoretical sense, the social science studies that concentrate on kin effects tend to be descriptive rather than explanatory and are more strongly empirically than theoretically orientated.

In the case of child outcomes, one of the main predictions among social scientists is that grandparents may increase children's wellbeing during risk situations, including parental death, divorce, severe illness or unemployment (Dunifon et al., 2014). The latent function hypothesis predicts that during "normal" times and stable family situations, grandparents have only a limited impact on child wellbeing, whereas a substantive effect may exist during times of family crises 
(Clingempeel et al., 1992). Thus, one may predict that the grandparental effect should be highest in risk conditions, such as in single-parent families and families with financial difficulties. In these situations, grandparents are predicted to compensate for the lack of family resources.

Stratification sociologists have investigated the potential status attainment from grandparents to grandchildren, making an important division between grandparental investment and endowment (Box 2.5). The meaning of grandparental investment is somewhat different among stratification sociologists than among evolutionary scholars. Perhaps the most important difference is that among sociologists, grandparental investment refers to conscious action, whereas evolutionary scholars note that grandparental investment can be also unconscious (in this book, we have adopted the latter definition; see Chapter 1: Box 1.2). The main difference between grandparental investment and endowment is that the former requires active grandparenting, whereas the latter may benefit children simply by existing. Whether grandparental investment and endowment help children achieve higher socioeconomic status is an important question in stratification studies (Pfeffer, 2014).

\section{Box 2.5 Grandparental endowment}

Grandparental endowments include any available resources from which grandchildren can potentially benefit, such as wealth, human and cultural resources, social networks, grandparental status or shared genes. Grandparental endowments can benefit children even after grandparents have passed away, such as through inheritance, trusts or accumulated wealth. Grandparental endowment differs from grandparental investment in that endowments cannot be two-way.

The compensation view has been utilised in social science studies to detect relations between the involvement of older parents and the childbearing of their adult children. It is predicted that kin support may influence fertility in countries with weak public support for families (Aassve et al., 2012; Thomese \& Liefbroer, 2013). The main point is that the support received from one's own parents can compensate for the lack of publicly provided support, such as the non-availability of publicly arranged child care services. Based on this perspective, in countries with strong public support for families, the influence of parents on their adult children's childbearing should be lower than in countries with weak public support for families.

Finally, grandparental involvement can have either positive or negative effects for grandparents themselves. If one expects that "it is good to be good" (Post, 2005), meaning that helping others is related to the helper's own wellbeing, it can be expected that grandparental involvement is associated with improved health and wellbeing among grandparents themselves (Arpino \& Bordone, 2014). 
However, it should be noted that whether the grandparental outcomes are positive or negative may be related to grandparents' opportunities to provide support to their descendants. The positive effect may exist if grandparents are not forced to be involved "too much" (Coall \& Hertwig, 2010). In contrast, the negative effect might arise when grandparents must be overly involved (Baker \& Silverstein, 2008; Chen \& Liu, 2012; Grinstead et al., 2003; Hughes et al., 2007). For instance, when grandparents fill the parental gap and serve as the main carers for their grandchildren, this situation may be too stressful for them (Dunifon, 2013). In their older age, grandparents may not be able to provide a high amount of support for others without severe costs to their own wellbeing. Thus, in these circumstances, grandparental involvement can be predicted to have negative outcomes for their own health and wellbeing.

\section{Differences and similarities}

In the previous sections, we have introduced evolutionary and social science models of intergenerational relations. In this sub-chapter, we concentrate on the differences and similarities between the evolutionary and social science approaches. Moreover, we discuss the pros and cons of both perspectives.

One of the most important strengths of evolutionary theory is its ability to provide a scientific basis for the reasons for the existence of close intergenerational relations and caring grandparenthood. Inclusive fitness (Hamilton, 1964) and parental investment (Trivers, 1972) theories offer ultimate explanations for the questions of why humans favour their close kin over more distant kin or nonkin and why humans in general invest in their descendants. According to the evolutionary perspective, the ultimate reason for kin investment is the possibility to gain benefits, measured as inclusive fitness. Once again, it is important to note that when evolutionary scientists consider fitness benefits, they emphasise that human behaviour that may lead to improved fitness is often unconscious by nature, meaning that individuals do not typically behave as they do because they are consciously attempting to increase their fitness; rather, they are following specific emotions and cues that lead to a certain behaviour (see Box 2.1). Another important point is that behaviour that was beneficial in the environment of evolutionary adaptedness may no longer be beneficial in modern societies (Tanskanen, 2013).

Obviously, the evolutionary framework also has limitations. Although the inclusive fitness theory underlines the phrase "all else being equal", which means that all potential confounding variables (such as the health and age of a grandparent or the geographical distance between the grandparent and grandchild) should be taken into account, evolutionary researchers have been less interested in variables related to grandparental investment other than genetic relatedness, sex and lineage. The current starting point is that multivariate models are essential when studying biased grandparental investment. However, the background variables are sometimes differently connected to the main explanatory variables (genetic relatedness, sex and lineage). Thus, some of them (e.g., emotional closeness or 
marital status of a grandparent) deserve more attention than has been given in earlier evolutionary research (but see, e.g., Pollet et al., 2013).

In addition, with regard to grandparental (or parental) investments, evolutionary research often takes into account only the grandparent's view (i.e., the investor's view). Studies of grandparental investment from the evolutionary perspective do not normally consider the receiver's willingness to accept the investment. However, all grandparental investments may not be accepted by parents (Barnett et al., 2010).

Human families are flexible by nature. This means that human family members are sensitive to environmental cues, learn from experience and may often facultatively adapt to the behavioural strategy for an existing situation, which tends to increase inclusive fitness (Barkow, 2006; Barrett et al., 2002). Compared with most other animals, human family systems are remarkably adaptable, including variation in subsistence, marriage and residence patterns (Sear, 2015). Nevertheless, the premises for the basic strategic decision patterns, whether they are conscious or unconscious, remain the same: they are often based on the outcomes of inclusive fitness, life history trade-offs, sex-specific reproductive strategies, the possibility of paternity uncertainty or the availability of alloparents. The question that links evolutionary research to social science family studies is thus related to the importance and effects of contextual factors.

The cultural context matters in the case of intergenerational relations and biased grandparental investment. The most obvious way to show how this is true is to study patrilocal cultures, in which a woman becomes part of her husband's kin after marriage (Kaptijn et al., 2013; Pashos, 2017). This usually means that a new couple will live much nearer to the man's kin than the woman's and that future children will grow up in the presence of their paternal grandparents and will most probably see their maternal grandparents only occasionally (but see Perry, 2017a, 2017b). This obviously affects which of the grandparents becomes closest to the grandchild (Pashos, 2000). In matrilocal populations, in turn, women stay with their own kin more often than men do, and their husbands are the ones who change their location after marriage (Leonetti et al., 2007; Sear, 2008). Naturally, in these formations, the women's kin become closer to the grandchild.

Other factors that may be associated with grandparental investment and that vary according to the socio-ecological context are geographical proximity between parental and grandparental generations; age of the grandparent, parent and child; socioeconomic status of the grandparent and parent; marital status of the grandparent and parent; and the number of grandchildren and grandchildren sets. These variables are related to need and opportunity structures (Szydlik, 2008, 2012) and may be similarly associated with grandparental investments in the case of all grandparents (e.g., the effect of grandparent's health or age), or the associations may vary according to sex, lineage or genetic relatedness (e.g., biological or in-law relationship) between parental and grandparental generations.

One theme is of particular interest: emotions (more precisely, emotional closeness) and the different understandings of emotional closeness in evolutionary and social science research. In evolutionary research, the emotional closeness 
between family members is often treated as a dependent variable, a measurement of an investment such as emotional support (e.g., Tanskanen \& Rotkirch, 2014). In addition, the emotional closeness of a specific type of grandparentparent relationship can be understood as a product of reproductive choices and their fitness consequences that are shaped by sex and lineage (Euler, 2011). The other way to understand emotional closeness in evolutionary research is to treat it as a mediator of an association between genetic relatedness and kin investment. Importantly, emotional closeness may mediate the association differently according to the degree of genetic relatedness (Pollet et al., 2013). The "kinship premium" hypothesis has its roots in inclusive fitness theory (Hamilton, 1964) and states that kinship has its own unique connection to investments in close kin even after controlling for emotional closeness (Curry et al., 2013; Hackman et al., 2015). This means that emotional closeness alone cannot account for investment in close kin; rather, individuals are more willing to act altruistically towards their close relatives than their more distant relatives or non-related friends, even after emotional closeness is taken into account.

In social science research, kin affection, which is a dimension of intergenerational solidarity measured as emotional closeness or relationship quality, has traditionally been understood as a main explanation for kin altruism (e.g., Chan \& Elder, 2000). Thus, kinship itself does not have its own unique influence on intergenerational support, nor does its impact differ between kin members, as is assumed in the kinship premium hypothesis.

In social science research, intergenerational relations are understood as a complex phenomenon. Several models have been developed among social scientists, and different dimensions have been used to describe the solidarity and conflict apparent in family relations. Social science scholars have also developed theories of intergenerational stake and women as kin keepers, which make somewhat similar predictions as evolutionary theories. The advantage of the social science approach is that it has a long tradition of describing and classifying different societal structures, cultural norms and socio-ecological circumstances that may help to understand family dynamics. In addition, it takes into account that the investments may not be automatically accepted.

According to the linked lives perspective, the lives of family members are related in that the relationships between any two persons also influence other relationships in the family system (King \& Elder, 1995). A common question related to the concept of linked lives is how significant the role of parents as gatekeepers between a grandparent and a grandchild actually is (Robertson, 1975; Thompson \& Walker, 1987). From an evolutionary viewpoint, due to consanguinity, sexspecific reproductive strategies and paternity uncertainty, the quality of the relationship between eight different parent-grandparent dyads should be expected to be better between genetic kin than between in-laws in the following order, from best to worst: mother-daughter, father-daughter, mother-son, father-son, motherin-law-son-in-law, father-in-law-son-in-law, father-in-law-daughter-in-law and mother-in-law-daughter-in-law (Euler, 2011). As we consider these dyadic relations from the viewpoint of linked lives and the fact that in an intergenerational 
framework all dyadic relations are associated with other dyadic relations, we may assume that the gatekeeping role of a daughter-in-law towards paternal grandparents should be the most significant. In addition, it is obvious that the gatekeeping role of parents should be more substantial when children are small and parental influence is high, although there may be differences between biological and inlaw relations, as mentioned above.

The intergenerational solidarity (e.g., Bengtson, 2001) and ambivalence (e.g., Lüscher \& Pillemer, 1998) models, the life course approach (e.g., Elder et al., 2003) and the ONFC model (Szydlik, 2016) have provided an increasingly nuanced picture of the factors related to the structure of intergenerational relations, support and conflict. From the viewpoint of ultimate and proximate reasons, these social science explanations can be understood as the proximate causes that promote or lessen kin support or conflict in modern societies. However, social science models or explanations can rarely answer the question of why intergenerational relations are formed the way they are. The focus is often on contextual explanations that change over time rather than explanations that enhance our understanding of the function and evolution (as well as the continuities and similarities) of intergenerational relations.

Despite the increasing interest in intergenerational relations during recent decades, the reasons for the existence of caring grandparenthood have been undertheorized among social scientists. When they provide hypotheses that can be empirically tested, the limitation is that they tend to be unable to present general principles that can logically and coherently explain a large amount of phenomena.

Social science studies have not traditionally examined humans as a biological species, although many of the key assumptions (e.g., the intergenerational stake hypothesis or women as kin keepers) produce the same predictions as evolutionary theories. In the social science framework, there is no coherent and explanatory macro-level theoretical frame for intergenerational relations and grandparental investment that would integrate all assumptions and hypotheses. Here, the social science research would benefit from taking evolutionary theory into account.

\section{Conclusions}

In this chapter, we have outlined theoretical approaches to intergenerational relations from evolutionary and social science perspectives. Both fields of study have considered not only cooperation and support but also disagreements and conflict among relatives. The three cornerstones of evolutionarily relevant variables are genetic relatedness, sex and lineage. Evolutionary theories concerning intergenerational relations predict that biological grandparents invest more in their grandchildren than non-biological ones do, and among biological grandparents, maternal grandmothers invest the most, whereas paternal grandfathers invest the least. Both evolutionary and social science theories suggest that older generations provide more support to younger ones than vice versa, although the theoretical explanations behind these predictions are not the same. In social science studies, it is often presumed that receivers' needs and givers' opportunities influence kin investment in the way that 
increased needs and opportunities are related to increased kin support. Moreover, among both theoretical perspectives, the relations between parental and grandparental generations have been assumed to influence the amount of time and resources grandparents channel towards grandchildren. In the next chapters, we examine whether the theories presented above receive support from empirical studies.

\section{References}

Aassve, A., Meroni, E., \& Pronzato, C. (2012). Grandparenting and childbearing in the extended family. European Journal of Population, 28, 499-518.

Abbot, P., Abe, J., Alcock, J., Alizon, S., ... et al. (2011). Inclusive fitness theory and eusociality. Nature, 471, E1-E4.

Alvergne, A., Faurie, C., \& Raymond, M. (2009). Father-offspring resemblance predicts paternal investment in humans. Animal Behaviour, 78, 61-69.

Antfolk, J. (2014). Incest aversion: The evolutionary roots of individual regulation. Åbo: Åbo Akademi.

Antfolk, J., Lindqvist, H., Albrecht, A., \& Santtila, P. (2014). Self-reported availability of kinship cues during childhood is associated with kin-directed behavior to parents in adulthood. Evolutionary Psychology, 12, 148-166.

Arber, S., \& Timonen, V. (Eds.) (2012). Contemporary grandparenting: Changing family relationships in global contexts. Chicago: Policy Press.

Arpino, B., \& Bordone, V. (2014). Does grandparenting pay off? The effect of child care on grandparents' cognitive functioning. Journal of Marriage and Family, 76, 337-351.

Atkinson, M. P., Kivett, V. R., \& Cambell, R. T. (1986). Intergenerational solidarity: An examination of a theoretical model. Journal of Gerontology, 41, 408-416.

Atran, S. (2001). The Case for Modularity: Sin or Salvation? Evolution and Cognition, 7, $1-10$.

Baker, L. A., \& Silverstein, M. (2008). Preventive health behaviors among grandmothers raising grandchildren. Journals of Gerontology Series B: Psychological Sciences and Social Sciences, 63, S304-S311.

Barkow, J. H. (2006). Introduction: Sometimes the bus does wait. In J. H. Barkow (Ed.), Missing the revolution: Darwinism for social scientists (pp. 3-60). Oxford: Oxford University Press.

Barnett, M. A., Scaramella, L. V., Neppl, T. K., Ontai, L., \& Conger, R. D. (2010). Intergenerational relationship quality, gender, and grandparent involvement. Family Relations, 59, 28-44.

Barrett, L., Dunbar, R. I. M., \& Lycett, J. (2002). Human evolutionary psychology. Princeton: Princeton University Press.

Baydar, N., \& Brooks-Gunn, J. (1998). Profiles of grandmothers who help care for their grandchildren in the United States. Family Relations, 47, 385-393.

Bengtson, V. L. (1975). Generations and family effects in value socialization. American Sociological Review, 40, 358-371.

Bengtson, V. L. (2001). Beyond the nuclear family: The increasing importance of multigenerational bonds. Journal of Marriage and Family, 63, 1-16.

Bengtson, V. L., \& Kuypers, J. A. (1971). Generational difference and the developmental stake. Aging and Human development, 2, 249-260.

Bengtson, V. L., \& Roberts, R. E. (1991). Intergenerational solidarity in ageing families: An example of formal theory construction. Journal of Marriage and Family, 53, 856-870. 
Bracke, P., Christiaens, W., \& Wauterickx, N. (2008). The pivotal role of women in informal care. Journal of Family Issues, 29, 1348-1378.

Brent, L. J. N., Franks, D. W., Foster, E. A., Balcomb, K. C., Cant, M. A., \& Croft, D. P. (2015). Ecological knowledge, leadership, and the evolution of menopause in killer whales. Current Biology, 25, 746-750.

Bressan, P., \& Kramer, P. (2015). Human kin detection. Cognitive Science, 6, 299-311.

Broadfield, D. C. (2010). Grandparental investment and the epiphenomenon of menopause in recent human history. Behavioral and Brain Sciences, 33, 19-20.

Burton-Chellew, M. N., \& Dunbar, R. I. M. (2011). Are affines treated as biological kin? A test of Hughes's hypothesis. Current Anthropology, 52, 741-746.

Campbell, A. (2013). A mind of her own: The evolutionary psychology of women. Oxford: Oxford University Press.

Cant, M. A., \& Johnstone, R. A. (2008). Reproductive conflict and the separation of reproductive generations in humans. Proceedings of the National Academy of Sciences, $105,5332-5336$.

Chan, C. G., \& Elder, G. H., Jr. (2000). Martilineal advantage in grandchild-grandparent relations. The Gerontologist, 40, 179-190.

Chen, F., \& Liu, G. (2012). The health implications of grandparents caring for grandchildren in China. The Journals of Gerontology Series B: Psychological Sciences and Social Sciences, 67, 99-112.

Chisholm, J. S. (1999). Attachment and time preference: Relations between early stress and sexual behavior in a sample of American university women. Human Nature, 10, 51-83.

Chisholm, J. S., Quinlivan, J. A., Petersen, R. W., \& Coall, D. A. (2005). Early stress predicts age at menarche and first birth, adult attachment, and expected lifespan. Human Nature, 16, 233-265.

Chrastil, E. R., Getz, W. M., Euler, H. A., \& Starks, P. T. (2006). Paternity uncertainty overrides sex chromosome selection for preferential grandparenting. Evolution and Human Behavior, 27, 206-223.

Clingempeel, W. G., Colyar, J. J., Brand, E., \& Hetherington, E.M. (1992). Children's relationships with maternal grandparents: A longitudinal study of family structure and pubertal status effects. Child Development, 63, 1404-1422.

Coall, D. A., \& Hertwig, R. (2010). Grandparental investment: Past, present, and future. Behavioral and Brain Sciences, 33, 1-59.

Coall D. A., Hilbrand, S., \& Hertwig, R. (2014). Predictors of grandparental investment decisions in contemporary Europe: Biological relatedness and beyond. PLoS ONE, 9, e84082.

Coall D. A., Hilbrand, S., Sear, R., \& Hertwig, R. (2016). A new niche? The theory of grandfather involvement. In A. Buchanan \& A. Rotkirch (Eds.), Grandfathers: Global perspectives (pp. 21-44). London: Palgrave MacMillan.

Collins, D. A., Busse, C. D., \& Goodall, J. (1984). Infanticide in two populations of savanna baboons. In G. Hausfater \& S. B. Hrdy (Eds.), Infanticide: Comparative and evolutionary perspectives (pp. 193-216). Hawthorne, UK: Aldine.

Connidis, I. A. (2015). Exploring ambivalence in family ties: Progress and prospects. Journal of Marriage and Family, 77, 77-95.

Cox, M. J., \& Paley, B. (1997). Families as systems. Annual Review of Psychology, 48, 243-267.

Croft, D. P., Johnstone, R. A., Ellis, S., Nattrass, S., Franks, D. W., ... et al. (2017). Reproductive conflict and the evolution of menopause in killer whales. Current Biology, 27, 298-304. 
Crosnoe, R., \& Elder, G. H. (2002). Life course transitions, the generational stake, and grandparent-grandchild relationships. Journal of Marriage and Family, 64, 1089-1096.

Curry, O., Roberts, S. G. B., \& Dunbar, R. I. M. (2013). Altruism in social networks: Evidence for a "kinship premium." British Journal of Psychology, 104, 283-295.

Daly, M., \& Wilson, M. I. (1982). Whom are newborn babies said to resemble? Ethology and Sociobiology, 3, 69-78.

Danielsbacka, M., Tanskanen, A. O., Jokela, M., \& Rotkirch, A. (2011). Grandparental child care in Europe: Evidence for preferential investment in more certain kin. Evolutionary Psychology, 9, 3-24.

Danielsbacka, M., Tanskanen, A. O., \& Rotkirch, A. (2015). The Impact of genetic relatedness and emotional closeness on intergenerational relations. Journal of Marriage and Family, 77, 889-907.

Danielsbacka, M., Tanskanen, A. O., \& Rotkirch, A. (2017). The "kinship penalty": Parenthood and in-law conflict in contemporary Finland. Evolutionary Psychological Science, 3, 1-12.

Darwin, C. (1859). On the Origin of Species. London: John Murray.

DeBruine, L. M. (2004). Resemblance to self increases the appeal of child faces to both men and women. Evolution and Human Behavior, 25, 142-154.

DeBruine, L. M. (2005). Trustworthy but not lust-worthy: Context-specific effects of facial resemblance. Proceedings of the Royal Society of London B, 272, 919-922.

Dubas, J. S. (2001). How gender moderates the grandparent-grandchild relationship. Journal of Family Issues, 22, 478-492.

Dunifon, R. (2013). The influence of grandparents in the lives of children and adolescents. Child Development Perspectives, 7, 55-60.

Dunifon, R. E., Ziol-Guest, K. M., \& Kopko, K. (2014). Grandparent coresidence and family well-being: Implications for research and policy. The ANNALS of the American Academy of Political and Social Science, 654, 110-126.

Elder, G. H. (1994). Time, human aging and social change: Perspectives on the life course. Social Psychology Quarterly, 57, 4-15.

Elder, G. H., Jr., \& Johnson, M. K. (2003). The life course and aging: challenges, lessons, and new directions. In R. A. Settersten, Jr. (Ed.), Invitation to the life course: Toward new understandings of later life (pp. 48-81). Amityville, NY: Baywood.

Elder, G. H., Jr., Johnson, M. K., \& Crosnoe, R. (2003). The emergence and development of life course theory. In J. T. Mortimer \& M. J. Shanahan (Eds.), Handbook of the life course (pp. 3-22). New York: Kluwer.

Euler, H. A. (2011). Grandparents and extended kin. In C. A. Salmon \& T. K. Shackelford (Eds.), The Oxford handbook of evolutionary family psychology (pp. 181-207). New York: Oxford University Press.

Euler, H. A., \& Michalski, R. L. (2008). Grandparental and extended kin relationshps. In C. A. Salmon and T. K. Shackelford (Eds.), Family relationships: An evolutionary perspective (pp. 230-256). New York: Oxford University Press.

Euler, H. A., \& Weitzel, B. (1996). Discriminative grandparental solicitude as reproductive strategy. Human Nature, 7, 39-59.

Fischer, L. R. (1986). Linked lives: Adult daughters and their mothers. New York: Harper and Row.

Foster, E. A., Franks, D. W., Mazzi, S., Darden, S. K., Balcomb, K. C., Ford, J. K. B., \& Croft, D. P. (2012). Adaptive prolonged postreproductive life span in killer whales. Science, 337, 1313. 
Fox, M., Sear, R., Beise, J., Ragsdale, G., Voland, E., \& Knapp, L. A. (2010). Grandma plays favourites: X-chromosome relatedness and sex-specific childhood mortality. Proceedings of the Royal Society B: Biological Sciences, 277, 567-573.

Friedman, D., Hechter, M., \& Kanazawa, S. (1994). A theory of the value of children. Demography, 31, 375-401.

Friedman, D., Hechter, M., \& Kreager, D. (2008). A theory of the value of grandchildren. Rationality and Society, 20, 31-63.

Giarrusso, R., Stallings, M., \& Bengtson, V. L. (1995). The 'intergenerational stake' hypothesis revisited: parent-child differences in perceptions of relationships 20 years later. In V. L. Bengtson, K. W. Schaie \& L. M. Burton (Eds.), Intergenerational issues in aging: Effects of societal change (pp. 227-263). New York: Springer.

Grinstead, L. N., Leder, S., Jensen, S., \& Bond, L. (2003). Review of research on the health of caregiving grandparents. Journal of Advanced Nursing, 44, 318-326.

Hackman, J., Danvers, A., \& Hruschka, D. J. (2015). Closeness is enough for friends, but not mates or kin: Mate and kinship premiums in India and U.S. Evolution and Human Behavior, 36, 137-145.

Hagestad, G. (1985). Continuity and connectedness. In V. L. Bengston \& J. F. Robertson (Eds.), Grandparenthood (pp. 31-48). Beverly Hills: Sage.

Hagestad, G. (1986). The family: Women and grandparents as kin-keepers. In A. Pifer, \& L. Bronte (Eds.), Our aging society: Paradox and promise (pp.141-160). New York: Norton.

Haig, D. (2011). Genomic imprinting and the evolutionary psychology of human kinship. Proceedings of the National Academy of Science, 108, 10878-10885.

Hamilton, W. D. (1964). The genetical evolution of social behaviour (I and II). Journal of Theoretical Biology, 7, 1-52.

Hawkes, K. (2003). Grandmothers and the evolution of human longevity. American Journal Human Biology, 15, 380-400.

Hawkes, K. \& Blurton Jones, N. G. (2005). Human age structures, paleodemography, and the grandmother hypothesis. In E. Voland, A. Chasiotis \& W. Schiefenhövel (Eds.), Grandmotherhood: The evolutionary significance of the second half of female life (pp. 118-140). New Jersey: Rutgers University Press.

Hill, K. \& Kaplan, H. (1999). Life history traits in humans: Theory and empirical studies. Annual Review of Anthropology, 28, 397-430.

Hoff, A. (2007). Patterns of intergenerational support in grandparent-grandchild and parent-child relationships in Germany. Ageing \& Society, 27, 643-665.

Hopcroft, R. L. (2005). Parental status and differential investment in sons and daughters: Trivers-Willard revisited. Social Forces, 83, 1111-1136.

Hopcroft, R. L. (2010). Sociology: A Biosocial Introduction. London: Paradigm.

Hopcroft, R. L. (2015). Sociobiology at work in modern populations. In J. H. Turner, R. Machalek \& A. Maryanski (Eds.), Handbook on evolution and society: Toward an evolutionary social science (pp. 122-135). London: Routledge.

Hrdy, S. B. (1999). Mother nature: A history of mothers, infants, and natural selection. New York: Pantheon Books.

Hrdy, S. B. (2009). Mothers and others: The evolutionary origins of mutual understanding. Cambridge, MA: Harvard University Press.

Hughes, A. L. (1988). Evolution and human kinship. New York: Oxford University Press.

Hughes, M. E., Waite, L. J., LaPierre, T. A., \& Luo, Y. (2007). All in the family: The impact of caring for grandchildren on grandparents' health. The Journals of Gerontology Series B: Psychological Sciences and Social Sciences, 62, S108-S119. 
Kachel, F. A., Premo L. S., \& Hublin, J.-J. (2011). Grandmothering and natural selection. Proceedings of the Royal Society of London B: Biological Sciences, 278, 384-391.

Kaptijn, R., Thomese, F., Liefbroer, A. C., \& Silverstein, M. (2013). Testing evolutionary theories of discriminative grandparental investment. Journal of Biosocial Science, 45 , 289-310.

Kim, P. S., Coxworth, J. E., \& Hawkes, K. (2012). Increased longevity evolves from grandmothering. Proceedings of the Royal Society of London B: Biological Sciences, $279,4880-4884$.

King, V., \& Elder, G. H., Jr. (1995). American children view their grandparents: Linked lives across three rural generations. Journal of Marriage and Family, 57, 165-178.

Kokko, H. \& Jennions, M. D. (2003). It takes two to tango. Trends in Ecology \& Evolution, 18, 103-104.

Krupp, D. B., DeBruine, L. M., \& Jones, B. C. (2011). Cooperation and conflict in the light of kin recognition systems. In C. Salmon \& T. K. Shackelford (Eds.), The Oxford handbook of evolutionary family psychology (pp. 345-362). New York: Oxford University Press.

Künemund, H., \& Rein, M. (1999). There is more to receiving than needing: Theoretical arguments and empirical explorations of crowding in and crowding out. Ageing \& Society, 19, 93-121.

Laham, S. M., Gonsalkorale, K., \& von Hippel, W. (2005). Darwinian grandparenting: Preferential investment in more certain kin. Personality and Social Psychology Bulletin, 31, 63-72.

Lahdenperä, M. (2010). Evolution of prolonged longevity in humans. Turku: Annales Universitatis Turkuensis.

Lahdenperä, M., Gillespie, D. O. S., Lummaa, V., \& Russel, A. F. (2012). Severe intergenerational reproductive conflict and the evolution of menopause. Ecology Letters, $15,1283-1290$.

Lahdenperä, M., Mar, K. U., \& Lummaa, V. (2016). Nearby grandmother enhances calf survival and reproduction in Asian elephants. Scientific Reports, 6, 27213.

Lee, P. C. (1987). Allomothering among African elephants. Animal Behaviour, 35, 278-291.

Leitner, S. (2003). Varieties of familialism: The caring function of the family in comparative perspective. European Societies, 5, 353-375.

Lendon, J. P., Silverstein, M., \& Giarrusso, R. (2014). Ambivalence in older parent-adult child relationships: Mixed feelings, mixed measures. Journal of Marriage and Family, 76, 272-284.

Leonetti, D. L., Nath, D. C., \& Hehman, N. S. (2007). In-law conflict: Women's reproductive lives and the roles of their mothers and husbands among the matrilineal Khasi. Current Anthropology, 48, 861-890.

Lieberman, D., Tooby, J., \& Cosmides, L. (2007). The architecture of human kin detection. Nature, 445, 727-731.

Low, B. S. (1978). Environmental uncertainty and the parental strategies of marsupials and placentals. The American Naturalist, 112, 197-213.

Lummaa, V. (2007). Life-history theory, longevity and reproduction in humans. In R. I. M. Dunbar \& L. Barrett (Eds.), Oxford handbook of evolutionary psychology (pp. 397-413). New York: Oxford University Press.

Lüscher, K. (2002). Intergenerational ambivalence: Further steps in theory and research. Journal of Marriage and Family, 64, 585-593. 
Lüscher, K., \& Hoff, A. (2013). Intergenerational ambivalence: Beyond solidarity and conflict. In: I. Albert \& D. Ferring (Eds.), Intergenerational relations: European perspectives on family and society (pp. 39-63). Bristol: Policy Press.

Lüscher, K., \& Pillemer, K. (1998). Intergenerational ambivalence: A new approach to the study of parent-child relations in later life. Journal of Marriage and the Family, 60, 413-425.

Mace, R., \& Sear, R. (2005). Are humans cooperative breeders? In E. Voland, A. Chasiotis \& W. Schiefenhövel (Eds.), Grandmotherhood: The evolutionary significance of the second half of female life (pp. 143-159). New Jersey: Rutgers University Press.

Marcinkowska, U. M., \& Rantala, M. J. (2012). Sexual imprinting on facial traits of opposite-sex parents in humans. Evolutionary Psychology, 10, 621-630.

Mare, R. D. (2011). A multigenerational view of inequality. Demography, 48, 1-23.

Marlowe, F. (2000). The patriarch hypothesis: An alternative explanation of menopause. Human Nature, 11, 27-42.

Matthews, S. H., \& Sprey, J. (1985). Adolescents' relationships with grandparents: An empirical contribution to conceptual clarification. Journal of Gerontology, 40, 621-626.

Mayer, K. U. (2009). New directions in life course research. Annual Review of Sociology, $35,413-433$.

McBurney, D. H., Simon, J., Gaulin, S. J. C., \& Geliebter, A. (2002). Matrilateral biases in the investment of aunts and uncles: Replication in a population presumed to have high paternity certainty. Human Nature, 13, 391-402.

McLain, D. K., Setters, D., Moulton, M. P., \& Pratt, A. E. (2000). Ascription of resemblance of newborns by parents and nonrelatives. Evolution and Human Behavior, 21, 11-23.

Merton, Robert K. (1968). Social theory and social structure. New York: The Free Press.

Miller, G. E., Yu, T., Chen, E., \& Brody, G. H. (2015). Self-control forecasts better psychosocial outcomes but faster epigenetic aging in low-SES youth. Proceedings of the National Academy of Sciences, 112, 10325-10330.

Mortimer, J. T., \& Shanahan, M. J. (Eds.) (2007). Handbook of the life course. New York: Kluwer.

Mueller, Z., \& Litwin, H. (2011). Grandparenting and psychological well-being: How important is grandparent role centrality? European Journal of Ageing, 8, 109-118.

Nakamichi, M., Silldorff, A., Bringham, C., \& Sexton, P. (2004). Baby-transfer and other interactions between its mother and grandmother in a captive social group of lowland gorillas. Primates, 45, 73-77.

Norris, K. S., \& Pryor, K. (1991). Some thoughts on grandmothers. In K. Pryor \& K. S. Norris (eds.), Dolphin societies: Discoveries and puzzles (pp. 287-289). Berkeley, CA: University of California Press.

Pashos, A. (2000). Does paternity uncertainty explain discriminative grandparental solicitude? A cross-cultural study in Greece and Germany. Evolution and Human Behavior, 21, 97-109.

Pashos, A. (2017). Asymmetric caregiving by grandparents, aunts, and uncles and the theories of kin selection and paternity certainty: How does evolution explain human behavior toward close relatives? Cross-Cultural Research, 263-284.

Pashos, A., Schwarz, S., \& Björklund, D. F. (2016). Kin investment by step-grandparents more than expected. Evolutionary Psychology, 14, 1-13.

Paul, A. (2005). Primate dispositions for human grandmaternal behavior. In E. Voland, A. Chasiotis \& W. Schiefenhövel (Eds.), Grandmotherhood: The evolutionary significance of the second half of female life (pp. 21-37). New Brunswick, NJ: Rutgers University Press. 
Peccei, J. S. (2001). A critique of the grandmother hypotheses: Old and new. American Journal of Human Biology, 13, 434-452.

Perry, G. (2017a). Alloparental care and assistance in a normatively patrilocal society. Current Anthropology, 58, 114-123.

Perry, G. (2017b). Going home: How mothers maintain natal family ties in a patrilocal society. Human Nature, 28, 219-230.

Pettay, J. E., Lahdenperä, M., Rotkirch, A., \& Lummaa, V. (2016). Costly reproductive competition between co-resident females in humans. Behavioral Ecology, 27, 1601-1608.

Pfeffer, F. T. (2014). Multigenerational approaches to social mobility: A multifaceted research agenda. Research in Social stratification and Mobility, 35, 1-12.

Pillemer, K., Suitor, J. J., Mock, S. E., Sabir, M., Pardo, T. B., \& Sechrist, J. (2007). Capturing the complexity of intergenerational relations: Exploring ambivalence within later-life families. Journal of Social Issues, 63, 775-791.

Platek, S. M., Burch, R. L., Panyavin, I. S., Wasserman, B. H., \& Gallup, G. G., Jr. (2002). Reactions to children's faces: Resemblance affects males more than females. Evolution and Human Behavior, 23, 159-166.

Pollet, T. V., Nettle, D. \& Nelissen, M. (2006). Contact frequencies between grandparent and grandchildren in a modern society: Estimates of the impact of paternity uncertainty. Journal of Cultural and Evolutionary Psychology, 4, 203-213.

Pollet, T. V., Roberts, S. G. B., \& Dunbar, R. I. M. (2013). Going that extra mile: Individuals travel further to maintain face-to-face contact with highly related kin than with less related kin. PLoS ONE, 8: e53929.

Post, S. G. (2005). Altruism, happiness, and health: It's good to be good. International Journal of Behavioral Medicine, 12, 66-77.

Rice, W. R., Gavrilets, S., \& Friberg, U. (2010). The evolution of sex-specific grandparental harm. Proceedings of the Royal Society B: Biological Science, 277, 2727-2735.

Richardson, D. S., Burke, T., \& Komdeur, J. (2007). Grandparent helpers: The adaptive significance of older, postdominant helpers in the Seychelles warbler. Evolution, 61, 2790-2800.

Roberts, R. E., Richards, L. N., \& Bengtson, V. (1991). Intergenerational solidarity in families: Untangling the ties that bind. Marriage \& Family Review, 16, 11-46.

Robertson, J. F. (1975). Interaction in three generation families, parents as mediators: Toward a theoretical perspective. The International Journal of Aging and Human Development, 6, 103-110.

Rossi, A. S., \& Rossi, P. H. (1990). Of human bonding: Parent-child relations across the life course. New York: Aldine.

Rotkirch, A. (2018). Evolutionary family sociology. In R. L. Hopcroft (Ed.), Oxford handbook of evolution, biology, and society (pp. 451-478). Oxford: Oxford University Press.

Rotkirch, A., \& Janhunen, K. (2010). Maternal guilt. Evolutionary Psychology, 8, 90-106.

Sanderson, S. K. (2012). Rethinking sociological theory: Introducing and explaining a scientific theoretical sociology. London: Paradigm.

Sear, R. (2008). Kin and child survival in rural Malawi: Are matrilineal kin always beneficial in a matrilineal society? Human Nature, 19, 277-293.

Sear, R. (2015). Evolutionary contributions to the study of human fertility. Population Studies, 69, S39-S55.

Sear, R. (2016). Beyond the nuclear family: An evolutionary perspective on parenting. Current Opinion in Psychology, 7, 98-103. 
Sear, R., \& Coall D. A. (2011). How much does family matter? Cooperative breeding and the demographic transition. Population and Development Review, 37, 81-112.

Sear, R., \& Mace, R. (2008). Who keeps children alive? A review of the effects of kin on child survival. Evolution and Human Behavior, 29, 1-18.

Settersten, R. A. (2003). Propositions and controversies in life-course scholarship. In R. A. Settersten (Ed.), Invitation to the life course: Toward new understandings of later life (pp. 15-45). Amityville, NY: Baywood.

Sheng, X., \& Settles, B. H. (2006). Intergenerational relationships and elderly care in China: A global perspective. Current Sociology, 54, 293-313.

Silverstein, M., Giarrusso, R., \& Bengtson, V. L. (1998). Intergenerational solidarity and the grandparent role. In M. E. Szinovacs (Ed.), Handbook on grandparenthood (pp. 144-158). Westport, CT: Greenwood Press.

Smith, M. S. (1988). Research in developmental sociobiology: Parenting and family behavior. In K. B. MacDonald (Ed.), Sociobiological perspectives on human development (pp. 271-292). New York: Springer.

Sprey, J., \& Matthews, S. H. (1982). Contemporary grandparenthood: A systemic transition. Annals of the American Academy of Political and Social Sciences, 464, 91-103.

Stearns, S. C. (1992). The evolution of life histories. Oxford: Oxford University Press.

Strassmann, B. I. (2011). Cooperation and competition in a cliff-dwelling people. Proceedings of the National Academy of Sciences, 108, 10894-10901.

Strassmann, B. I., \& Garrard, W. M. (2011). Alternatives to the grandmother hypothesis: A meta-analysis of the association between grandparental and grandchild survival in patrilineal populations. Human Nature, 22, 201-222.

Szydlik, M. (2008). Intergenerational solidarity and conflict. Journal of Comparative Family Studies, 39, 97-114.

Szydlik, M. (2012). Generations: Connections across the life course. Advances in Life Course Research, 17, 100-111.

Szydlik, M. (2016). Sharing lives: Adult children and parents. New York: Routledge.

Tanskanen, A. O. (2013). The association between grandmaternal investment and early years overweight in the UK. Evolutionary Psychology, 11, 417-425.

Tanskanen, A. O., Danielsbacka, M., \& Erola, J. (2016). Educational test scores among adolescents in three-generational households in 20 countries. Finnish Yearbook of Population Research, 51, 3-22.

Tanskanen, A. O., Danielsbacka, M., \& Rotkirch, A. (2014). Multi-partner fertility is associated with lower grandparental investment from in-laws in Finland. Advances in Life Course Research, 22, 41-48.

Tanskanen, A. O., \& Rotkirch, A. (2014). The impact of grandparental investment on mothers' fertility intentions in four European countries. Demographic Research, 30, $1-26$.

Tanskanen, A. O., Rotkirch, A., \& Danielsbacka, M. (2011). Do grandparents favor granddaughters? Biased grandparental investment in the UK. Evolution and Human Behavior, 32, 407-415.

Thomese, F., \& Liefbroer, A. C. (2013). Child care and child births: The role of grandparents in the Netherlands. Journal of Marriage and Family, 75, 403-421.

Thompson, L., \& Walker, A. J. (1987). Mothers as mediators of intimacy between grandmothers and their young adult granddaughters. Family Relations, 36, 72-77.

Trivers, R. L. (1972). Parental investment and sexual selection. In B. Campbell (Ed.), Sexual selection and the descent of man 1871-1971 (pp. 136-179). Chicago: Aldine.

Trivers, R. L. (1974). Parent-offspring conflict. American Zoologist, 14, 249-264. 


\section{Theories on intergenerational relations}

Trivers, R. L (2002). Natural selection and social theory: Selected papers of Robert Trivers. New York: Oxford University Press.

Trivers, R. L., \& Willard, D. E. (1973). Natural selection of parental ability to vary the sex ratio of offspring. Science, 179, 90-92.

Westermarck, E. (1921). The history of human marriage. Oxford: Macmillan.

Willson, A. E., Shuey, K. M., \& Elder, G. H. (2003). Ambivalence in the relationship of adult children to aging parents and in-laws. Journal of Marriage and Family, 65, $1055-1072$.

Wroblewski, E. E. (2008). An unusual incident of adoption in a wild chimpanzee (Pan troglodytes) population at Gombe National Park. American Journal of Primatology, 70, 995-998. 


\section{Structure of intergenerational relations}

On 19 January 2017, the British newspaper the Daily Express reported on the first British family to have six generations alive at the same time (Jeeves, 2017). The oldest family member was the great-great-great-grandmother, 103-year-old Hilda, followed by great-great-grandmother Jean, 83 years old, and great-grandmother Sue, 62 years old. Grandmother Niki was 43 years old, mother Aimee was 18 , and the youngest family member was three-week-old Finley. According to the Guinness World Records (2017), the largest number of living family generations ever was seven: great-great-great-great-grandparent Augusta, aged 109 years 97 days, her daughter aged 89, granddaughter aged 70, great-granddaughter aged 52 , great-great-granddaughter aged 33, great-great-great-granddaughter aged 15, and her son as the youngest generation. The record was achieved in 1989 in the US.

Although it is still rare to have seven, six or even five living family generations, it is nevertheless true that currently, mostly due to rising life expectancy, more children have more living grandparents, and it is increasingly common to have living great-grandparents. For instance, at the end of 2011 in Finland, a Nordic welfare state with one of the most rapidly ageing populations in Europe, children had an average of 2.9 living grandparents (Statistics Finland, 2012). Similarly, British children today have, on average, three living grandparents during most of their childhood, mainly due to longer lifespans (Murphy, 2011). If we consider demographics from the grandparents' point of view, in European countries, more than 80 per cent of older adults aged 60-79 have at least one grandchild (Puur et al., 2011). Thus, grandparenthood tends to last much longer than it did 100 or even 50 years ago (Chapman et al., 2017).

As well as increases in the number of relatives in a vertical line, shared years between grandparents and grandchildren (or great-grandparents and great-grandchildren) are also increasing. For instance, in pre-industrial Finland (roughly before the year 1870), the average number of years a grandchild had at least one living grandmother fluctuated around five years (Chapman et al., 2017). At the same time as industrialisation, the shared lifetime between grandchildren and grandmothers started to increase, reaching 24 years for the cohort born in 1950-1959. Grandfathers were mostly absent from grandchildren's lives in preindustrial Finland, and if they were alive, the shared years of life were, on average, two years up to 1880 . The shared lifetime with grandfathers subsequently began 
to increase, reaching 16 years for the 1920-1929 and 1930-1939 birth cohorts. According to a study of the US and 24 European countries, the average number of shared years between grandparents and grandchildren is today more than 20 years, but this number varies considerably among Western countries (Leopold \& Skopek, 2015). The longest lifetimes with grandchildren (35 years) are expected among grandmothers in East Germany and the US, whereas the shortest shared years of life (21 years) are expected among grandfathers in West Germany and Spain. In addition, the length of grandparenthood is currently more strongly influenced by the timing of fertility (among both grandparental and parental generations) than by the timing of mortality.

In this chapter, we are interested in how intergenerational family relations are structured, what kind of dyadic relations they include and how these dyadic relations are similar or different from each other. First, we define the concept of intergenerational relations and present reasons for their importance in humans. Second, we briefly consider how intergenerational relations have changed from historical times to the present day, and the unique features of current intergenerational relations. Third, we present the basic structure of intergenerational family relations, examine in-law relationships compared to the relationship with one's own kin, and consider intergenerational relations in blended families. Finally, we discuss whether intergenerational relationships today are more important than ever before, as has been claimed (e.g., Bengtson, 2001).

\section{Concept}

In this book, intergenerational relations are specifically defined as the relations between family generations rather than between demographic generations, different age groups, or social generations, all of which refer to generations in society rather than in families. Demographic generations (or cohorts) can be defined as people born during the same age period (e.g., the leading edge of baby boomers in the US born between 1946 and 1955). The term "age group" refers to people who are at a certain age at a certain time point and can thus be defined, for instance, as children, adolescents, adults, middle aged or elderly. The main difference between a cohort and an age group is that the cohort to which a person belongs does not change, whereas as people grow older, they move into different age groups. Finally, to be a social generation, people belonging to the same birth cohort need common and shared experiences that unify them into the same group (e.g., generation $\mathrm{X}$ or generation $\mathrm{Y}$ ). In general, social generation is a problematic construction, and there is no agreement on the criterion of social generation even among generation scholars.

"Family generation" refers to parents and their descendants who belong to the same family line. The length of the family generation is typically around 30 years (i.e., the approximate age when people have their first child). Depending on different factors, such as the socio-economic status, genes, sex and country of residence, the actual length of family generations in individual families varies considerably. 
The three family generations considered in the present book are grandparents, parents and children. In some cases, we scrutinise the relations within two-generational settings, such as when studies on a specific topic, such as intergenerational ambivalence in family relations, are conducted only (or mostly) between adult children and their parents. Intergenerational relations between family generations may mean direct relations and interaction between two generations, or more complex relations in which, for instance, the middle generation (i.e., the parents) mediates the intergenerational relations between grandparents and grandchildren.

In the prior literature, the term "multigenerational relations" has often been used as a synonym for intergenerational relations. Although there has been discussion regarding whether these two terms are in fact synonymous (e.g., Brownell \& Resnick, 2005), we consider them both to refer to the relationship between persons who belong to two different family generations. However, for the sake of clarity, and because some have argued that the term "intergenerational relations" refers to the exchange and influence between generations whereas the term "multigenerational relations" refers only to sample composition (i.e., multigenerational households) or phenomena affecting more than one generation (Villar, 2007), in this book, we prefer to use the term "intergenerational relations".

Relations between family generations are typically described as dyadic relationships between two individuals from different family generations. These kinds of dyadic relations include, for instance, relations between mothers and daughters or mothers-in-law and daughters-in-law, as well as between fathers and sons or fathers-in-law and sons-in-law. These relations do not have to be between two consecutive family generations though, and dyadic relationships can also be studied, for instance, between granddaughters and maternal grandmothers. However, it is very likely that in this case, the middle generation (i.e., the parents) influences the relationship between their daughters and mothers or mothers-in-law. Therefore, it is often noted that all dyadic relations are linked with other family relations, creating a system of linked lives (King \& Elder, 1995) in which, for instance, the relations between a daughter-in-law and a mother-in-law influence the relations between a paternal grandmother and her grandchild. In this book, these separate dyadic relations as well as the combination of linked lives in intergenerational family relations will be scrutinised.

\section{More years together}

In the 19th century, life expectancy fluctuated between 30 and 40 years. Since then, it has steadily increased in all countries (with the exception of the two world wars in the 20th century), exceeding or approaching, at least in developed countries, 80 years (Roser, 2017). One main cause for the increase in life expectancy is the decline in childhood mortality (i.e., the number of children dying before their fifth birthday). However, life expectancy has risen in all age groups, not just among children. Whereas in the 1850 s a five-year-old child could expect to live 55 years, a five-year-old child in developed countries now has, on average, 82 years of lifetime, which means there has been an increase of 27 years. A 50-year-old 
individual could expect to live, on average, another 12 years in the 19th century, whereas a 50-year-old today in developed countries has, on average, 33 years ahead, meaning 21 additional years of lifetime. In addition to the decline of childhood mortality, another important reason for the increase in life expectancy is the decrease in health inequality between and within countries (Roser, 2016).

Despite the increasing health equality between countries, life expectancy still varies between countries even in the developed world, from the US average of 79.3 to Japan's average of 83.7 (see Figure 3.1). Furthermore, it is important to take into account healthy life expectancy, which also varies between countries. For instance, healthy life expectancy at age 50 in 2009 was 24.9 years for women and 22 years for men in Sweden, 21.4 years for women and 20.6 years for men in the UK, and 17.7 years for women and 16.6 years for men in Finland (Loichinger \& Weber, 2016). These numbers show that contemporary life expectancy and healthy life expectancy vary according to country and sex. Even more variance occurs when one considers different socioeconomic classes within a country (Margolis \& Wright, 2017). The increase in life expectancy has contributed primarily to the lifespan of those who are better off, whereas life expectancy for the lowest quintile has been stagnant since the late 1980s (Mackenbach et al., 2008; Tarkiainen et al., 2013).

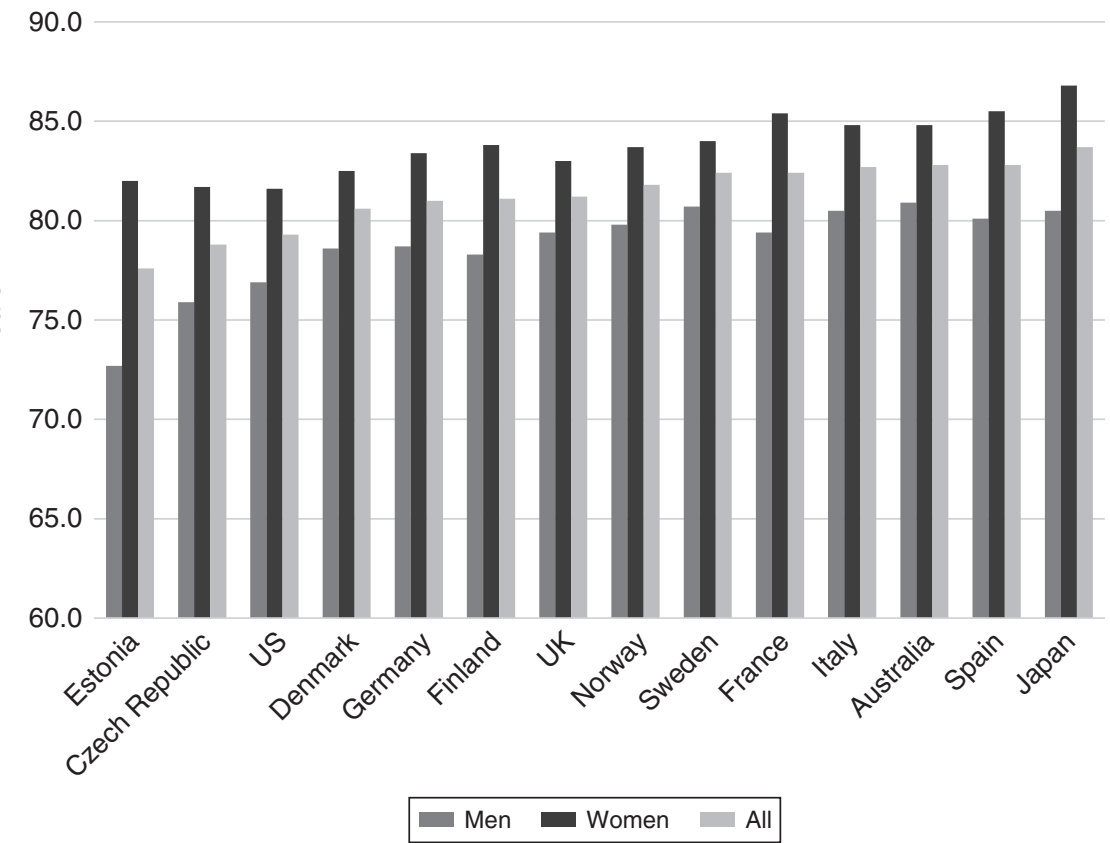

Figure 3.1 Life expectancy in selected countries.

Source: World Health Organization: World Health Statistics 2016: Monitoring health for the SDGs: Annex B. 
Because of increased life expectancy, grandparents and grandchildren have more shared years of life on average than ever before (Bengtson, 2001). However, the increase in shared years appears to be largest in Western countries in which life expectancy is lower. This is because grandparents who live the longest typically experience an entry into grandparenthood much later than grandparents with lower life expectancy do (Leopold \& Skopek, 2015). Thus, the increase in shared years is distributed unequally among grandparents according to country of residence, sex and socioeconomic status. Simultaneously with the increase in shared years of life between grandparents and grandchildren, the number of grandchildren in the Western world has decreased, which means that the time spent with each grandchild may increase (Buchanan \& Rotkirch, 2013). Thus, contemporary grandparents have the potential to become a significant part of their grandchildren's lives.

Other recent demographic trends, such as fertility decline and postponement in Western countries, have delayed the transition to grandparenthood (Leopold \& Skopek, 2015; Margolis, 2016), which may decrease the number of shared years between family generations in the future. Age at first birth has risen steadily in several countries. For instance, in Nordic countries, it has risen from 23-24 years among pre-1955 birth cohorts to more than 28 years among birth cohorts from 1980 and later (Lappegård, 2000). The trend has been similar in other Western European countries (Leopold \& Skopek, 2015). The increase in age at first birth among women in the highest socioeconomic groups is even greater. It remains to be seen whether rising life expectancy can keep up with rising age at first birth, so that the average length of grandparenthood does not start to diminish.

\section{Living fast and dying young}

The number of simultaneously living family generations depends on the age at first birth and life expectancy, as discussed above. The example of extremely long genealogies presented at the beginning of this chapter requires the lifespan of the oldest family member to be far above the average life expectancy and the age at first birth to be lower than average among the majority of mothers in the genealogical line. These two things are not commonly present in the same families.

Life history theory (introduced in Chapter 2) offers an evolutionary explanation for the different timing of life events among several species (e.g., Hill \& Kaplan, 1999; Stearns, 1992). The speed of life history (i.e., the length of a generation) varies between individuals. The plasticity of life history timing is very high in humans, but certain traits are believed to be associated with the reproductive strategy an individual follows. Environmental, social and heritable factors may influence the pacing of life history timing. For instance, if an individual has evolutionary reason to expect his or her own life to be short, having children early is reasonable (Nettle, 2010). If, however, one's own life expectancy seems long, it might make sense to invest in increasing one's own resources and to begin reproducing later. Accordingly, "fast" and "slow" life history strategies have been claimed to follow boundaries between lower and upper socioeconomic groups. 
Life history theory is an especially useful tool in family studies and is used to investigate the association between socioeconomic status and both age at first birth and life expectancy. Existing studies are few, but indicate that individuals in lower socioeconomic groups have lower age at first birth and lower overall life expectancy, whereas individuals in higher socioeconomic groups tend to have children at an older age and have a higher overall live expectancy (e.g., Low et al., 2008).

\section{Basic structure of intergenerational family relations}

The basic structure of intergenerational family relations from the viewpoint of a child is presented in Figure 3.2. A child has a biological mother and father and their biological parents (i.e., maternal and paternal grandparents, respectively). As the genealogy proceeds higher, the number of members of an older generation is always the preceding one multiplied by two, meaning that a child has two parents, four grandparents, eight great-grandparents, and so on. A child shares 50 per cent of his or her genes with both parents and approximately 25 per cent of his or her genes with each grandparent. Further generations divide the average genetic relatedness by two, meaning that, for instance, the great-great-great-great-grandmother Augusta mentioned at the beginning of this chapter is only approximately 1.56 per cent related to her great-great-great-great grandson.

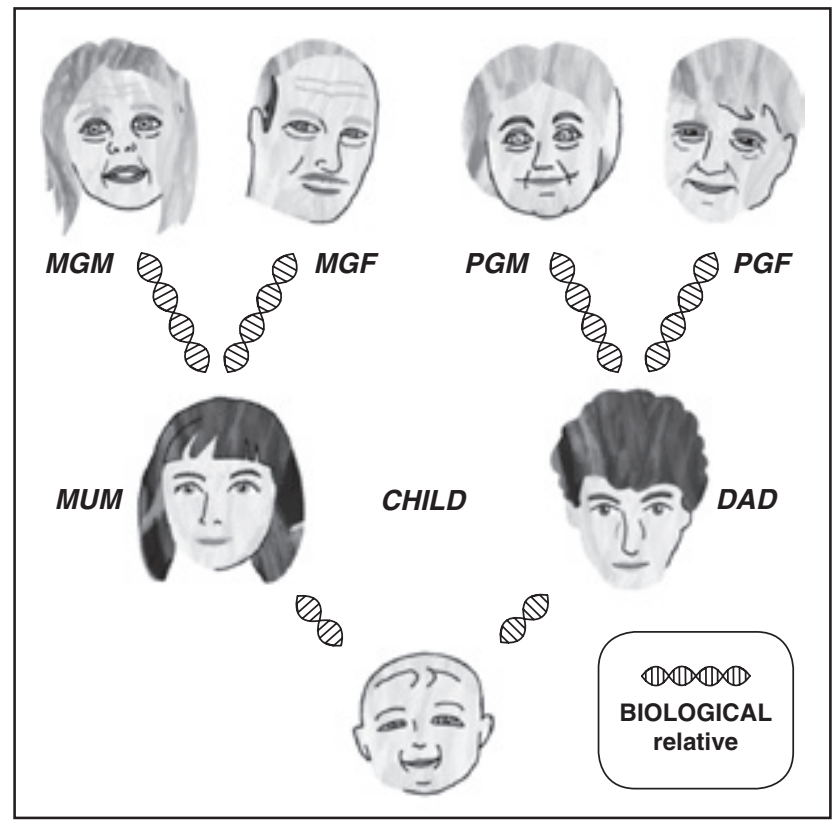

Figure 3.2 Child-parent-grandparent relationships from the child's perspective. Picture designed by Lasse Määttä. 
The picture of three-generational lineage looks slightly different when it is perceived from the grandparents' perspective. This is illustrated in Figure 3.3, which shows the same relations as Figure 3.2 starting from the top and going downwards in a descending line. The grandparent generation is now labelled mother and father; they have a daughter and a son who both have a daughter and a son, labelled grandchildren. With the help of this figure, one can better understand the double role grandparents often have. This means that, for instance, a grandmother can simultaneously be a maternal grandmother and a paternal grandmother if she has grandchildren via a daughter and a son. Figure 3.3 also shows the potential dilution effect, meaning that if a grandparent has more than one grandchild, especially if the grandchildren are via different children (i.e., there are different grandchild sets), the grandparental investment in a particular grandchild may be more limited (Elder \& Conger, 2014; Mueller \& Elder, 2003).

Another difference in Figures 3.2 and 3.3 is that Figure 3.2 shows both the maternal and paternal lineages of a child in an ascending line, whereas Figure 3.3 shows only one descending line of relatedness between family generations. In Figure 3.2, we thus have two different families who are connected through a common descendant, whereas in Figure 3.3, we have descendants from the same family (their spouses who come from outside are not shown in the figure). This means that all solid lines presented in Figures 3.2 and 3.3 illustrate biological relationships between relatives. Next, we turn to relations with in-laws.

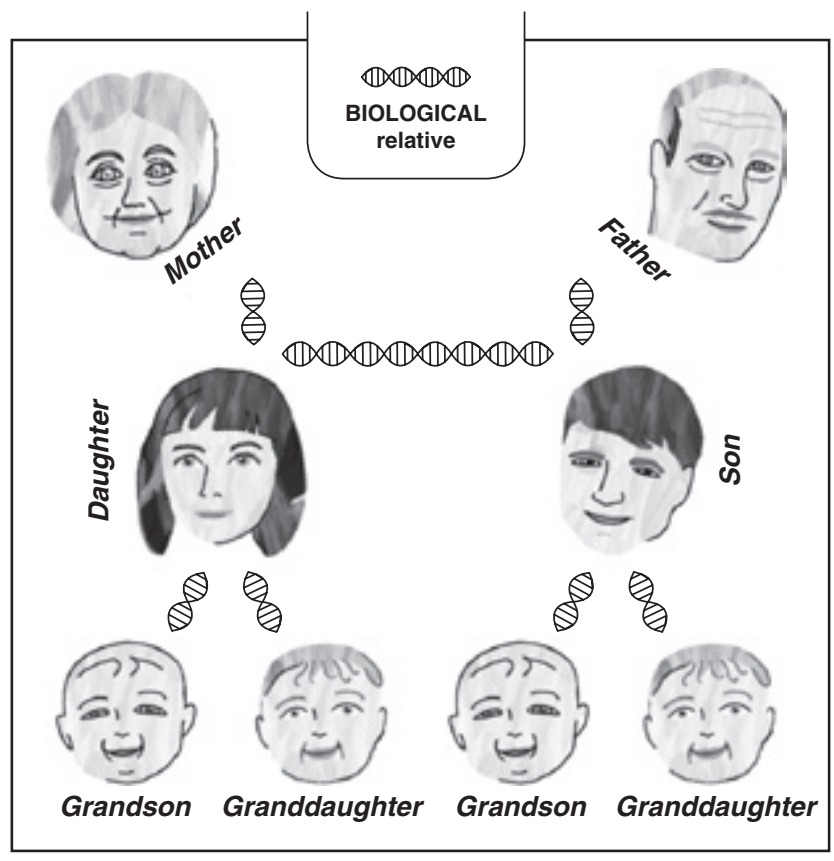

Figure 3.3 Grandparent-child-grandchild relationships from grandparents' perspective. Picture designed by Lasse Määttä. 


\section{In-laws vs. own kin}

According to a well-known proverb, "a mother-in-law is the devil in the house". In-law (or affine) relations are a source of many anecdotes and jokes that reveal that the relationships with one's own parents and parents-in-law or one's own children and children-in-law are crucially different. Humans are a unique species not because we have problematic in-law relationships but because we have them at all. In-law relations are formed due to monogamy (or serial polygamy) and the fact that both mothers and fathers and their respective kin may form attachments to children and invest time and resources in rearing them (Hrdy, 1999; 2009). This means that parents typically must form a relationship with another side of the child's kin (Apostolou, 2011; 2016).

Figure 3.4 illustrates intergenerational relations among children, parents and grandparents, including biological and in-law relationships between the parental and grandparental generations. There are eight possible dyadic relationships between the parental and grandparental generations; four of the relationships are between biological relatives, and four are between in-laws. Following the solid line via a child, two unrelated families become related. In Figure 3.4, for instance, the paternal grandmother whose direct relationship with her daughter-in-law is nonbiological has a genetic relationship to her via a child who is related to the father, who in turn is related to his mother, the paternal grandmother. Consequently, the existence of a common descendant can be expected to influence relationships

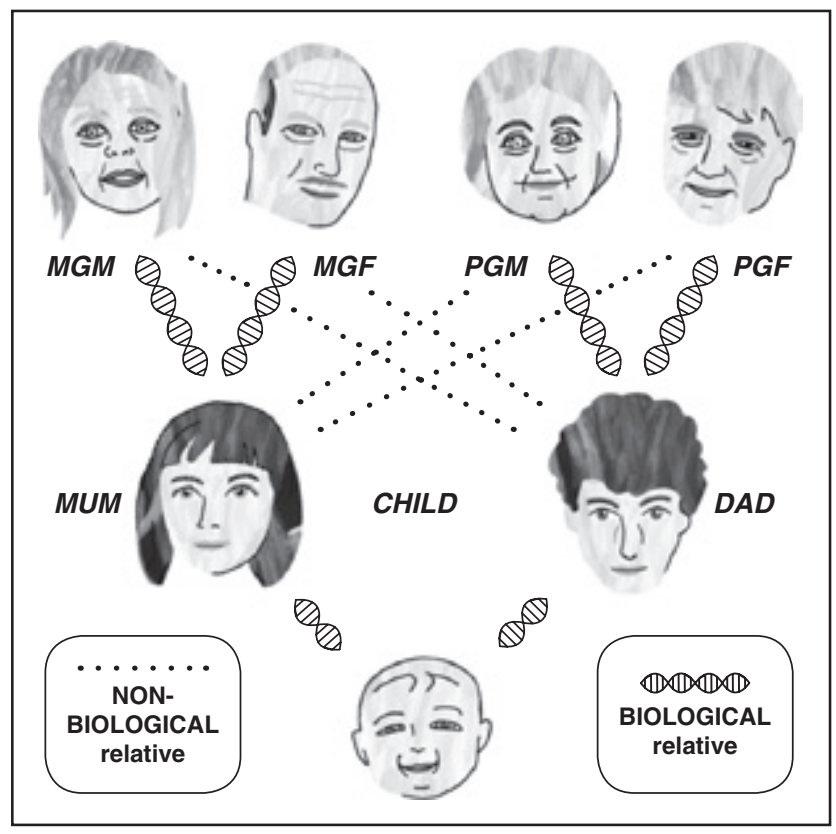

Figure 3.4 Biological and non-biological intergenerational family relationships. Picture designed by Lasse Määttä. 
between in-laws more than it influences relationships with biological parents (Danielsbacka et al., 2015; Hughes, 1988).

\section{Blended families}

In addition to longer life expectancy, increased age at first birth and a lower number of children, the growing number of divorces has changed the formation of families and, consequently, the formation of intergenerational relations (Lesthaeghe, 2014). Although blended families are not a new phenomenon and existed in historical and traditional populations, the main difference is that they are now typically formed due to divorce, whereas they were previously formed mostly due to the death of a spouse (Lesthaeghe, 1983; Kalmijn, 2007). Figures 3.5a and 3.5b present one combination of intergenerational relationships in blended families. The left-hand figure shows the relations within a family in which a mother has a child from a previous union and a couple has one child together in a current union. This means that the paternal grandparents as well as the father have a step-relationship with the child from the woman's previous union. The right-hand figure shows the same type of situation from a father's perspective: a father has a child from a previous union and a couple has one child together from a current union. In this case, the maternal grandparents as well as the mother have a step-relationship with the father's child from the previous union.

All humans have exactly four biological grandparents and two parents, whether living or not. In Figures 3.5a and 3.5b, these parents and grandparents are shown as relations to a couple's common child, but a child from a previous union will have a biological parent and two biological grandparents who are not shown in the figure. Thus, in these cases, a child from a previous union may have a total of six grandparents and three parents. If the other biological parent also has a new spouse, a child may have a total of four parents and eight grandparents. Increased rates of divorce in parental as well as grandparental generations in Western societies cause the proportion of non-biological grandparents and parents to increase. In particular, there are several ways that children can have non-biological grandmothers or grandfathers (Coall et al., 2014; Pashos et al., 2016). For instance, stepgrandchildren may appear in the family because the grandparent has divorced and has acquired a new spouse who has grandchildren (see Figure 3.6). As in Figures 3.5a and 3.5b, union dissolution may occur in the parental generation, and the children of the new spouse will consequently be stepgrandchildren of the grandparents (Tanskanen et al., 2014; Westphal et al., 2015). In addition, grandparents or their children may have foster or adopted children (see Figures 3.7 and 3.8). If children are adopted by their parents, they may have up to four non-biological grandparents, unless the adoption is within the family (e.g., adopting a sibling's child), in which case the parents and grandparents actually are, to some degree, genetically related to the (grand) child. If the adopted child's non-biological grandparents from the maternal and paternal sides happen to divorce and remarry, the child may have a total of eight non-biological grandparents. 


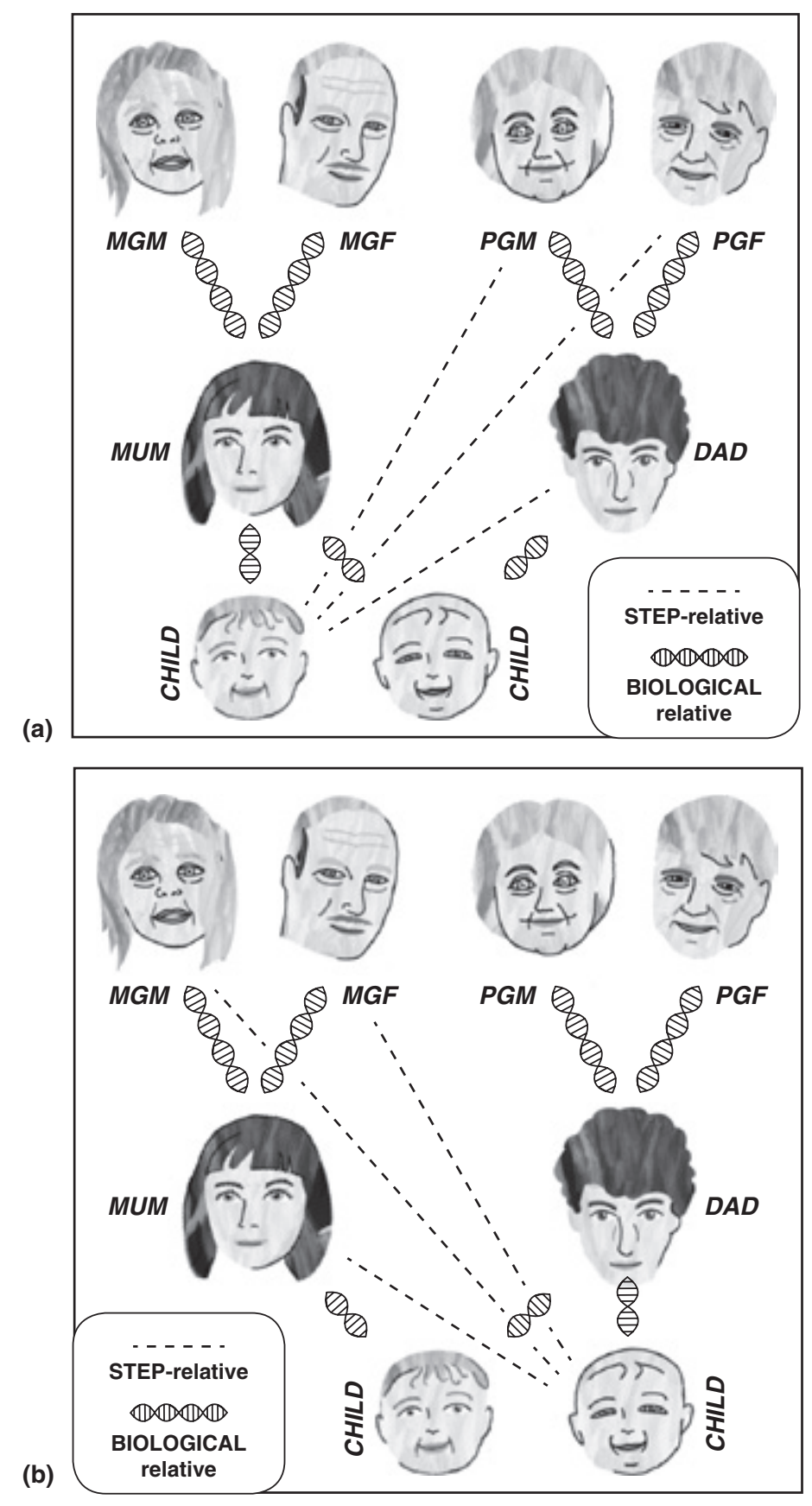

Figure 3.5 (a) Family types in which mothers have children with different partners. (b) Family types in which fathers have children with different partners. Picture designed by Lasse Määttä. 


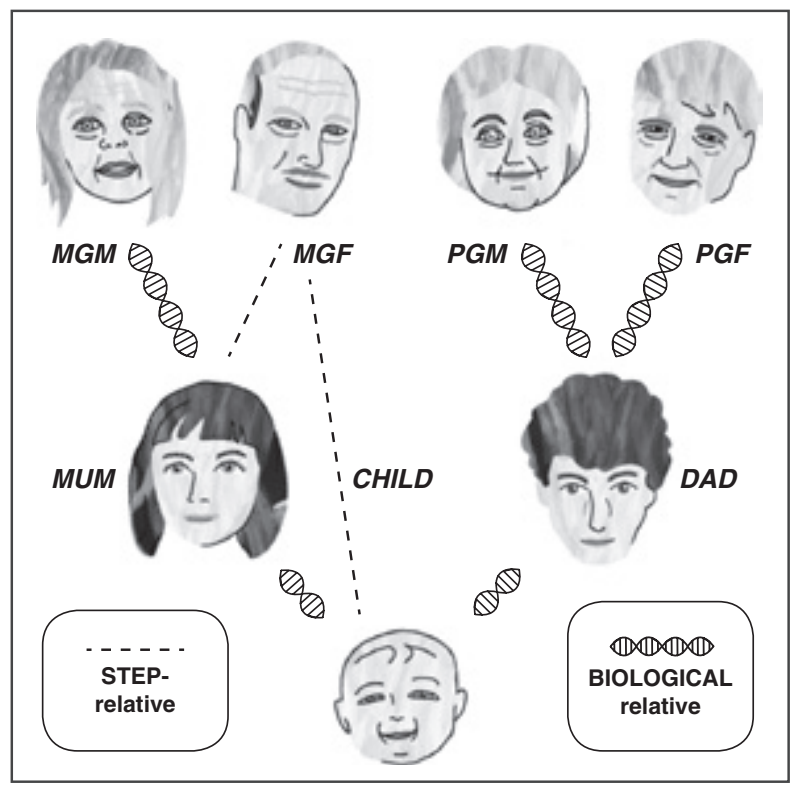

Figure 3.6 Family types when mothers have a stepparent (example in the figure considers maternal grandfather's step-relatedness to a grandchild). Picture designed by Lasse Määttä.

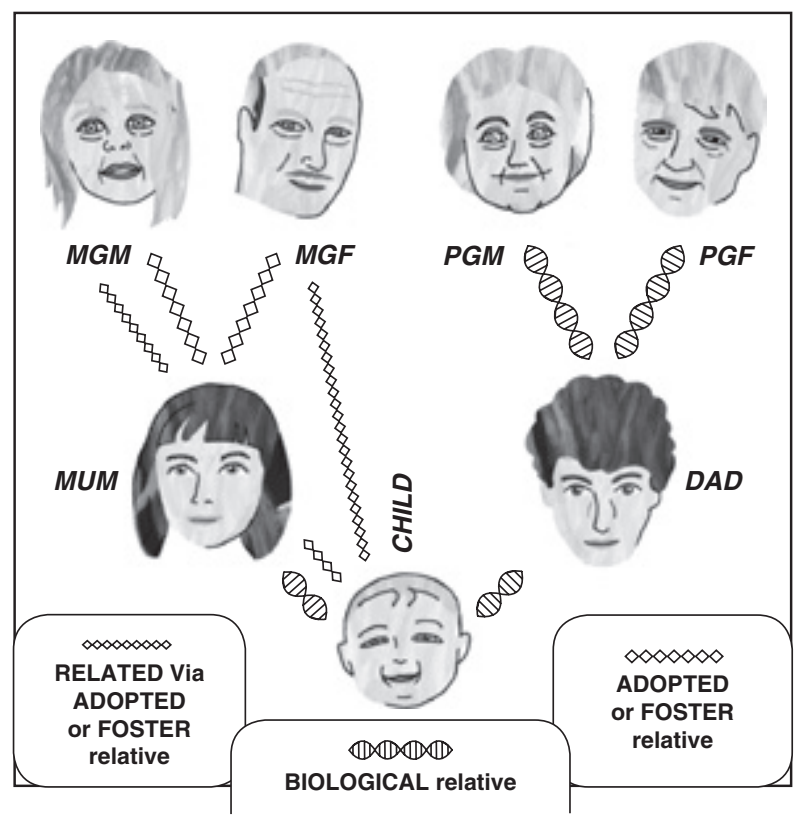

Figure 3.7 Family types when mothers have foster or adoptive parents (example in the figure considers maternal grandparents' relatedness to a grandchild). Picture designed by Lasse Määttä. 


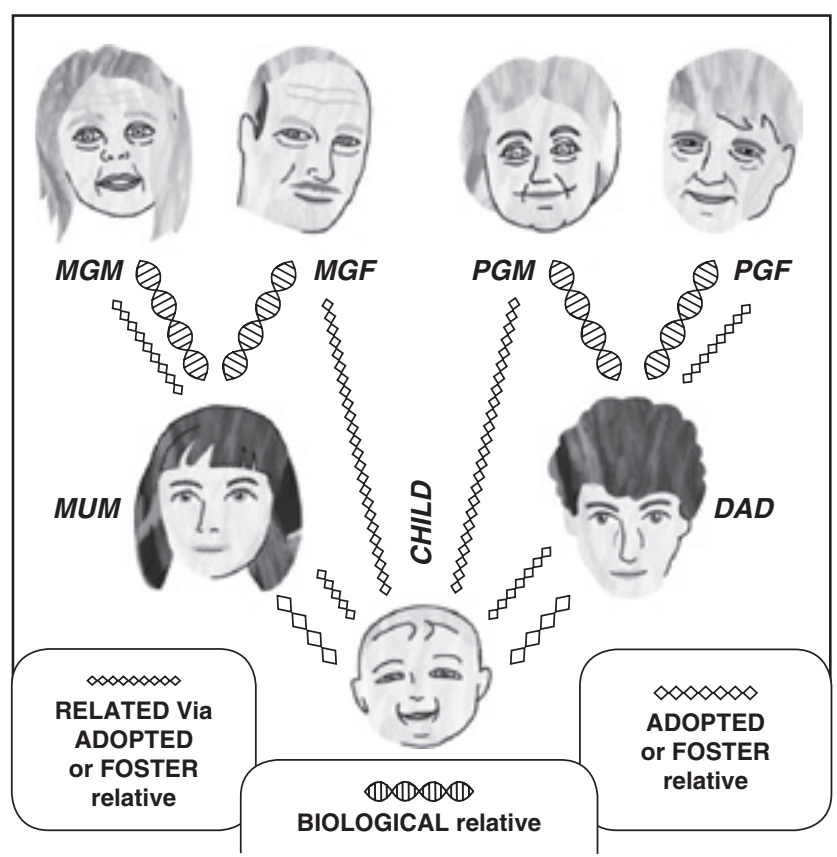

Figure 3.8 Family types when children have foster or adoptive parents. Picture designed by Lasse Määttä.

\section{Conclusions}

In this chapter, we have presented the changing demography of intergenerational relationships. We have also illustrated the different dyadic relationships that are included in three-generational relations and showed the intergenerational relationships from different perspectives, specifically, the viewpoints of children, parents and grandparents. Because of increasing longevity and decreasing fertility in Western populations, families with only one child and all four grandparents living are becoming more common. As divorce rates have increased (and may continue to grow), the number of stepgrandparents is also likely to increase. These changes may, on one hand, increase grandparental opportunities to invest in any particular grandchild; on the other hand, they may dilute grandchildren's opportunities to interact with all grandparents. In the future, grandparents may more often compete with each other for access to the lives of their grandchildren. Thus, it will be important to understand the basis on which the spontaneous choices of intergenerational support allocation are made. In the next chapters, we will examine the factors related to intergenerational relationships; the way people in contemporary societies help their relatives; the types of outcomes of close relationships among family members with regard to children, parents and grandparents who are most likely to quarrel with one another; and what we know about other extended kin, such as aunts and uncles. 


\section{References}

Apostolou, M. (2011). In-law preferences in a post-industrial society: What parents want in an in-law and how this differs from what their children want in a spouse. Family Science, 2, 186-195.

Apostolou, M. (2016). In-law preferences: Do fathers and mothers agree on what they want in a daughter-in-law and in a son-in-law? Evolutionary Psychological Science, 2, 189-198.

Bengtson, V. L. (2001). Beyond the nuclear family: The increasing importance of multigenerational bonds. Journal of Marriage and Family, 63, 1-16.

Brownell, P., \& Resnick, R. P. (2005). Intergenerational-multigenerational relationships: Are they synonymous? Journal of Intergenerational Relationships, 3, 67-75.

Buchanan, A., \& Rotkirch, A. (Eds.) (2013). Fertility rates and population decline: No time for children? New York: Palgrave Macmillan.

Chapman, S. N., Lahdenperä, M., Pettay, J. E., \& Lummaa, V. (2017). Changes in length of grandparenthood in Finland 1790-1959. Finnish Yearbook of Population Research, $52,3-13$.

Coall, D. A., Hilbrand, S., \& Hertwig, R. (2014). Predictors of grandparental investment decisions in contemporary Europe: Biological relatedness and beyond. PLoS ONE, 9, e84082.

Danielsbacka, M., Tanskanen, A. O., \& Rotkirch, A. (2015). Impact of genetic relatedness and emotional closeness on intergenerational relations. Journal of Marriage and Family, 77, 889-907.

Elder, G. H., \& Conger, R. D. (2014). Children of the land: Adversity and success in rural America. Chicago: University of Chicago Press.

Guinness World Records. (2017). Most living generations (ever). Retrieved 9 June 2017 from http://www.guinnessworldrecords.com

Hill, K., \& Kaplan, H. (1999). Life history traits in humans: Theory and empirical studies. Annual Review of Anthropology, 28, 397-430.

Hrdy, S. B. (1999). Mother nature: A history of mothers, infants and natural selection. New York: Pantheon.

Hrdy, S. B. (2009). Mothers and others: The evolutionary origins of mutual understanding. Cambridge, MA: Harvard University Press.

Hughes, A. L. (1988). Evolution and human kinship. New York: Oxford University Press. Jeeves, P. (2017, January 19). Family become first in Britain "to have SIX generations all alive at the same time". Daily Express. Retrieved from https://www.express.co.uk

Kalmijn, M. (2007). Explaining cross-national differences in marriage, cohabitation, and divorce in Europe, 1990-2000. Population Studies, 61, 243-263.

King, V., \& Elder, G. H., Jr. (1995). American children view their grandparents: Linked lives across three rural generations. Journal of Marriage and Family, 57, 165-178.

Lappegård, T. (2000). New fertility trends in Norway. Demographic Research, 2. https:// doi.org/10.4054/DemRes.2000.2.3

Leopold, T., \& Skopek, J. (2015). The demography of grandparenthood: An international profile. Social Forces, 94, 801-832.

Lesthaeghe, R. (1983). A century of demographic and cultural change in Western Europe: An exploration of underlying dimensions. Population and Development Review, 9, 411-435.

Lesthaeghe, R. (2014). The second demographic transition: A concise overview of its development. Proceedings of the National Academy of Sciences of the United States of America, 111, 18112-18115. 
Loichinger, E., \& Weber, D. (2016). Trends in working life expectancy in Europe. IIASA Working Paper WP16-2004 (March).

Low, B. S., Hazel, A., Parker, N., \& Welch, K. B. (2008). Influences of women's reproductive lives: Unexpected ecological underpinnings. Cross-Cultural Research, 42, 201-219.

Mackenbach, J. P., Stirbu, I., Roskam, A.-J. R., Schaap, M. M., Menvielle, G., Leinsalu, M., \& Kunst, A. E. (2008). Socioeconomic inequalities in health in 22 European countries. The New England Journal of Medicine, 358, 2468-2481.

Margolis, R. (2016). The changing demography of grandparenthood. Journal of Marriage and Family, 78, 610-622.

Margolis, R., \& Wright, L. (2017). Healthy grandparenthood: How long is it, and how has it changed? Demography, 54, 2073-2099.

Mueller, M. M., \& Elder, G. H. (2003). Family contingencies across the generations: grandparent-grandchild relationships in holistic perspective. Journal of Marriage and Family, 65, 404-417.

Murphy, M. (2011). Long-term effects of the demographic transition on family and kinship networks in Britain. Population and Development Review, 37, 55-80.

Nettle, D. (2010). Dying young and living fast: Variation in life history across English neighborhoods. Behavioral Ecology, 21, 387-395.

Pashos, A., Schwarz, S., \& Björklund, D. F. (2016). Kin investment by step-grandparents More than expected. Evolutionary Psychology, 14, 1-13.

Puur, A., Sakkeus, L., Põldma, A., \& Herm, A. (2011). Intergenerational family constellations in contemporary Europe: Evidence from the Generations and Gender Survey. Demographic Research, 25, 135-172.

Roser, M. (2016). Health inequality. OurWorldInData.org. Retrieved 10 July 2017 from https://ourworldindata.org/health-inequality/

Roser, M. (2017). Life expectancy. OurWorldInData.org. Retrieved 10 July 2017 from https://ourworldindata.org/life-expectancy/

Statistics Finland. (2012, November 9). Families [e-publication]. Helsinki: Statistics Finland. Retrieved 9 May 2017 from http://www.stat.fi/til/perh/2011/02/perh_2011_ 02_2012-11-09_tie_001_en.html

Stearns, S. C. (1992). The evolution of life histories. Oxford: Oxford University Press.

Tanskanen, A. O., Danielsbacka, M., \& Rotkirch, A. (2014). Multi-partner fertility is associated with lower grandparental investment from in-laws in Finland. Advances in Life Course Research, 22, 41-48.

Tarkiainen, L., Martikainen, P., \& Laaksonen, M. (2013). The changing relationship between income and mortality in Finland, 1988-2007. Journal of Epidemiology and Community Health, 67, 21-27.

Villar, F. (2007). Intergenerational or multigenerational? A question of nuance. Journal of Intergenerational Relationships, 5, 115-117.

Westphal, S. H., Poortman, A.-R., \& Van der Lippe, T. (2015). What about the grandparents? Children's postdivorce residence arrangements and contact with grandparents. Journal of Marriage and Family, 77, 424-440. 


\section{Factors related to intergenerational relations}

Why do grandparents tend to play favourites? This question is often asked in different forums, such as advice columns, columns and chats (e.g., Hax, 2015). There are three common features in these writings. First, mothers are typically the ones who complain that some of the grandparents are playing favourites. It is much harder to find fathers writing about the subject matter in these forums. Second, the paternal grandmother is typically the person accused by the mother. Third, in addition to biological paternal grandparents, stepgrandparents (particularly the stepgrandparents of children from the mother's previous unions) are blamed for preferring their own biological grandchildren. These points direct interest towards factors that are relevant when we want to understand the grandparental tendency to play favourites. These factors are genetic relatedness, sex and lineage.

In Chapter 3, we outlined the demography and the structure of intergenerational family relations. However, a multitude of factors are related to intergenerational relations and influence the role of grandparents, parents and children. In addition to genetic relatedness, sex and lineage, these may include geographical distance and emotional closeness between family members. Moreover, individual characteristics such as health, education and marital status and broader economic and cultural factors are related to intergenerational relations. In this chapter, we focus on the different factors that tend to shape intergenerational relations. We answer the question: do grandparents have a robust tendency to actually play favourites? In addition, we answer the following questions: how do parents and children assess their relationships with grandparents? Are some dyadic relationships closer than others? Which relatives are most likely to quarrel? How is divorce in grandparental or parental generations related to intergenerational relations?

In this chapter, we mostly concentrate on studies that have investigated intergenerational relations among three generations. These studies have analysed relations either between grandparents and grandchildren or between parents and grandparents when grandchildren exist. However, we also refer to studies that have investigated intergenerational relations among two generations, namely, between adult children and older parents in cases in which grandchildren do not exist. Some of these studies are introduced because they can provide important knowledge on intergenerational family relations that may be relevant for threegenerational relations. 


\section{Genetic relatedness}

The genetic relatedness tends to matter in grandparental investment behaviour. In Chapter 2, we presented the theoretical background of the ultimate reasons for potential differences in investments in kin and non-kin, and in Chapter 3, we discussed different constellations of non-biological grandparenthood and intergenerational relations, which include stepparents and stepgrandparents as well as families with adopted children. Here, we present in more detail how genetic relatedness has been shown in previous studies to be associated with kin investments and relations.

An increasing amount of empirical evidence has indicated that kin relations are substantially different from non-kin relations. For instance, individuals report that they are emotionally closer and have stronger tendencies of obligation towards their biological kin compared to non-biological kin (e.g., Rossi \& Rossi, 1990; Willson et al., 2003). Individuals also provide more support to their close kin compared with distant kin or non-kin (e.g., Anderson, 2011; Pollet \& Hoben, 2011) and expect less gratitude in return for provided assistance (Rotkirch et al., 2014). Although close relatives are often also emotionally close, the tendency to provide support for close kin exists even after the emotional closeness is taken into account (Korchmaros \& Kenny, 2001). Also potentially very costly help (e.g., donating a kidney) is most likely offered to close kin rather than distant or non-kin (Curry et al., 2013; Neyer \& Lang, 2003).

However, not all non-biological kin relations are the same. Two-generational studies have shown that non-related adopted children are acquired intentionally and may be treated like biological children (Segal et al., 2015), whereas stepchildren are acquired via mating, meaning that they come with the new spouse. Investment in stepchildren may sometimes be more related to a mating effort than an investment in stepchildren as such. Previous evidence has shown that parents tend to treat their biological children better than their stepchildren (e.g., Anderson, 2011; Daly \& Wilson, 1985). To clarify, adoption is often within-family adoption, meaning that adoptive parents are related to their adopted children, which further distinguishes adoptive children from stepchildren. For instance, when one adopts a child of his or her full sibling, this adoptive parent shares, on average, 25 per cent of the same genes as the adopted child. In addition, age of a child when relation with parental figure starts is crucial. Whether children are adopted or are stepchildren may also influence intergenerational relations among grandparents, parents and children.

It is worth noting that studies comparing the investments of biological and nonbiological grandparents are scarce. As there are several ways one can have nonbiological children and grandchildren (see Chapter 3), the study of non-biological grandparenthood can rapidly become very complex. The low number of such studies has shown that, in line with inclusive fitness theory (Hamilton, 1964), investments are more often made by biological than by non-biological grandparents. A study investigating the child care provided by biological and non-biological grandparents for their descendants with large-scale and nationally representative 
survey data from 11 European countries found that biological grandparents provided intensive child care (daily or weekly basis) more often compared to nonbiological grandparents (Coall et al., 2014). Interestingly, the study showed that biological grandparents were more likely than non-biological grandparents to never provide child care.

A study analysing a non-representative sample of US and German college students who retrospectively reported grandparental investment in their childhood found that biological grandparents invested more than stepgrandparents did (Pashos et al., 2016). In addition, the study showed that biological grandmothers invested more than biological grandfathers and that stepgrandmothers invested less in their stepgrandchildren compared to stepgrandfathers. The latter was the case especially when the stepgrandparent was the biological grandparent's new spouse (i.e., the grandparent remarried when the grandchild's parent was already adult). This finding may be explained by either incidental exposure or mating effort, meaning that the stepgrandparent (that is, a biological grandparent's new spouse) might be either incidentally exposed to the grandchild of his or her new spouse or may invest in the stepgrandchild with the intention of performing as a good spouse. The same situation does not exist when the other parent is a stepparent, which makes both of his or her parents stepgrandparents to a child. Especially in the latter cases, the investment by stepgrandparents may be diminished because there is no possible incidental exposure effect or mating effort involved (Tanskanen et al., 2014).

Another recent study compared the kin investments of biological and stepgrandparents (Gray \& Brogdon, 2017). This study was based on non-representative data including younger adults from the US who had a long-time heterosexual partner and at least one biological child less than five years old. Again, this study found that biological grandparents invested more in grandchildren than stepgrandparents did. In addition, the study showed that stepgrandfathers tended to invest more in their stepgrandchildren compared to stepgrandmothers. This finding again indicated that the investment of stepgrandfathers may be related to mating effort in that older men may try to appeal to their new spouses (i.e., grandmothers) by investing time and resources in their grandchildren.

The above-mentioned studies have examined the potential effect of genetic relatedness in intergenerational relations among heterosexual couples. Another way to study whether genetic relatedness plays a role in intergenerational relations is to study same-sex couples. Obviously, and in contrast to heterosexual parent families, in same-sex parent families, there are no sex differences between parents, so the effect of genetic relatedness can be studied in a more robust setting. However, relatively little is known about how the intergenerational ties in same-sex parent families are constructed, and even less is known about grandparental investments in same-sex families. Due to the relatively small number of same-sex families, the scarce existing investigations tend to be based on smallscale samples (e.g., Reczek, 2014, 2016).

In a US study of 37 lesbian-mother families, children were more likely to have regular contact with grandparents and other relatives from the side of the 
biological rather than the non-biological mother (Patterson et al., 1998). Another study from the US compared contact with grandparents among children conceived via donor insemination by lesbian and heterosexual mothers and found that among 80 participating families (55 lesbian and 25 heterosexual), children of both lesbian and heterosexual parents had more frequent contact with the parents of their biological mother than with the parents of their father or other mother (Fulcher et al., 2002). This finding contradicts the kin keeper theory (e.g., Dubas, 2001) that assumes that women who are socialised to care for others should invest in kin despite genetic relatedness.

An important aspect of intergenerational relations among humans is that they include in-laws. In traditional societies, cross-cousin marriages may have been relatively common (Chagnon et al., 2017; Chapais, 2010, pp. 98, 251), meaning that in these circumstances, children-in-law and parents-in-law were actually genetically related to each other. Because the degree of genetic relatedness among first cousins is approximately 12.5 per cent, in these families, the degree of genetic relatedness between children-in-law and parents-in-law is approximately 25 per cent. In contemporary Western societies, romantic relationships are rarely formed between relatives; thus, in-laws are not typically genetically related to each other. In present-day nations, in-law relations are found to differ from biological kin relations in that individuals tend to feel emotionally closer and have stronger feelings of obligation towards their biological kin compared to their inlaws (e.g., Euler et al., 2001; Waynforth, 2011; Willson et al., 2003).

For a long time, evolutionary scholars paid only limited attention to in-law relations. It was assumed that because in-laws are not genetically related, they do not have a special bond; rather, the relationship between them is like the relationship between any other non-related individuals. However, this view ignores the "inverse" genetic relatedness that forms between in-laws via common descendants (Danielsbacka et al., 2015; Hughes, 1988). Consequently, the existence of a common descendant can be expected to influence relations between in-laws by making them more similar to relations with biological kin. Overall, in-law relations should be closer than other non-kin relations but not as close as the relationship with biological relatives.

The first empirical test of whether in-laws are treated more like kin or like other non-related individuals such as friends or acquaintances was conducted using non-representative data from contemporary Belgium (Burton-Chellew \& Dunbar, 2011). The Belgian study found that the association between contact frequency and emotional closeness was quite similar for in-laws and biological kin but different for non-kin friends. Regarding the assumption that common descendants might be associated with relationship closeness with in-laws, another study with Finnish data compared emotional closeness towards parents and parents-in-law and found that men with children were closer to their mothers-in-law than were men without children (Danielsbacka et al., 2015). Using the same data, the authors tested whether conflict proneness towards parents and parents-in-law differed if a couple had a child or not (Danielsbacka at al., 2017). First, it was found that the Finns reported higher conflict occurrence with their own parents 
than with their in-laws. Second, compared to childless couples, parents were as likely to report conflicts with their own parents but more likely to report conflicts with their parents-in-law. Taking into account several socio-demographic factors as well as the contact frequencies and emotional closeness between the parties concerned did not alter the results.

Whether closeness and conflicts with in-laws are perceived the same way from the viewpoint of both adult generations (parents and grandparents) is another question. A study of Israeli daughters-in-law and mothers-in-law indicates that this may not be the case (Linn \& Breslerman, 1996). The Israeli study found that the younger women felt that their relationship towards their mother-in-law either improved or was stable over time, whereas their mothers-in-law felt that the relationship improved or deteriorated over time. More importantly, the daughtersin-law thought the improvement occurred as a function of detachment (they did not see each other as much as in the beginning of the relationship), whereas the mothers-in-law viewed the improvement as a function of attachment (the daughters-in-law had grown to like them more).

In addition, it may be that closeness and conflicts with in-laws are not perceived the same way as closeness and conflicts with one's own parents. It may be, for instance, that individuals quarrel with in-laws over different issues than they do with their own kin or that the disagreements with in-laws are more severe than those with their own kin. It is likely that the relationship with in-laws is also more easily disrupted than the relationship with one's own kin and is probably greatly affected by the relationship with the spouse. Studies evaluating these issues, however, are scarce.

Concerning genetic relatedness, evolutionary scholars have also noted that the sex of a grandchild may influence the amount of investment grandparents channel towards their descendants. Because of asymmetrical sex-chromosome relatedness all grandparent-grandchild dyads do not share an equal amount of genes with one another. Several studies from different populations have tested whether the asymmetry in $\mathrm{X}$ and $\mathrm{Y}$ chromosome inheritance biases grandparental investment (e.g., Chapman et al., 2018; Chrastil et al., 2006; Fox et al., 2010; Johow et al., 2011; Rice et al., 2010; Tanskanen et al., 2011; see Chapter 2). According to sexchromosome relatedness, maternal grandmothers and grandfathers should invest equally in granddaughters and grandsons, whereas paternal grandmothers should invest more in granddaughters than in grandsons and paternal grandfathers should invest more in grandsons than in granddaughters. However, no clear and robust evidence exists for the predicted patterns of sex discrimination based on asymmetrical sex-chromosome inheritance that would be consistently repeated.

Finally, in evolutionary studies, several factors have been used as cues for genetic relatedness. One of the basic ideas is that the resemblance provides cues for grandparents regarding genetic certainty with their grandchildren; when the resemblance increases, so does the likelihood of relatedness. Resemblance can manifest, for instance, as facial or odour resemblance as well as the resemblance of personality or other behavioural traits. The effect of grandparent-grandchild resemblance on grandparental investment behaviour should vary according 
to paternity uncertainty, meaning that the investment of paternal grandfathers should be the most dependent on grandparent-grandchild resemblance, whereas the investment of maternal grandmothers should be the least dependent (Euler, 2011; see Chapter 2). Using a retrospective and non-representative sample from Germany, it was found that grandparent-grandchild resemblance played a greater role among grandfathers than among grandmothers and among paternal rather than maternal grandparents (Euler \& Weitzel, 1996). Although these findings were not very robust, they provide some support for the evolutionary predictions. However, it is worth noting that the potential effect of grandparent-grandchild resemblance on grandparental investment has been studied very rarely, and more research is called for.

\section{Sex and lineage}

There is strong evidence showing that across societies, mothers are the most important persons who guarantee children's survival and wellbeing (Sear \& Mace, 2008; see Chapter 6). Campbell (2013) introduced the phrase "Mothers Matter Most", which elucidates this important role of mothers and can be referred to as the "MMM principle". This principle can be extended by one generation with the phrase "Mother's Mothers Matter Most", or the "MMMM principle". The MMMM principle refers to the fact that maternal grandmothers tend to be the most important persons for children among all members of extended kin.

Studies of grandparental investment have found that grandmothers invest more in their grandchildren than grandfathers do (Euler, 2011). This finding is in line with the kin keeper theory and the sex effect hypothesis (e.g., Dubas, 2001; Euler, 2011; see Chapter 2). In line with the matrilateral effect and sex-specific reproductive strategies (Coall \& Hertwig, 2011; see Chapter 2), it has also been found that maternal grandparents tend to invest more in their descendants than paternal grandparents do (Daly \& Perry, 2017; Perry \& Daly, 2017). A combination of theories predicting either sex or lineage differences in grandparental investment has also been utilised. For instance, Euler and Weitzel (1996) explained greater care by maternal grandfathers compared to paternal grandmothers as a combination of paternity uncertainty and sex-specific reproductive strategies. Empirical tests of these theories tend to overlap, and evidence for one can often be interpreted as evidence for the other.

The terms "biased grandparental investment pattern" (Danielsbacka et al., 2015) and "discriminative grandparental solicitude" (Euler \& Weitzel, 1996) have been used to refer to the observation that the maternal grandmother typically invests the most in a grandchild, followed by the maternal grandfather, then the paternal grandmother, and finally the paternal grandfather. This pattern has been supported in several studies controlling for numerous possible confounding factors and with a wide range of investment variables, including care provided during childhood, emotional closeness, relationship closeness, financial support and contact frequency (e.g., Bishop et al., 2009; Danielsbacka et al., 2011; Eisenberg, 1988; Euler \& Weitzel, 1996; Jamison et al., 2002; Matthews \& Sprey, 1985; 
Pollet et al., 2006, 2007; Uhlenberg \& Hammill, 1998). Previously it has been argued that grandparents may not be reliable informants regarding their investment in grandchildren because a strong cultural norm of treating all children equally exists in contemporary Western countries (see Coall \& Hertwig, 2010, and responses for discussion). However, clear and consistent variance in grandparental investment reported by grandparents themselves indicates that grandparents are not unreliable respondents, as some researchers have claimed on the basis that they may wish to present themselves as equal investors in all children. So, the pattern of biased grandparental investment is not limited only to the reports of parents and grandchildren.

Perhaps the most often used theoretical explanation for the biased grandparental investment pattern is based on paternity uncertainty, meaning that maternal grandmothers, who do not have an uncertain link of paternity between themselves and their daughters' children, invest the most, whereas paternal grandfathers, who have two uncertain links between themselves and their sons' children, invest the least (Euler, 2011; see Chapter 2). Maternal grandfathers and paternal grandmothers both have one uncertain link between them and their grandchildren and tend to invest more than paternal grandfathers and less than maternal grandmothers.

The common finding that maternal grandfathers invest slightly more than paternal grandmothers in their descendants may be due to the preferential investment in more certain kin; the latter grandparent often has a daughter's children to invest in as well (see Chapters 2 and 3). Laham and colleagues (2005) were the first to test the preferential investment hypothesis by using data from almost 800 Australian students. They measured grandparental investment by a "feeling thermometer", where participants were asked to rate how close they felt to their biological grandparents on a range from 0 to 100 , where 0 indicated "cold or negative feelings" and 100 represented "warm or positive feelings". These ratings were obtained separately from all four grandparent types, and respondents were asked to consider only the grandparents they could remember from their childhood. In general, participants reported more warm feelings towards their maternal grandfathers than their paternal grandmothers. However, the closeness towards maternal grandfathers and paternal grandmothers was dependent on the presence of cousins. There was no difference in reported closeness towards paternal grandmothers and maternal grandfathers in cases where there was a lack of other investment options (i.e., grandparents did not have grandchildren via other adult children). This result supports the preferential investment theory.

Another study tested the preferential investment theory using data on almost 200 college students from the US (Bishop et al., 2009). The study included only students who reported having all four grandparents still alive and investigated several grandparental investment measures, including contact frequency, emotional closeness and financial support. In line with several previous investigations, the study found that maternal grandparents tend to invest more in their grandchildren compared to paternal grandparents. However, maternal grandfathers were not found to invest more than paternal grandmothers in cases where the paternal 
grandmothers had more certain investment options available (i.e., grandchildren via a daughter). Thus, the investigation did not provide support for the preferential investment theory.

The most important limitations of the two studies reviewed above (Bishop et al., 2009; Laham et al., 2005) are that they both used small-scale and nonrepresentative data in which grandparental behaviour was evaluated from the perspective of grandchildren rather than grandparents. Because of these limitations, Danielsbacka and colleagues (2011) conducted a study that tested the preferential investment hypothesis with multinational and representative data from 13 European countries. Grandparents provided information on how often they looked after their grandchildren. The sample included more than 22,000 observations, making it possible to draw reliable comparisons between different dyads. The authors found that when paternal grandmothers had no preferential investment options (i.e., grandchildren via a daughter), the difference between investments made by paternal grandmothers and maternal grandfathers practically disappeared (maternal grandfathers and paternal grandmothers had a 21 per cent likelihood of looking after a grandchild on at least a weekly basis). However, clear differences between maternal grandfathers and paternal grandmothers (16 per cent vs. 10 per cent) were apparent if paternal grandmothers had a more preferable investment option available. Hence, these findings support the idea that the higher investment of maternal grandfathers in their grandchildren compared to paternal grandmothers is partly due to the fact that paternal grandmothers usually also have grandchildren via a daughter and may prefer to invest in their daughter's children over their son's children.

Obviously, the cultural context shapes the biased structure of intergenerational relations. For instance, in patrilocal societies, a woman becomes part of her husband's kin after marrying, which may influence the pattern of biased grandparental investment (Daly \& Perry, 2017; Pashos, 2017). In patrilocal systems, a new couple usually lives much nearer to the man's kin than the woman's kin; thus, future children will grow up in the presence of their paternal grandparents and likely see their maternal grandparents only occasionally. This phenomenon affects which of the grandparents becomes closest to the grandchild (Pashos, 2000). In matrilocal populations, women stay with their own kin more often than men do, and their husbands are the ones who change their location after marriage (Leonetti et al., 2007; Sear, 2008). Naturally, in these family formations, the women's kin become closer to the grandchild. From this point of view, modern and fairly equal Western societies that lack clear patrilocal or matrilocal living arrangements provide a good platform for the study of behavioural patterns regarding intergenerational relations because people can largely choose the relatives with whom they are willing to interact.

Despite the convincing results regarding biased grandparental investment in modern Western societies, the main pattern can vary substantially between cultures, as mentioned above. For instance, in contemporary rural Greece, paternal grandmothers are more involved than maternal grandmothers (Pashos, 2000). Results stressing investments from paternal kin are also found for rural Iowa 
farmers in the US (King \& Elder, 1995; King et al., 2003) and in rural Italy (Smorti et al., 2012). In China, which has a predominantly patrilineal culture, a grandparental investment bias towards the children of sons has been found (e.g., Kaptijn et al., 2013). Common to these studies is that the observed societies are patrilocal by nature or have a strong preference for patrilineal kin.

In addition to sex and lineage, several studies have taken the sex of a grandchild into account. Among social scientists, it is often predicted that same-sex grandparent-grandchild dyads are closer to one another compared to mixed-sex dyads (e.g., Dubas, 2001; Hagestad, 1985; see Chapter 2). Based on this view, grandmothers should invest more in granddaughters than in grandsons, whereas grandfathers should invest more in grandsons than in granddaughters. Previous studies on the topic, however, have provided mixed results. Some studies have found that granddaughters report better relationships with both grandmothers and grandfathers than grandsons do (e.g., Creasey \& Koblewski, 1991; Danielsbacka \& Tanskanen, 2012; Euler \& Weitzel, 1996; Salmon, 1999), whereas others have identified a closer relationship in same-sex grandparent-grandchild dyads (Dubas, 2001), and several studies have found no evidence of sex discrimination by grandparents (e.g., Block, 2000; Höpflinger \& Hummel, 2006; Mueller \& Elder, 2003; Triadó et al., 2005).

\section{Relations between parental and grandparental generations}

The issues of whether parents provide more support to their adult children than they receive or whether parents feel emotionally closer to their children than vice versa have been the topics of several studies. For instance, a study published in the early 1970s found that the older generation had a more optimistic view of intergenerational relations compared to the younger generation (Bengtson \& Kuypers, 1971). Subsequently, a wide body of research has found that parents provide more support to adult children than they receive in return (e.g., Albertini et al., 2007; Deindl \& Brandt, 2011; Kohli, 1999). Social scientists have explained these findings using the intergenerational stake hypothesis (e.g., Bengtson \& Kuypers, 1971; see Chapter 2), which emphasises that parents have more at "stake" in their relations with their children because parents want to ensure that joint family values are transferred from older generations to younger ones. Evolutionary researchers explain the same phenomenon by the reproductive value hypothesis (e.g., Hughes, 1988; see Chapter 2), which predicts that individuals typically have an unconscious tendency to invest in those family members who have the highest current or future reproductive value.

Both the intergenerational stake and reproductive value perspectives predict that older generations provide more support to younger generations than vice versa. However, empirical studies have shown that there are also important differences related to the type of support. Financial support tends to flow most strongly from older generations to younger ones, whereas time transfers (e.g., practical help) are more likely directed not only downwards but also upwards (e.g., AttiasDonfut et al., 2005; Fokkema et al., 2008). 
To date, the division between upward and downward support has been predominantly studied in two-generational investigations of adult children and parents. However, the intergenerational stake hypothesis has been tested among grandparents and grandchildren as well. In a German study, kin support was indicated by two measures, financial (i.e., money, gifts or other monetary help) and instrumental (e.g., cleaning, repair or shopping) support (Hoff, 2007). The findings showed that grandparents provided more financial and instrumental support for their grandchildren than vice versa, meaning that the results were in line with the intergenerational stake hypothesis. These results were also in accordance with the evolutionary hypothesis based on reproductive value, which argues that from an inclusive fitness perspective, it is more beneficial to invest in younger than older relatives (Hughes, 1988).

An interesting question is whether intergenerational kin support is reciprocal (see also rational grandparent model, Chapter 2). Some studies have tested whether the child care help provided by grandparents to their adult children in the past is associated with the future support adult children provide to their older parents. A study using data from the UK found that adult children who received child care help from their parents from the time they left full-time education to the age of 42 were more likely to provide instrumental support to their parents at age 50 compared to adult children who reported that they did not receive child care help from parents (Evandrou et al., 2016). In the UK study, the results were quite similar between women and men. A Dutch study found that adult sons who received regular child care help from their parents earlier gave more instrumental and emotional support to their parents 13 years later compared to adult sons who received less child care help, if any (Geurts et al., 2012). However, the same result was not found among adult daughters. Finally, an investigation based on data from Germany showed that support between grandparents and grandchildren was rarely reciprocal (Hoff, 2007). Grandparental financial support towards grandchildren was not associated with the instrumental support grandparents subsequently received from their grandchildren.

With regard to intergenerational relations, particularly grandparental investments, one clear limitation of evolutionary studies is that they often take into account only the potential investor's view (that is, the grandparent's perspective) and rarely consider the receiver's willingness to accept the investment. In the real world, however, grandparents cannot take for granted the acceptance of their investment, which may be partly or wholly rejected by the parents of the grandchildren (Barnett et al., 2010).

In recent years, we have witnessed several discussions in which grandparents have stated that their investment has been rejected by adult children. For instance, there was a heated discussion in Helsingin Sanomat, the largest daily newspaper in Finland, about grandparents' rights to have contact with their descendants. In these discussions, several older people expressed concern that their adult children excluded them from the family. Based on a Finnish survey conducted in 2012, approximately 5 per cent of younger and middle-aged parents reported that they felt the need to restrict grandparents' interaction with their grandchildren 
(Danielsbacka et al., 2013). The highest percentage was found among dyads of daughters-in-law and mothers-in-law, with 7 per cent of daughters-in-law reporting the need for restriction. Unfortunately, the survey did not gather information on how often this actually leads parents to restrict grandparents. Based on the same Finnish survey, the most frequently reported reason why parents believed that grandparental investment should be restricted was related to grandparents' problems with alcohol. The phenomenon in which some parents are willing to restrict interaction between grandparents and grandchildren may be universal (Buchanan \& Rotkirch, 2016), although it is obvious that parental reasons to restrict grandparents may vary substantially between different families and societies.

In general, the relationship quality of parent-grandparent and grandparent-grandchild dyads involves a situation in which the better the relationship is between the parent and grandparent, the better the relationship also is between the grandparent and the grandchild (e.g., Chan \& Elder, 2000; King \& Elder, 1995; Uhlenberg \& Hammill, 1998). Moreover, it is found that increased relationship quality between parents and grandparents is associated with better relationship quality between children and parents (Hank et al., 2017). Interestingly, the quality of the relationship between in-laws may have an even greater effect on grandparent-grandchild relationship quality than the relationship between parents and their adult children (Fingerman, 2004). This means that in-law relations may be in a central position to either improve or impair intergenerational relations between grandparents and grandchildren.

Parents-in-law (or children-in-law) are often treated in research either totally differently from own parents (or children) or practically the same (e.g., when own parents and parents-in-law are combined together). In terms of emotional closeness and contact frequency, the in-law relationship is much closer to the relationship towards own kin than non-kin (Burton-Chellew \& Dunbar, 2011), but it is different from the relationship towards own kin (e.g., Rossi \& Rossi, 1990). Hughes (1988) was the first to include the in-law relationship theoretically within the larger frame of family relations. He predicted that human kin altruism would vary not only by the initial degree of genetic relatedness but also through individuals who become related to each other through marriage. In-laws, who are usually not closely genetically related, become "inversely" genetically related to each other through common descendants (i.e., a grandchild) (Danielsbacka et al., 2015).

Most studies have concentrated on the adult child-parent relationship (e.g., Kaufman \& Uhlenberg, 1998; Schwarz et al., 2005; Silverstein \& Bengtson, 1997), and only a few have considered the relationship between adult children and parents-in-law (but see Danielsbacka et al., 2015; Danielsbacka et al., 2017; Euler et al., 2001; Fingerman, 2004; Willson et al., 2003). Even more scarce are studies examining the association between emotional closeness and biased grandparental investment (but see Chan \& Elder, 2000; Danielsbacka et al., 2015), although the quality of the relationship between parents and grandparents is strongly associated with the quality of the relationship between grandparents and grandchildren, as discussed above. 


\section{Factors related to intergenerational relations}

A study conducted with Finnish data revealed how emotional closeness towards own parents and parents-in-law is associated with a biased grandparental investment pattern (Danielsbacka et al., 2015). The pattern remained robust after controlling for perceived emotional closeness when the analysis was restricted to include only biological kin (that is, women and men who answered only for their own parents). However, when the question was asked only of women who answered for their own parents and parents-in-law, after controlling for emotional closeness, the difference in child care provision between one's own mother and one's mother-in-law disappeared, whereas for men, after controlling for emotional closeness, the difference in received child care between one's own mother and one's mother-in-law was accentuated. Thus, emotional closeness does shape the biased grandparental investment pattern, but it does so differently for kin and in-laws.

These results are in line with another study that used data from grandchildren in rural Iowa to show that the matrilineal advantage in intergenerational kin relations reflects lineage differentials (Chan \& Elder, 2000). The authors of the Iowa study explained the resulting bias in grandparental investments by the notion of existing matrilineal bias in the parent-grandparent relation (maternal grandparents are closer to the couple than paternal grandparents are) and by the kin-keeping role of mothers. Thus, the closeness of the parent-grandparent relationship was used as an explanation for grandparental investments in grandchildren. However, the evolutionary reason for preferring one grandparent over others may be that the parents "measure" (probably unconsciously) the trustworthiness and motivation of a child minder.

According to both the linked lives and evolutionary perspectives, an important question is whether relations between parental and grandparental generations change when adult children experience entry into parenthood. To date, however, studies directly investigating this issue have been surprisingly scarce. In a classic study, Fischer (1983) used data from 33 adult daughters, 30 mothers and 24 mothers-in-law from the US and found more intimacy, contact and intergenerational support and less conflict between adult daughters who were mothers themselves and their mothers than between childless daughters and mothers. In addition, the study found more tensions between daughters-in-law who had children and mothers-in-law compared to childless daughters-in-law and mothers-in-law. The main limitation of this study was that the results were based on a small-scale, nonrepresentative and cross-sectional sample.

Another study investigated the association between parenthood status and intergenerational relations using nationally representative survey data from Finland (Danielsbacka et al., 2015). This investigation found that parenthood was associated with improved emotional closeness reported by daughters towards their own mothers and by sons towards their mothers-in-law and fathers-in-law. However, the study could not detect similar correlations in other adult child-parent or adult child-parent-in-law dyads. These results partially support the hypothesis based on Hughes' (1988) notion of the inverse relatedness of in-laws and shared reproductive interests. Because of the shared reproductive interest in the 
future generation, in-laws as well as parents can be expected to be emotionally closer to a couple with children than to a childless couple. However, the results did not straightforwardly follow this prediction. One explanation may be that the feelings parents have towards their own parents and their parents-in-law are the products of sex-specific reproductive strategies (Euler, 2011). Having a child may enhance the perceived closeness to maternal grandparents because they (particularly the maternal grandmother) have the greatest interest in the wellbeing of the grandchild. It could also be claimed that the closer attachment to maternal grandparents is due to the fact that the mother and father simply see them more often than the paternal grandparents.

A study conducted again with the Finnish data suggests that younger and middle-aged adults have a higher amount of conflicts with their own parents compared to their in-laws (Danielsbacka et al., 2017). Compared to childless couples, couples with children reported a similar amount of conflict with their own parents. However, women and men with children had significantly more conflicts with their parents-in-law than did childless couples. These results were robust even after controlling for contact and emotional closeness between generations, in addition to several other factors.

Although the two Finnish studies on associations between parenthood status and intergenerational relationship quality used nationally representative data, the most important limitation was that the data were cross-sectional. This means that based on these findings, it cannot be claimed that having a child causally influences intergenerational relations. To provide stronger evidence for causal interpretations, longitudinal data including repeated measures from the same participants and concentration on within-person variation over time should be used. A recent study investigated whether relations between adult children and their parents improve or deteriorate after a child arrives using German data with six annual follow-up waves between 2009 and 2014 (Tanskanen, 2017). The study found that the amount of contact between daughters and mothers improved after the daughters experienced entry into motherhood. In addition, it was found that the intimacy and emotional closeness between sons and mothers diminished after the sons had their first child. These findings indicate that parenthood may indeed bring couples closer to the woman's kin. Unfortunately, because of data limitations, the study could not investigate changes in inlaw relations.

\section{Socio-demographic factors}

Perhaps the most acknowledged body of social science studies about intergenerational relations has investigated socioeconomic factors related to kin contact, support and conflict. These studies have provided a large amount of empirical results showing several factors that shape kin relations. Many of these studies have investigated whether kin investments are associated with potential recipients' need for help and potential helpers' opportunities to provide support (e.g., Szydlik, 2012, 2016). Needs and opportunities tend to be strongly related to the 
life course phase of an individual. Next, we provide some general findings based on two-generational studies of adult children and older parents.

\section{Two-generational studies}

According to need structures, two-generational studies have found several factors that are related to support provided by older parents to their adult children. For instance, adult children who have lower income tend to receive more financial support from their parents compared to better-off adult children (Deindl \& Brandt, 2011; Majamaa, 2013). In addition, research indicates that need structures are related to support from adult children to their older parents. Parents who are in poorer health receive more support than do their counterparts with better health (e.g., Bonsang, 2007; Brandt, 2013). Moreover, according to need structures, the age of children and parents may be a factor because the need for support is typically highest among youngest children and oldest parents, meaning that kin support follows an age-dependent pattern (Fokkema et al., 2008; Kalmijn \& Saraceno, 2008).

An increasing amount of two-generational studies have also investigated how opportunity structures shape intergenerational relations between adult children and parents. For instance, older adults who are still working provide less support than do those outside of working life (e.g., Albertini at al., 2007; Brandt, 2013). As geographical distance between family members increases, the likelihood of providing support decreases (e.g., Bonsang, 2007; Brandt \& Deindl, 2013). Moreover, people with better financial conditions provide more support to kin than do their poorer counterparts (Fokkema et al., 2008).

Need and opportunity structures are not only important in the case of kin support; they may also play a role in the case of intergenerational ambivalence, or mixed feelings and behaviour towards a relative belonging to another generation. For instance, adult children's problems or discontinuities that could increase the need for parental support, such as unemployment, health difficulties or educational challenges, are associated with increased intergenerational ambivalence reported by their parents (Fingerman et al., 2008; Pillemer \& Suitor, 2002; Willson et al., 2003). These findings indicate that parents' feelings of ambivalence towards their children increase if children are unable to fulfil parental expectations (Lendon et al., 2014). Parental ambivalence towards their adult children has also been associated with factors related to decreased opportunities to provide support, namely, parental unemployment and health problems (Kiecolt et al., 2011). From the children's perspective, parental health is associated with intergenerational ambivalence in that children who report more parental health difficulties also report more feelings of ambivalence (Fingerman et al., 2008; Fingerman, 2004; Willson et al., 2003).

\section{Three-generational studies}

We now turn to three-generational studies that include grandparents, parents and grandchildren. In their classic study, Uhlenberg and Hammill (1998) described 
six factors associated with grandparental investment. In this study, grandparental investment was measured as contact frequency with a grandchild set. The study sample consisted of more than 4,500 US grandparent-grandchild dyads, and separate analyses were performed for women and men. In addition to the three factors discussed above (i.e., sex, lineage and the quality of the relationship between grandparents and parents), their predictors of contact were the number of grandchild sets a grandparent had, geographic distance between grandparents and grandchildren and the marital status of the grandparent. These three factors can be assumed to be related to opportunity structures.

In the US study, geographical distance was a strong predictor of contact (Uhlenberg \& Hammill, 1998). This finding is a common result in several other studies (e.g., Pollet et al., 2006, 2007) and is fairly self-evident since people who live closer to each other have better opportunities to interact personally. According to the US study, the number of grandchild sets (i.e., the number of children with children) matters; as the number of sets increases, the likelihood of frequent contact with any particular set decreases (Uhlenberg \& Hammill, 1998). This finding has been confirmed in other studies as well (e.g., Coall et al., 2009). Finally, in the US investigation, grandparents' marital status was associated with contact in that married grandparents had the most frequent contact with grandchildren, followed by those who were widowed, remarried and divorced. This association was particularly strong for grandfathers (Uhlenberg \& Hammill, 1998). The effect of marital status may differ in the cases of grandmothers and grandfathers; in particular, divorce may be more detrimental to grandfathers' contact with grandchildren than to grandmothers' contact. It can be argued that because ageing grandfathers more often have a partner, they may gain a relative advantage because being married increases the probability of maintaining contact with children and grandchildren for both grandfathers and grandmothers (Knudsen, 2012, 2016).

In line with this argument, the study with the sample of 538 Iowan grandparents found that fewer contacts and poorer relationship quality between a grandparent and a grandchild existed if the grandparent was divorced (King, 2003). Moreover, these associations were stronger for grandfathers and paternal grandparents than for grandmothers and maternal grandparents. According to the Iowan study, however, grandparental divorce was negatively associated with grandparent-grandchild relationship quality only if the relationship between the grandparent and parent was weak. Similarly, it was found with the Finnish data that although both divorce and remarriage were associated with reduced contact and child care help among grandmothers and grandfathers compared to never-divorced ones, this was especially the case for grandfathers (Danielsbacka \& Tanskanen, 2016, 2018). The most dramatic change was the reduction in child care provided by grandfathers: 83 per cent of grandfathers who were married to the child's grandmother reported providing child care during the last 12 months, whereas only 58 per cent of remarried and 53 per cent of divorced grandfathers reported doing so. In addition, among married (never-divorced) and divorced grandparents, grandmothers invested significantly more than grandfathers did. This result is consistent with the above-mentioned studies showing that marital disruption has more negative 
effects for men than for women in relation to kin support (King, 2003; Knudsen, 2012; Uhlenberg \& Hammill, 1998).

We can conclude that older men tend to suffer much more in terms of grandchild contact if they lose their spouse (that is, the grandmother of their grandchildren), which is consistent with the incidental exposure hypothesis (Euler, 2011; see Chapter 2). However, the reason for loneliness appears to be significant. Divorced and remarried men may have lower levels of contact with their grandchildren than widowed men do because the ex-spouse (that is, the grandmother of the grandchild) may compete with them for time with the grandchildren. Obviously, in the case of widowed grandparents, this competition does not exist.

We have reviewed studies examining how grandparental opportunities to provide support may shape kin relations. In addition, several studies have found that the need for support is often related to grandparental investment. For instance, adult children who are living without a partner tend to receive more grandparental child care help than adult children with partners (Hank \& Buber, 2009; Jappens \& Van Bavel, 2012), and unemployed adult children receive more child care help from older parents than their employed counterparts (e.g., Coall et al., 2014). Moreover, younger grandchildren, who obviously are highly dependent on other people's support, tend to receive more grandparental investment compared to older grandchildren (e.g., Igel \& Szydlik, 2011).

\section{Country-level differences}

In the previous sub-chapter, we discussed how need and opportunity structures shape intergenerational relations at the individual level. Next, we review studies that have concentrated on country-level differences in intergenerational relations. These studies emphasise that welfare state and family policy practices affect intergenerational kin support and investments, especially via need and opportunity structures. If public services, such as child care services, are free or sufficiently advantageous, there is less need for regular child care help from grandparents. Moreover, rewarding pension systems may increase grandparents' opportunities to provide informal help. Thus, the country of residence may substantially influence the amount of grandparental investment.

It is obvious that there are stronger and weaker welfare states. Two mutually exclusive hypotheses are provided to explain how the type of welfare state may affect intergenerational relations (e.g., Künemund \& Rein, 1999; see Chapter 2). The crowding-out hypothesis predicts that advantageous public support and services "crowd out" informal kin support. According to this view, intergenerational family help is a consequence of poor public support and services, meaning that grandparents should invest in their grandchildren as a result of weak welfare state support. The counterargument, the crowding-in hypothesis, states that extensive welfare state support can help individuals to provide more informal help to one another. Thus, it is argued that strong welfare states may "crowd in" intergenerational support and even strengthen family relations. 
Perhaps the most comprehensive empirical country comparisons have been produced by using the multinational Survey of Health, Ageing and Retirement in Europe data. One such study indicated that the likelihood of grandparents providing "any" child care (i.e., at least once a year) was highest in Denmark, the Netherlands, France and Sweden, whereas the lowest likelihood existed in Spain and Italy (Hank \& Buber, 2009). In contrast, intensive grandchild care (i.e., on at least a weekly basis) was provided most often in Greece, Italy and Spain, whereas the lowest likelihood of intensive care was apparent in Sweden, Denmark, France and the Netherlands. In other words, in (Nordic) countries where more generous welfare services exist (e.g., Sweden and Denmark), there is no need for extensive child care help. Instead, more grandparents look after their grandchildren occasionally, whereas the situation is opposite in "weaker" welfare states (e.g., Italy and Spain), where more grandparents are needed to look after their grandchildren on a daily basis, but the number of grandparents who do not help at all is higher. Thus, significant country differences in grandparental child care tend to exist among European countries.

Somewhat similar conclusions have been made in another investigation using the Survey of Health, Ageing and Retirement in Europe data (Igel \& Szydlik, 2011). This study concluded that in countries with higher levels of public support for families, a higher number of grandparents provide grandchild care occasionally. In countries with lower levels of publicly provided child care arrangements, a small part of grandparents were "forced" to look after their grandchildren intensively. Thus, strong welfare states can motivate grandparents to participate in the lives of their grandchildren without the risk of being overburdened. Moreover, the combination of informal and formal child care may be the best solution not only for grandparents but also for the parents of small children. In particular, the combination of formal and informal support can help working mothers effectively combine family and working life arrangements (Wheelock \& Jones, 2002).

In addition, socio-ecological factors of both parents and grandparents tend to vary substantially across European countries, and differences in intensive child care provided by grandparents may be related to these individual-level factors rather than country differences per se (Di Gessa, et al., 2016). For instance, Southern European parents tend to be older and are more likely to be married and have only one child compared to parents from other parts of Europe. In addition, Southern European grandparents are less educated and less likely to participate in paid work compared to their counterparts from other European countries. Interestingly, there seems to be no support for cross-country differences in intensive grandparental child care to be explained by individual-level factors. Instead, differences related to the availability of publicly provided child care arrangements and female labour force participation tend to be the key forces shaping differences in grandparental child care. Obviously, female labour force participation is closely related to attitudes towards sex roles, which can vary substantially between countries (Jappens \& Van Bavel, 2012).

Although grandparental investment tends to vary substantially between countries, another study using the Survey of Health, Ageing and Retirement in 
Europe showed that the biased grandparental investment pattern exists in different country groups (Danielsbacka et al., 2011). The study found that across different European regions (i.e., in Southern Europe, Eastern Europe, Central Europe and Northern Europe), maternal grandmothers were most likely to provide child care on at least a weekly basis, followed by maternal grandfathers and paternal grandmothers and finally paternal grandfathers. These results hold even after controlling country- as well as individual-level socio-demographic differences (e.g., parental labour force participation, grandparent's job situation and geographical distance). Thus, it can be concluded that although grandparental investment varies between contemporary European countries, the biased grandparental investment pattern tends to remain robust.

\section{Conclusions}

In this chapter, we have reviewed the existing literature on grandparental investment and the quality of intergenerational relations by emphasising the factors associated with them. The empirical findings show that the investment of grandparents varies strongly according to evolutionarily relevant variables: genetic relatedness, sex and lineage. Thus, grandparents tend to have a robust tendency to allocate their investment differently for their children and grandchildren; however, they do not necessarily make biased investment decisions consciously. Existing studies support the evolutionary theoretical predictions that biological grandparents invest more in their grandchildren than non-biological grandparents do, and among biological grandparents, maternal grandmothers typically invest the most and paternal grandfathers invest the least. Moreover, when receivers' needs for help and givers' opportunities to provide support increase, the amount of kin investment also tends to increase. Better parent-grandparent relationship quality is associated with better grandparent-grandchild relationship quality. The relationship quality between in-laws (e.g., mother-in-law and daughter-in-law) is more likely than that between biological kin (e.g., mother and daughter) to be associated with grandparental investment. Whether the grandparental investment examined in the current chapter is associated with kin outcomes is another question that is investigated in the next chapters.

\section{References}

Albertini, M., Kohli, M., \& Vogel, C. (2007). Intergenerational transfers of time and money in European families: Common patterns - different regimes? Journal of European Social Policy, 17, 319-334.

Anderson, K. G. (2011). Stepparenting, divorce, and investment in children. In C. Salmon \& T. K. Shackelford (Eds.), The Oxford handbook on evolutionary family psychology (pp. 97-112). New York: Oxford University Press.

Attias-Donfut, C., Ogg, J., \& Wolff, F. C. (2005). European patterns of intergenerational financial and time transfers. European Journal of Ageing, 2, 161-173.

Barnett, M. A., Scaramella, L. V., Neppl, T. K., Ontai, L., \& Conger, R. D. (2010). Intergenerational relationship quality, gender, and grandparent involvement. Family Relations, 59, 28-44. 
Bengtson, V. L., \& Kuypers, J. A. (1971). Generational difference and the developmental stake. Aging and Human Development, 2, 249-260.

Bishop, D., Meyer, B., Schmidt, T., \& Gray, B. (2009). Differential investment behavior between grandparents and grandchildren: The role of paternity uncertainty. Evolutionary Psychology, 7, 66-77.

Block, C. E. (2000). Dyadic and gender differences in perceptions of the grandparentgrandchild relationship. The International Journal of Aging and Human Development, 51, 85-104.

Bonsang, E. (2007). How do middle-aged children allocate time and money transfers to their older parents in Europe? Empirica, 34, 171-188.

Brandt, M. (2013). Intergenerational help and public assistance in Europe: A case of specialization? European Societies, 15, 26-56.

Brandt, M., \& Deindl, C. (2013). Intergenerational transfers to adult children in Europe: Do social policies matter? Journal of Marriage and Family, 75, 235-251.

Buchanan, A., \& Rotkirch, A. (Eds.) (2016). Grandfathers: Global perspectives. London: Palgrave Macmillan.

Burton-Chellew, M. N. \& Dunbar, R. I. M. (2011). Are affines treated as biological kin? A test of Hughes's hypothesis. Current Anthropology, 52, 741-746.

Campbell, A. (2013). A mind of her own: The evolutionary psychology of women. Oxford: Oxford University Press.

Chagnon, N., Lynch, R. F., Shenka, M. K., Hames, R., \& Flinn, M. V. (2017). Cross-cousin marriage among the Yanomamö shows evidence of parent-offspring conflict and mate competition between brothers. Proceedings of the National Academy of Sciences, 114, E2590-E2607.

Chan, C. G., \& Elder, G. H., Jr. (2000). Martilineal advantage in grandchild-grandparent relations. The Gerontologist, 40, 179-190.

Chapais, B. (2010). Primeval kinship: How pair-bonding gave birth to human society. Cambridge, MA: Harvard University Press.

Chapman, S. N., Pettay, J. E., Lummaa, V., \& Lahdenperä, M. (2018). Limited support for the X-linked grandmother hypothesis in pre-industrial Finland. Biology Letters, 14. https://doi.org/10.1098/rsbl.2017.0651

Chrastil, E. R., Getz, W. M., Euler, H. A., \& Starks, P. T. (2006). Paternity uncertainty overrides sex chromosome selection for preferential grandparenting. Evolution \& Human Behavior, 27, 206-223.

Coall, D. A., \& Hertwig, R. (2010). Grandparental investment: Past, present, and future. Behavioral and Brain Sciences, 33, 1-59.

Coall, D. A., \& Hertwig, R. (2011). Grandparental investment: A relic of the past or a resource for the future? Current Directions in Psychological Science, 20, 93-98.

Coall D. A., Hilbrand, S., \& Hertwig, R. (2014). Predictors of grandparental investment decisions in contemporary Europe: Biological relatedness and beyond. PLoS ONE, 9, e84082.

Coall, D. A., Meier, M., Hertwig, R., Wänke, M., \& Höpflinger, F. (2009). Grandparental investment: The influence of reproductive timing and family size. American Journal of Human Biology, 21, 455-463.

Creasey, G. L., \& Koblewski, P. J. (1991). Adolescent grandchildren's relationships with maternal and paternal grandmothers and grandfathers. Journal of Adolescence, 14, 373-387.

Curry, O., Roberts, S. G. B., \& Dunbar, R. I. M. (2013). Altruism in social networks: Evidence for a "kinship premium". British Journal of Psychology, 104, 283-295. 
Daly, M., \& Perry, G. (2017). Matrilateral bias in human grandmothering. Frontiers in Sociology, 2. https://doi.org/10.3389/fsoc.2017.00011

Daly, M., \& Wilson, M. (1985). Child abuse and other risks of not living with both parents. Ethology and Sociobiology, 6, 197-210.

Danielsbacka, M., \& Tanskanen, A. O. (2012). Adolescent grandchildren's perceptions of grandparents' involvement in UK: An interpretation from life course and evolutionary theory perspective. European Journal of Ageing, 9, 329-341.

Danielsbacka, M., \& Tanskanen, A. O. (2016). Grandfather involvement in Finland: Impact of divorce, remarriage and widowhood. In A. Buchanan, \& A. Rotkirch (Eds.), Grandfathers: Global perspectives (pp. 183-197). London: Palgrave Macmillan.

Danielsbacka, M., \& Tanskanen, A. O. (2018). Marital disruption and intergenerational relations among older Finns. Contemporary Social Science, 13. https://doi.org/10.1080/ 21582041.2017.1422794

Danielsbacka, M., Tanskanen, A. O., Hämäläinen, H., Pelkonen, I., Haavio-Mannila, E., Rotkirch, A., Karisto, A., \& Roos, J. P. (2013). Sukupolvien vuorovaikutus: Auttaminen ja yhteydenpito suurten ikäluokkien ja heidän lastensa elämässä [Intergenerational relations: Helping and interaction in the life of Finnish baby boomers and their adult children]. Vä estöntutkimuslaitoksen julkaisusarja D 58/2013. Helsinki: Vä estöliitto.

Danielsbacka, M., Tanskanen, A. O., Jokela, M., \& Rotkirch, A. (2011). Grandparental child care in Europe: Evidence for preferential investment in more certain kin. Evolutionary Psychology, 9, 3-24.

Danielsbacka, M., Tanskanen, A. O., \& Rotkirch, A. (2015). The impact of genetic relatedness and emotional closeness on intergenerational relations. Journal of Marriage and Family, 77, 889-907.

Danielsbacka, M., Tanskanen, A. O., \& Rotkirch, A. (2017). The "kinship penalty": Parenthood and in-law conflict in contemporary Finland. Evolutionary Psychological Science, 4, 1-12.

Deindl, C., \& Brandt, M. (2011). Financial support and practical help between older parents and their middle-aged children in Europe. Ageing \& Society, 31, 645-662.

Di Gessa, G., Glaser, K., \& Tinker, A. (2016). The impact of caring for grandchildren on the health of grandparents in Europe: A lifecourse approach. Social Science \& Medicine, 152, 166-175.

Dubas, J. S. (2001). How gender moderates the grandparent-grandchild relationship. Journal of Family Issues, 22, 478-492.

Eisenberg, A. R. (1988) Grandchildren's perspectives on relationships with grandparents: The influence of gender across generations. Sex Roles, 19, 205-217.

Euler, H. A. (2011). Grandparents and extended kin. In C. A. Salmon \& T. K. Shackelford (Eds.), The Oxford handbook of evolutionary family psychology (pp. 181-207). New York: Oxford University Press.

Euler, H. A., Hoier, S., \& Rohde, P. A. (2001). Relationship-specific closeness of intergenerational family ties: Findings from evolutionary psychology and implications for models of cultural transmission. Journal of Cross-Cultural Psychology, 32, 147-158.

Euler, H. A., \& Weitzel, B. (1996). Discriminative grandparental solicitude as reproductive strategy. Human Nature, 7, 39-59.

Evandrou, M., Falkingham, J., Gomez-Leon, M., \& Vlachantoni, A. (2016). Intergenerational flows of support between parents and adult children in Britain. Ageing \& Society, 1-31.

Fingerman, K. L. (2004). The role of offspring and in-laws in grandparents' ties to their grandchildren. Journal of Family Issues, 25, 1026-1049. 
Fingerman, K. L., Hay, E. L., \& Birditt, K. (2004). The best of ties, the worst of ties: Close, problematic, and ambivalent social relationships. Journal of Marriage and Family, 66, 792-808.

Fingerman, K. L., Pitzer, L., Lefkowitz, E. S., Birditt, K. S., \& Mroczek, D. (2008). Ambivalent relationship qualities between adults and their parents: Implications for the well-being of both parents. Journals of Gerontology Series B: Psychological and Social Sciences, 63, 362-371.

Fischer, R. L. (1983). Mothers and mothers-in-law. Journal of Marriage and the Family, 45, 187-192.

Fokkema, T., ter Bekke, S., \& Dykstra, P. A. (2008). Solidarity between parents and their adult children. Netherlands Interdisciplinary Demographic Institute. Amsterdam: Aksant.

Fox, M., Sear, R., Beise, J., Ragsdale, G., Voland, E., \& Knapp, L. A. (2010). Grandma plays favourites: X-chromosome relatedness and sex-specific childhood mortality. Proceedings of the Royal Society B: Biological Sciences, 277, 567-573.

Fulcher, M., Chan, R. W., Raboy, B., \& Patterson, C. J. (2002). Contact with grandparents among children conceived via donor insemination by lesbian and heterosexual mothers. Parenting, 2, 61-76.

Geurts, T., Poortman, A. R., \& van Tilburg, T. G. (2012). Older parents providing child care for adult children: Does it pay off? Journal of Marriage and Family, 74, 239-250.

Gray, P. B., \& Brogdon, E. (2017). Do step- and biological grandparents show differences in investment and emotional closeness with their grandchildren? Evolutionary Psychology, 15, 1-9.

Hagestad, G. O. (1985). Continuity and connectedness. In V. L. Bengston \& J. F. Robertson (Eds.), Grandparenthood (pp. 31-48). Beverly Hills: Sage.

Hamilton, W. D. (1964). The genetical evolution of social behaviour (I and II). Journal of Theoretical Biology, 7, 1-52.

Hank, K., \& Buber, I. (2009). Grandparents caring for their grandchildren: Findings from the 2004 Survey of Health, Ageing, and Retirement in Europe. Journal of Family Issues, 30, 53-73.

Hank, K., Salzburger, V., \& Silverstein, M. (2017). Intergenerational transmission of parent-child relationship quality: Evidence from a multi-actor survey. Social Science Research, 67, 129-137.

Hax, C. (2015, July 11). When grandparents play favorites, nobody wins. The Washington Post. Retrieved from https://www.washingtonpost.com

Hoff, A. (2007). Patterns of intergenerational support in grandparent-grandchild and parent-child relationships in Germany. Ageing \& Society, 27, 643-665.

Hughes, A. L. (1988). Evolution and human kinship. New York: Oxford University Press.

Höpflinger F., \& Hummel, C. (2006). Heranwachsende Enkelkinder und ihre Großeltern. Zeitschrift für Gerontologie und Geriatrie, 39, 33-40.

Igel, C., \& Szydlik, M. (2011). Grandchild care and welfare state arrangements in Europe. Journal of European Social Policy, 21, 210-224.

Jamison, C. S., Cornell, L. L., Jamison, P. L., \& Nakazato, H. (2002). Are all grandmothers equal? A review and a preliminary test of the "grandmother hypothesis" in Tokugawa, Japan. American Journal of Physical Anthropology, 119, 67-76.

Jappens, M., \& Van Bavel, J. (2012). Regional family norms and child care by grandparents in Europe. Demographic Research, 27, 85-120. 
Johow, J., Fox, M., Knapp, L. A., \& Voland, E. (2011). The presence of a paternal grandmother lengthens interbirth interval following the birth of a granddaughter in Krummhörn (18th and 19th centuries). Evolution and Human Behavior, 32, 315-325.

Kalmijn, M., \& Saraceno, C. (2008). A comparative perspective on intergenerational support: Responsiveness to parental needs in individualistic and familialistic countries. European Societies, 10, 479-508.

Kaptijn, R., Thomese, F., Liefbroer, A. C., \& Silverstein, M. (2013). Testing evolutionary theories of discriminative grandparental investment. Journal of Biosocial Science, 45 , 289-310.

Kaufman, G., \& Uhlenberg, P. (1998). Effects of life course transitions on the quality of relationships between adult children and their parents. Journal of Marriage and the Family, 60, 924-938.

Kiecolt, K. J., Blieszner, R., \& Savla, J. (2011). Long-term influences of intergenerational ambivalence on midlife parents' psychological well-being. Journal of Marriage and Family, 73, 369-382.

King, V. (2003). The legacy of a grandparent's divorce: Consequences for ties between grandparents and grandchildren. Journal of Marriage and Family, 65, 170-183.

King, V., \& Elder, G. H., Jr. (1995). American children view their grandparents: Linked lives across three rural generations. Journal of Marriage and Family, 57, 165-178.

King, V., Silverstein, M., Elder, G. H., Jr., Bengtson, V. L., \& Conger, R. D. (2003). Relations with grandparents: Rural midwest versus urban southern California. Journal of Family Issues, 24, 1044-1069.

Knudsen, K. (2012). European grandparents' solicitude: Why older men can be relatively good grandfathers. Acta Sociologica, 55, 231-250.

Knudsen, K. (2016). Good grandfathers have a partner. In A. Buchanan \& A. Rotkirch (Eds.), Grandfathers: Global perspectives (pp. 165-181). London: Palgrave Macmillan.

Kohli, M. (1999). Private and public transfers between generations: Linking the family and the state. European Societies, 1, 81-104.

Korchmaros, J. D., \& Kenny, D. A. (2001). Emotional closeness as a mediator of the effect of genetic relatedness on altruism. Psychological Science, 12, 262-265.

Künemund, H., \& Rein, M. (1999). There is more to receiving than needing: Theoretical arguments and empirical explorations of crowding in and crowding out. Ageing \& Society, 19, 93-121.

Laham, S. M., Gonsalkorale, K., \& von Hippel, W. (2005). Darwinian grandparenting: Preferential investment in more certain kin. Personality and Social Psychology Bulletin, 31, 63-72.

Lendon, J. P., Silverstein, M., \& Giarrusso, R. (2014). Ambivalence in older parent-adult child relationships: Mixed feelings, mixed measures. Journal of Marriage and Family, 76, 272-284.

Leonetti, D. L., Nath, D. C., \& Hehman, N. S. (2007) In-law conflict: Women's reproductive lives and the roles of their mothers and husbands among the matrilineal Khasi. Current Anthropology, 48, 861-890.

Linn, R., \& Breslerman, S. (1996). Women in conflict: On the moral knowledge of daughters-in-law and mothers-in-law. Journal of Moral Education, 25, 291-307.

Majamaa, K. (2013). The effect of socio-economic factors on parental financial support from the perspectives of the givers and the receivers. European Societies, 15, 57-81.

Matthews, S. H., \& Sprey, J. (1985). Adolescents' relationships with grandparents: An empirical contribution to conceptual clarification. Journal of Gerontology, 40, 621-626. 
Mueller M. M., \& Elder G. H. (2003) Family contingencies across the generations: Grandparent-grandchild relationships in holistic perspective. Journal of Marriage and Family, 65, 404-417.

Neyer, F. J., \& Lang, F. R. (2003). Blood is thicker than water: Kinship orientation across adulthood. Journal of Personality and Social Psychology, 84, 310-321.

Pashos, A. (2000). Does paternity uncertainty explain discriminative grandparental solicitude? A cross-cultural study in Greece and Germany. Evolution and Human Behavior, 21, 97-109.

Pashos, A. (2017). Asymmetric caregiving by grandparents, aunts, and uncles and the theories of kin selection and paternity certainty: How does evolution explain human behavior toward close relatives? Cross-Cultural Research, 51, 263-284.

Pashos, A., Schwarz, S., \& Björklund, D. F. (2016). Kin investment by step-grandparents More than expected. Evolutionary Psychology, 14, 1-13.

Patterson, C. J., Hurt, S., \& Mason, C. D. (1998). Families of the lesbian baby boom: Children's contact with grandparents and other adults. American Journal of Orthopsychiatry, 68, 390-399.

Perry, G., \& Daly, M. (2017). A model explaining the matrilateral bias in alloparental investment. Proceedings of the National Academy of Sciences, 114, 9290-9295.

Pillemer, K., \& Suitor, J. J. (2002). Explaining mothers' ambivalence toward their adult children. Journal of Marriage and Family, 64, 602-613.

Pollet, T. V., \& Hoben, A. D. (2011). An evolutionary perspective on siblings: Rivals and resources. In C. Salmon \& T. K. Shackelford (Eds.), The Oxford handbook on evolutionary family psychology (pp. 128-148). New York: Oxford University Press.

Pollet, T. V., Nettle, D., \& Nelissen, M. (2006). Contact frequencies between grandparent and grandchildren in a modern society: Estimates of the impact of paternity uncertainty. Journal of Cultural and Evolutionary Psychology, 4, 203-213.

Pollet, T. V., Nettle, D., \& Nelissen, M. (2007). Maternal grandmothers do go the extra mile: Factoring distance and lineage into differential contact with grandchildren. Evolutionary Psychology, 5, 832-843.

Reczek, C. (2014). The intergenerational relationships of gay men and lesbian women. Journals of Gerontology, Series B: Psychological Sciences and Social Sciences, 69, 909-919.

Reczek, C. (2016). Ambivalence in gay and lesbian family relationships. Journal of Marriage and Family, 78, 644-659.

Rice, W. R., Gavrilets, S., \& Friberg, U. (2010). The evolution of sex-specific grandparental harm. Proceedings of the Royal Society B: Biological Science, 277, 2727-2735.

Rossi, A. S., \& Rossi, P. H. (1990). Of human bonding: Parent-child relations across the life course. New York: Aldine.

Rotkirch, A., Lyons, M., David-Barrett, T., \& Jokela, M. (2014). Gratitude for help among adult friends and siblings. Evolutionary Psychology, 12, 673-686.

Salmon, C. A. (1999). On the impact of sex and birth order on contact with kin. Human Nature, 10, 183.

Schwarz, B., Trommsdorff, G., Albert, I., \& Mayer, B. (2005). Adult parent-child relationships: Relationship quality, support, and reciprocity. Applied Psychology, 54, $396-417$.

Sear, R. (2008). Kin and child survival in rural Malawi: Are matrilineal kin always beneficial in a matrilineal society? Human Nature, 19, 277-293.

Sear, R., \& Mace, R. (2008). Who keeps children alive? A review of the effects of kin on child survival. Evolution and Human Behavior, 29, 1-18. 
Segal, N. L., Norman, P. L., Graham, J. L., \& Miller, S. A. (2015). Do parents favor their adoptive or biological children? Predictions from kin selection and compensatory models. Evolution and Human Behavior, 36, 379-388.

Silverstein, M., \& Bengtson, V. L. (1997). Intergenerational solidarity and the structure of adult child-parent relationships in American families. American Journal of Sociology, 103, 429-460.

Smorti, M., Tschiesner, R., \& Farneti, A. (2012). Grandparents-grandchildren relationship. Procedia - Social and Behavioral Sciences, 46, 895-898.

Szydlik, M. (2012). Generations: Connections across the life course. Advances in Life Course Research, 17, 100-111.

Szydlik, M. (2016). Sharing lives: Adult children and parents. New York: Routledge.

Tanskanen, A. O. (2017). Intergenerational relations before and after offspring arrive: A within-person investigation. Social Science Research, 67, 138-146.

Tanskanen, A. O., Danielsbacka, M., \& Rotkirch, A. (2014). Multi-partner fertility is associated with lower grandparental investment from in-laws in Finland. Advances in Life Course Research, 20, 41-47.

Tanskanen, A. O., Rotkirch, A., \& Danielsbacka, M. (2011). Do grandparents favor granddaughters? Biased grandparental investment in the UK. Evolution and Human Behavior, 32, 407-415.

Triadó, C., Villar, F., Solé, C., Osuna M.-J., \& Pinazo, S. (2005). The meaning of grandparenthood: Do adolescent grandchildren perceive the relationship and role in the same way as their grandparent do? Journal of Intergenerational Relationships, 3 , $101-121$.

Uhlenberg, P., \& Hammill, B. G. (1998). Frequency of grandparent contact with grandchild sets: Six factors that make a difference. The Gerontologist, 38, 276-285.

Waynforth, D. (2011). Grandparental investment and reproductive decisions in the longitudinal 1970 British cohort study. Proceedings of the Royal Society B: Biological Sciences, 279, 1155-1160.

Wheelock, J., \& Jones, K. (2002). "Grandparents are the next best thing": Informal childcare for working parents in urban Britain. Journal of Social Policy, 31, 441-463.

Willson, A. E., Shuey, K. M., \& Elder, G. H. (2003). Ambivalence in the relationship of adult children to aging parents and in-laws. Journal of Marriage and Family, 65, 1055-1072. 


\section{Grandparents and parental childbearing}

On 13 May 2012, The New York Times published an article on childless women who are coming to egg freezing clinics with their parents (Gootman, 2012). The "would-be grandparents" are willing to pay the egg freezing costs for their daughters in the hope that their daughters, who have postponed their childbearing, are someday willing to start a family. One can consider that paying their daughters' egg freezing provides an extreme case of how older parents can support the childbearing of their adult children. A more typical way is that older parents provide practical, emotional or financial support that may influence adult children's fertility decisions. Whether kin support may influence fertility decisions of adult children is a topic that has received considerable attention, especially among evolutionary scholars. In this chapter we concentrate on the parental childbearing because fertility is an extremely important topic from the inclusive fitness perspective.

In this chapter, we prefer to use the term "kin investment" instead of grandparental investment because of its broader meaning. We use the term "kin investment" to refer to investments made by older parents or in-laws towards their descendants. These kin investors may or may not be grandparents, but those who are not yet grandparents may be grandparents-to-be; that is, they may experience entry into grandparenthood in the future. In this chapter, we first review studies that have investigated the association between the presence of kin and fertility in traditional and historical populations. Next, we concentrate on associations between kin investment and childbearing in contemporary societies.

\section{Kin and fertility in traditional and historical populations}

An extensive review article by Sear and Coall (2011) asked whether parents or in-laws have an effect on adult children's childbearing decisions. The review included all published studies at that time that have investigated whether the presence of parents or parents-in-law was associated with female fertility in traditional and historical populations. The term "traditional and historical populations" refers to natural fertility and mortality populations without modern medical care, contraceptive technology or welfare services. The populations included in the review 
varied substantially in content and ranged from small-scale hunter-gatherer communities to large-scale historical and agricultural societies. Studies from diverse populations were included because this type of information can help to identify general trends that are not only the results of population-specific cultural features (see also Sear \& Mace, 2008; Chapter 6 for discussion).

In traditional and historical populations, the potential parental effect on female fertility is typically measured by parental presence in the same household or in the same village as adult children. The basic assumption behind the use of parental presence as a proxy for investment is based on the simple fact that when parents live close to their adult children, they have a higher likelihood of interacting with them. This was particularly the case in traditional and historical populations with limited opportunities to travel long distances. In the reviewed studies, female fertility was measured by several indicators, including age at first birth, length of birth intervals, total number of children born and length of reproductive span (Sear \& Coall, 2011).

Overall, the review showed that in 87 per cent of studies (34/39), the presence of at least one parent or in-law was associated with female fertility. However, differences between parents and in-laws were detected. The presence of mothers correlated with increased female fertility in 58 per cent of studies $(7 / 12)$, the presence of fathers in 63 per cent of studies (5/8), the presence of mothers-in-law in 67 per cent of studies (4/6) and the presence of fathers-in-law in 60 per cent of studies $(3 / 5)$. Moreover, the presence of mothers correlated with decreased fertility in 17 per cent of cases (2/12). These results indicate that parents-in-law (i.e., the husbands' parents) may have a somewhat higher influence on female fertility compared to own parents. These results provide limited support (if any) for the sex-specific reproductive strategies model, which assumes that parents-in-law, particularly mothersin-law, may increase female fertility (Euler, 2011; see Chapter 2).

A study using data from rural Gambia gathered between 1950 and 1974 showed that the presence of parents-in-law was associated with decreased birth intervals among females, whereas this was not the case when only own parents were present (Sear et al., 2003). Similarly, a study that analysed the potential parental effect on fertility in India found an association between the presence of mothers-in-law and decreased birth intervals among females (Leonetti et al., 2005). However, other studies have found that the presence of both own parents and parents-in-law is similarly associated with female fertility (e.g., Tymicki, 2004). Moreover, some studies from traditional and historical populations have not detected a correlation between kin presence and fertility (Sear \& Mace, 2008).

In addition to sex-specific reproductive strategies, the potentially different effect of the older generation on the fertility of their adult children is explained by the grandmother hypothesis. The grandmother hypothesis states that human females gain fitness benefits by ceasing their reproduction early and concentrating on investing in their children or grandchildren instead. According to the grandmother hypothesis, grandmothers can be assumed to improve the fertility of their adult children and children-in-law (e.g., Voland et al., 2005). In recent decades, predictions based on the grandmother hypothesis have been investigated in 
several studies. For instance, using church register data from a historical Finnish population between 1702 and 1823, Lahdenperä and colleagues (2004) showed that the presence of mothers and mothers-in-law hastened females' entry into parenthood and was associated with decreased birth intervals and an increased amount of lifetime fertility (i.e., increased family size). In another study using the same data, these authors did not find similar effects among fathers and fathersin-law on female fertility (Lahdenperä et al., 2007). Although these results are in line with the grandmother hypothesis, other empirical tests of the grandmother hypothesis have produced mixed results; although some have detected support for the grandmother hypothesis, others have not (see Coall \& Hertwig, 2010, for a review).

Studies using data from past populations have also indicated the existence of reproductive competition among kin. It has been noted that reproductive conflict may occur between mothers and daughters or between mothers-in-law and daughters-in-law if females from different generations reproduce simultaneously (Lahdenperä et al., 2012). Theoretically, this finding provides support for the grandmother hypothesis because it also suggests that for older females, there may be more harm than benefit in reproducing simultaneously with their children or children-in-law. However, because mothers and daughters are typically related to each other's descendants whereas mothers-in-law and daughters-in-law are not, reproductive conflict is more likely to occur among the latter dyads (Cant \& Johnstone, 2008; see Chapter 2). A study of pre-industrial Finns found that simultaneous reproduction by daughters-in-law and mothers-in-law was associated with a dramatic decline in descendant survivorship, whereas a strong association was not found in the case of simultaneous reproduction between daughters and mothers (Lahdenperä et al., 2012). It is rare that mothers-in-law and daughters-inlaw reproduce at the same time, and the potential harm this produces to descendant survival may be one of the reasons.

A more common situation in humans is that reproductive competition occurs between same-aged and unrelated females who are dependent on the same resources. Again, using data from pre-industrial Finland, scholars found reproductive conflict in households where several unrelated and reproductive-aged women lived together (Pettay et al., 2016). This type of living arrangement is common in patrilineal joint families where brothers remain in their childhood homes and sisters marry out. The study found that the risk of childhood mortality substantially increased if coresiding women reproduced near the same time (i.e., within two years). However, findings from the same Finnish populations showed that the presence of potential female competitors (i.e., unrelated daughters-inlaw) was not associated with female fertility (i.e., entry into motherhood and agespecific reproduction) (Pettay et al., 2017).

\section{Kin and fertility in contemporary societies}

In recent decades, fertility rates have declined globally (e.g., Balbo et al., 2013; Billari \& Kohler, 2004); in many countries, they are currently below the 
replacement level of 2.1 children per woman. The replacement level indicates the number of children needed to maintain the current population size. Decreased fertility rates may lead to problems related to the capacity of welfare states to provide services to their citizens (McDonald, 2006). For instance, low-fertility societies may experience labour force shortages, particularly in societies that age rapidly. In ageing societies, governments also have pressure to cut pensions and welfare benefits directed towards older citizens. In the future, low fertility rates may even threaten public child care, education and social welfare systems. Thus, it is unsurprising that there has been great concern in many countries to improve fertility rates.

Social science studies have commonly considered how fertility rates can be improved via formal state support and family policies. For instance, based on cross-national data including 16 European countries, it was found that increased public expenditure in programmes to help women reconcile working and family life was associated with increased fertility rates (Kalwij, 2010). In addition, an Italian study found that parents who had the opportunity to use formal child care arrangements had a higher probability of having another child (Del Boca, 2002), but similar associations were not found in studies using data from Sweden (Andersson et al., 2004) and Germany (Hank \& Kreyenfeld, 2003). These results indicate that even though it may be possible to influence fertility decisions via family policies, important country-based differences exist.

Social science studies have rarely considered whether informal support received from kin can increase fertility. This omission may be related to the fact that there has been a lack of social science theories that directly predict whether kin should influence fertility. Perhaps the most important hypothesis assumes that kin can compensate for the lack of other (i.e., public) support and thus increase fertility. However, the question of whether there is a difference in fertility outcomes based on the type of helper (i.e., whether the support is provided by kin or by the state) has rarely been discussed. In contrast, evolutionary theory assumes that kin may influence fertility because the reproductive decisions of relatives are strongly related to one's own inclusive fitness. Based on evolutionary theory, whether the kin effect on fertility is positive, negative or negligible may be related to several factors, including the type of kin that provide support as well as the ecological environment.

The possible effects of kin on fertility have been studied in present-day populations with different levels of welfare. Moreover, the potential kin effect on fertility has been studied with many different fertility indicators and kin investment factors. These fertility indicators include intentions to have a child, entry into parenthood, probability of having another child, age at first birth, total number of children and length of birth intervals. Kin investments or proxies for kin investment are measured by geographical proximity between adult children and parents, parental coresidence, parental survival status (whether a parent is alive or dead), emotional support, contact frequency between adult children and parents, and grandparental child care help. 


\section{Kin presence and fertility}

Below, we report the results of studies that have investigated whether parental presence is associated with the childbearing of adult children in contemporary societies. In this set of studies, the potential "parental effect" is typically measured by indicating whether parents or in-laws live in the same household or town as their adult children. Moreover, kin availability is sometimes measured by parental survival status, indicating whether the parent is dead or alive. This indicator is used because living kin members can be assumed to have more influence on fertility decisions compared to kin members who have passed away. However, it is important to note that the parental effect on adult children's fertility decisions may exist even after parents have died, such as via inheritances and cumulative wealth (see Chapter 2: Box 2.4). When possible, we carefully report potentially different kin effects on female fertility between different types of relatives, namely, mothers or fathers and mothers-in-law or fathers-in-law.

Several studies examining the potential kin influence on fertility have been conducted with data from lower- or middle-income populations (i.e., contemporary developing societies). One such study used large-scale data from Thailand and measured the potential kin effects by the length of multigenerational coresidence with parents or parents-in-law after a couple marries (Snopkowski \& Sear, 2013). This study found that living with the husband's parents (i.e., paternal kin) was associated with decreased time of entry into parenthood and increased probability of having a second or subsequent child. In addition, post-marital coresidence with the wife's parents (i.e., maternal kin) correlated with decreased time to having the first child but was not correlated with the probability of having a second or subsequent child.

Another study analysing longitudinal data from Indonesia measured kin availability using several factors, namely, survival status of parents, multigenerational coresidence, residence in the same village, contact frequency and help received from parents or parents-in-law (Snopkowski \& Sear, 2016). The study revealed that the kin effect varied by both the type of kin availability indicator and parity. Married women's coresidence with mothers, fathers and mothers-in-law was associated with an increased likelihood of having a first child. Fathers-inlaw's survival correlated with an increased probability of entry into parenthood among women. Perhaps surprisingly, however, women with mothers-in-law and fathers-in-law living in different regions had a higher likelihood of having a child compared to women with mothers-in-law and fathers-in-law living in the same village. Finally, when women already had no more than two children, the help received from mothers and mothers-in-law was associated with increased fertility.

Studies have also examined the potential effect of kin presence on fertility using data from higher-income populations (i.e., affluent Western nations). For instance, a study conducted using longitudinal data from (West) Germany found that women living in the same town as their parents had a higher likelihood of entry into parenthood compared to women who lived farther from their parents (Hank \& Kreyenfeld, 2003). Another study showed that increased parental 
survival status was associated with higher fertility among Italian women (Del Boca, 2002).

A more recent study from Japan investigated the correlation between kin availability and fertility by conducting two separate analyses based on parity (Fukukawa, 2013). First, it was found that postnuptial coresidence with both parents and parents-in-law was associated with women's increased likelihood of having a first child. Although this study found this effect among both parents and in-laws, it also revealed that the association was stronger among those living with in-laws than with parents. Second, the study analysed whether postnuptial coresidence with parents or in-laws correlated with the probability of having a second child. The study showed that coresidence with mothers-in-law was associated with an increased likelihood of having another child.

Another study based on cross-national data from eight European countries (Austria, Belgium, Bulgaria, France, Georgia, Lithuania, Norway and Russia) investigated whether coresidence or survival status of parents was associated with women's fertility (Schaffnit \& Sear, 2014). In this study, fertility was measured by age at first birth, total number of children and lifetime childlessness. Women were considered childless if they had not given birth by age 45 because it is unlikely to experience entry into motherhood after this age. Having a living mother correlated with the daughter's lower age at first birth and a lower likelihood of lifetime childlessness. Moreover, coresidence with parents was associated with increased age at first birth, increased risk for lifetime childlessness and a lower total number of children. These results may be related to the fact that in contemporary Europe, the reason for multigenerational coresidence is that adult children have higher needs for parental help or must take care of their older parents. Either way, the study indicates that coresidence may delay adult children's own childbearing (see also Huber et al., 2017).

Although several studies have detected associations between kin presence and fertility, it is not obvious how parents or in-laws can boost adult children's fertility (if they even can). The association could occur via several potential mechanisms. First, parents and in-laws may influence the fertility of their descendants by providing help and support. Perhaps the most important type of support older kin can provide towards younger ones is child care help, which can be defined as an investment of time, care and resources in descendants. In addition to child care help, emotional support may make a difference, perhaps because emotional support received from kin can provide "insurance" to adult children by signalling that other forms of support are available if needed (Tanskanen \& Rotkich, 2014).

Second, kin may influence fertility by propagating pro-natal values and norms (Newson et al., 2005). Based on the inclusive fitness theory (Hamilton, 1964), kin could be assumed to provide pro-natal messages that encourage childbearing, whereas similar messages may not be given by non-kin. Although these pro-natal messages may be unconscious rather than conscious, they may have an effect on fertility decisions. If kin provide more pro-natal messages than non-kin do, the increase of kin in one's social networks should also increase fertility. A previous 
study found support for this "kin priming" prediction with British data showing that women who had more relatives in their social networks had a higher probability of having a first child than did women who had fewer relatives in social networks (Mathews \& Sear, 2013).

Although it is often assumed that help provided by parents to their adult children is the mechanism that explains the effect of parental presence on fertility, there has been a lack of studies testing this hypothesis. Using Indonesian data, a study investigated whether parental help is the mechanism between parental presence and adult children's fertility (Snopkowski \& Sear, 2016). The authors predicted that there should be a causal pathway between geographical distance, contact frequency, parental help and fertility. They argued that this pathway should exist because residential proximity increases contact frequency, contact frequency increases the amount of help provided by parents and help provided by parents increases the fertility of adult children. Their findings provided support for this prediction among mothers, mothers-in-law and fathers-in-law, indicating that parental presence may make a difference because parents provide support to their descendants.

Finally, it is important to note that indicators used in previous studies for the kin effect have several problems (see Sear \& Coall, 2011; Snopkowski \& Sear, 2016, for discussion). For instance, the survival status of parents may overestimate the kin effect on fertility if it results from some third factor that explains both parental survival and the fertility of adult children (e.g., shared genes or wealth). With regard to coresidence, it may be that more family-orientated individuals end up living in the same household with their kin, meaning that the kin effect on fertility may be overestimated. Moreover, living in the same household or near kin may be associated with low resources, meaning that those who need most help live close to their kin. Thus, individuals living with or near kin may substantially differ from those living farther from kin, which may also influence results concerning associations between kin presence and fertility. Although scholars have attempted to control for as many potential confounding factors as possible, it is difficult, if not impossible, to consider all such factors.

\section{Kin investment and fertility}

In the previous sub-chapter, we reviewed studies that investigated the potential parental effect on their adult children's fertility using kin presence (e.g., living in the same town with parents or parental survival status) as a proxy for investment. These studies suffer from the fact that it is unclear whether the kin who are present actually invest at all (but see Snopkowski \& Sear, 2016). In addition to studies investigating the association between kin presence and fertility, studies have more directly investigated the association between kin investment and fertility. In these studies, the indicators of female fertility were childbearing intentions, entry into parenthood and probability of having another child. Furthermore, kin investment is measured by contact frequency and emotional closeness between adult children and parents as well as grandparental child care help. 
A Dutch study that examined the association between older parents' support and childbearing of adult children found that younger parents who received child care help from their mothers had a higher probability of having another child during the follow-up period of 8-10 years (Kaptijn et al., 2010). These authors found that there was no difference between maternal and paternal grandmothers. Moreover, they showed that individuals were not more or less likely to experience entry into parenthood if their parents were already providing child care help to their siblings' children, indicating that direct support, rather than signals showing that kin support could be available, may make the difference (but see Schaffnit \& Sear, 2017b). Another study that also used data from the Netherlands found that working parents who received child care from both maternal and paternal grandparents were more likely to have another child compared to parents who received child care help only from maternal or paternal grandparents (Thomese \& Liefbroer, 2013).

In contrast to the Dutch studies, an investigation conducted in the UK found no association between grandparental child care help and parental fertility between ages 30 and 34 (Waynforth, 2011). This was also the case when kin investment was measured by financial support. However, the UK study found that the increased contact frequency that 30-year-old women and men reported towards their own parents was associated with the increased probability of having another child. Moreover, increased relationship closeness between women and their parents was correlated with increased fertility. Perhaps surprisingly, the UK study found no correlations between the investment of parents-in-law and fertility among either women or men.

Another study from the UK found somewhat different results (Tanskanen et al., 2014). The authors used the Millennium Cohort Study data and analysed whether contact frequency with parents or in-laws correlated with women's increased probability of having another child during a follow-up period of almost five years. It was concluded that women's contact with mothers-in-law and fathers-in-law correlated with a higher likelihood of having a second child. However, contact with their own mothers and fathers correlated with women's lower likelihood to deliver a third or subsequent child. Using the same Millennium Cohort data, another investigation found that only moderate contact between women and parents-in-law was associated with increased probability to have another child after taking into account the forms of direct support (e.g., child care and financial help) women receive (Schaffnit \& Sear, 2017a). This finding indicates that the way kin investments are operationalised tends to affect the results.

It is also notable that because siblings share the same parents, the potential influence of kin support on fertility may be related to the presence or absence of siblings' children. This prediction was tested with data from 11 European countries (Aassve et al., 2012). These authors found that grandparental child care help provided on at least a weekly basis was associated with increased fertility of parents if the existing grandchildren were at least three years old. However, a similar association was not detected when the existing grandchildren were under three years old. Moreover, the authors found a decreased likelihood of having another 
child among individuals whose parents already provided child care to their siblings' children, indicating that there may be a reproductive conflict between siblings (see Chapter 2).

Fertility-related outcomes can also be measured by childbearing intentions. Although the intention to have another child tends to be a fairly good proxy for actual fertility, it is not equivalent to it. There may be several reasons why childbearing intentions are not realised, including economic hardship, lack of a suitable partner and increased maternal age. Moreover, contemporary European women's fertility intentions are found to be higher than their actual number of children (Harknett \& Hartnett, 2014). Thus, it is important to study fertility intentions rather than only actual fertility because kin investment may influence intentions, although these intentions are not always realised. Using data from four European countries (Bulgaria, France, Lithuania and Norway), a study investigated whether the investment women received from parents or parents-in-law correlated with their intentions to have another child (Tanskanen \& Rotkirch, 2014). Kin investment was measured by child care help and the emotional support parents or parents-in-law provided to their daughters or daughters-in-law. The study found that child care help from fathers and emotional support from mothers, fathers and mothers-in-law were associated with women's increased intentions to have a second or a third child.

\section{Teenage mothers vs. postponement}

Teenage pregnancies have been shown to have detrimental consequences for teenage mothers themselves, their children and society as a whole. Thus, it is unsurprising that in recent decades in many Western countries, particularly the US, several strategies have been implemented to decrease the number of teenage pregnancies. The fact that teenage pregnancies declined in the US by more than 40 per cent between 2006 and 2014 may indicate that some of these strategies have been successful (Romero et al., 2016). Nevertheless, it should be noted that teenage pregnancies are still common in the US, and variation between ethnic groups is high. Moreover, it is well known that socioeconomic disadvantages (e.g., low income, low level of education and high rate of unemployment) are related to teenage pregnancies (Penman-Aguilar et al., 2013). Obviously, one important aspect of teenage pregnancies is the coresidence among grandparents, teenage mothers and grandchildren.

Evolutionary life history theory provides one potential explanation for why kin presence may increase teenage pregnancies in low socioeconomic status groups. There is increasing evidence that women in disadvantaged socioeconomic conditions and those with limited possibilities to expand their socioeconomic resources (e.g., via education) may follow a fast life history strategy, meaning that they start their reproductive career at a relatively early age (Low et al., 2008; Nettle, 2010). In these circumstances, the availability of grandparents-to-be (i.e., the parents of the teenager) may signal (likely unconsciously) to teenage girls that having a child is a potential option to "consider". Thus, the presence of grandparents-to-be may provide the "final push" that leads to teenage girls' entry into motherhood. 
Often, the most important help providers for teenage mothers are their own mothers. In some studies, these maternal grandmothers are found to benefit the teenage mothers, for instance, by improving their possibilities for involvement in education and working life (Dunifon et al., 2014). In contrast, teenage mothers living in three-generational households may have less-improved parental skills. It is important to note, however, that the potentially detrimental effect of coresidence among grandparents, teenage mothers and grandchildren may be related to a selection effect, meaning that teenage mothers with low levels of parenting skills end up living with their own parents (Dunifon et al., 2014). Based on prior findings, the potentially detrimental consequences of coresidence for grandchildren may arise when the family suffers from poverty, the coresidence is permanent rather than momentary and the availability of grandparental care limits the mother's development (Coall \& Hertwig, 2010).

In addition to "too early childbearing" represented by teenage mothers, life history theory may explain why some women delay their childbearing (see Billari et al., 2007, for delayed childbearing). Women who have high expectations of improving their own resources may delay childbearing until they believe that they can provide a secure growth environment for their child. Moreover, in families with high socioeconomic standing, grandparents-to-be may encourage their daughters to invest in their own "growth" and development rather than in early childbearing. This so-called slow life history strategy may also result from individuals' cues regarding their own life expectancy and that of potential alloparents. Delaying entry into parenthood and investing in their own capital causes women to be able to invest more resources in their future children. However, when childbearing is delayed too long, these women may have difficulty having a child.

\section{Conclusions}

In this chapter, we have examined whether grandparental investment is associated with parental fertility. In almost all traditional and historical populations studied, the presence of at least one parent or in-law correlates with female fertility. Nonetheless, there is only limited support for predictions derived from the grandmother hypothesis and sex-specific reproductive strategies that the presence of some specific parent or parent-in-law will be the most crucial. Furthermore, studies detecting an association between kin investment and fertility in contemporary societies have provided mixed results, indicating that the associations are both complex and dependent on context. Hence, it seems that in present-day affluent societies with maternity leaves and public child care services, kin investment is not as important for fertility as it may have been in previous populations. This issue is discussed more in Chapter 9.

\section{References}

Aassve, A., Meroni, E., \& Pronzato, C. (2012). Grandparenting and childbearing in the extended family. European Journal of Population, 28, 499-518. 
Andersson, G., Duvander, A.-Z., \& Hank, K. (2004). Do child-care characteristics influence continued child bearing in Sweden? An investigation of the quantity, quality, and price dimension. Journal of European Social Policy, 14, 407-418.

Balbo, N., Billari, F. C., \& Mills, M. (2013). Fertility in advanced societies: A review of research. European Journal of Population, 29, 1-38.

Billari, F., \& Kohler, H.-P. (2004). Patterns of low and lowest-low fertility in Europe. Population Studies, 58, 161-176.

Billari, F. C., Kohler, H.-P., Andersson, G., \& Lundström, H. (2007). Approaching the limit: Long-term trends in late and very late fertility. Population and Development Review, 33, 149-170.

Cant, M. A., \& Johnstone, R. A. (2008). Reproductive conflict and the separation of reproductive generations in humans. Proceedings of the National Academy of Sciences, 105, 5332-5336.

Coall, D. A., \& Hertwig, R. (2010). Grandparental investment: Past, present, and future. Behavioral and Brain Sciences, 33, 1-59.

Del Boca, D. (2002). The effect of child care and part time opportunities on participation and fertility decisions in Italy. Journal of Population Economics, 15, 549-573.

Dunifon, R. E., Ziol-Guest, K. M., \& Kopko, K. (2014). Grandparent coresidence and family well-being: Implications for research and policy. The Annals of the American Academy of Political and Social Science, 654, 110-126.

Euler, H. A. (2011). Grandparents and extended kin. In C. A. Salmon \& T. K. Shackelford (Eds.), The Oxford handbook of evolutionary family psychology (pp. 181-207). New York: Oxford University Press.

Fukukawa, Y. (2013). Grandparental investment and reproductive success in modern Japanese society. Journal of Evolutionary Psychology, 11, 35-48.

Gootman, E. (2012, May 13). So eager for grandchildren, they're paying the egg-freezing clinic. The New York Times. Retrieved from http://www.nytimes.com

Hamilton, W. D. (1964). The genetical evolution of social behaviour (I and II). Journal of Theoretical Biology, 7, 1-52.

Hank, K., \& Kreyenfeld, M. (2003). A multilevel analysis of child care and women's fertility decisions in Western Germany. Journal of Marriage and Family, 65, 584-596.

Harknett, K., \& Hartnett, C. S. (2014). The gap between births intended and births achieved in 22 European countries, 2004-07. Population Studies, 68, 265-282.

Huber, S., Zahourek, P., \& Fieder, M. (2017). Living with own or husband's mother in the household is associated with lower number of children: A cross-cultural analysis. Royal Society Open Science, 4. https://doi.org/10.1098/rsos.170544

Kalwij, A. (2010). The impact of family policy expenditure on fertility in Western Europe. Demography, 47, 503-519.

Kaptijn, R., Thomese, F., van Tilburg, T. G., \& Liefbroer, A. C. (2010). How grandparents matter: Support for the cooperative breeding hypothesis in a contemporary Dutch population. Human Nature, 21, 393-405.

Lahdenperä M., Gillespie D. O. S., Lummaa V., \& Russell, A. F. (2012). Severe intergenerational reproductive conflict and the evolution of menopause. Ecology Letters, $15,1283-1290$.

Lahdenperä, M., Lummaa, V., Helle, S., Tremblay, M., \& Russell, A. F. (2004). Fitness benefits of prolonged post-reproductive lifespan in women. Nature, 428, 178-181.

Lahdenperä, M., Russell, A. F., \& Lummaa, V. (2007). Selection for long lifespan in men: Benefits of grandfathering? Proceedings of the Royal Society B: Biological Sciences, 274, 2437-2444. 
Leonetti, D. L., Nath, D. C., Hemam, N. S., \& Neill, D. B. (2005). Kinship organization and the impact of grandmothers on reproductive success among the matrilineal Khasi and patrilineal Bengali of northeast India. In E. Voland, A. Chasiotis \& W. Schiefenhövel (Eds.), Grandmotherhood: The evolutionary significance of the second half of female life (pp. 194-214). New Brunswick, NJ: Rutgers University Press.

Low, B. S., Hazel, A., Parker, N., \& Welch, K. B. (2008). Influences of women's reproductive lives: Unexpected ecological underpinnings. Cross-Cultural Research, 42, 201-219.

Mathews, P., \& Sear, R. (2013). Does the kin orientation of a British woman's social network influence her entry into motherhood? Demographic Research, 28, 313-340.

McDonald, P. (2006). Low fertility and the state: The efficacy of policy. Population and Development Review, 32, 485-510.

Nettle, D. (2010). Dying young and living fast: Variation in life history across English neighborhoods. Behavioral Ecology, 21, 387-395.

Newson, L., Postmes, T., Lea, S. E. G., \& Webley, P. (2005). Why are modern families small? Toward an evolutionary and cultural explanation for the demographic transition. Personality and Social Psychology Review, 9, 360-375.

Penman-Aguilar, A., Carter, M., Snead, M. C., \& Kourtis, A. P. (2013). Socioeconomic disadvantage as a social determinant of teen childbearing in the US. Public Health Reports, 128, 5-22.

Pettay, J. E., Lahdenperä, M., Rotkirch, A., \& Lummaa, V. (2016) Costly reproductive competition between co-resident females in humans. Behavioral Ecology, 27, 1-8.

Pettay, J. E., Lahdenperä, M., Rotkirch, A., Lummaa, V., \& Pruitt, J. (2017). Effects of female reproductive competition on birth rate and reproductive scheduling in a historical human population. Behavioral Ecology, 29, 333-341. https://doi.org/10.1093/beheco/arx168

Romero, L., Pazol, K., Warner, L., Cox, S., Kroelinger, C., Besera, G., Brittain, A., Fuller, T. R., Koumans, E., \& Barfield, W. (2016). Reduced disparities in birth rates among teens aged 15-19 Years - United States, 2006-2007 and 2013-2014. Morbidity and Mortality Weekly Report, 65, 409-414.

Schaffnit, S. B., \& Sear, R. (2014). Wealth modifies relationships between kin and women's fertility in high-income countries. Behavioral Ecology, 25, 834-842.

Schaffnit, S. B., \& Sear, R. (2017a). Support for new mothers and fertility in the United Kingdom: Not all support is equal in the decision to have a second child. Population Studies, 71, 345-361.

Schaffnit, S., \& Sear, R. (2017b). Supportive families versus support from families: The decision to have a child in the Netherlands. Demographic Research, 37, 414-454.

Sear, R., \& Coall D. A. (2011). How much does family matter? Cooperative breeding and the demographic transition. Population and Development Review, 37, 81-112.

Sear, R., \& Mace, R. (2008). Who keeps children alive? A review of the effects of kin on child survival. Evolution and Human Behavior, 29, 1-18.

Sear, R., Mace, R., \& McGregor, I. A. (2003). The effects of kin on female fertility in rural Gambia. Evolution and Human Behavior, 24, 25-42.

Snopkowski, K., \& Sear, R. (2013). Kin influences on fertility in Thailand: Effects and mechanisms. Evolution and Human Behavior, 34, 130-138.

Snopkowski, K., \& Sear, R. (2016). Does grandparental help mediate the relationship between kin presence and fertility? Demographic Research, 34, 467-498.

Tanskanen, A. O., Jokela, M., Danielsbacka, M., \& Rotkirch, A. (2014). Grandparental effects on fertility vary by lineage in the United Kingdom. Human Nature, 25, 269-284. 
Tanskanen, A. O., \& Rotkirch, A. (2014). The impact of grandparental investment on mothers' fertility intentions in four European countries. Demographic Research, 30, $1-26$.

Thomese, F., \& Liefbroer, A. C. (2013). Child care and child births: The role of grandparents in the Netherlands. Journal of Marriage and Family, 75, 403-421.

Tymicki, K. (2004). The kin influence on female reproductive behaviour: The evidence from the reconstitution of Bejsce parish registers, 18th to 20th centuries, Poland. American Journal of Human Biology, 16, 508-522.

Voland, E., Chasiotis, A., \& Schiefenhövel, W. (Eds.). (2005). Grandmotherhood: The evolutionary significance of the second half of female life. New Brunswick, NJ: Rutgers University Press.

Waynforth, D. (2011). Grandparental investment and reproductive decisions in the longitudinal 1970 British cohort study. Proceedings of the Royal Society B: Biological Sciences, 279, 1155-1160. 


\section{Grandparents and child wellbeing}

In previous chapters of this book, it has become clear that grandparents are, as part of the human species' typical childrearing practices (cooperative breeding), often highly involved in the lives of their grandchildren. The way this involvement may benefit the grandchild, however, is another question. If the involvement of grandparents increases child wellbeing as they interact, for instance, by teaching grandchildren to read, one could assume that grandparental involvement can truly improve child development. In this chapter, we review studies investigating whether grandparental presence has been associated with improved child survival in historical and traditional societies and whether grandparental investment correlates with child wellbeing in modern welfare states.

\section{Who kept children alive in traditional and historical populations?}

It is estimated that in the evolutionary past of humans, less than 50 per cent of children reached maturity and had their own children (Wells \& Stock, 2007). Several studies have investigated whether grandparental presence correlates with child survival in traditional and historical societies. In these studies, the potential grandparental effect is typically measured by grandparental presence in the same household or the same village as their descendant. An extensive review of 45 studies on associations between kin presence and child survival in traditional and historical populations reveals that the presence of different grandparent types may be differently associated with child survival (Sear \& Mace, 2008). The studies included in the review were conducted with data collected from several different populations, including 18th- and 19th-century populations from Germany, Sweden and Finland and contemporary hunter-gatherers. Most of the natural fertility (or small scale) populations included in the review were horticulturalists or agriculturalists. The authors of the review have argued that it is important to include different populations to achieve the largest and most diverse data possible. The common feature of all populations reviewed is that they are so-called high-fertility and high-mortality societies, and in most of these populations, modern medical care or other health and welfare services are not available (see also Chapter 5). 
Diversity in the reviewed populations also creates problems. Perhaps the most important limitation is that including very different populations in the same review tends to mask the differences between them. For instance, the populations included both matrilineal and patrilineal cultures, in which family relations can be substantially different. In patrilineal families, females live near their parents-in-law, whereas their own parents often live further away. This situation is likely to shape intergenerational relations substantially. In patrilineal families, all daughters-in-law compete with each other for the investment of their parents-inlaw, whereas in matrilineal families, daughters compete with their sisters for the investment of their own parents. All females living in matrilineal families are genetically related and can be sure that they share the same genes with all children delivered by their female kin. In patrilineal populations, the children delivered by daughters-in-law are related to the husband and his kin. Obviously, this is the case only if the husband is actually the biological father of the child or if one of his male relatives (e.g., a brother) is the father. Thus, in patrilineal families, it is in the reproductive interests of the husband and his kin to ensure paternity certainty and obstruct paternity uncertainty. Despite these limitations, the advantage of including several different populations in the review is that this approach may show general trends in associations between kin presence and fertility.

In the review article, child survival was measured among children of different ages, ranging from between 0 and 24 weeks to between 0 and 15 years (Sear \& Mace, 2008). According to the review, maternal presence was related to increased child survival rates in all studies (28/28), and fathers' was associated with child survival in 32 per cent of cases $(7 / 22)$. With regard to potential intergenerational effects, the presence of a maternal grandmother was related to increased survival rates among children in 69 per cent of studies (9/13), and the presence of paternal grandmothers was related to increased survival rates in 53 per cent of cases $(9 / 17)$. The presence of maternal grandfathers correlated with increased survival rates among children in 17 per cent of cases $(2 / 12)$, and the presence of paternal grandfathers correlated with increased survival rates among children in 25 per cent of studies (3/12). Moreover, the presence of paternal grandfathers was related to decreased survival rates in 25 per cent of cases $(3 / 12)$. The latter result may be related to resource competition between paternal grandfathers and grandchildren (e.g., Sheppard \& Sear, 2016; Strassmann, 2011; see Chapter 2).

Perhaps one of the most comprehensive previous studies on the topic concerns a pre-modern patrilocal Finnish population (Lahdenperä et al., 2004). This study found that the presence of grandmothers was associated with increased survival probability among children aged two to five years. The authors of the Finnish study did not separate effects between maternal and paternal grandmothers. Other studies have shown that the effect between maternal and paternal grandmothers may differ based on the age of children. For instance, a study of the population of Krummhörn from historical Germany (between 1720 and 1874) showed that the existence of maternal grandmothers was associated with increased likelihood of infant survival among grandchildren between ages six and 12 months (Voland \& Beise, 2002; see also Beise \& Voland, 2002). In contrast, the existence of paternal 
grandmothers correlated with decreased likelihood of survival among grandchildren less than a month old. Moreover, a study analysing data from 17th- and 18thcentury Quebec showed that the presence of maternal grandmothers correlated with increased child survival when the child was aged one to three, whereas the presence of paternal grandmothers correlated with child survival only during the first month of life (Beise, 2005). Overall, paternal grandmothers may have the most (either positive or negative) influence among newborn children, whereas the effect of maternal grandmothers may be strongest among toddlers (Sear \& Mace, 2008).

The association between grandparental presence and grandchild survival has often been investigated with large-scale demographic data including, for instance, church register data (e.g., Lahdenperä et al., 2007; Voland \& Beise, 2005), anthropometric data (e.g., Sear et al., 2000) and other population register data (e.g., Campbell \& Lee, 1996). Obviously, these data do not tell us what grandparents do in practice that may help to keep their grandchildren alive. It is not grandparental presence per se that may make a difference but rather what grandparents are doing when they are present.

One significant mechanism may be that by looking after grandchildren, grandparents decrease fatal injuries among them. Another important way that grandmothers may have increased child survival is by improving their nutritional status. For instance, Hawkes and colleagues (1997) found that among Hadza huntergatherers, support provided by grandmothers increased the amount of food received by grandchildren and thus improved grandchildren's growth. In addition, a study using data from rural Gambia found that the presence of maternal grandmothers was associated with both improved nutrition and survival of children (Sear et al., 2000). One study found that in rural Ethiopia, maternal grandmothers help parents with heavy domestic tasks, and paternal grandmothers help with farming (Gibson \& Mace, 2005). Moreover, it was found that among Hadza women, grandmothers worked the longest working hours in foraging (Hawkes et al., 1989).

The association between grandparental presence and grandchild survival could also be related to the sex of the grandchildren. Patrilocal societies provide a clear example because in these societies, parents and grandparents commonly prefer boys to girls. In cultures where boys are preferred to girls, grandparental presence can be assumed to correlate more with the survival of boys than of girls. A metaanalysis including six patrilocal populations showed, however, that in 83 per cent of populations $(5 / 6)$, the presence of paternal grandmothers was associated with better survival probability among girls than boys (Fox et al., 2010). These findings did not support the prediction that grandparents improve the survival of boys more than of girls in patrilocal societies.

Among evolutionary biologists, it is assumed that the asymmetrical inheritance of sex chromosomes may lead different grandparent types to improve the survival of granddaughters and grandsons differently (see Chapter 2). This may be due to investment differences between grandparental types. According to a meta-analysis of seven populations, the sex chromosome predictions were partially supported (Fox et al., 2010). In all populations, boys were more likely to 
survive with maternal than paternal grandmothers, and in 86 per cent of populations $(6 / 7)$, girls were more likely to survive with paternal grandmothers than boys were. However, only in 57 per cent of populations (4/7) were girls more likely to survive with paternal than maternal grandmothers. The latter finding contrasts with the sex chromosome prediction.

A recent study tested hypotheses related to the asymmetrical inheritance of sex chromosomes using data from historical and patrilocal Finland (Chapman et al., 2018). The presence of maternal grandmothers was more likely to be associated with the increased survival of grandsons than the presence of paternal grandmothers was. Moreover, the presence of paternal grandmothers was more likely to be associated with the survival of granddaughters compared to the presence of maternal grandmothers. Both of these findings are in line with the sex chromosome hypothesis. However, in contrast to the hypothesis, the presence of paternal grandmothers was not more likely than the presence of maternal grandmothers to be associated with the granddaughter's survival.

\section{Grandparents and child wellbeing in contemporary societies}

As discussed above, there is evidence that in historical and traditional populations, grandparents may have played an important role by keeping their grandchildren alive. In present-day affluent Western societies with low rates of childhood mortality, grandparents are not needed to keep small children alive as they were in past societies. This means that the measured child outcome should no longer be grandchild survival but rather child wellbeing, measured by "softer" aspects such as early-years development, academic success, physical health and psychological wellbeing (Sear \& Coall, 2011). Below, we focus on the association of grandparental investment and child wellbeing in three types of family arrangements, namely, the investment of non-coresiding grandparents, grandparental presence in three-generational households and custodial grandparent families where children are raised without parental presence. First, however, we introduce some key points on why child wellbeing is so important.

\section{Child wellbeing matters}

In contemporary Western societies, it is widely accepted that children have the right to live in safe, healthy and stable environments that provide opportunities to learn and develop. In the Western world, children's rights are protected by both national and international laws and conventions (e.g., the United Nations Convention on the Rights of the Child). As child wellbeing is a highly important issue, it is also studied intensively in different disciplines.

In existing studies, child wellbeing has been measured by both cognitive and non-cognitive outcomes. Cognitive skills are varied and highly age dependent and thus have been measured with several indicators. Age-standardised mathematics, reading and writing skill tests are common measurements of cognitive skills among children of different ages. Perhaps one of the best-known national 
measures is the SAT test used in the US, which measures reading, mathematics and writing skills among high school juniors and seniors. Achievement tests often tend to correlate with more general cognitive skill indicators such as IQ, although they are not equivalent (Heckman \& Kautz, 2012). In current societies, different achievement tests have enormous importance and have been used to evaluate the success of single pupils, schools and even nations.

In addition to cognitive achievements, non-cognitive outcomes among children have received attention among scholars. In the literature, non-cognitive achievements have been called by several names, including socio-emotional outcomes, character skills, non-cognitive abilities and soft skills. The terms chosen by scholars are often related to the discipline; psychologists tend to favour the term "socio-emotional outcome", whereas economists and sociologists often use the term "non-cognitive skill". Moreover, the chosen term tends to be related to assumptions of the stability or flexibility of these wellbeing indicators. The term "trait" refers to more stable characteristics, perhaps with high heritability, whereas the terms "skill" and "achievement" indicate that the wellbeing indicators are more flexible and are products of learning. In the literature, the term "skill" is widely used, although it is noted that rather than a skill, the behaviour tends to be the outcome of personality and other traits (Lundberg, 2013). Nevertheless, it is important to note that socio-emotional or non-cognitive outcomes are often closely related to personality traits, such as neuroticism, which is one of the "Big Five" personality traits and can be defined as a lack of emotional stability (Heckman, 2011). Thus, it is unsurprising that personality traits are sometimes used to indicate non-cognitive outcomes.

Studies have consistently demonstrated that cognitive assessments in childhood predict socioeconomic success in later life. For example, a study using six longitudinal surveys that were conducted in the US, the UK and Canada demonstrated that cognitive achievements among pre-school-aged children strongly predicted educational success in adolescence (Duncan et al., 2007). Moreover, two longitudinal studies that were conducted in the UK found that increased developmental skills in early childhood were associated with improved academic achievement in adolescence and higher salaries in adulthood (Currie \& Thomas, 1999, 2001; Feinstein \& Duckworth, 2006). Finally, it has been shown that low levels of childhood cognitive skills are associated with risk behaviour in later life, which implies that individuals who have fewer skills are at greater risk for teenage pregnancies, daily smoking and drug use (Heckman et al., 2006).

Better non-cognitive test scores are found to relate to improved outcomes in adolescence and adulthood. For example, two separate studies conducted in the UK found that emotional and behavioural difficulties at age three predicted decreased academic achievement at age 14 and 16 (Bornstein et al., 2013; Washbrook et al., 2013). Furthermore, studies conducted in New Zealand determined that increased behavioural difficulties at age three correlated with increased financial difficulties, a higher risk of engaging in antisocial behaviour and health problems at age 32 (Moffitt et al., 2011; Odgers et al., 2008). Thus, both cognitive and non-cognitive 
outcomes during childhood are appropriate proxies for children's future success. This also makes them important indicators of child wellbeing.

\section{Investment of grandparents living separately from their grandchildren}

A systematic literature review by Sear and Coall (2011) concentrated on the associations between grandparental investment and child wellbeing in contemporary societies. This review included 13 studies that analysed the potential effect of grandparental investment (measured by, e.g., grandparental involvement, child care and nurturance) on children's psychological adjustment (measured by, e.g., a child behaviour checklist and socio-emotional wellbeing). This review showed that in 77 per cent of studies (9/13), grandparental investment correlated with improved wellbeing among grandchildren. In the review, a large number of studies investigated the association between grandparental investment and child wellbeing in so-called high-risk family circumstances, which refer to family conditions where there is extra stress on children. For instance, during times of parental divorce or severe illness of a family member, children are likely to experience heavy strain and may be dependent on extra support.

Studies that aim to determine whether grandparents can benefit their grandchildren in high-risk situations have often investigated the association between grandparental investment and child wellbeing in different family formations (Attar-Schwartz \& Buchanan, 2011). A US study, for instance, found that in single-parent families, the financial and emotional involvement of grandparents correlated with adolescent grandchildren's improved academic achievements and prosocial behaviour (Yorgason et al., 2011). Another US study found that adolescent grandchildren's close ties with maternal grandmothers after parental separation were associated with fewer psychological problems (Henderson et al., 2009). In addition, some studies have shown that grandparental investment correlates with improved child wellbeing in a low-risk context where no extra stress among children exists (e.g., the UK study by Attar-Schwartz et al., 2009). However, not all studies have found a positive association between grandparental investment and child outcomes. For instance, a US study showed that the relationship quality between adolescent grandchildren and their grandparents neither increased nor decreased educational achievement or the likelihood of performing risky behaviour among grandchildren (Dunifon \& Bajracharya, 2012).

One of the crucial limitations of several studies is that they did not separate grandparents by sex and lineage. Studies that have applied this separation have found that the investment of all grandparent types may not relate similarly to child wellbeing. Two previous studies using data from the UK found that closeness towards maternal grandmothers and grandfathers was associated with decreased emotional and behavioural problems among adolescent grandchildren, although similar associations were not found in the case of paternal grandparents (Lussier et al., 2002; Tanskanen \& Danielsbacka, 2012). Moreover, in the UK study, increased parent-grandparent contact frequency at the children's age of three was 
found to be associated with improved educational test scores among children at age five (Tanskanen \& Danielsbacka, 2016).

Most previous studies on associations between grandparental investment and grandchild outcomes have used cross-sectional surveys (e.g., Attar-Schwartz et al., 2009; Wild, 2016) or longitudinal data that measure grandparental investment at time point one and child outcome at time point two without investigating within-child effects (e.g., Tanskanen \& Danielsbacka, 2016; Yorgason et al., 2011). Despite this methodological limitation, in several studies it is assumed, at least implicitly, that grandparental investment has causal effects on child wellbeing (see Coall \& Hertwig, 2010; Buchanan \& Rotkirch, 2016, for discussion). However, based on the most recent evidence, this may not be the case.

Using three waves of the British Millennium Cohort Study including children between the ages of nine months and five years, an association between grandparental investment (measured by parent-grandparent contact and grandparental financial support) and child cognitive development as well as socio-emotional wellbeing was investigated (Tanskanen \& Danielsbacka, 2017). The study tested both between-child and within-child associations, where between-child associations indicate results across children and within-child associations represent the child's variation over time. Within-child models in these analyses provide the strong test of causality in associations between grandparental investment and child outcomes. It was found that grandparental investment was indeed associated with improved cognitive development and decreased emotional and behavioural problems among children. However, these associations were detected only in between-child models, not within-child models comparing the same children over time. The findings did not provide support for the assumption that grandparental investment has a causal effect on child outcomes.

In previous studies, child outcomes have typically been indicated by educational, developmental and socio-emotional measures. Grandparental investment may, however, correlate with other types of child outcomes as well. One such factor may be childhood overweight, which is an epidemic in several presentday Western nations. Childhood overweight can have long-term effects because it tends to correlate with increased risk of diabetes, heart diseases and premature mortality in later life (Al Mamun et al., 2009; Ebbeling et al., 2002; Reilly \& Kelly, 2011). The type of child care may influence childhood overweight. Based on an extensive review of studies published between 2000 and 2016, scholars found that informal care provided by relatives, neighbours and friends was often associated with overweight (Alberdi et al., 2016).

An increasing amount of research shows that in many traditional and historical populations, the presence of grandmothers is often correlated with increased survival rates of children, as discussed earlier in this chapter. One reason for these results may be that grandmothers living near their descendants may have helped to improve child nutrition. However, the grandmaternal investment that may have improved child nutrition in past populations may have different outcomes in presentday affluent societies. A recent study found an association between grandparental child care and early-years overweight and obesity in the UK (Tanskanen, 2013). 
The study found that children whose primary carers between the ages of nine months and three years were their grandmothers were more likely to be overweight or obese at age three compared to children whose primary carers were their parents. This result held even after socioeconomic status, ethnicity and country of residence, among other factors, were controlled for. The finding indicates that grandmothers may still improve the nutritional status of children in presentday societies. However, as with several other evolved behavioural strategies, the outcome of grandmaternal investment may no longer be beneficial.

\section{Three-generational households}

In a three-generational or multigenerational household, children live with both their parent(s) and grandparent(s). The prevalence of three-generational households varies among Western nations. For instance, approximately 25 per cent or more of adolescents in Southern European countries are living in three-generational households, whereas the amount of children living in multigenerational households is less than 5 per cent in Scandinavian countries, and the number in Central European countries is located between these two regions (Kreidl \& Hubatkova, 2014). In early childhood, the number of children living in three-generational households is often even higher. For instance, by age five, almost a quarter of US children are living in three-generational families; these numbers are 8 per cent in the UK and 11 per cent in Australia (Pilkauskas \& Martinson, 2014).

Some children in Western countries are more likely than others to live in three-generational households. Using data from the US, the UK and Australia, the socio-demographic constellation of three-generational households was investigated (Pilkauskas \& Martinson, 2014). Despite differences in the prevalence of three-generational households in the US, the UK and Australia, the sociodemographic constellation was quite similar between them. In all three countries, children belonging to ethnic minority groups were more likely to live in multigenerational families than children belonging to ethnic majorities. Similarly, in all three countries, children with younger mothers who were less educated and had lower income more often lived in three-generational households compared to their higher socioeconomic status counterparts. According to another study, there are signs that financial condition at both the individual level and the national level may be associated with the number of three-generational households. An approximately 30 per cent increase in three-generational households was reported in the US between 2001 and 2012, which may be closely related to the Great Recession that began in 2008 (Dunifon et al., 2014).

An increasing number of studies have investigated child wellbeing in threegenerational households. These studies are often conducted in the US, where the amount of multigenerational families is higher compared to several other Western countries. Whether grandparental presence is associated with increased or decreased child wellbeing often depends on the basis for comparison for children living in multigenerational families (Dunifon et al., 2014). For instance, the most relevant reference group for three-generational families with two biological 
parents and grandparent may be the two-generational intact family. In contrast, a three-generational family with a single parent and a grandparent should be compared to a single-parent family without a grandparent. In previous studies, the reference group for three-generational households has varied from one study to another, which may explain the mixed results found in these studies.

Using data from the US, some scholars have found that children living in threegenerational households have more behavioural problems (Pittman \& Boswell, 2007) and lower academic achievement (McLanahan \& Sandefur 1994) compared to children from two-generational families. However, some studies have found no difference in child wellbeing between children living in three-generational and two-generational families (Deleire \& Kalil, 2002), and one study showed that adolescent children who lived with a single mother and grandparent at some point in their childhood achieved higher educational attainment than children who lived all of their childhood with a single mother only (Aquilino, 1996). A study that used data from 36 countries found a general trend showing that grandparental presence correlates with lower educational attainment among 15-year-old children (Kreidl \& Hubatkova, 2014). Finally, in addition to academic attainment, a previous investigation conducted in the US found that grandparental presence may correlate with negative health outcomes among grandchildren (Krueger et al., 2015).

One potential explanation for the results showing that grandparental presence in three-generational households is associated with poorer outcomes among grandchildren is that at older ages, grandparents are dependent on support and resources from the middle generation (i.e., the adult children of grandparents). If adult children are forced to take care of their elderly parents, they may have less time and resources to invest in their children, who, in turn, may achieve lower levels of wellbeing. Thus, one potential explanation for the previous findings is based on the resource competition model (Strassmann et al., 2006; Strassmann \& Garrard, 2011). Individuals who live in the same household and are dependent on the same resources may compete with each other for these resources. The scarcer the household resources are, the more likely this competition is. In threegenerational households, the resource for which grandparents and children may compete is parental time, which is always finite. If parents invest a large amount of time in their elderly parents, they have less time to invest in their children. This may have detrimental effects on children because parental involvement tends to be associated with educational achievement among children (e.g., Epstein, 2001; Fan \& Chen, 2001; Hango, 2007; Park, 2008; Sénéchal \& Young, 2008).

One study tested three predictions derived from the resource competition model using data on 15-year-old adolescents from 20 Western countries (Tanskanen et al., 2016). First, it was predicted that living in three-generational households with grandparents would be associated with a decreased level of parental involvement because in these households, parents invest time not only in their children but also in their elderly parents (i.e., the grandparents). Second, it was assumed that living in three-generational households would correlate with decreased educational test scores. The third hypothesis predicted that grandparental presence 
would have more negative effects on child educational achievement in families where parental investment was already at a lower level. The findings provided support for all three hypotheses. Moreover, it was found that coresiding with grandparents in three-generational households mediated the relation between parental involvement and educational achievement among children, indicating that the reason for poorer outcomes among children may indeed be grandparental presence, which might diminish the time parents are able to invest in their children.

Although grandparental coresidence may be associated with poorer outcomes for adolescent grandchildren in some circumstances, grandparental presence may still be associated with improved outcomes among younger grandchildren. Moreover, the association between grandparental presence and outcomes of adolescent grandchildren may be related to the age of the grandparents rather than the grandchildren. Typically, when grandchildren are older, coresiding grandparents are also older. Younger grandparents tend to be healthier and have more resources compared to older ones (e.g., Danielsbacka \& Tanskanen, 2012; Hank \& Buber, 2009), meaning that at a younger age, grandparents tend to have more opportunities to invest in their grandchildren. In contrast, at an older age, grandparents are more likely to be dependent on help themselves and may be receivers rather than providers of support (Pfeffer, 2014). It may also be easier for grandparents to have a beneficial effect on younger grandchildren than on older ones. For instance, to improve adolescent development, grandparents should have advanced skills, whereas increasing the wellbeing of toddlers may demand only grandparental willingness to be involved. This may be one central difference between grandparents in the past and grandparents today; grandparents in historical societies had the most cumulative knowledge, whereas grandparents today may not be able to keep up with rapid developments of progress in technology or science.

One study attempted to investigate whether grandparental presence in three-generational households benefits grandchildren when they are toddlers (Tanskanen \& Danielsbacka, 2016). In this study, the coresiding grandparents were approximately 53 years old. Grandchild outcomes were measured by the lack of unintended injuries experienced in the home environment. In present-day Western societies, unintended injuries are the most common cause of mortality in early childhood and thus are important indicators of child wellbeing. Using data from the UK, the study found that grandparental coresidence in the same household as adult children and grandchildren was associated with a decreased risk of injuries among toddlers aged between nine months and three years. These results indicate that grandparental presence may indeed benefit grandchildren when they are very young.

Finally, it is important to note that whether grandparental presence is associated with positive or negative outcomes among grandchildren may be highly dependent on cultural variation. For instance, in several Asian and African countries where it is typical for grandparents to live in the same household as their adult children and grandchildren, grandparental absence rather than presence may have detrimental effects on grandchildren. For instance, a longitudinal study from Taiwan found that long-term coresidence with grandparents (mostly paternal 
grandparents) was associated with improved cognitive outcomes (measured by maths, language, science and logical reasoning skills) among adolescents (Pong \& Chen, 2010). Another study that used the same data from Taiwan indicated that although the association existed in single-parent and two-parent families, the effect was particularly strong in single-father families (Chen, 2016). In Taiwan, adolescents more often live in single-father than single-mother families and more often with paternal than maternal grandparents. In addition, a study conducted in South Africa showed that the involvement of maternal grandmothers was associated with fewer emotional and peer problems among adolescent grandchildren only when grandparents and grandchildren lived together in three-generational households (Levetan \& Wild, 2016). However, more studies are warranted from countries where intergenerational coresidence is the norm to achieve a more nuanced picture of potential grandparental effects on child wellbeing in threegenerational families.

\section{Custodial grandparent families}

The term "custodial grandparent family" refers to a family arrangement in which grandchildren are living with and raised by their grandparents without parental presence. Synonyms for custodial grandparent families are grandparent-headed households, skipped generation families, kangaroo families and grandfamilies. The number of custodial grandparent families is much lower than the number of three-generational households. Child wellbeing in grandparent-headed families has received considerable attention in the US, where approximately 2 per cent of children are raised by their grandparents (Dunifon et al., 2014).

In the US almost half of the children who are living in grandparent-headed households live with both their grandmother and grandfather, 46 per cent live with a grandmother only, and 5 per cent live with a grandfather only (Dunifon et al., 2014). Maternal grandparents are more likely than paternal grandparents to raise their grandchildren and provide more stable family arrangements to children (Perry et al., 2014). The US evidence indicates high cultural variation in the prevalence of grandparent-headed families. These family arrangements are most common among African Americans ( 3.9 per cent of children live in custodial grandparent households), followed by Whites ( 1.6 per cent), Hispanics ( 1.5 per cent) and Asians (0.4 per cent) (Dunifon et al., 2014).

There is evidence that children living in custodial grandparent households have a higher amount of problem behaviour (Pittman, 2007; Sun, 2003) and mental health problems (Bilaver et al., 1999; Smith \& Palmieri, 2007) compared to children living in other family arrangements. However, as was the case for three-generational households, an important issue is the comparison group for custodial grandparent families. Children living in custodial grandparent families have already experienced some type of stressful event leading them to leave the parental home. These types of events can manifest in several ways and may include, for instance, severe parental illness, drug use or even death. These negative experiences are likely to decrease grandchild wellbeing. 
In addition, living apart from parents is likely to have negative influences. For instance, one study showed that children raised by kin without parental presence had lower academic achievements and were more likely to be suspended from school (Billing et al., 2002). Finally, it is well known that grandparent-headed families often have economically disadvantaged conditions, and children living in these households suffer from poverty (Dunifon et al., 2014). Thus, the lower wellbeing outcomes of children living in custodial grandparent households may be related to family instability and poverty rather than the custodial grandparent arrangement per se.

Because children living in custodial grandparent households are in a special situation, it may be more relevant to compare them to children living in other potentially risky family situations. One study found that children living in custodial grandparent families had similar health and educational outcomes as children living in single-mother families (Solomon \& Marx, 1995). Another study showed that children placed in kin foster care had less problem behaviour compared to children placed in non-kin foster care (Rubin et al., 2008). Thus, it may be that in high-risk conditions, grandparental presence may act as a buffer against even greater losses of wellbeing among children that could be experienced if the grandparents were not there for their grandchildren.

\section{Multigenerational relations and social stratification}

In the previous sections, we have presented findings on the associations between grandparental investment and child wellbeing. In recent decades, the potential grandparent effect has also been investigated in studies of social mobility and stratification, which have examined whether socioeconomic inequalities are transmitted from older generations to younger ones. Socioeconomic inequalities exist when the socioeconomic family background determines the child's socioeconomic status in later life.

A classic question in social stratification literature has been whether and to what extent parental socioeconomic characteristics (i.e., educational attainment, occupational status or income) correlate with those of their children. Studies from different societies measuring different socioeconomic factors have consistently shown parents' status strongly correlating with that of their adult children (e.g. Becker \& Tomes, 1986; Bourdieu 1977; Ganzeboom et al., 1991; Hout \& DiPrete 2006). In addition to this two-generation paradigm, in recent decades, an increasing number of studies have examined potential three-generational effects and asked whether grandparents' higher socioeconomic status correlates with the higher status of grandchildren after the parents' status is controlled for (e.g., Chan \& Boliver, 2013; Warren \& Hauser, 1997). These studies have attempted to test whether grandparental status has a "direct effect" on the status of grandchildren (although these studies can provide only limited evidence for causal effects). Perhaps the most important reason to believe that this is the case is that the wealth of resources can be easily transmitted over several generations (Mare, 2011). In fact, grandparental influence on grandchild outcomes may exist even 
after grandparents die, via inheritance, trusts and accumulated wealth (Madoff, 2010; Piketty, 2000).

Previous multigenerational stratification studies have analysed whether grandparental socioeconomic status measured by income and educational level (e.g., Loury, 2006; Warren \& Hauser, 1997; Lindahl et al., 2015; Zeng \& Xie, 2014), social class (e.g., Beck, 1983; Erola \& Moisio, 2007; Chan \& Boliver, 2013; Hertel \& Groh-Samberg, 2014) or cultural capital (Møllegaard \& Jæger, 2015) is associated with grandchildren's outcomes. These previous studies have found mixed results. Although some have found that grandparental status correlates with grandchild status (e.g., Chan \& Boliver, 2013; Modin et al., 2012), others have found that the correlation is either very weak or negligible (e.g., Erola \& Moisio, 2007; Warren \& Hauser, 1997).

The mixed results may be related to the fact that it is not obvious how the potential "grandparental effect" occurs (i.e., what the proximate mechanisms are). In social mobility and stratification research, it is argued that the effect grandparents may have on their grandchildren's status attainment may be based on either investments or endowments. In the stratification literature, the term "grandparental investment" is used to refer to conscious acts; thus, the meaning is somewhat different from its use in evolutionary studies (and elsewhere in this book; see Chapter 1: Box 1.2). Grandparental investments may include several actions indicating grandparental involvement in grandchildren's lives, such as financial help, emotional support, care and practical help. These investments can be divided into those that demand grandparental presence or face-to-face contact between grandparents and grandchildren (e.g., child care help) and those that do not (e.g., financial transfers).

Grandparental endowments constitute any available resources from which grandchildren can potentially benefit, including economic wealth, human and cultural capital, social networks, grandparental status and shared genes (see Chapter 2: Box 2.4). Grandparental endowments can be separated into three categories based on grandparental presence. The first group includes those endowments that probably benefit children more if the grandparent is present, such as social status, networks and cultural capital. Second, some endowments are independent of whether grandparents are present (or even alive) or not, such as shared genes between grandparents and grandchildren. Finally, inheritance represents the type of endowment that may benefit children the most after grandparents have passed away. Although wealth can be transferred from one generation to another via pre-heritance, the most important source of transfers of wealth tends to exist after the member belonging to the older generation has died (Madoff, 2010). The most important difference between investments and endowments is that endowments can benefit grandchildren simply by existing, whereas investments always require grandparental conscious or unconscious actions.

There may be different sets of mechanisms related to grandparental investments or endowments that are associated with the potential grandparental effect. If grandparental investments that require grandparental presence provide a proximate explanation for child outcomes, the most obvious precondition is that grandparents must be alive. Moreover, one may assume that grandparents should 
be in reasonably good health to benefit their grandchildren. Another important precondition for investments is that grandparents cannot live geographically far from their grandchildren. Coresidence with grandchildren in multigenerational households obviously provides grandparents with the opportunity for involvement in their grandchildren's lives (Mare, 2011). However, as discussed above, in present-day Western societies, living arrangements in three-generational households are often related to family poverty, meaning that the potentially positive grandparental effect could be overridden by other factors, and there is a possibility of resource competition that may diminish the potentially beneficial effects. Thus, in contemporary Western countries, the most beneficial effect may exist when grandparents live near their grandchildren but not in the same household.

Studies examining the mechanisms that account for potential multigenerational effects have been scarce. One recent exception is a study that used large-scale data from the Netherlands (Knigge, 2016). This study investigated the association between the occupational status of grandfathers (and great-grandfathers) and grandsons. The study's purpose was to test whether the grandparental influence is based on grandparental investments requiring grandparental presence (e.g., contact) or grandparental endowments that do not require grandparental presence. Shared lifetime between grandparents and grandchildren as well as geographical distance between them were used as proxies for contact because both of these improve the probability of contact. The study showed that an increase in shared lifetime and a decrease in geographical distance predicted a stronger grandfather effect on grandsons' occupational status. In addition, the positive association seemed to exist even though it was unlikely that grandfathers invested time in their grandchildren. Thus, the study found support for both mechanisms, grandparental investments and endowments.

To the best of our knowledge, no previous studies have examined whether shared genes between grandparents and grandchildren influence multigenerational inheritance. However, some studies have found an influence of shared genes from a two-generational perspective among parents and children. The evidence has shown that correlation between parents' and children's education is higher in families with biological children compared to families with adopted children (e.g., Björklund et al., 2007; Plug, 2004). One important limitation related to these studies is that adopted children may include children adopted by kin (e.g., nieces or nephews adopted by their parents' siblings). A very recent study from the Netherlands responded to this problem (Scheeren et al., 2017). Using register data, the authors investigated whether parental education and income correlated with the education of children adopted from a foreign country. These authors showed that there was a stronger correlation between the educational levels of parents and children among biological than non-biological parent-child pairs, but parental incomes correlated with the education of both biological and adopted children.

\section{Conclusions}

This chapter has reviewed studies concerning the association between grandparental investment and child wellbeing. In line with the grandmother hypothesis, 


\section{Grandparents and child wellbeing}

studies from traditional and historical societies have shown that the presence of grandmothers, particularly maternal grandmothers, has often been associated with improved child survival, whereas the role of grandfathers seems to be much less important. Studies detecting an association between grandparental investment and child wellbeing in contemporary Western societies have provided mixed results. The existing evidence indicates that whether the outcomes of grandparental investments are positive, negative or negligible could be highly dependent on family structures, circumstances and socioeconomic factors. Because studies aiming to identify causal associations between grandparental investment and child outcomes are scarce, it is difficult to determine whether the actual "grandparent effect" exists. Much more research on causal associations between grandparental investment and child outcomes is needed before final conclusions can be made regarding whether grandparents can improve child wellbeing in contemporary affluent societies.

\section{References}

Alberdi, G., McNamara, A. E., Lindsay, K. L., Scully, H. A., Horan, M. H., Gibney, E. R., \& McAuliffe, F. M. (2016). The association between childcare and risk of childhood overweight and obesity in children aged 5 years and under: A systematic review. European Journal of Pediatrics, 175, 1277-1294.

Al Mamun, A., Cramb, S. M., O'Callaghan, M. J., Williams, G. M., \& Najman, J. M. (2009). Childhood overweight status predicts diabetes at age 21 years: A follow-up study. Obesity, 17, 1255-1261.

Aquilino, W. S. (1996). The life course of children born to unmarried mothers: Childhood living arrangements and young adult outcomes. Journal of Marriage and the Family, 58, 293-310.

Attar-Schwartz, S., \& Buchanan, A. (2011) Grandparent-adolescent relationships. In R. J. R. Levesque (Ed.), Encyclopedia of adolescence (pp. 1213-1225). New York: Springer.

Attar-Schwartz, S., Tan, J.-P., Buchanan, A., Flouri, E., \& Griggs, J. (2009). Grandparenting and adolescent adjustment in two-parent biological, lone-parent, and step-families. Journal of Family Psychology, 23, 567-575.

Beck, S. H. (1983). The role of other family members in intergenerational occupational mobility. Sociological Quarterly, 24, 273-285.

Becker, G. S., \& Tomes, N. (1986). Human capital and the rise and fall of families. Journal of Labor Economics, 4, S1-S39.

Beise, J. (2005). The helping grandmother and the helpful grandmother: The role of maternal and paternal grandmothers in child mortality in the 17th and 18th century population of French settlers in Quebec, Canada. In E. Voland, A. Chasiotis \& W. Schiefenhövel (Eds.), Grandmotherhood: The evolutionary significance of the second half of the female life (pp. 215-238). New Brunswick, NJ: Rutgers University Press.

Beise, J., \& Voland, E. (2002). A multilevel event history analysis of the effects of grandmothers on child mortality in a historical German population: Krummhörn, Ostfriesland, 1720-1874. Demographic Research, 7, 469-498.

Bilaver, L. A.,Jaudes, P. K., Koepke, D., \& Goerge, R. M. (1999). Note on research: The health of children in foster care. The Social Service Review, 73, 401.

Billing, A., Macomber, J., \& Kortenkamp, K. (2002). Children cared for by relatives: What do we know about their well-being? Washington, DC: The Urban Institute. 
Björklund, A., Jäntti, M., \& Solon, G. (2007). Nature and nurture in the intergenerational transmission of socioeconomic status: Evidence from Swedish children and their biological and rearing parents. The BE Journal of Economic Analysis \& Policy, 7, 1-23.

Bornstein, M. H., Hahn, C. S., \& Wolke, D. (2013). Systems and cascades in cognitive development and academic achievement. Child Development, 84, 154-162.

Bourdieu, P. (1977). Reproduction in education, society, and culture. Beverly Hills: Sage.

Buchanan, A., \& Rotkirch, A. (Eds.) (2016). Grandfathers: Global perspectives. London: Palgrave Macmillan.

Campbell, C., \& Lee, J. Z. (1996). A death in the family: Household structure and mortality in rural Liaoning: Life-event and time-series analysis, 1792-1867. History of the Family, 1, 297-328.

Chan, T. W., \& Boliver, V. (2013). Social mobility over three generations in Britain. American Sociological Review, 78, 662-678.

Chapman, S. N., Pettay, J. E., Lummaa, V., \& Lahdenperä, M. (2018). Limited support for the X-linked grandmother hypothesis in pre-industrial Finland. Biology Letters, 14. https://doi.org/10.1098/rsbl.2017.0651

Chen, W. C. (2016). The role of grandparents in single-parent families in Taiwan. Marriage \& Family Review, 52, 41-63.

Coall, D. A., \& Hertwig, R. (2010). Grandparental investment: Past, present, and future. Behavioral and Brain Sciences, 33, 1-59.

Currie, J., \& Thomas, D. (1999). Early test scores, socioeconomic status and future outcomes. National Bureau of Economic Research Working Paper No. 6943. Cambridge, MA: National Bureau of Economic Research.

Currie, J., \& Thomas, D. (2001). Early test scores, school quality, and SES: Long-run effects on wage and employment outcomes. Worker Wellbeing in a Changing Labor Market, 20, 103-132.

Danielsbacka, M., \& Tanskanen, A. O. (2012). Adolescent grandchildren's perceptions of grandparents' involvement in UK: An interpretation from life course and evolutionary theory perspective. European Journal of Ageing, 9, 329-341.

Deleire, T., \& Kalil, A. (2002). Good things come in threes: Single-parent multigenerational family structure and adolescent adjustment. Demography, 39, 393-413.

Duncan, G. J., Dowsett, C. J., Claessens, A., Magnuson, K., Huston, A. C., Klebanov, P., ... et al. (2007). School readiness and later achievement. Developmental Psychology, 43, 1428-1446.

Dunifon, R., \& Bajracharya, A. (2012). The role of grandparents in the lives of youth. Journal of Family Issues, 33, 1168-1194.

Dunifon, R. E., Ziol-Guest, K. M., \& Kopko, K. (2014). Grandparent coresidence and family well-being: Implications for research and policy. The Annals of the American Academy of Political and Social Science, 654, 110-126.

Ebbeling, C., Pawlak, D., \& Ludwig, D. (2002). Childhood obesity: Public-health crisis, common sense cure. Lancet, 360, 473-482.

Epstein, J. L. (2001). School, family, and community partnerships: Preparing educators and improving schools. Boulder, CO: Westview.

Erola, J., \& Moisio, P. (2007). Social mobility over three generations in Finland, 19502000. European Sociological Review, 23, 169-183.

Fan, X., \& Chen, M. (2001). Parental involvement and students' academic achievement: A meta-analysis. Educational Psychology Review, 13, 1-22.

Feinstein, L., \& Duckworth, K. (2006). Development in the early years: Its importance for school performance and adult outcomes. London: Centre for Research on the Wider Benefits of Learning. 


\section{Grandparents and child wellbeing}

Fox, M., Sear, R., Beise, J., Ragsdale, G., Voland, E., \& Knapp, L. A. (2010). Grandma plays favourites: X-chromosome relatedness and sex-specific childhood mortality. Proceedings of the Royal Society B: Biological Sciences, 277, 567-573.

Ganzeboom, H. B. G., Treiman, D. J., \& Ultee, W. C. (1991). Comparative intergenerational stratification research: Three generations and beyond. Annual Review of Sociology, 17, 277-302.

Gibson, M. A., \& Mace, R. (2005). Helpful grandmothers in rural Ethiopia: A study of the effect of kin on child survival and growth. Evolution and Human Behavior, 26, 469-482.

Hango, D. (2007). Parental investment in childhood and educational qualifications: Can greater parental involvement mediate the effects of socioeconomic disadvantage? Social Science Research, 36, 1371-1390.

Hank, K., \& Buber, I. (2009). Grandparents caring for their grandchildren: Findings from the 2004 Survey of Health, Ageing, and Retirement in Europe. Journal of Family Issues, 30, 53-73.

Hawkes, K., O’Connell, J. F., \& Blurton Jones, N. G. (1989). Hardworking Hadza grandmothers. In V. Standen \& R. A. Foley (Eds.), Comparative socioecology: The behavioural ecology of humans and other mammals (pp. 341-366). London: Basil Blackwell.

Hawkes, K., O’Connell, J. F., \& Blurton Jones, N. G. (1997). Hadza women's time allocation, offspring provisioning and the evolution of long postmenopausal life spans. Current Anthropology, 38, 551-578.

Heckman, J. J. (2011). Integrating personality psychology into economics. IZA Discussion Paper Series No. 5950. Bonn, Germany: Forschungsinstitut zur Zukunft der Arbeit. Retrieved 6 July 2017 from http://nbn-resolving.de/urn:nbn:de:101:1-201109297482

Heckman, J. J., \& Kautz, T. (2012). Hard evidence on soft skills. Labour Economics, 19, 451-464.

Heckman, J. J., Stixrud, J., \& Urzua, S. (2006). The effects of cognitive and noncognitive abilities on labor market outcomes and social behavior. Journal of Labor Economics, 24, 411-482.

Henderson, C. E., Hayslip, B., Jr., Sanders, L. M., \& Louden, L. (2009). Grandmothergrandchild relationship quality predicts psychological adjustment among youth from divorced families. Journal of Family Issues, 30, 1245-1264.

Hertel, F. R., \& Groh-Samberg, O. (2014). Class mobility across three generations in the US and Germany. Research in Social Stratification and Mobility, 35, 35-52.

Hout, M., \& DiPrete, T. A. (2006). What we have learned: RC28's contributions to knowledge about social stratification. Research in Social Stratification and Mobility $24,1-20$.

Knigge, A. (2016). Beyond the parental generation: The influence of grandfathers and great-grandfathers on status attainment. Demography, 53, 1219-1244.

Kreidl, M., \& Hubatkova, B. (2014). Does coresidence with grandparents reduce the negative association between sibship size and reading test scores? Research in Social Stratification and Mobility, 38, 1-17.

Krueger, P. M., Jutte, D. P., Franzini, L., Elo, I., \& Hayward, M. D. (2015). Family structure and multiple domains of child well-being in the United States: A cross-sectional study. Population Health Metrics, 13, 6.

Lahdenperä, M., Lummaa, V., Helle, S., Tremblay, M., \& Russell, A. F. (2004). Fitness benefits of prolonged post-reproductive lifespan in women. Nature, 428, $178-181$. 
Lahdenperä, M., Russell, A. F., \& Lummaa, V. (2007). Selection for long lifespan in men: Benefits of grandfathering? Proceedings of the Royal Society B: Biological Sciences, 274, 2437-2444.

Levetan, J. L., \& Wild, L. G. (2016). The implications of maternal grandmother coresidence and involvement for adolescent adjustment in South Africa. International Journal of Psychology, 51, 356-365.

Lindahl, M., Palme, M., Massih, S. S., \& Sjögren, A. (2015). Long-term intergenerational persistence of human capital: An empirical analysis of four generations. Journal of Human Resources, 50, 1-33.

Loury, L. D. (2006). All in the extended family: Effects of grandparents, aunts, and uncles on educational attainment. The American Economic Review, 96, 275-278.

Lundberg, S. (2013). Educational inequality and the returns to skills. IZA Discussion Paper No. 7595. Bonn, Germany: Forschungsinstitut zur Zukunft der Arbeit.

Lussier, G., Deater-Deckard, K., Dunn, J. \& Davies, L. (2002). Support across two generations: Children's closeness to grandparents following parental divorce and remarriage. Journal of Family Psychology, 16, 363-376.

Madoff, R. D. (2010). Immortality and the law: The rising power of the American dead. New Haven, CT: Yale University Press.

Mare, R. D. (2011). A multigenerational view of inequality. Demography, 48, 1-23.

McLanahan, S., \& Sandefur, G. (1994). Growing up with a single parent: What hurts, what helps? Cambridge, MA: Harvard University Press.

Modin, B., Erikson, R., \& Vågerö, D. (2012). Intergenerational continuity in school performance: Do grandparents matter? European Sociological Review, 29, 858-870.

Moffitt, T. E., Arseneault, L., Belsky, D., Dickson, N., Hancox, R. J., Harrington, H., ... et al. (2011). A gradient of childhood self-control predicts health, wealth, and public safety. Proceedings of the National Academy of Sciences, 108, 2693-2698.

Møllegaard, S., \& Jæger, M. M. (2015). The effect of grandparents' economic, cultural, and social capital on grandchildren's educational success. Research in Social Stratification and Mobility, 42, 11-19.

Odgers, C. L., Moffitt, T. E., Broadbent, J. M., Dickson, N., Hancox, R. J., Harrington, H., ... et al. (2008). Female and male antisocial trajectories: From childhood origins to adult outcomes. Development and Psychopathology, 20, 673-716.

Park, H. (2008). Home literacy environments and children's reading performance: A comparative study of 25 countries. Educational Research and Evaluation, 14, 489-505.

Perry, G., Daly, M., \& Macfarlan, S. (2014). Maternal foster families provide more stable placements than paternal families. Children and Youth Services Review, 46, 155-159.

Pfeffer, F. T. (2014). Multigenerational approaches to social mobility. A multifaceted research agenda. Research in Social Stratification and Mobility, 35, 1-12.

Piketty, T. (2000). Theories of persistent inequality and intergenerational mobility. Handbook of Income Distribution, 1, 429-476.

Pilkauskas, N. V., \& Martinson, M. L. (2014). Three-generation family households in early childhood: Comparisons between the United States, the United Kingdom, and Australia. Demographic Research, 30, 1639-1652.

Pittman, L. D. (2007). Grandmothers' involvement among young adolescents growing up in poverty. Journal of Research on Adolescence, 17, 89-116.

Pittman, L. D. \& Boswell, M. K. (2007). The role of grandmothers in the lives of preschoolers growing up in urban poverty. Applied Developmental Science, 11, 20-42.

Plug, E. (2004). Estimating the effect of mother's schooling on children's schooling using a sample of adoptees. The American Economic Review, 94, 358-368. 


\section{Grandparents and child wellbeing}

Pong, S. L, \& Chen, V. W. (2010). Co-resident grandparents and grandchildren's academic performance in Taiwan. Journal of Comparative Family Studies, 41, 111-129.

Reilly, J. J. \& Kelly, J. (2011). Long-term impact of overweight and obesity in childhood and adolescence on morbidity and premature mortality in adulthood: Systematic review. International Journal of Obesity, 35, 891-898.

Rubin, D. M., Downes, K. J., O’Reilly, A. L. R., Mekonnen, R., Luan, X., \& Localio, R. (2008). Impact of kinship care on behavioral well-being for children in out-of-home care. Archives of Pediatrics \& Adolescent Medicine, 162, 550-556.

Scheeren, L., Das, M., \& Liefbroer, A. C. (2017). Intergenerational transmission of educational attainment in adoptive families in the Netherlands. Research in Social Stratification and Mobility, 48, 10-19.

Sear, R. \& Coall D. A. (2011). How much does family matter? Cooperative breeding and the demographic transition. Population and Development Review, 37, 81-112.

Sear, R., \& Mace, R. (2008). Who keeps children alive? A review of the effects of kin on child survival. Evolution and Human Behavior, 29, 1-18.

Sear, R., Mace, R., \& McGregor, I. A. (2000). Maternal grandmothers improve the nutritional status and survival of children in rural Gambia. Proceedings of the Royal Society B: Biological Sciences, 267, 1641-1647.

Sénéchal, M., \& Young, L. (2008). The effect of family literacy interventions on children's acquisition of reading from kindergarten to grade 3: A meta-analytic review. Review of Educational Research, 78, 880-907.

Sheppard, P. \& Sear, R. (2016) Do grandparents compete with or support their grandchildren? In Guatemala, paternal grandmothers may compete, and maternal grandmothers may cooperate. Royal Society Open Science, 3. https://doi.org/10.1098/rsos.160069

Smith, G. C., \& Palmieri, P. A. (2007). Risk of psychological difficulties among children raised by custodial grandparents. Psychiatric Services, 58, 1303-1310.

Solomon, J., \& Marx, J. (1995). To grandmother's house we go: Health and school adjustment of children raised solely by grandparents. The Gerontologist, 35, 386-394.

Strassmann, B. I. (2011). Cooperation and competition in a cliff-dwelling people. Proceedings of the National Academy of Sciences of the United States of America, 108, 10894-10901.

Strassmann, B. I., \& Garrard, W. M. (2011). Alternatives to the grandmother hypothesis: A meta-analysis of the association between grandparental and grandchild survival in patrilineal populations. Human Nature, 22, 201-222.

Strassmann, B. I., Hug, B. F., \& Welch, K. (2006). A new twist on the grandmother hypothesis: Adverse impact of paternal grandmothers on Dogon grandsons. American Journal of Human Biology, 18, 275-276.

Sun, Y. (2003). The well-being of adolescents in households with no biological parents. Journal of Marriage and Family, 65, 894-909.

Tanskanen, A. O. (2013). The association between grandmaternal investment and early years overweight in the UK. Evolutionary Psychology, 11, 417-425.

Tanskanen, A. O., \& Danielsbacka, M. (2012). Beneficial effects of grandparental involvement vary by lineage in the UK. Personality and Individual Differences, 53, 985-988.

Tanskanen, A. O., \& Danielsbacka, M. (2016). Maternal grandfathers and child development in England. In A. Buchanan \& A. Rotkirch (Eds.), Grandfathers: Global perspectives (pp. 217-228). London: Palgrave Macmillan. 
Tanskanen, A. O., \& Danielsbacka, M. (2017). Multigenerational effects on children's cognitive and socioemotional outcomes: A within-child investigation. Child Development, 88, 1-13. https://doi.org/10.1111/cdev.12968

Tanskanen, A. O., Danielsbacka, M., \& Erola, J. (2016). Educational test scores among adolescents in three-generational households in 20 countries. Finnish Yearbook of Population Research, 51, 3-22.

Voland, E., \& Beise, J. (2002). Opposite effects of maternal and paternal grandmothers on infant survival in historical Krummhörn. Behavavioral Ecology and Sociobiolology, $52,435-443$.

Voland, E., \& Beise, J. (2005). The husband's mother is the devil in the house. Data on the impact of the mother-in-law on stillbirth mortality in historical Krummhörn (1750-1874) and some thoughts on the evolution of postgenerative female life. In E. Voland, A. Chasiotis, \& W. Schiefenhövel (Eds.), Grandmotherhood: The evolutionary significance of the second half of female life (pp. 239-255). New Brunswick, NJ: Rutgers University Press.

Warren, J. R., \& Hauser, R. M. (1997). Social stratification across three generations: New evidence from the Wisconsin Longitudinal Survey. American Sociological Review, 62, 561-572.

Washbrook, E., Propper, C., \& Sayal, K. (2013). Pre-school hyperactivity/attention problems and educational outcomes in adolescence: Prospective longitudinal study. The British Journal of Psychiatry, 203, 265-271.

Wells, J. C. K., \& Stock, J. T. (2007). The biology of the colonizing ape. American Journal of Physical Anthropology, 134, 191-222.

Wild, L. (2016). Grandfather involvement and adolescent well-being in South Africa. In A. Buchanan \& A. Rotkirch (Eds.), Grandfathers: Global perspectives (pp. 249-266). London: Palgrave Macmillan.

Yorgason, J., Padilla-Walker, L., \& Jackson, J. (2011). Nonresidential grandparents' emotional and financial involvement in relation to early adolescent and grandchild outcomes. Journal of Research on Adolescence, 21, 552-558.

Zeng, Z., \& Xie, Y. (2014). The effects of grandparents on children's schooling: Evidence from rural China. Demography, 51, 599-617. 


\section{Grandparent wellbeing}

Is grandparenthood or active grandparenting beneficial to grandparents themselves, or do grandparents potentially experience harm while investing in their grandchildren? In Chapters 5 and 6, the main interest was directed towards the potential profitability of grandparental investments in parents and grandchildren. Here, we shift the focus to grandparents and the potential grandparent outcomes from merely being a grandparent or actively grandparenting.

Recently, an increasing number of studies have concentrated on the associations between grandparenthood or grandparental investment and the outcomes for grandparents themselves. Initially, we must separate the terms grandparenthood and active grandparenting because they refer to two different phenomena. The first term means that an individual is a grandparent (i.e., having grandchildren), and the latter represents an active interaction and involvement (e.g., keeping in contact or providing emotional support, financial aid or child care) with a grandchild. Related to this division, on the one hand, researchers have attempted to disentangle whether grandparenthood is associated with improved happiness and life satisfaction or even decreased mortality among older people, and on the other hand, they have attempted to determine whether active grandparenting is associated with increased self-perceived improvements in health and cognitive function or decreased depression (e.g., Arpino \& Bordone, 2014; Powdthavee, 2011). Theoretically, any benefits to the wellbeing of grandparents themselves from grandparenthood or active grandparenting may be derived from several factors.

One obvious reason for the growing interest in grandparental wellbeing is the fact that life expectancy and the number of elderly people are increasing among Western populations. The relevance of the study of grandparental outcomes is also derived from the fact that the health of the helpers is important in contemporary, ageing societies because it provides a new perspective on older people as providers of assistance and simultaneously investigates benefits they may gain from these helping behaviours (Coall \& Hertwig, 2010). In addition, grandparenthood or active grandparenting may have wider societal effects. For instance, one study showed that older women who experienced an entry into grandmotherhood had an 8 per cent greater likelihood of retiring than older women who had not experienced the birth of a grandchild (Lumsdaine \& Vermeer, 2015). Thus, some 
older adults may prefer to spend time with newborn grandchildren rather than continue their working career.

The possible benefits for the wellbeing of grandparents themselves in turn may result from positive emotions attached to grandparenthood. In previous populations, grandparental presence was associated with the outcomes of adult children and grandchildren (e.g., Sear \& Coall, 2011; see Chapters 5 and 6), but this finding does not explain the conscious motive behind grandparents' altruistic acts. Grandparents are not likely to consciously think about "spreading their genes" when supporting their descendants but rather have some kind of proximate push that may encourage a certain type of behaviour (Hrdy, 1999). Evolutionary theory offers one potential candidate motive for this impetus, as it argues that emotions may work as proximate mechanisms encouraging behaviour that has produced fitness benefits in our evolutionary past (Buss, 2000). Thus, although the evolutionary function of active grandparenting may not improve the wellbeing of grandparents per se, the wellbeing benefits may be by-products of evolutionarily beneficial actions (Buss, 2000; de Waal, 2008; Euler, 2011). Grandparents may experience positive feelings when they are spending time with their grandchildren, and these positive feelings may in turn increase their motivation to invest more time and resources in their grandchildren in the future. These positive emotions may also represent the mechanisms underlying possible associations between grandparenthood and decreased mortality (Hilbrand et al., 2017a; KoivumaaHonkanen et al., 2000; Liu et al., 2016).

In addition to potential health and wellbeing benefits grandparents may gain from grandparenthood or active grandparenting, one obvious advantage is that the help they have provided to their children and grandchildren could be reciprocated later in life when they are in need of assistance (Friedman et al., 2008). Although the prediction has not gained strong support from empirical research in Western countries (Coall \& Hertwig, 2010), reciprocity may be an important issue in some countries (e.g., in China or other Asian countries) where filial obligations are strong (e.g., Sheng \& Settles, 2006). For instance, a study conducted in rural China showed that in skipped-generation households, where grandparents were raising their grandchildren due to parents' labour migration, the middle generation (parents) felt more filial obligations towards the oldest generation (grandparents) than did non-skipped-generation households (Cong \& Silverstein, 2012). This trend resulted in selective grandparenting, meaning that the best strategy for elders to ensure later support from their adult children was to bond with one adult child rather than all adult children by, for instance, only providing grandchild care for one particular child.

In this chapter, we review the literature concerning different aspects of grandparenting: grandparenthood and its association with the subjective wellbeing (e.g., life satisfaction) and mortality of older people, as well as active grandparenting and its association with grandparental health and wellbeing. The latter is further divided into three different contexts: grandparents who are primary carers for their grandchildren, grandparents who live in three-generational households and grandparents who see and interact with their grandchildren but do not live with 
them (see also Chapter 6). Coall and Hertwig (2010, 2011) have hypothesized that the association between grandparental child care (or overall active grandparenting) and the health of grandparents is nonlinear (in a reversed U-shape curve). Negative effects might arise when no grandparental investment occurs and when grandparental investment reaches the highest level, for instance, in the form of custodial care. This chapter also discusses whether this hypothesis is supported.

\section{Grandparenthood and wellbeing}

Several researchers have explored the association between parenthood and happiness or life satisfaction (e.g., Aassve et al., 2012; Hansen, 2012; Lyubomirsky \& Boehm, 2010; Myrskylä \& Margolis, 2014; Stanca, 2012), but the results were mixed. Some studies have revealed a direct positive, albeit modest, association between childbearing and happiness (Aassve et al., 2012), whereas others have shown that the experience of having a child may increase parental wellbeing in the short term (e.g., Myrskylä \& Margolis, 2014). However, a majority of studies have not identified this association or have detected a negative association (see Hansen, 2012, for a review). Thus, although most people will have children at some point in their life, parenthood does not tend to be associated with a permanent increase in happiness or subjective wellbeing (Lyubomirsky \& Boehm, 2010).

Although the birth of a child may not increase parental happiness or subjective wellbeing, the experience of becoming a grandparent might. This apparent paradox could be due to several reasons. One is that the role of grandparents significantly differs from that of parents; in contemporary Western societies, grandparents usually have no direct responsibilities regarding their grandchildren's welfare, with the exception of older adults who are primary carers for their grandchildren (Coall \& Hertwig, 2010). Thus, the experience of having a grandchild may provide happiness and life satisfaction for grandparents without the stress that parents may experience when a child arrives. Grandchildren are often termed warmly as the desserts of life, indicating that becoming a grandparent signifies a positive life event. Thus, the experience of having a grandchild might increase individuals' happiness and subjective wellbeing, although having a child does not.

Much less research about the association between grandparenthood and subjective wellbeing is available than corresponding studies of these associations with parenthood. To the best of our knowledge, only a few previous studies have investigated the association between grandparenthood and happiness or life satisfaction using nationally representative data. Using data from approximately 2,300 older Finns aged between 62 and 67 years, grandparenthood (i.e., just being a grandparent) was not associated with increased self-rated happiness after controlling for several potential confounding factors (Danielsbacka \& Tanskanen, 2016). In contrast, a preliminary study analysing the data from almost 12,000 individuals aged 40 and above in the UK determined that being a grandparent was associated with increased life satisfaction, whereas being a parent was not (Powdthavee, 2011).

Regarding possible sex and lineage-specific differences in the association between grandparenthood and happiness or life satisfaction, some studies have 
separated the grandparents by sex and lineage. One study showed that the expectations and experiences of grandparenthood varied according to grandparents' sex and lineage (Somary \& Stricker, 1998). The authors conducted a study of 152 grandparents-to-be whose first grandchild was still in utero. After the grandchild was born, they interviewed 103 grandparents again and found that grandmothers expected and experienced more satisfaction from being a grandparent than did grandfathers. Moreover, maternal grandparents were more satisfied with being a grandparent than they expected, whereas paternal grandparents' expectations did not differ from their experiences. A body of studies based on small-scale and nonrepresentative samples shows that grandmothers tend to be more satisfied with being a grandparent than are grandfathers (e.g., Neugarten \& Weinstein, 1964; Thiele \& Whelan, 2008; Thomas, 1986).

None of the above-mentioned studies has investigated whether becoming a grandparent has an effect on the subjective wellbeing of older people. Previous studies have compared different groups of people (e.g., those who are grandparents and those who are not), and thus, the findings may reflect only differences between individuals and not an individual's variation over time. To the best of our knowledge, only one preliminary study has investigated whether becoming a grandparent is associated with self-rated life satisfaction and meaning of life (Tanskanen et al., 2017). Using longitudinal data from older Europeans between 2004 and 2015 and within-person regressions that focus on each participant's variation in subjective wellbeing over time, becoming a grandparent was associated with increased meaning of life scores, but these effects were not observed on self-rated life satisfaction.

In addition to studies investigating associations between grandparenthood and subjective wellbeing, studies have also analysed whether being a grandparent is associated with an individual's health and mortality. Using register data encompassing the entire Norwegian population, the experience of becoming a grandmother after the age of 50 was associated with significantly lower mortality (Christeansen, 2014). However, disadvantages may also occur. The Norwegian study showed that women who became grandmothers in their $30 \mathrm{~s}$ or $40 \mathrm{~s}$ and all grandfathers, particularly men who became grandfathers at an early age, had significantly higher mortality rates. These findings may be due to the selection effects related to socioeconomic status or may reflect the relationships between an individual and his/her children and grandchildren. Selection processes that are most likely related to socioeconomic status may reflect different life history strategies, as earlier and higher fertility along with a shorter life expectancy (fast strategy) may be a characteristic of people with lower resources, whereas later fertility with a longer life expectancy (slow strategy) may be a characteristic of people with higher resources (Belsky et al., 1991; Lummaa, 2007; see Chapters 2 and 3).

\section{Active grandparenting and wellbeing}

Based on studies presented in the preceding section, some (although not univocal) evidence shows that grandparenthood (i.e., just being a grandparent) might 
be associated with the wellbeing of grandparents. A branch of studies has also examined whether active grandparenting (e.g., looking after grandchildren) produces health and wellbeing benefits for the grandparents. The starting point in these studies is that helping others may be associated with the health of the helpers themselves. Although some researchers have found that active grandparenting is associated with increased health and wellbeing among older adults (e.g., Mahne \& Huxhold, 2015; Tsai et al., 2013), others have not detected these associations or have reported negative associations (e.g., Baker \& Silverstein, 2008; Hughes et al., 2007).

One potential reason for the contradictory results is that they depend on the context of grandparenting, which causes possible selection effects. In practice, the results may depend on whether grandparents are custodial grandparents (i.e., primary carers for their grandchildren), living with the parents and grandchildren in three-generational households or are involved with grandchildren's lives without living with them (non-coresiding grandparents). These three contexts differ considerably in terms of active grandparenting and grandparental wellbeing. In Chapter 6, we reviewed studies concerning grandparental investment and child wellbeing within similar contexts. However, one must consider that the different contexts represent somewhat different experiences for grandparents than for grandchildren. Next, we scrutinise research on grandparental investments and grandparental wellbeing according to this contextual division.

\section{Custodial grandparents}

Custodial grandparents are primary carers for their grandchildren. Recently, the number of these "skipped-generation households" or "grandfamilies" has increased in many Western countries, including the US, the UK and Australia (Grinstead et al., 2003; Hayslip et al., 2017; Taylor et al., 2016). Currently, among Western countries, the number of custodial grandparent families is the highest in the US, where approximately 2 per cent of children are raised by their grandparents (Dunifon et al., 2014; Pilkauskas \& Dunifon, 2016). Grandparents may be responsible for raising their grandchildren for many reasons, but among the most common reasons in Western countries are parental teenage pregnancy, drug addiction, mental or physical health problems, incarceration, distance employment, relationship breakdown and death (e.g., Bunch et al., 2007; Hadfield, 2014; Strom \& Strom, 2011).

Most of the research on custodial grandparent families is conducted using data from the US. According to the US evidence, custodial grandparents are more often women (grandmothers) than men (grandfathers) and are more often from the maternal than the paternal side (Dunifon et al., 2014; see Chapter 6). In most cases, custodial grandparents in the US are members of lower socioeconomic classes and often are single women (Fuller-Thomson et al., 1997; Heywood, 1999; Minkler \& Fuller-Thomson, 2000). In addition, the custodial grandparents in the US are often African-Americans and typically aged between 50 and 59 years, whereas very few are under 40 years or over 80 years (Ellis \& Simmons, 2014). 
Thus, in the US, custodial grandparent families are predominantly a selected group, which inevitably affects any comparison between the custodial grandparents and non-custodial grandparents. According to several studies, grandparents raising grandchildren have a higher risk of developing health problems, including limitations in daily living activities, chronic conditions, coronary heart disease, depressive symptoms, elevated stress levels and poorer self-rated health (Baker \& Silverstein, 2008; Blustein et al., 2004; Lee et al., 2003; Minkler \& FullerThomson, 1999; Musil et al., 2010; Ross \& Aday, 2006; Strawbridge et al., 1997). Many of the detrimental effects on the health of grandparents in skipped-generation households are likely due to the grandparents' characteristics and history rather than exclusively due to caring responsibilities. For instance, one study from the US showed that an association between caring responsibilities and decreasing health among custodial grandmothers compared to non-custodial grandmothers was predominantly due to the medical history of custodial grandmothers (Hughes et al., 2007).

In addition to negative associations, US studies indicate that custodial grandparent families may experience some positive effects as well. For instance, in these families bonds between grandparents and grandchildren are typically very warm, grandparents may exhibit an increased purpose for life as they are raising their grandchildren and the parenting styles of grandparents may include wisdom and maturity that comes with age and experience (Dunifon et al., 2014).

Finally, the cultural differences potentially related to grandparental wellbeing in custodial grandparent families are important to note. In some Asian countries, where grandfamilies are more traditional and common phenomena, the experience of being a custodial grandparent is associated with increased rather than decreased wellbeing among older adults (Chen \& Liu, 2012; Ku et al., 2013; Thang \& Mehta, 2012), mainly because the reasons underlying custodial grandparenting are, in many cases, different in Asia than in Western countries.

Due to cultural variation in filial norms and care arrangements, some Chinese grandparents, even in skipped-generation households, experience better psychological wellbeing than do grandparents in single-generation households (Silverstein et al., 2006). This finding is particularly true in rural China, where the tradition of three-generational coresidence has been altered due to economic changes and long-distance working (Cong \& Silverstein, 2012; Silverstein et al., 2006). Because the middle generation (i.e., parents) are frequently not working and living in the same area as the oldest generation (i.e., grandparents), custodial grandparents may receive more assistance from their adult children (e.g., financial help) than older individuals who live in single-generation households. This reciprocal help between parents and grandparents tends to result in a better wellbeing of custodial grandparents compared to non-custodial grandparents (Cong \& Silverstein, 2012; Silverstein et al., 2006).

Moreover, a longitudinal study from Taiwan suggests that grandparents in skipped-generation households may receive greater benefits than non-carers in terms of reduced mobility limitations (i.e., fewer problems with physical health; 
$\mathrm{Ku}$ et al., 2013). Thus, cultural traditions tend to determine whether custodial grandparenting is associated with positive or negative outcomes among grandparents. Perhaps the most important underlying cause of the mixed results reported in previous studies is the difference in the composition of custodial grandparent families between Western and Asian countries.

\section{Three-generational households}

The terms "three-generational" or "multigenerational" families refer to a living arrangement where children, parents and grandparents are living together in the same household. The number of three-generational households varies remarkably among Western countries, as discussed in Chapter 6. The reasons why families adopt these kinds of living arrangements are usually related to child care arrangements or providing care and maintenance for the grandparents.

In the current era of welfare state retrenchment in many Western countries, society is placing growing demands on increasing the responsibility of family members to ensure the wellbeing of their own family. Thus, accurate and up-todate information on the effects this kind of living arrangement on children, parents and grandparents is extremely important. In practice, current developments indicate that three-generational households may again become more common, as they were in the beginning of the 20th century (Ruggles, 2003).

Three-generational households can consist of a single mother, child and grandparent(s); a single father, child and grandparent(s); or both parents, child and grandparent(s). The reasons for three generations to live together vary according to this composition. For single parents, the parent and child are more likely to have moved into the grandparents' home, and the grandparents will provide assistance to the parent and child. These types of households typically consist of a single mother, child and grandparent(s). In addition, economic crises tend to facilitate adult children moving in with their parents (Keene \& Batson, 2010). If three generations live together in two-parent, child and grandparent families, grandparent(s) have most likely moved into their child's household and are in need of assistance themselves (Dunifon et al., 2014). Spousal loss or declining health may act as catalysts for parents to move in with their adult children (Keene \& Batson, 2010).

Studies examining whether living in three-generational households is associated with improved or impaired outcomes among grandparents are scarce (Dunifon et al., 2014) and similar to custodial grandparenting, three-generational households in general are studied primarily in the US (Dunifon et al., 2016). Based on the results from the few available studies, coresidence may not be very beneficial for grandparents themselves. Coresidence is associated with reduced wellbeing among grandparents, including higher stress and depression levels (Musil \& Ahmad, 2002). These results may, however, reflect the selection effect, similar to custodial grandparents, meaning that grandparents who live in three-generational households are already in poorer health than grandparents who do not live in these households (Deaton \& Stone, 2013; Hughes et al., 2007). 
In some Asian countries, living in three-generational families is much more common than in Western countries. This situation is partially explained by the influence of Confucianism, which promotes a tradition of filial responsibility (Burr \& Mutchler, 1999; Speare \& Avery, 1993). However, living in three-generational households may not be beneficial for grandparents in Asian countries either. A study conducted using longitudinal Chinese data found that grandparents who lived in three-generational households actually experienced a slightly more rapid decline in health than those who lived independently (Chen \& Liu, 2012). In particular, grandparents who provided high-intensity care for very young grandchildren experienced an accelerated decline in health, whereas grandparents who provide lower-intensity care may even experience a protective effect on their health. However, positive associations between grandparents' health and better psychological wellbeing with coresidence with children and grandchildren have also been found compared to grandparents living in single-generation households (Silverstein et al., 2006).

Depending on the reasons and cultural context, living in three-generational households may be either beneficial or detrimental to grandparents. Similar to grandchild outcomes (see Chapter 6), resource competition can negatively influence grandparental wellbeing if the reason grandparents live with their adult children and grandchildren is that they cannot manage living alone. Thus, they may need more resources (e.g., care and help with daily activities) than they provide (e.g., by assisting with grandchild care), and therefore, a competitive situation may arise over the time and resources of the middle generation. In addition, living in a three-generational household and providing intense assistance to adult children and grandchildren (e.g., grandchild care) may overburden grandparents and subsequently result in poorer grandparental outcomes than for grandparents living in single-generation households.

\section{Grandparents living separately from their grandchildren}

The largest group of caregiving grandparents, particularly in Western countries, includes grandparents who do not live with their grandchildren but provide different kinds of support to them more or less frequently. Grandparents in different countries provide different amounts of care (Di Gessa et al., 2016a), but the pattern of biased grandparental investment tends to be remarkably robust, at least in Western countries (Danielsbacka et al., 2011; see also Chapter 4). Thus, if we postulate an association between grandparental investment and grandparental outcomes, this association should be particularly pronounced among maternal grandmothers. However, as indicated in the studies described below, the results have been mixed.

An increasing number of studies have investigated associations between active grandparenting and grandparental outcomes among non-coresiding grandparents. For instance, according to a study conducted among Chilean grandparents, grandfathers who provided any help to their grandchildren experienced better life satisfaction, and the ability to provide material help was associated with 
better mental health two years later (Grundy et al., 2012). Moreover, Chilean grandmothers who provided any help to their grandchildren had lower risks of depression. In contrast, a study conducted among European grandparents suggested that a 10-hour monthly increase in time spent in child care increased the probability of experiencing any depressive symptoms by approximately 3 percentage points for grandmothers and approximately 5.5 percentage points for grandfathers, indicating negative outcomes for grandparents (Brunello \& Rocco, 2016). Finally, again providing different results, a US study examining longitudinal data between 1998 and 2002 found no evidence that grandchild care would have overall negative or any substantial positive associations with the health of non-coresiding grandparents, as measured by several variables, such as self-rated health, depressive symptoms and functional limitations, although some health deficits were observed among grandmothers in skipped-generation households (Hughes et al., 2007).

In addition, grandparental care is found to associate with some benefits in self-rated health, based on longitudinal data collected from older Europeans (Di Gessa et al., 2016b). However, no significant associations between grandparental child care and depressive symptoms or limitations in daily living activities were detected. Even after considering lifetime experiences (i.e., prior health), grandmaternal child care was associated with better health outcomes, as measured using several indicators (Di Gessa et al., 2016c). Similar associations were not found among grandfathers.

Another study conducted with data from Germany investigated whether grandparents' relationships with adolescent and adult grandchildren were associated with the grandparents' subjective wellbeing (Mahne \& Huxhold, 2015). The quality of the relationship (measured by contact frequency and emotional closeness) with grandchildren was associated with grandparents' wellbeing (a better relationship was reflected in better subjective wellbeing), but it was also moderated by grandparents' educational level in the case of negative aspects of wellbeing. A high-quality relationship with descendants was associated with a lower level of negative aspects of wellbeing (negative affect and loneliness) only among highly educated grandparents.

For non-coresiding grandparents, these mixed results are potentially related to methodological issues. Many of the above-mentioned positive associations between active grandparenting and grandparents' subjective wellbeing (Di Gessa et al., 2016b, 2016c; Mahne \& Huxhold, 2015), better life satisfaction, better mental health and a lower risk of depression (Grundy et al., 2012) may be based on between-person variations (i.e., the differences exist between active and non-active grandparents) rather than within-person variations (i.e., active grandparenting is associated with subsequent changes in health or wellbeing within a grandparent over time). Although some have used longitudinal data, they still have compared different caregiving groups, such as grandparents who provide any care and those who do not. Consequently, based only on between-person variation, we cannot claim that changes in child care frequencies would causally affect grandparents' health over time. Thus, health deficits observed among 
grandparental caregivers in some studies may be due to grandparents' prior characteristics and not caregiving responsibilities per se.

Attempts to understand the causal nature of associations between active grandparenting and grandparental outcomes have just begun. After controlling for several background characteristics and unobservable endogeneity using the instrumental variable approach, a positive association between grandparental child care support and grandparents' cognitive abilities measured as verbal fluency was observed among European grandparents (Arpino \& Bordone, 2014). Thus, based on these findings, the prior characteristics of grandparent are not the only reason for the positive association. However, the authors did not observe evidence of an association between child care and other measures of grandparental cognitive function.

To date, only a few studies using within-person approaches have been conducted (Ates, 2017; Danielsbacka et al., 2017; Ku et al., 2012, 2013; Reinkowski, 2013). One preliminary study used three waves of longitudinal Survey of Health, Ageing and Retirement in Europe data from older Europeans but did not detect within-person associations between grandparental child care and grandparental health (Reinkowski, 2013). Another preliminary study conducted with the same data that included five data waves and more outcome variables did not detect substantial within-person associations either (Danielsbacka et al., 2017). The only exception in the latter study was a small but significant within-person effect of grandchild care on decreased limitations in the daily living activities of a grandparent.

A longitudinal study from Taiwan reported a positive within-individual association between the provision of child care and grandparents' health, but it did not distinguish the effect of caregiving according to the grandparents' coresidence status (Ku et al., 2012). When the sample was separated by the grandparents' coresidence status, the within-person effect among non-coresiding grandparents was attenuated and was no longer statistically significant (Ku et al., 2013). Finally, an investigation based on longitudinal data from Germany did not detect withinperson associations between grandparental child care and self-rated health among grandparents (Ates, 2017). These findings imply that the associations between active grandparenting and improved wellbeing could be based on between-person variations and selection bias, indicating that healthier grandparents with an initially better wellbeing provide more child care than other grandparents or that an unobservable third factor associated with both child care and health is responsible for the association.

In addition, researchers have studied whether active grandparenting (looking after a grandchild) is associated with grandparents' mortality and whether this association is mediated with improved health as a consequence of active grandparenting (Hilbrand et al., 2017a, 2017b). First, based on longitudinal German data, grandparents who looked after their grandchildren had lower mortality rates than the respective non-helpers (Hilbrand et al., 2017a). A follow-up study with the same data found that although active grandparenting was significantly associated with longevity, the associations were partially (but not completely) mediated 
by prospective health (Hilbrand et al., 2017b). Health was responsible for only 22 per cent of the association between helping behaviour and longevity among grandparents. Thus, the straight translation of health benefits into longevity cannot be assumed, but rather other pathways by which helping behaviour might increase longevity may exist.

Finally, the loss of contact with a grandchild has been shown to correlate with mental strain and disadvantages for grandparents. A study of 442 grandparents from the US observed that grandparents aged between 55 and 80 years who, for some reason, lost contact with at least one of their grandchildren suffered more depressive symptoms than grandparents who experienced no loss of contact with their grandchildren (Drew \& Silverstein, 2007). As shown in another study, grandparents who had lost their young grandchild due to premature death experienced more severe depressive or post-traumatic stress disorder symptoms if they had provided care for their deceased grandchild than non-caregiving grandparents (Youngblut et al., 2015).

\section{Conclusions}

A growing number of studies have investigated the association between grandparenthood or active grandparenting and grandparental health, wellbeing and mortality, with mixed results. It is not clear whether having grandchildren (i.e., being or becoming a grandparent) is associated with improved wellbeing among older individuals. In the case of active grandparenting, the context - whether grandparents are custodial, live in three-generational households or do not live with their grandchildren - has been shown to be crucial. Cross-sectional evidence indicates positive health and wellbeing outcomes for grandparents from moderate grandparental investment. However, existing studies that have examined whether changes in the amount of grandparental investment are associated with corresponding changes in grandparental wellbeing have not found evidence for either increased or decreased wellbeing. It could be that the selection effect exists, meaning that those grandparents who are in good health in the first place are also more actively involved in their grandchildren's life. Nevertheless, more studies on this topic are warranted.

\section{References}

Aassve, A., Meroni, E., \& Pronzato, C. (2012). Grandparenting and childbearing in the extended family. European Journal of Population, 28, 499-518.

Arpino, B., \& Bordone, V. (2014). Does grandparenting pay off? The effect of child care on grandparents' cognitive functioning. Journal of Marriage and Family, 76, $337-351$.

Ates, M. (2017). Does grandchild care influence grandparents' self-rated health? Evidence from a fixed effects approach. Social Science \& Medicine, 190, 67-74.

Baker, L. A., \& Silverstein, M. (2008). Preventive health behaviors among grandmothers raising grandchildren. Journals of Gerontology Series B: Psychological Sciences and Social Sciences, 63, S304-S311. 
Belsky, J., Steinberg, L., \& Draper, P. (1991). Childhood experience, interpersonal development, and reproductive strategy: An evolutionary theory of socialization. Child Development, 62, 647-670.

Blustein, J., Chan, S., \& Guanais, F. C. (2004). Elevated depressive symptoms among caregiving grandparents. Health Services Research, 39, 1671-1690.

Brunello, G., \& Rocco, L. (2016). Is childcare bad for the mental health of grandparents? Evidence from SHARE. IZA Discussion Paper Series No. 10022. Bonn, Germany: Forschungsinstitut zur Zukunft der Arbeit.

Bunch, S. G., Eastman, B. J., \& Moore, R. R. (2007). A profile of grandparents raising grandchildren as a result of parental military deployment. Journal of Human Behaviour in the Social Environment, 15, 1-12.

Burr, J. A., \& Mutchler, J. E. (1999). Race and ethnic variation in norms of filial responsibility among older persons. Journal of Marriage and the Family, 61, 674-687.

Buss, D. M. (2000). The evolution of happiness. American Psychologist, 55, 15-23.

Chen, F., \& Liu, G. (2012). The health implications of grandparents caring for grandchildren in China. The Journals of Gerontology, Series B: Psychological Sciences and Social Sciences, 67, 99-112.

Christeansen, S. G. (2014). The association between grandparenthood and mortality. Social Science and Medicine, 118, 89-96.

Coall, D. A., \& Hertwig, R. (2010). Grandparental investment: Past, present, and future. Behavioral and Brain Sciences, 33, 1-59.

Coall, D. A., \& Hertwig, R. (2011). Grandparental investment: A relic of the past or a resource for the future? Current Directions in Psychological Science, 20, 93-98.

Cong, Z., \& Silverstein, M. (2012). Custodial grandparents and intergenerational support in rural China. In K. K. Mehta \& L. L. Thang (Eds.), Experiencing grandparenthood: An Asian perspective (pp. 109-128). New York: Springer.

Danielsbacka, M., Tanskanen, A. O., Jokela, M., \& Rotkirch, A. (2011). Grandparental child care in Europe: Evidence for preferential investment in more certain kin. Evolutionary Psychology, 9, 3-24.

Danielsbacka, M., \& Tanskanen, A. O. (2016). The association between grandparental investment and grandparents' happiness in Finland. Personal Relationships, 23, 787-800.

Danielsbacka, M., Tanskanen, A. O., Coall, D. A., \& Jokela, M. (2017). Does grandparental investment improve health and well-being of older Europeans? Working Papers on Social and Economic Issues 11/2017. Turku, Finland: Turku Center for Welfare Research.

Deaton, A., \& Stone, A. (2013). Grandpa and the snapper: The wellbeing of the elderly who live with children. NBER Working Paper 19100. Cambridge, MA: National Bureau of Economic Research.

de Waal, F. B. M. (2008). Putting the altruism back into altruism: The evolution of empathy. Annual Review of Psychology, 59, 279-300.

Di Gessa, G., Glaser, K., Price, D., Ribe, E., \& Tinker, A. (2016a). What drives national differences in intensive grandparental childcare in Europe? The Journals of Gerontology Series B: Psychological Sciences and Social Sciences, 71, 141-153.

Di Gessa, G., Glaser, K., \& Tinker, A. (2016b). The health impact of intensive and nonintensive grandchild care in Europe: New evidence from SHARE. The Journals of Gerontology Series B: Psychological Sciences and Social Sciences, 71, 867-879.

Di Gessa, G., Glaser, K., \& Tinker, A. (2016c). The impact of caring for grandchildren on the health of grandparents in Europe: A lifecourse approach. Social Science \& Medicine, 152, 166-175. 


\section{Grandparent wellbeing}

Drew, L. M., \& Silverstein M. (2007). Grandparents' psychological well-being after loss of contact with their grandchildren. Journal of Family Psychology, 21, 372-379.

Dunifon, R., Kopko, K., Chase-Lansdale, P. L., \& Wakschlag, L. (2016). Multigenerational relationships in families with custodial grandparents. In M. Harrington Meyer \& Y. Abdul-Malak (Eds.), Grandparenting in the United States (pp. 133-159). Amityville, NY: Baywood.

Dunifon, R. E., Ziol-Guest, K. M., \& Kopko, K. (2014). Grandparent coresidence and family well-being: Implications for research and policy. The Annals of the American Academy of Political and Social Science, 654, 110-126.

Ellis, R. R., \& Simmons, T. (2014). Coresident grandparents and their grandchildren: 2012. Population characteristics. Washington, DC: United States Census Bureau.

Euler, H. A. (2011). Grandparents and extended kin. In C. A. Salmon \& T. K. Shackelford (Eds.), The Oxford handbook of evolutionary family psychology (pp. 181-210). New York: Oxford University Press.

Friedman, D., Hechter, M., \& Kreager, D. (2008). A theory of the value of grandchildren. Rationality and Society, 20, 31-63.

Fuller-Thomson, E., Minkler, M., \& Driver, D. (1997). A profile of grandparents raising grandchildren in the United States. The Gerontologist, 37, 406-411.

Grinstead, L. N., Leder, S., Jensen, S., \& Bond, L. (2003). Review of research on the health of caregiving grandparents. Journal of Advanced Nursing, 44, 318-326.

Grundy, E. M., Albala, C., Allen, E., Dangour, A. D., Elbourne, D., \& Uauy, R. (2012). Grandparenting and psychosocial health among older Chileans: A longitudinal analysis. Aging \& Mental Health, 16, 1047-1057.

Hadfield, J. C. (2014). The health of grandparents raising grandchildren: A literature review. Journal of Gerontological Nursing, 40, 32-42.

Hansen, T. (2012). Parenthood and happiness: A review of folk theories versus empirical evidence. Social Indicators Research, 108, 29-64.

Hayslip, B., Fruhauf, C. A., \& Dolbin-MacNab, M. L. (2017). Grandparents raising grandchildren: What have we learned over the past decade? The Gerontologist, 57. https://doi.org/10.1093/geront/gnx106

Heywood, E. M. (1999). Custodial grandparents and their grandchildren. The Family Journal, 7, 367-372.

Hilbrand, S., Coall, D., Gerstorf, D., \& Hertwig, R. (2017a). Caregiving within and beyond the family is associated with lower mortality for the caregiver: A prospective study. Evolution and Human Behavior, 38, 397-403.

Hilbrand, S., Coall, D. A., Meyer, A. H., Gerstorf, D., \& Hertwig, R. (2017b). A prospective study of associations among helping, health, and longevity. Social Science \& Medicine, 187, 109-117.

Hrdy, S. B. (1999). Mother Nature: A history of mothers, infants and natural selection. New York: Pantheon.

Hughes, M. E., Waite, L. J., LaPierre, T. A., \& Luo, Y. (2007). All in the family: The impact of caring for grandchildren on grandparents' health. The Journals of Gerontology Series B: Psychological Sciences and Social Sciences, 62, S108-S119.

Keene, J. R., \& Batson, C. D. (2010). Under one roof: A review of research on intergenerational coresidence and multigenerational households in the United States. Sociology Compass, 4, 642-657.

Koivumaa-Honkanen, H., Honkanen, R., Viinamäki, H., Heikkilä, K., Kaprio, J., \& Koskenvuo, M. (2000). Self-reported life satisfaction and 20-year mortality in healthy Finnish adults. American Journal of Epidemiology, 152, 983-991. 
Ku, L.-J. E., Stearns, S. C., van Houtven, C. H., \& Holmes, G. M. (2012). The health effects of caregiving by grandparents in Taiwan: An instrumental variable estimation. Review of Economics of the Household, 10, 521-540.

Ku, L.-J. E., Stearns, S. C., van Houtven, C. H., Lee, S.-Y. D., Dilworth-Anderson, P., \& Konrad, T. R. (2013). Impact of caring for grandchildren on the health of grandparents in Taiwan. Journals of Gerontology, Series B: Psychological Sciences and Social Sciences, 68, 1009-1021.

Lee, S., Colditz, G., Berkman, L., \& Kawachi, I. (2003) Caregiving to children and grandchildren and risk of coronary heart disease in women. American Journal of Public Health, 93, 1939-1944.

Liu, B., Floud, S., Pirie, K., Green, J., Peto, R., \& Beral, V. (2016). Does happiness itself directly affect mortality? The prospective UK Million Women Study. The Lancet, 387, 874-881.

Lummaa, V. (2007). Life-history theory, longevity and reproduction in humans. In R. I. M. Dunbar \& L. Barrett (Eds.), The Oxford handbook of evolutionary psychology (pp. 397-413). New York: Oxford University Press.

Lumsdaine, R. L., \& Vermeer, S. J. C. (2015). Retirement timing of women and the role of care responsibilities for grandchildren. Demography, 52, 433-454.

Lyubomirsky, S., \& Boehm, J. K. (2010). Human motives, happiness, and the puzzle of parenthood: Commentary on Kenrick et al. (2010). Perspectives on Psychological Science, 5, 327-334.

Mahne, K., \& Huxhold, O. (2015). Grandparenthood and subjective well-being: Moderating effects of educational level. Journals of Gerontology, 70, 782-792.

Minkler, M., \& Fuller-Thomson, E. (1999). The health of grandparents raising grandchildren: Results of a national study. American Journal of Public Health, 89, 1384-1389.

Minkler, M., \& Fuller-Thomson, E. (2000). Second time around parenting: Factors predictive of grandparents becoming caregivers for their grandchildren. The International Journal of Aging and Human Development, 50, 185-200.

Musil, C. M., \& Ahmad, M. (2002). The health of grandmothers: A comparison by caregiver status. Journal of Aging and Health, 14, 96-121.

Musil, C. M., Gordon, N. L., Warner, C. B., Zauszniewski, J. A., Standing, T., \& Wykle, M. (2010). Grandmothers and caregiving to grandchildren: Continuity, change and outcomes over 24 months. The Gerontologist, 51, 86-100.

Myrskylä, M., \& Margolis, R. (2014). Happiness: Before and after the kids. Demography, $51,1843-1866$.

Neugarten, B. L., \& Weinstein, K. K. (1964). The changing American grandparent. Journal of Marriage and the Family, 26, 199-204.

Pilkauskas, N. V., \& Dunifon, R. E. (2016). Understanding grandfamilies: Characteristics of grandparents, nonresident parents, and children. Journal of Marriage and Family, $78,623-633$.

Powdthavee, N. (2011). Life satisfaction and grandparenthood: Evidence from a nationwide survey. IZA Discussion Paper Series No. 5869. Bonn: Germany, Forschungsinstitut zur Zukunft der Arbeit.

Reinkowski, J. (2013). Should we care that they care? Grandchild care and its impact on grandparent health. IFO Working Paper No. 165. Leibniz: Leibniz Institute for Economic Research at the University of Munich.

Ross, M. E. T., \& Aday, L. A. (2006) Stress and coping in African American grandparents who are raising their grandchildren. Journal of Family Issues, 27, 912-932. 


\section{Grandparent wellbeing}

Ruggles, S. (2003) Multigenerational families in nineteenth-century America. Continuity and Change, 18, 139-165.

Sear, R., \& Coall, D. A. (2011). How much does family matter? Cooperative breeding and the demographic transition. Population and Development Review, 37, 81-112.

Sear, R., \& Mace, R. (2008). Who keep children alive? A review of the effects of kin on child survival. Evolution and Human Behavior, 29, 1-18.

Sheng, X., \& Settles, B. H. (2006). Intergenerational relationships and elderly care in China: A global perspective. Current Sociology, 54, 293-313.

Silverstein, M., Cong, Z., \& Li, S. (2006). Intergenerational transfers and living arrangements of older people in rural China: Consequences for psychological wellbeing. The Journals of Gerontology, Series B: Psychological Sciences and Social Sciences, 61, 256-266.

Somary, K., \& Stricker, G. (1998). Becoming a grandparent: A longitudinal study of expectations and early experiences as a function of sex and lineage. The Gerontologist, $38,53-61$.

Speare, A., \& Avery, R. (1993). Who helps whom in older parent-child families? Journal of Gerontology, 48, S64-S73.

Stanca, L. (2012). Suffer the little children: Measuring the effects of parenthood on wellbeing worldwide. Journal of Economic Behavior \& Organization, 81, 742-750.

Strawbridge, W. J., Wallhagen, M. I., Shema, S. J., \& Kaplan, G. A. (1997). New burdens or more of the same? Comparing grandparent, spouse, and adult-child caregivers. The Gerontologist, 37, 505-510.

Strom, P. S., \& Strom, R. D. (2011). Grandparent education: Raising grandchildren. Educational Gerontology, 37, 910-923.

Tanskanen, A. O., Danielsbacka, M., \& Coall, D. A. (2017). Entry into grandparenthood and subjective well-being among older Europeans. Working Papers on Social and Economic Issues 6/2017. Turku, Finland: Turku Center for Welfare Research.

Taylor, M. F., Marquis, R., Batten, R., \& Coall, D. A. (2016). Understanding the mental health travails of custodial grandparents. Occupational Therapy in Mental Health, 32, 259-280.

Thang L. L., \& Mehta, K. K. (2012) Conclusion: Change and continuity of grandparenting in contemporary Asia. In K. K. Mehta \& L. L. Thang (Eds.), Experiencing grandparenthood: An Asian perspective (pp. 145-157). New York: Springer.

Thiele, D. M., \& Whelan, T. A. (2008). The relationship between grandparent satisfaction, meaning, and generativity. The International Journal of Aging and Human Development, $66,21-48$.

Thomas, J. L. (1986). Gender differences in satisfaction with grandparenting. Psychology and Aging, 1, 215-219.

Tsai, F.-J., Motamed, S., \& Rougemont, A. (2013). The protective effect of taking care of grandchildren on elders' mental health? Associations between changing patterns of intergenerational exchanges and the reduction of elders' loneliness and depression between 1993 and 2007 in Taiwan. BMC Public Health, 13, 1-9.

Youngblut, J. M., Brooten, D., Blais, K., Kilgore, C., \& Yoo, C. (2015). Health and functioning in grandparents after a young grandchild's death. Journal of Community Health, 40, 956-966. 


\section{What about aunts and uncles?}

Previous chapters have outlined the significance of grandparent-grandchild relationships. If we consider other intergenerational relationships in addition to those between grandparents, parents and grandchildren, the obvious focus is the relationships between aunts/uncles and nieces/nephews. Aunts/uncles share approximately the same amount of genes with their nieces/nephews as grandparents share with their grandchildren (i.e., the average number of shared genes between aunts/ uncles and nieces/nephews is 25 per cent) (see Figure 8.1 ). Thus, from the inclusive fitness perspective (Hamilton, 1964), the reasons why aunts/uncles choose to invest in their nieces/nephews are similar to the reasons why grandparents choose to invest in their grandchildren. Average relatedness to nieces/nephews who are monozygotic twins is even higher, and it is actually the same as relatedness to ones' own children (50 per cent), whereas the average number of shared genes with nieces/nephews from half-siblings is 12.5 per cent (see Figures 8.2 and 8.3).

Similar to grandparents, aunts and uncles often serve as alloparents who are highly involved in the lives of their nieces and nephews (Hrdy, 1999, 2009). Thus, aunts and uncles belong to the social group that is described as "very important non-parental persons" for a child (Chang et al., 2010). However, relationships between aunts/uncles and nieces/nephews are in many ways different from relationships between grandparents and grandchildren. An important element related to this specific family relationship is that aunts and uncles may serve as important confederates for a child.

Another feature that separates aunts and uncles from grandparents is that they belong to a different family generation, meaning that these two groups of alloparents typically are in different life stages. When children are small, aunts and uncles often have their own small children or are in the position where they may have children in the future, whereas grandparents likely do not have current small children or will not have children in the future themselves. Moreover, in contrast to grandmothers and grandfathers from same lineage, aunts and uncles do not usually live with each other in the same households in contemporary Western societies. Thus, the investments of aunts and uncles in their nieces and nephews are more independent than the investments of grandmothers and grandfathers. This means that studies examining the investment behaviours of aunts and uncles may provide important answers to many evolutionary and social science hypotheses 


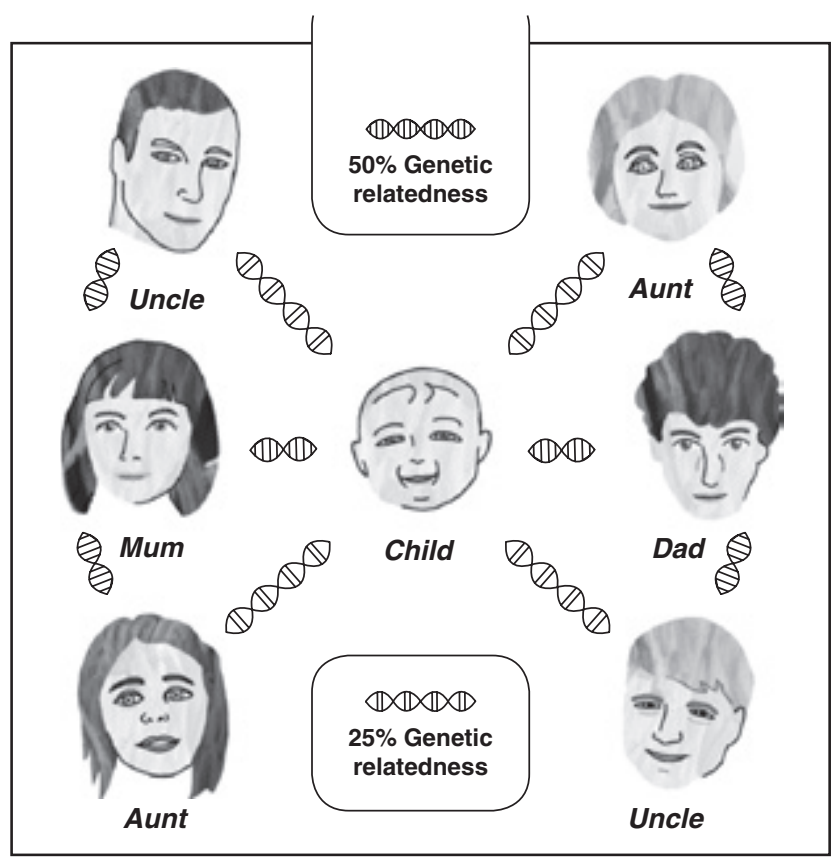

Figure 8.1 Relatedness among aunts, uncles, parents and niece/nephew. Picture designed by Lasse Määttä.

that cannot be studied as reliably among grandparents. Although aunts and uncles participate in the lives of their nieces and nephews in several ways, fewer studies about aunts and uncles have been published than studies about grandparents. The term "forgotten kin" appropriately describes the situation of aunts and uncles in family studies (Milardo, 2010).

In this chapter, we consider relationships between aunts/uncles and nieces/ nephews. First, we discuss which factors shape adult sibling relationships because these relations may significantly influence interactions between aunts/uncles and nieces/nephews. Next, we introduce the factors that are associated with kin investments made by aunts and uncles. Then, we discuss whether the socioeconomic status of aunts/uncles correlates with that of nieces/nephews. Finally, we present some concluding remarks.

\section{Adult sibling relationships}

Relationships between aunts/uncles and nieces/nephews are correlated with the relationships between adult siblings, namely, the child's parents and his or her siblings. The sibling relationship is a unique family relationship in humans, mainly because it is the longest lasting social tie in our species (Cicirelli, 1995). Sibling relationships are also ambivalent by nature, meaning that they include altruism, mutual support and emotional closeness as well as conflicts and quarrels. 


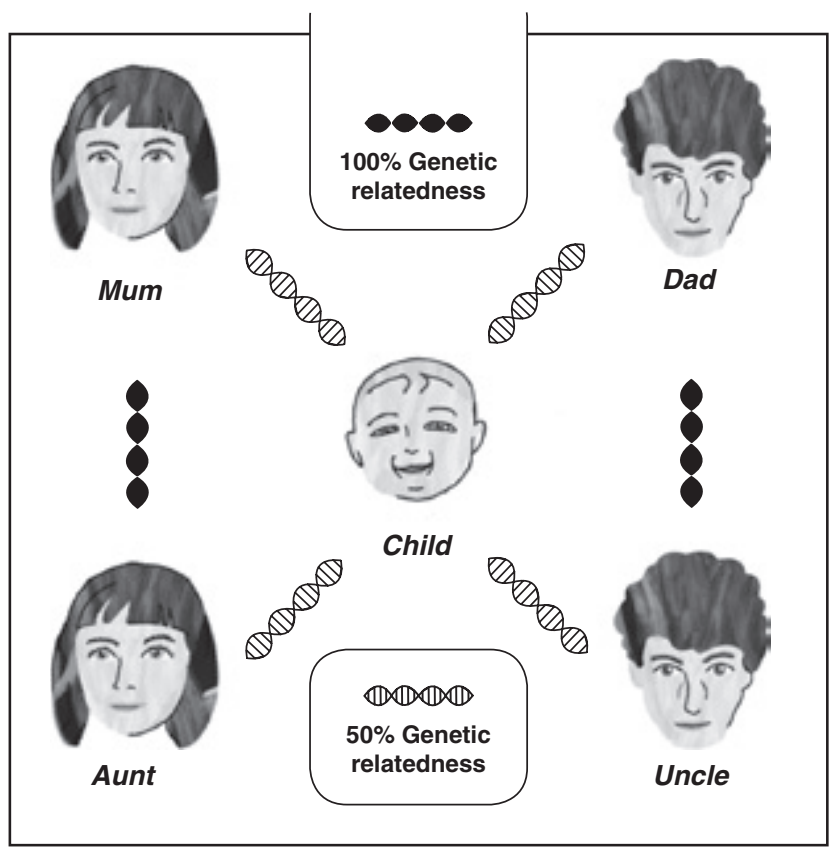

Figure 8.2 Relatedness among aunt, uncle, parents and niece/nephew when maternal aunt and paternal uncle are monozygotic twins to mother and father. Picture designed by Lasse Määttä.

Conflicts between siblings are more common in early and late childhood when the competition over parental resources is the highest, whereas in adulthood, siblings tend to provide support and resources to one another (Pollet \& Hoben, 2011).

From an evolutionary perspective, two important factors that potentially shape adult sibling relationships are sex and genetic relatedness. In previous studies, a good relationship with one's sisters is associated with increased wellbeing and happiness and decreased levels of depression among both women and men, whereas good relationships with one's brothers are not similarly associated with these outcomes (Pollet \& Hoben, 2011). These findings are consistent with the sex effect hypothesis that close kin ties with women may be more important than similar ties with men.

Genetic relatedness has also been shown to correlate with the quality of sibling relationships, as full siblings have more contact and report more emotional closeness towards each other than half-siblings (Pollet, 2007; Tanskanen \& Danielsbacka, 2014). This finding was also observed in a Mormon Fundamentalist population, where traditional values prevent members from favouring full siblings over half-siblings (Jankowiak \& Diderich, 2000). Moreover, an interesting set of studies has tested the potential effect of genetic relatedness using twin data. Monozygotic twin pairs, who share 100 per cent of the same genes, report more closeness, cooperation and familiarity towards each other than dizygotic 


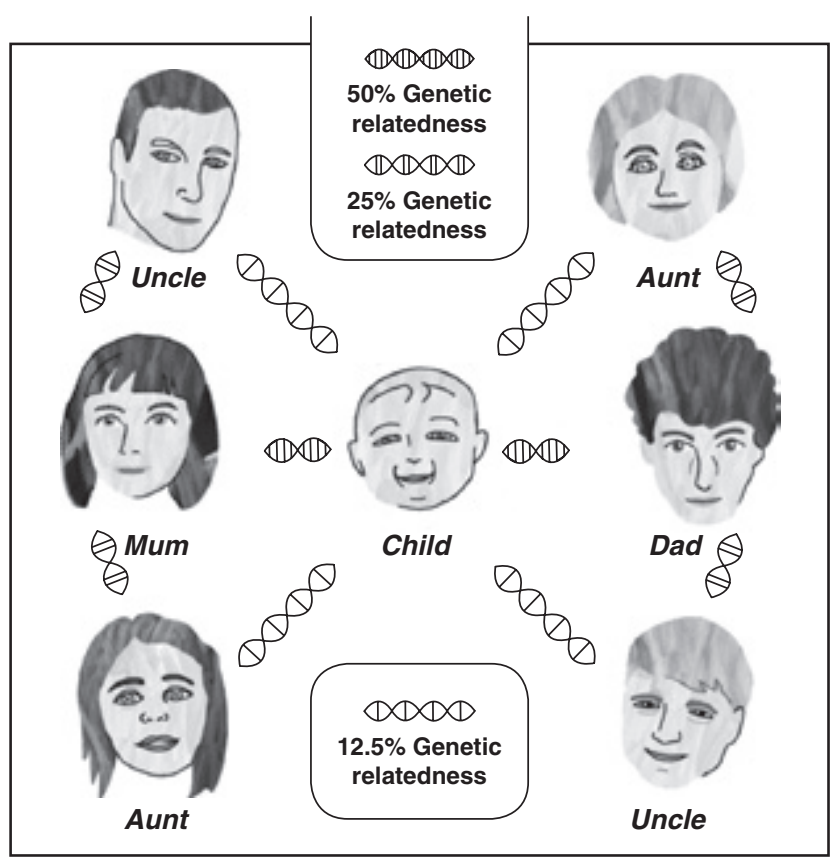

Figure 8.3 Relatedness among aunts, uncles, parents and niece/nephew when aunts and uncles are half-siblings to mother and father. Picture designed by Lasse Määttä.

twin pairs, who share around 50 per cent of the same genes (e.g., Neyer, 2002; Segal et al., 2003). These results are consistent with the inclusive fitness theory that predicts an increase in the extent of kin investments as the degree of genetic relatedness increases.

Siblings typically belong to the same generation, and thus, they also experience significant life events (e.g., entry into parenthood) at approximately the same time. When both siblings have children, they tend to have similar needs and may provide mutual help in child care and other issues (Tanskanen \& Danielsbacka, 2017a). Moreover, siblings' children are often playmates, perhaps making their parents also closer to one another. For childless individuals, the experience of having a niece or nephew may provide them an opportunity to engage in childbearing activities and form closer bonds with their siblings who have children. Individuals who have a niece or nephew may also encourage a renewal of sibling relationships, which could have been less active after the siblings moved away from their parents' home.

\section{Kin investments by aunts and uncles}

Evolutionary researchers postulate that aunts and uncles should invest in their kin in a manner consistent with their reproductive interests (Pollet \& Hoben, 2011). 
From a reproductive perspective, important factors dividing investments in nieces and nephews are sex, lineage and genetic relatedness. These factors are also associated with grandparental investments in grandchildren (e.g., Danielsbacka et al., 2011; see Chapter 4). As a result of the sex effect, aunts are predicted to invest more than uncles. Because of paternity uncertainty, maternal aunts and uncles should invest more than paternal aunts and uncles. Finally, according to the inclusive fitness theory, the investment is predicted to increase as the degree of genetic relatedness between kin increases.

\section{Sex and lineage}

During recent decades, the sex and linage differences in kin investments by aunts and uncles have been investigated primarily in studies in which nieces and nephews are the informants. Nieces and nephews may report the investments made by aunts and uncles more reliably than aunts and uncles, whose reports could be biased because aunts and uncles may claim that they treat all nieces and nephews equally. This bias may be particularly observed in societies that strongly encourage equal treatment of all family members. One of the first studies to examine the roles of sex and lineage in relationships between aunts or uncles and nieces or nephews analysed a sample of 285 college students in Pittsburgh (Gaulin et al., 1997). These college students were asked to report how much concern aunts and uncles have shown towards their welfare. In the study, only biological relationships were included, and aunts and uncles were separated by sex and lineage. Consistent with the evolutionary prediction based on paternity uncertainty, Pittsburgh area college students reported that maternal aunts and uncles showed more concern about their welfare than paternal aunts and uncles. The authors also considered that the phrase "concern about welfare" can bias the responses. For instance, if one has only paternal aunts or uncles, she or he may report higher rates of concern by paternal kin than individuals with both paternal and maternal aunts and uncles because the first group has no reference category with which to compare (i.e., they do not have maternal aunts or uncles who can invest more than paternal relatives).

Later, partly the same group of scholars (McBurney et al., 2002) performed a similar survey of Orthodox Jewish college students. In this population, infidelity in marriage is highly discouraged, leading to the assumption that paternity uncertainty should not play an important role among the members of this population. When comparing the "concern about welfare" of aunts and uncles between the Pittsburgh and Orthodox Jewish samples, the authors observed quite similar results. Based on these findings, they concluded that the biased investments by aunts and uncles may reflect the uncertain paternity in human evolutionary history rather than in present-day societies.

One of the main limitations in several studies of the biased investment patterns of aunts and uncles is that they have used small-scale and non-representative surveys of university students, that is to say "WEIRD" (Western, Educated, Industrialised, Rich and Democratic) samples (Henrich et al., 2010). Another 
important limitation may be that the information about the investments of aunts and uncles is gathered from the perspective of nieces and nephews because nieces and nephews tend to have a limited knowledge of background characteristics related to their aunts and uncles. Thus, several potential confounding factors could be missing in these studies.

A large-scale and nationally representative study of two generations of Finnish aunts and uncles addressed some of these limitations (Tanskanen \& Danielsbacka, 2017b). Participants included older adults (aged between 62 and 67 years) and younger adults (aged between 19 and 50 years). In this study, kin investments were measured by contact frequency, which is postulated to be a good proxy for overall investment because several other types of investment (e.g., child care and emotional support) require some sort of contact. The contact frequency variable included both face-to-face contact and other types of contact (e.g., contact via phone or Internet). First, aunts and uncles reported more contact with their sister's children than their brother's children. This finding is consistent with the evolutionary prediction based on paternity uncertainty. Next, the preferential investment hypothesis was investigated among aunts and uncles (see Laham et al., 2005; Chapters 2 and 4). For aunts and uncles, the preferential investment hypothesis predicts that if aunts and uncles have the option to invest in both their sisters' and brothers' children, they will invest more in their sisters' children than in their brothers' children. In support of the hypothesis, when individuals' sisters and brothers had children, these individuals invested more in their sisters' children.

\section{Genetic relatedness}

Individuals share an average of 25 per cent of their genes with their nieces and nephews from full siblings and 12.5 per cent of their genes with nieces and nephews from half-siblings. Based on the inclusive fitness theory (Hamilton, 1964), individuals will invest more time and resources in their full siblings' children than in their half-siblings' children. However, few studies have investigated this prediction.

Using the above-mentioned two-generational Finnish surveys, the role of genetic relatedness in contact frequencies between aunts/uncles and nieces/nephews was investigated (Tanskanen \& Danielsbacka, 2014). Because childhood proximity between siblings (i.e., between the children's parents and aunts or uncles) is likely to influence kin relationships during adulthood, the authors divided half-sibling relationships into relationships between maternal half-siblings and paternal halfsiblings. Siblings who have the same mother were assumed to have been raised together because in Finland, children typically stay with their mother if parents separate. Consistent with the inclusive fitness theory, respondents reported more contact with their nieces and nephews from full siblings than from half-siblings, even when the lineage of half-sibling relatedness, age differences among siblings and several other factors were taken into account. Moreover, more contacts were reported with nieces and nephews from sisters than brothers, which is consistent with the sex effect hypothesis. 
Two studies have used twin data and investigated relationships between aunts/ uncles and nieces/nephews (Segal \& Marelich, 2011; Segal et al., 2007). Studies with twin data provide unique information on how genetic relatedness shapes intergenerational relationships, as monozygotic twins share 100 per cent of the same genes, meaning that they are "genetic parents" to their nieces and nephews who, correspondingly, are "genetic children" to their aunts and uncles. In contrast, dizygotic twins are related to their nieces and nephews to a similar extent as any other full siblings, making them an important control group. Both monozygotic and dizygotic twins are usually raised together, and thus, they have grown up in a shared environment. First, the authors analysed data from 248 monozygotic twins and 75 dizygotic twins (Segal et al., 2007). Their analyses were based on a 12-item closeness questionnaire in which they asked responding aunts and uncles about the closeness of their relationship with a specific niece or nephew (e.g., whether they like to be with their niece or nephew and how close they feel to their niece or nephew). Monozygotic twins expressed greater closeness towards their nieces and nephews than did dizygotic twins. These results were consistent with the inclusive fitness theory. Later, a replicate study performed by the same authors with a larger sample including 419 twins obtained results that were similar to the original study (Segal \& Marelich, 2011).

\section{Other factors relating to investments by aunts and uncles}

In addition to sex, lineage and genetic relatedness, other factors are associated with investments by aunts and uncles. Studies have identified several features that may shape the kin relationships, and these factors are related to the characteristics of nieces and nephews, their parents and their aunts and uncles themselves.

Kin relationships tend to vary throughout life. From the perspective of aunts and uncles, two important factors potentially shaping their behaviours are the existence of their own children and the existence of a spouse, as these factors are likely related to the reproductive interests of aunts and uncles. First, individuals share 50 per cent of their genes with their own children and 25 per cent with their nieces and nephews from full siblings; thus, from an inclusive fitness perspective, when "all else is equal", individuals experience greater benefits when they invest resources in their own children rather than in nieces and nephews. Consistent with this hypothesis, women without children tend to invest more in their nieces and nephews than those with children (Pollet et al., 2006; Tanskanen, 2015).

Second, having a spouse could be a factor because it increases the likelihood the individual will have children in the future. Thus, when individuals have a spouse, they may be willing to invest more in their future reproduction than in supporting their siblings in their reproduction-related efforts. Fertility declines with age among both men and women, but men can potentially have children until they die, whereas women cannot have children after menopause. Because age is related to individuals' reproductive views, older aunts in particular, who are beyond their fertile years, may gain fitness benefits by investing in their nieces and nephews. In contrast, if aunts and uncles are younger and can potentially have 
children in the future, they may be more willing to invest in having their own children than in their extended kin (Hughes, 1988).

The ages of nieces and nephews may be a factor because younger children typically need more support than older children. Once again, for childless older aunts and uncles, investments in their nieces and nephews with high reproductive potential could be the best strategy to increase their own inclusive fitness. The number of siblings and the number of siblings with children (i.e., nieces and nephews) may significantly influence the level of investments by aunts and uncles. Because aunts' and uncles' time and other resources are limited, every new kin member is likely to diminish the possibilities for investment in other relatives. If aunts and uncles have nieces or nephews from several siblings, they may be forced to choose in whom they will and will not invest. Although the total number of nieces and nephews may also have an effect, the number of "niece and nephew sets" (i.e., nieces and nephews from a certain sibling) has a greater effect (e.g., Tanskanen \& Danielsbacka, 2017b). It appears that aunts and uncles face the same dilution effect as grandparents (see Chapter 4).

The socioeconomic status of aunts and uncles is related to their opportunities to provide support for their descendants. Thus, the financial status of aunts and uncles is important in their ability to provide monetary assistance and gifts because individuals with more resources can invest in kin to a greater extent. In addition, the educational level of aunts and uncles divides their investments in nieces and nephews, as higher educated aunts and uncles have been shown to have more contact with their nieces and nephews than their lower educated counterparts (Pollet \& Hoben, 2011; Tanskanen \& Danielsbacka, 2014).

One of the most robust findings in the kin investment literature is that geographical distance tends to shape the investment behaviours of individuals. When the geographical distance between aunts/uncles and nieces/nephews increases, the opportunities for face-to-face contact decrease (Pollet \& Hoben, 2011). Finally, the quality of relationships between siblings may influence the frequency of contacts between aunts and uncles with their nieces and nephews. In practice, similar to grandparent-grandchild contacts, parents can act as "gatekeepers" by either enhancing or preventing the interactions between aunts/uncles and nieces/nephews. If siblings have a good relationship, aunts and uncles are also likely involved in the lives of their nieces and nephews. However, if severe conflicts exist between siblings, aunts and uncles may have no contact with nieces and nephews in the worst-case scenario. According to empirical evidence, the quality of relationships between siblings is indeed related to the amount of interaction between aunts/uncles and nieces/nephews. Based on data from Finland, an increase in the emotional closeness between siblings was associated with the increased contact frequency between aunts/uncles and nieces/nephews (Tanskanen \& Danielsbacka, 2017b).

\section{Aunts, uncles and social stratification}

In Chapter 6, we reviewed social stratification studies investigating associations between the social status of grandparents and grandchildren. Here, we review 
the relatively scarce number of previous social stratification studies investigating whether the socioeconomic status of aunts and uncles correlates with that of their nieces and nephews. Because the higher rates of divorce in Western countries may reduce the direct influence of parents, aunts and uncles may play an important role in status attainment in contemporary societies. Moreover, the increased number of childless individuals suggests that more aunts and uncles do not have their own children, and thus, they may have greater opportunities to influence the lives of their nieces and nephews.

Compared to studies concentrating on the potential effect of grandparental status on grandchild status, the intergenerational status attainment that aunts and uncles potentially transmit towards their nieces and nephews has several strengths (Lehti \& Erola, 2017). When studying the "grandparent effect", scholars are forced to limit their investigation to a relatively small number of kin members. Every individual has four biological grandparents, whether they are living or already passed away. However, an individual may have many more aunts and uncles. For instance, if a child's mother and father each have four siblings, then the child has eight aunts or uncles. When an individual has a larger number of aunts and uncles, the variance between these relatives' socioeconomic statuses is also likely to increase because they usually do not have totally similar statuses. Moreover, the previously studied grandparent generation has typically been born at a time before educational expansion occurred, and thus most grandparents achieved comparatively low educational levels. In contrast, the generation of aunts and uncles that is typically studied is younger and has had more opportunities to achieve higher levels of education than those in a typical grandparent generation. Thus, the variation in educational attainment among aunts and uncles is also higher.

There are several reasons to believe aunts and uncles have different effects on status attainment. Perhaps the most important differences are based on two important evolutionary variables, namely, sex and lineage. As discussed above, aunts tend to invest more time and resources in their nieces and nephews than uncles, and individuals will invest more in their sisters' children than in their brothers' children. Thus, the status of aunts may be more important than the status of uncles, and the status of maternal aunts or uncles more important than the status of paternal aunts or uncles. According to a recent study using high-quality register data from Finland, the high educational level of maternal aunts and uncles compensated for the low educational level of parents to a greater extent than the status of paternal aunts and uncles (Lehti \& Erola, 2017). In addition, a US study showed that the better educational achievements (measured by years of education) by maternal aunts and uncles correlated with better educational attainments of nieces and nephews (Loury, 2006). Unfortunately, the US study had information only on maternal kin and thus it was not possible to study the potential impact of paternal aunts and uncles.

The proximate mechanisms behind the potential influences of aunts and uncles are unclear. One potential mechanism is that the direct investments in nieces and nephews (e.g., spending time with them or providing money) or indirect investments via siblings (e.g., help with household costs or other issues) may make a 
difference. Aunts and uncles may also serve as role models or mentors for their nieces and nephews (Milardo, 2010), which influences the children. Obviously, in this case, the influence is probably greater on children who have more contact with their aunts and uncles. However, the potential aunt or uncle effect does not necessarily depend on face-to-face contact. For instance, geographical proximity was not associated with the correlations between the status of aunts/uncles and nieces/nephews in a US study (Jæger, 2012). According to this study, the correlation between the socioeconomic status of grandparents and grandchildren could be almost exhaustively explained by the status of aunts and uncles, indicating that the status of aunts and uncles but not grandparents may be transmitted over generations.

\section{Conclusions}

In addition to grandparents, aunts and uncles often represent an important group of alloparents who invest time and resources in their nieces and nephews. Similar to grandparents, all aunts and uncles do not invest equally in their descendants, and the investment of aunts and uncles varies by evolutionarily relevant variables: genetic relatedness, sex and lineage. Aunts tend to invest more than uncles do, and maternal aunts and uncles invest more than paternal aunts and uncles do. In addition, individuals typically invest in their full siblings' children more than in their half-siblings' children and more in the children of identical twins than of non-identical twins. Apart from genetic relatedness, sex and lineage, several socio-demographic factors shape intergenerational relationships between aunts and uncles and nieces and nephews. For instance, when the geographical distance between these relatives increases, the investment in the younger family generation decreases, and when the emotional closeness among siblings increases, the investment aunts and uncles channel towards their nieces and nephews also increases. Finally, there is some evidence indicating that the socioeconomic statuses of aunts and uncles can be transmitted to nieces and nephews; however, more studies on this topic are necessary.

\section{References}

Chang, E. S., Greenberger, E., Chen, C., Heckhausen, J., \& Farruggia, S. P. (2010). Nonparental adults as social resources in the transition to adulthood. Journal of Research on Adolescence, 20, 1065-1082.

Cicirelli, V. G. (1995). Sibling relationships across the life span. New York: Plenum.

Danielsbacka, M., Tanskanen, A. O., Jokela, M., \& Rotkirch, A. (2011). Grandparental child care in Europe: Evidence for preferential investment in more certain kin. Evolutionary Psychology, 9, 3-24.

Gaulin, S. J. C., McBurney, D. H., \& Brakeman-Wartell, S. L. (1997). Matrilateral biases in the investment of aunts and uncles: A consequence and measure of paternity. Human Nature, 8, 139-151.

Hamilton, W. D. (1964). The genetical evolution of social behaviour (I and II). Journal of Theoretical Biology, 7, 1-52. 
Henrich, J., Heine, S. J., \& Norenzayan, A. (2010). The weirdest people in the world. Behavioral and Brain Sciences, 33, 61-83.

Hrdy, S. B. (1999). Mother Nature: Natural selection and the female of the species. London: Chatto \& Windus.

Hrdy, S. B. (2009). Mothers and others: The evolutionary origins of mutual understanding. Cambridge, MA: The Belknap Press of Harvard University Press.

Hughes, A. L. (1988). Evolution and human kinship. New York: Oxford University Press.

Jæger, M. M. (2012). The extended family and children's educational success. American Sociological Review, 77, 903-922.

Jankowiak, W., \& Diderich, M. (2000). Sibling solidarity in a polygamous community in the USA: Unpacking inclusive fitness. Evolution and Human Behavior, 21, 125-139.

Laham, S. M., Gonsalkorale, K., \& von Hippel, W. (2005). Darwinian grandparenting: Preferential investment in more certain kin. Personality and Social Psychology Bulletin, $31,63-72$.

Lehti, H., \& Erola, J. (2017). How do aunts and uncles compensate for low parental education in children's educational attainment? In J. Erola \& E. Kilpi-Jakonen (Eds.), Social inequality across the generations: The role of compensation and multiplication in resource accumulation (pp. 89-111). Cheltenham, UK: Edward Elgar.

Loury, L. D. (2006). All in the extended family: Effects of grandparents, aunts, and uncles on educational attainment. The American Economic Review, 96, 275-278.

McBurney, D. H., Simon, J., Gaulin, S. J. C., \& Geliebter, A. (2002). Matrilateral biases in the investment of aunts and uncles: Replication in a population presumed to have high paternity certainty. Human Nature, 13, 391-402.

Milardo, R. M. (2010). The forgotten kin: Aunts and uncles. Cambridge: Cambridge University Press.

Neyer, F. J. (2002). Twin relationships in old age: A development perspective. Journal of Personality and Social Relationships, 19, 155-177.

Pollet, T. V. (2007). Genetic relatedness and sibling relationship characteristics in a modern society. Evolution and Human Behavior, 28, 176-185.

Pollet, T. V., \& Hoben, A. D. (2011). An evolutionary perspective on siblings: Rivals and resources. In C. A. Salmon \& T. K. Shackelford (Eds.), The Oxford handbook on evolutionary family psychology (pp. 128-148). New York: Oxford University Press.

Pollet, T. V., Kuppens, T., \& Dunbar, R. I. M. (2006) When nieces and nephews become important: Differences between childless women and mothers in relationships with nieces and nephews. Journal of Cultural and Evolutionary Psychology, 4, 83-93.

Segal, N. L., Hershberger, S. L., \& Arad, S. (2003). Meeting one's twin: Perceived social closeness and familiarity. Evolutionary Psychology, 1, 70-95.

Segal, N. L., \& Marelich, W. D. (2011). Social closeness and gift giving by twin parents toward nieces and nephews: An update. Personality and Individual Differences, 50, $101-105$.

Segal, N. L., Seghers, J. P., Marelich, W. D., Mechanic, M., \& Castillo, R. (2007). Social closeness of monozygotic and dizygotic twin parents toward their nieces and nephews. European Journal of Personality, 21, 487-506.

Tanskanen, A. O. (2015). Childlessness and investment in nieces, nephews, aunts, and uncles in Finland. Journal of Biosocial Science, 47, 402-406.

Tanskanen, A. O., \& Danielsbacka, M. (2014). Genetic relatedness predicts contact frequencies with siblings, nieces and nephews: Results from the generational transmissions in Finland surveys. Personality and Individual Differences, 55, 5-11. 


\section{What about aunts and uncles?}

Tanskanen, A. O., \& Danielsbacka, M. (2017a). Parenthood status and relationship quality between siblings. Journal of Family Studies, 1-12.

Tanskanen, A. O., \& Danielsbacka, M. (2017b). Contact frequencies with nieces and nephews in Finland: Evidence for the preferential investment in more certain kin theory. Journal of Social and Personal Relationships, 34, 26-43. 


\section{An evolutionary social science approach}

Taking steps toward a multidisciplinary framework is not easy, because the involved disciplines have different goals, terminologies, assumptions, methods, and to some extent conflicting worldviews.

(Coall \& Hertwig, 2010, p. 40)

Despite these challenges, we are convinced that the research programme that considers theories and findings from different disciplines is crucial to achieving a comprehensive picture of intergenerational relations and human family life. As defined in the beginning of this book, one of our aims is to decrease the boundaries between social science scholars and evolutionary scholars by bringing together research from different fields of study and giving an extensive account of current issues about intergenerational family relations. We began by defining humans as a cooperative breeding species, introducing key demographic and societal trends that potentially shape intergenerational relations, discussing the problems related to intradisciplinarity and defining the aims of the book (Chapter 1). We then presented evolutionary and social science theories on intergenerational relations (Chapter 2) and a basic structure of these relations (Chapter 3). Furthermore, we reviewed the existing literature on the factors that are known to be associated with intergenerational relations (Chapter 4) and studies that have examined whether grandparental investment is associated with parental fertility (Chapter 5), grandchild outcomes (Chapter 6) and the wellbeing of grandparents themselves (Chapter 7). Finally, we discussed the intergenerational transfers made by aunts and uncles, who share approximately the same amount of genes with their nieces and nephews shared by grandparents with their grandchildren but who are rarely studied (Chapter 8).

In this concluding Chapter 9, we outline the evolutionary social science approach to intergenerational family relations, which goes well beyond the traditional nature-versus-nurture distinction and provides pathways for illustrating how different perspectives on intergenerational relations can benefit one another and be combined. First, we present the reservations related to historical and cultural traditions and how they may influence the usefulness of the evolutionary social science approach. Next, we explicitly describe the evolutionary social science research programme and provide hypotheses that can be formulated from it. 


\section{Time and place}

Human life is always bound to the time and place in which one lives. This means that cultural traditions and historical period shape individuals' social behaviours and family structures. Next, we present two different societal circumstances that are clear examples of the ways in which culture shapes human family behaviour: patrilocality and the rise of the modern welfare states.

As argued earlier in this book, in contemporary Western societies, one of the most robust differences in grandparental investment behaviour is that maternal grandparents invest more than paternal ones do (e.g., Danielsbacka et al., 2011; see Chapter 4). However, this matrilateral bias may be overridden if the cultural context favours patrilocality (Pashos, 2000, 2017). In patrilocal societies, a couple and their children typically live with or near the husband's parents, whereas in matrilocal societies, they live near the wife's parents. This residence pattern obviously affects the amount of contact between the grandparents and grandchildren and thus how emotionally close to the grandchildren they are and how many opportunities they have to invest in them. Therefore, in patrilocal populations, paternal grandparents have more opportunities to form emotionally close ties with grandchildren than maternal grandparents do, whereas in matrilocal populations, the opposite is true (e.g., Kaptijn et al., 2013; Leonetti et al., 2007).

We argue that contemporary Western societies, which typically lack clear and strongly normative patrilocal or matrilocal residence patterns, provide a good context for the study of differences in intergenerational relations because in these societies, people can largely choose the relatives with whom they are willing to interact. When cultural traditions do not promote or even force individuals to behave in a certain way, deeply rooted evolutionary behavioural tendencies based on emotions and natural instincts may become more apparent.

In addition, the rise of welfare states means that a huge amount of welfare responsibilities that have traditionally been carried by families have now been transferred to the state. As the dependence on informal kin support decreases, individuals can more voluntarily choose the relatives with whom they want to spend time and support. Thus, the liberalisation of familial and sex roles, the loosening of strict behavioural norms and the institutional development of the welfare state have diminished the strong role of restrictive cultural practices in intergenerational relations. Some have proposed that these processes have also diminished the role of kinship (e.g., Giddens, 1991) or biologically rooted factors in family life (e.g., Carsten, 2000). However, the opposite situation could also be true. That is, biological factors could shape intergenerational relations to a larger extent than in societies where human behaviour is highly regulated by cultural norms. Thus, we argue that human behaviour in liberalised societies does not become more random; instead, it may become more influenced by evolved predispositions.

In fact, studies conducted in contemporary Western societies have consistently found that intergenerational relations are shaped by evolutionarily important factors, specifically, genetic relatedness, sex and lineage (e.g., Salmon \& Shackelford, 2011; see Chapter 4). As the power of restrictive cultural traditions 
is decreasing in Western states, evolutionarily adapted behavioural tendencies may become clearer. For this reason, it can also be assumed that the evolutionary social science research programme will be an especially useful approach to studying intergenerational relations in contemporary Western societies. Furthermore, the evolutionary social science approach may be better at predicting biased kin investment rather than the potential outcomes of kin investment. We will discuss this topic next.

\section{Outcomes of current grandparental investment}

In Chapters 5, 6 and 7, we presented current studies examining the outcomes of grandparental investment in the case of parental fertility, child development and grandparent wellbeing. Many studies have focused on these topics; however, the results for contemporary societies remain mixed.

Studies have shown that in pre-modern and historical populations, grandparental investment is often correlated with improved fertility for adult children and improved grandchild survival (e.g., Sear \& Coall, 2011; see Chapters 5 and 6). However, there is no clear evidence that grandparental investment continues to be associated with adult children's fertility in contemporary Western societies. The lack of consistent results on fertility outcomes of kin support in contemporary societies may be due to the fact that modern Western welfare states are very different from traditional and historical societies. In affluent welfare states with very low infant and child mortality, maternity leaves and public child care services, kin support is no longer as crucial for reproduction and survival as it was in previous populations.

A clear limitation of the studies on grandchild outcomes in contemporary Western societies is that their results are mainly based on correlational evidence. Because correlation does not mean causality, the findings may reflect differences between children rather than within-child variation over time (meaning that an increase or decrease in the amount of grandparental investment would have direct influence on grandchild wellbeing). A recent study showed that the association between grandparental investment and child outcomes in contemporary UK may not be causal (Tanskanen \& Danielsbacka, 2017). However, many more longitudinal studies with methods detecting causal association between grandparental investment and child wellbeing are required before justifiable conclusions can be made.

Overall, it may be difficult to find evidence that grandparental investment is associated with either parental fertility or child outcomes because there are now more macro-level factors that can confound associations between kin investment and kin outcomes. Based on the current evidence, perhaps the most relevant (although not exhaustive) argument is that the potential outcomes of grandparental investment are likely to be highly dependent on environmental circumstances. For instance, grandparental support can be especially valuable for children during family crises (e.g., Sear \& Coall, 2011; see Chapter 5). Therefore, the potential "grandparent effect" may be visible in "risky" situations in which grandchildren 
are forced to handle extra stress, for instance, severe parental illness, divorce or even death. In these family circumstances, grandparents can help grandchildren, for instance, by acting as the grandchildren's guardians.

With regard to the direct outcomes for grandparents themselves, it has been proposed that there are some health and wellbeing benefits from active grandparenting, as long as the grandparenting duties are not overwhelming (Coall \& Hertwig, 2010, 2011). One may argue that if grandparental caregiving offered a selective advantage in our evolutionary past (Hawkes \& Coxworth, 2013), contemporary grandparents should have an evolutionary propensity towards helping their descendants (Hilbrand et al., 2017). However, evolutionary theory does not predict that changes in grandparental investment will have within-individual effects on grandparental health and wellbeing over time (i.e., grandparents who increase their investment in grandchildren will experience corresponding wellbeing benefits). If there are selective advantages of higher-caregiving tendencies, then these differences should in fact exist between individuals, not within them. Studies from present-day societies support this claim (e.g., Ates, 2017; see Chapter 7). Nevertheless, more studies on this topic are warranted.

Overall, it may not be realistic to expect that grandparental investment will produce similar outcomes in contemporary societies as it may have in traditional and historical populations. However, based on the theoretical reasoning and empirical evidence reviewed in this book, it might be more reasonable to assume that biases in grandparental investment (based on genetic relatedness, sex and lineage) should exist in contemporary societies (see Chapter 4). Unconscious evolutionary tendencies to invest in kin in descending rather than ascending order, to prefer kin to non-kin and to prefer relatives from the maternal side tend to hold true. Thus, we propose that the evolutionary social science approach is most applicable when one explains kin investment patterns rather than these investments' potential outcomes. Next, we formulate an evolutionary social science framework to examine intergenerational relations and generate hypotheses developed from it.

\section{Research programme and hypotheses}

Social scientists and evolutionary researchers often study the same issues related to intergenerational relations; however, they do so from different perspectives. One division between evolutionary and social science explanations involves the extent to which each discipline is interested in ultimate reasons ("why" questions) and proximate mechanisms ("how" questions) (Tinbergen, 1963; see Chapter 2: Box 2.1). As an increasing number of social scientists have noted, the advantage of the evolutionary perspective is that it can serve as a macro-level theory that logically incorporates different fields, theories and hypotheses (e.g., Hopcroft, 2016, 2018), which means it takes the ultimate reasons into account. It is obvious that ultimate and proximate approaches are complementary to each other. The aim of the evolutionary social science approach is to combine these two theoretical perspectives while explaining the complex nature of intergenerational family relations. 
The most important evolutionary factors that should be taken into account in the evolutionary social science research programme are genetic relatedness, sex and lineage, which have been shown to shape family relations in contemporary Western societies (e.g., Salmon \& Shackelford, 2011; see Chapter 4). In the evolutionary social science research programme, several other factors, which are more dependent on the cultural context and need and opportunity structures (e.g., family structure, residential distance and socioeconomic status), are combined with these three cornerstones of intergenerational relations.

Based on ultimate-level theories, the evolutionary social science approach generates three important starting premises, which are involved in formulating the more specific hypotheses. First, in non-biological kin relations (e.g., among in-laws or step-relatives), the investment in kin should be more facultative than in biological relations. It is important to note that investment is channelled through psychological attachment and emotional closeness, which tend to vary with a degree of genetic relatedness. However, in cases such as the adoption of young children the nature of the bond may not substantially differ from that of biological children (e.g., Rotkirch, 2018; see Chapter 4). Second, when the likelihood of relatedness decreases (e.g., in the case of different grandparent types), the investment also becomes more dependent on other factors; for instance, investment by maternal grandmothers (who have no uncertain paternity links between them and their grandchildren) is the most likely, whereas investment by paternal grandfathers (who have two uncertain paternity links) is the most facultative. Finally, when testing evolutionary social science hypotheses, it is important to keep in mind that differences in kin investment should not occur in every particular situation but rather when "all else is equal" (see Chapter 2).

The research programme introduced here also has certain specific data requirements. First, it is important that all relatives are separated from one another by sex and lineage. In the case of grandparents, this means that the data should have information on all four grandparent types (i.e., maternal grandmother, maternal grandfather, paternal grandmother and paternal grandfather). Second, to adequately study evolutionary social science hypotheses, there should be exact information on the genetic relatedness between the parties involved (e.g., whether the grandparent-grandchild relationship is biological or non-biological). Third, in the ideal situation, the data should have information on all three generations studied, specifically, grandparents, parents and children. Fourth, to study evolutionary social science hypotheses, large and representative data are essential because evolutionarily adapted behaviour patterns are population-based averages rather than present in every individual case. Finally, to study changes in intergenerational relations, longitudinal and repeated measured data are useful because they make it possible to study, for instance, whether changes in family structure (e.g., marital disruption) are associated with changes in intergenerational relations (e.g., emotional closeness with parents or parents-in-law). Currently, we are witnessing a rapid data explosion, with a large amount of high-quality and longitudinal data freely available to researchers. Nonetheless, these data are not typically designed to take evolutionary predictions into account. One of the potential advances of 
the evolutionary social science approach is that evolutionarily relevant variables (that is, genetic relatedness, sex and lineage) as well as theoretical evolutionary predictions can be taken into account while gathering large-scale social science data about intergenerational relations.

Next, we will generate general guidelines and provide examples of evolutionary social science hypotheses related to three timely and relevant research themes in the field of intergenerational relations: 1) need and opportunity structures, 2) blended families and 3) parent-grandparent relationship quality. The hypotheses presented below concern grandparents; however, the same logic can be extended to other relatives (e.g., aunts and uncles).

\section{Need and opportunity structures}

Potential receivers' need for help and givers' opportunity to provide help inevitably shape intergenerational transfers (e.g., Szydlik, 2016; see Chapter 4). Different individual-level variables related to "need structures" include, for instance, parental working status, socioeconomic situation, the number of children and their age. Individual-level factors related to the "opportunity structures" include, for instance, grandparents' health, working status, socio-economic status, number of children and grandchildren and residential distance between grandparents and grandchildren. Additionally, country-based differences in social and family policies tend to shape intergenerational relations. Welfare benefits such as the availability of public day care services, policies that facilitate the balance between work and family life and a decent level of old age pension represent clear examples of societal-level factors related to need and opportunity structures.

With regard to need structures, it is obvious that when parents' or children's need for help increases, so does the amount of help grandparents provide to their descendants (e.g., Hank \& Buber, 2009; see Chapter 4). However, this increase in needs does not influence the relative difference in the allocation of investment from different grandparent types; in other words, it does not change the biased grandparental investment pattern based on genetic relatedness, sex and lineage (e.g., Danielsbacka et al., 2011; see Chapter 4). Regardless of whether there is a greater or lesser need for support, biological grandparents should invest more than non-biological ones, and maternal grandmothers should invest the most and paternal grandfathers the least.

In terms of opportunity structures, grandparental opportunities to provide help may shape intergenerational relations differently based on genetic relatedness, sex and lineage. Investment in biological and maternal kin is more likely, whereas investment in non-biological and paternal relatives is more facultative, which means that when grandparents invest in their biological kin or daughter's family, other factors do not confound investment as much as they do in the case of investment by non-biological and paternal grandparents. For instance, when residential distance between grandparents and grandchildren increases, maternal grandmothers are the most likely to visit their descendants (Pollet et al., 2007). Based on need and opportunity structures, the following can be predicted: 
Hypothesis 1: When the receivers' need for support increases, biological grandparents are more likely invest than non-biological grandparents, and among biological grandparents, maternal grandmothers are the most likely to invest, whereas paternal grandfathers are the least likely to invest.

Hypothesis 2: Decreased opportunities to invest decrease the investment of biological grandparents less than that of non-biological grandparents, and among biological grandparents, the investment of maternal grandmothers is decreased the least and that of paternal grandfathers is decreased the most.

\section{Blended families}

One of the most important changes to potentially shape intergenerational family relations is the increased amount of divorces and remarriages in contemporary Western societies in recent decades. Although blended families have also been common in historical populations, the situation is somewhat different in contemporary families than it has been in the past. In historical societies, blended families were typically formed after the death of a spouse, which obviously means that ex-spouses were not present. In contemporary societies, blended families are mostly formed due to separation, meaning that contemporary blended families often include step- and adoptive children, step- and half-siblings and ex-spouses and their relatives.

Divorce in the parental generation may not shape the intergenerational relations among all grandparent-grandchild dyads similarly. Because children typically live with their mothers when parents separate in contemporary Western societies, the role of maternal grandparents tends not to substantially diminish (and may even increase), whereas the role of paternal grandparents may diminish considerably. In fact, parental divorce may even lead paternal grandparents to lose contact with their grandchildren (Kruk \& Hall, 1995). In addition, because maternal grandparents typically invest more in any situation, one may assume the following:

Hypothesis 3: If children stay with the father after parental divorce, maternal grandparents will invest more than paternal grandparents do if the children stay with the mother.

Remarriage in the parental generation may influence the intergenerational relations among grandparents, parents and grandchildren (Tanskanen et al., 2014). In particular, grandparental investment may be related to whether adult children and their spouses (i.e., the middle generation) have their own children only from the current union or from both previous and current unions. In the first case, the grandchild sets (i.e., the set of children from a specific adult child) include only biological grandchildren; in the latter case (if a spouse of an adult child has children from a previous union), they include both biological and stepgrandchildren. Overall, grandparents can be predicted to invest more in fully biological grandchild sets than in sets that include stepgrandchildren, meaning that grandparents 
can channel less investment to their grandchild sets if their children-in-law have their own children from previous unions (note that the duration of the relationship between grandparent and stepgrandchild among other potentially confounding factors should be taken into account). Thus, the following can be expected:

Hypothesis 4: Maternal grandparents invest equally and paternal grandparents invest less in their grandchild set when a mother also has children from a previous union.

Hypothesis 5: Paternal grandparents invest equally and maternal grandparents invest less in their grandchild set when a father also has children from a previous union.

If divorce occurs in the grandparental generation, the most likely prediction is that it diminishes grandfathers' investment more than that of grandmothers (Danielsbacka \& Tanskanen, 2016; 2018), which could be due to several factors. For instance, according to the incidental exposure hypothesis, grandfathers are exposed to grandchildren when grandmothers take care of them; thus, without grandmothers' presence, grandfathers' investment decreases. When lineage is also taken into account, divorce is predicted to have the most detrimental effect on paternal grandfathers' investment and the smallest effect on maternal grandmothers' investment. Due to mating effort, remarriage among both grandmothers and grandfathers most likely decreases the investment in their own biological grandchildren. Partly due to incidental exposure, remarried grandfathers' investment may diminish more than that of grandmothers, especially if grandfathers' new spouses also have biological grandchildren. Widowhood is not as likely as divorce to decrease grandmothers' or grandfathers' investment in grandchildren.

Hypothesis 6: Divorce and remarriage in the grandparental generation decreases the investment of grandfathers more than that of grandmothers and decreases the investment of paternal grandfathers most and the investment of maternal grandmothers least.

Hypothesis 7: Widowed grandparents invest more in their grandchildren than divorced or remarried ones do because there are no ex-spouses to dilute the investment option.

\section{Parent-grandparent relationship quality}

Parent-grandparent relationship quality has been shown in several studies to be associated with the grandparent-grandchild relationship and grandparental investment (e.g., Chan \& Elder, 2000; see Chapter 4). Although poorer parent-grandparent relationship quality is predicted to be associated with deteriorated investment 
among all grandparents, the degree to which this investment diminishes can be assumed to depend on genetic relatedness, sex and lineage. According to genetic relatedness, the poor relationship quality between parents and grandparents should influence the investment made by biological grandparents less than it should influence that by non-biological grandparents (particularly stepgrandparents) because the investment of non-biological grandparents tends to be more facultative than that of biological grandparents. In addition, the influence of parent-grandparent relationship quality on grandparental investment can be predicted to differ between the four types of grandparents based on sex and lineage. Because the investment of maternal grandmothers is the most likely and the investment of paternal grandfathers the most facultative, poor parent-grandparent relationship quality should have the greatest influence on the investment by paternal grandfathers and the least influence on that of maternal grandmothers. The following can thus be assumed:

Hypothesis 8: Poorer parent-grandparent relationship quality decreases the investment of biological grandparents less than it decreases that of nonbiological grandparents, and among biological grandparents, it decreases the investment of paternal grandfathers most and the investment of maternal grandmothers least.

With regard to the relations between an individual's own kin and in-laws, it is important to note that there are eight dyadic relationships between parents and grandparents (e.g., Danielsbacka et al., 2015; see Chapter 3): four between biological kin and four between in-laws. The in-law relationship between the parental and grandparental generation is typically non-biological in Western countries (i.e., spouses are not related to each other). Thus, the quality of this relationship can be predicted to influence the grandparent-grandchild relationship more strongly than that between parents and their own parents. One can predict the following:

Hypothesis 9: Poor parent-grandparent relationship quality decreases the investment of an individual's own parents less and that of one's parents-in-law more.

\section{Conclusions}

In this chapter, we have provided an evolutionary social science research programme on intergenerational relations and formulated various hypotheses. We have argued that the evolutionary social science approach is most helpful for investigating biases in kin investments rather than the potential outcomes of these investments. Moreover, this approach may be the most useful for studies conducted in contemporary Western societies because liberalisation and the loosening of strict cultural norms may make evolutionarily adapted tendencies more visible than they were in traditional and highly normative societies. We hope that the present book encourages researchers to explore intergenerational family relations with the help of the evolutionary social science approach. 


\section{References}

Ates, M. (2017). Does grandchild care influence grandparents' self-rated health? Evidence from a fixed effects approach. Social Science \& Medicine, 190, 67-74.

Carsten, J. (2000). Introduction: Cultures of relatedness. In J. Carsten (Ed.), Cultures of relatedness: New approaches to the study of kinship (pp. 1-36). Cambridge: Cambridge University Press.

Chan, C. G., \& Elder, G. H., Jr. (2000). Martilineal advantage in grandchild-grandparent relations. The Gerontologist, 40, 179-190.

Coall, D. A., \& Hertwig, R. (2010). Grandparental investment: Past, present, and future. Behavioral and Brain Sciences, 33, 1-59.

Coall, D. A., \& Hertwig, R. (2011). Grandparental investment: A relic of the past or a resource for the future? Current Directions in Psychological Science, 20, 93-98.

Danielsbacka, M., \& Tanskanen, A. O. (2016). Grandfather involvement in Finland: Impact of divorce, remarriage and widowhood. In A. Buchanan \& A. Rotkirch (Eds.), Grandfathers: Global perspectives (pp. 183-197). London: Palgrave Macmillan.

Danielsbacka, M., \& Tanskanen, A. O. (2018). Marital disruption and intergenerational relations among older Finns. Contemporary Social Science, 13. https://doi.org/10.1080/ 21582041.2017.1422794

Danielsbacka, M., Tanskanen, A. O., Jokela, M., \& Rotkirch, A. (2011). Grandparental child care in Europe: Evidence for preferential investment in more certain kin. Evolutionary Psychology, 9, 3-24.

Danielsbacka, M., Tanskanen, A. O., \& Rotkirch, A. (2015). The impact of genetic relatedness and emotional closeness on intergenerational relations. Journal of Marriage and Family, 77, 889-907.

Giddens, A. (1991). Modernity and self identity. Cambridge: Polity Press.

Hank, K., \& Buber, I. (2009). Grandparents caring for their grandchildren: Findings from the 2004 Survey of Health, Ageing, and Retirement in Europe. Journal of Family Issues, 30, 53-73.

Hawkes, K., \& Coxworth, J. E. (2013). Grandmothers and the evolution of human longevity: A review of findings and future directions. Evolutionary Anthropology, 22, 294-302.

Hilbrand, S., Coall, D., Gerstorf, D., \& Hertwig, R. (2017). Caregiving within and beyond the family is associated with lower mortality for the caregiver: A prospective study. Evolution and Human Behavior, 38, 397-403.

Hopcroft, R. L. (2016). Grand challenges in evolutionary sociology and biosociology. Frontiers in Sociology, 1. https://doi.org/10.3389/fsoc.2016.00002

Hopcroft, R. L. (Ed.) (2018). Oxford handbook of evolution, biology, and society. Oxford: Oxford University Press.

Kaptijn, R., Thomese, F., Liefbroer, A. C., \& Silverstein, M. (2013). Testing evolutionary theories of discriminative grandparental investment. Journal of Biosocial Science, 45, 289-310.

Kruk, E., \& Hall, B. L. (1995). The disengagement of paternal grandparents subsequent to divorce. Journal of Divorce \& Remarriage, 23, 131-148.

Leonetti, D. L., Nath, D. C., \& Hehman, N. S. (2007) In-law conflict: Women's reproductive lives and the roles of their mothers and husbands among the matrilineal Khasi. Current Anthropology, 48, 861-890.

Pashos, A. (2000). Does paternity uncertainty explain discriminative grandparental solicitude? A cross-cultural study in Greece and Germany. Evolution and Human Behavior, 21, 97-109. 
Pashos, A. (2017). Asymmetric caregiving by grandparents, aunts, and uncles and the theories of kin selection and paternity certainty: How does evolution explain human behavior toward close relatives? Cross-Cultural Research, 51, 263-284.

Pollet, T. V., Nettle, D., \& Nelissen, M. (2007). Maternal grandmothers do go the extra mile: Factoring distance and lineage into differential contact with grandchildren. Evolutionary Psychology, 5, 832-843.

Rotkirch, A. (2018). Evolutionary family sociology. In R. L. Hopcroft (Ed.), Oxford handbook of evolution, biology, and society (pp. 451-478). Oxford: Oxford University Press.

Salmon, C. A., \& Shackelford, T. K. (Eds.) (2011). The Oxford handbook of evolutionary family psychology. New York: Oxford University Press.

Sear, R., \& Coall, D. A. (2011). How much does family matter? Cooperative breeding and the demographic transition. Population and Development Review, 37, 81-112.

Szydlik, M. (2016). Sharing lives: Adult children and parents. New York: Routledge.

Tanskanen, A. O., \& Danielsbacka, M. (2017). Multigenerational effects on children's cognitive and socioemotional outcomes: A within-child investigation. Child Development, 88. https://doi.org/10.1111/cdev.12968

Tanskanen, A. O., Danielsbacka, M., \& Rotkirch, A. (2014). Multi-partner fertility is associated with lower grandparental investment from in-laws in Finland. Advances in Life Course Research, 20, 41-47.

Tinbergen, N. (1963). On aims and methods of ethology. Ethology, 20, 410-433. 
$\because$ Taylor \& Francis

Taylor \& Francis Group

http://taylorandfrancis.com 


\section{Index}

Page numbers in italics refer to figures. Page numbers in bold refer to tables.

Aassve, A. 35, 94, 122

Abbot, P. 18

achievement tests 104

active grandparenting 120-122, 123-130

adaptations $14-15$

Aday, L. A. 125

adolescent grandchildren, grandparent presence and 108-109, 110

adoptive grandchildren $21,57,64$, 113,151

adult children, support for 71-72

age at first birth 53,54

age-dependent pattern 76

age groups, definition of 50

Ahmad, M. 126

Al Mamun, A. 106

Alberdi, G. 106

Albertini, M. 71, 76

alcohol, problems with 73

allomothers/alloparents 1, 15, 135, 144

Alvergne, A. 25, 26

ambivalence: direct measures of 32-33; indirect 32-33; intergenerational 27 , 31-33, 39, 76; parental 76;

psychological 32; sociological 32

Anderson, K. G. 64

Andersson, G. 90

Antfolk, J. 25, 26

Apostolou, M. 56

Aquilino, W. S. 108

Arber, S. 27

Arpino, B. 35, 120, 129

Ates, M. 129, 150

Atkinson, M. P. 30

Atran, S. 14-15

attachment 67

Attar-Schwartz, S. 105, 106

Attias-Donfut, C. 71 aunts 135-144

Avery, R. 127

Bajracharya, A. 105

Baker, L. A. 36, 124, 125

Balbo, N. 89

Barkow, J. H. 6, 37

Barnett, M. A. 37, 72

Barrett, L. 37

Batson, C. D. 126

Baydar, N. 27

Beck, S. H. 112

Beck, U. 2

Becker, G. S. 111

becoming a grandparent 123

behavioural difficulties 104, 108, 110

Beise, J. 102

Belgium 66, 92

Belsky, J. 123

Bengston, V. L. 4, 30, 39, 50, 53, 71, 73

between-child models 106

biased intergenerational relations $\mathbf{2 8}$

biased investments: by aunts and uncles 139-140; by grandparents $21-25,22$, 68-71, 74, 80, 152; patterns of 149

Bilaver, L. A. 110

Billari, F. C. 96

Billing, A. 111

biological grandparents compared to non-biological grandparents 64-65

birth intervals $1-2,88-89$

Bishop, D. 68, 69, 70

Björklund, A. 113

blended families 57, 58-60, 153-154

Block, C. E. 71

Blurton Jones, N. G. 17

Blustein, J. 125

Boehm, J. K. 122 
Boliver, V. 111, 112

Bonsang, E. 76

Bordone, V. 35, 120, 129

Bornstein, M. H. 104

Boswell, M. K. 108

Bourdieu, P. 111

Bracke, P. 29

brain size 1

Brandt, M. 71, 76

Brent, L. J. N. 16

Breslerman, S. 67

Bressan, P. 25

Broadfield, D. C. 17

Brogdon, E. 65

Brooks-Gunn, J. 27

Brownell, P. 51

Brunello, G. 128

Buber, I. 3, 7, 78, 79, 109, 152

Buchanan, A. 3, 73, 106

Bunch, S. G. 124

Burr, J. A. 127

Burton-Chellew, M. N. 18, 66, 73

Buss, D. M. 121

Campbell, A. 23, 68

Campbell, C. 102,

Cant, M. A. 27, 89

Carsten, J. 148

Chagnon, N. 66

Chan, C. G. 29, 38, 73, 74, 154

Chan, T. W. 111, 112

Chang, E. S. 135

Chapais, B. 66

Chapman, S. N. 67, 103

character skill 104

Chen, F. 36, 125, 127

Chen, M. 108

Chen, V. W. 110

Chen, W. C. 110

childbearing 87-96, 122; see also fertility decisions; fertility rates

childbearing intentions 95

child care: biological versus non-biological grandparents and 64-65; country-level differences in 78-80; divorce and remarriage and 77; emotional closeness and 106; fertility decisions and 94-95; fertility rates and 90; future support and 72; grandparent wellbeing and 129 childhood mortality 51-52, 89, 109

childhood overweight 106-107

child outcomes 34-35

children's rights 103

child survival 100-103, 106, 114 child's viewpoint 54, 54

child wellbeing 100-114

Chisholm, J. S. 17

Chrastil, E. R. 22, 23, 67

Christeansen, S. G. 123

Cicirelli, V. G. 136

Clingempeel, W. G. 35

Clinton, H. 1

Coall, D. A. 4, 5, 7, 12, 16, 17, 21, 34, 36, $57,65,67-69,77-78,87-89,93,96$, 103, 105-106, 120-122, 147, 149-150

cognitive assessments 104

cognitive skills 103-105, 106

cohort, definition of 50

Collins, D. A. 16

conceptualisation 13

Confucianism 127

Cong, Z. 121, 125

Conger, R. D. 55

Connidis, I. A. 32

conscious motives 15

contact frequency 77-78, 93, 94, 140

cooperative breeding species, humans as $1-2,15$

coresidence: child wellbeing and 107-110; fertility rates and 91-92, 93; grandparent wellbeing and 126-127; teenage pregnancy and 95-96

country-level differences 78-80, 152

cousins 66,69

Cox, M. J. 33

Coxworth, J. E. 150

Creasey, G. L. 71

Croft, D. P. 16

Crosnoe, R. 33

cross-cousin marriages 66

crowding-in hypothesis 31,78

crowding-out hypothesis 31,78

cultural traditions, custodial grandparent families and 125-126

custodial grandparent families 110-111, $121,124-126$

Daly, M. 1, 25, 64, 68, 70

Danielsbacka, M. 20, 22, 24, 56-57, 66, 68-75, 77, 79-80, 105-106, 109, 122, $127,129,137-140,142,148-149$, $152,154-155$

Darwin, C. 14

Deaton, A. 126

DeBruine, L. M. 25

Deindl, C. 71, 76

delayed childbearing 96

Del Boca, D. 90, 92 
Deleire, T. 108

demographic generations 50

demographics 49

dependent childhood 2

depressive symptoms, loss of contact and 130

descendant quality 17

descendant survival, simultaneous reproduction and 89

Desjardins, J. K. 1

detachment 67

De Waal, F. B. M. 121

Diderich, M. 137

Di Gessa, G. 79, 127, 128

dilution effect 142

DiPrete, T. A. 111

direct measures of ambivalence 32-33

discriminative grandparental solicitude 68

divorces 57, 60, 77-78, 143, 153-154

dominant paradigm 5

downward investments 8

Drew, L. M. 130

Dubas, J. S. 28, 29, 30, 66, 68, 71

Duckworth, K. 104

Dunbar, R. I. M. 18, 66, 73

Duncan, G. J. 104

Dunifon, R. 36, 124, 126

dyadic relations, definition of 51

educational achievement 108-109, 111, 113,143

egg freezing 87

Eisenberg, A. R. 68

Elder, G. H. 33, 55

Elder, G. H. Jr. 29, 33, 38, 39, 51, 71, 73, 74,154

Ellis, R. R. 124

emotions/emotional closeness 16, 37-38, 73-74, 93, 121, 151

empirical success 12

Epstein, J. L. 108

Erola, J. 112, 143

Esping-Andersen, G. 2

Euler, H. A. 15-16, 21, 22, 24, 26, 38, 66, 68-69, 71, 73, 75, 78, 88, 121

evolutionary approaches 4-5

evolutionary social science, as term 5

evolutionary social science approach 147-155

evolutionary theories on intergenerational relations $14-27,36-38,39-40$

facial resemblance 25, 67-68

family generation, definition of 50
Fan, X. 108

favouring, unconscious 15

favourites, playing 63

Feinstein, L. 104

female labour force participation 79

Fergusson, E. 3

fertility decisions $87-88$

fertility outcomes 149

fertility rates: decline in 89-90; kin presence and 91-93

financial support 71-72, 76

Fingerman, K. L. 73, 76

Fischer, R. L. 29-30, 74

Fokkema, T. 71, 76

foster carers 3

Foster, E. A. 16

Fox, M. 22, 23, 67, 102

Friedman, D. 28, 34, 121

Fukukawa, Y. 92

Fulcher, M. 66

Fuller-Thomson, E. 124, 125

Ganzeboom, H. B. G. 111

Garrard, W. M. 17, 26, 108

gatekeepers 29-30, 38, 142

Gaulin, S. J. C. 139

gender differences: in child survival 102-103; in grandparental investment/ involvement 68-71

genetic relatedness $18, \mathbf{1 9}, 21,54$, 64-68, 135, 136-138, 137, 140-141, 151,155

geographical distance 77, 142

Geurts, T. 72

Giarrusso, R. 29

Gibson, M. A. 102

Giddens, A. 2, 148

grandmother hypothesis $17,88-89$

grandparental endowment 35, 112-113

grandparental investment/involvement:

child wellbeing and 105-114;

description of 3,4 ; effects of 7 ; factors associated with 77 ; gender differences in 68-71; genetic relatedness and 64-65; maternal versus paternal 68-71; outcomes of 34-36, 149-150; socioeconomic status and $112-113$

grandparental outcomes 35-36 grandparenthood 120-121, 122-124, 130 grandparenting, selective 121

grandparents: child wellbeing and 100-114; legal rights of 3; societal changes and 2-3; viewpoint of 55, 55; wellbeing of $120-130,150$ 
Gray, P. B. 65

Grinstead, L. N. 36, 124

Grundy, E. M. 128

Hackman, J. 38

Hadfield, J. C. 124

Hagestad, G. 28, 29, 30, 71

Haig, D. 25

Hall, B. L. 153

Hamilton, W. D. 17-18, 20-21, 22, 23, 36, $38,64,92,135,140$

Hammill, B. G. 68-69, 73, 76-78

Hango, D. 108

Hank, K. 3, 7, 73, 78, 79, 90, 91, 109, 152

Hansen, T. 122

happiness $122-123$

Harknett, C. S. 95

Harknett, K. 95

Hauser, R. M. 111, 112

Hawkes, K. 4, 17, 102, 150

Hayslip, B. 124

health equality, increase in 52

Heckman, J. J. 104

Henderson, C. E. 105

Henrich, J. 139

Hertel, F. R. 112

Hertwig, R. 4-5, 7, 12, 17, 21, 34, 36, $68-69,89,96,106,120-122,147,150$

Heywood, E. M. 124

high-risk family circumstances 105

Hilbrand, S. 121, 129, 130, 150

Hill, K. 16, 17, 53

Hoben, A. D. 64, 137, 138, 142

Hoff, A. 8, 28, 30, 32, 72

Hopcroft, R. L. 5, 6, 14, 20, 150

Höpflinger, F. 71

Hout, M. 111

Hrdy, S. B. 1, 15, 56, 121, 135

Hubatkova, B. 107, 108

Huber, S. 92

Hughes, A. L. 18, 22, 31, 57, 66, 71-75, 141-142

Hughes, M. E. 36, 124-126, 128

Hummel, C. 71

hunter-gatherer populations $1-2,88$

Huxhold, O. 124, 128

Igel, C. 78, 790

incest aversion 25

incidental exposure hypothesis $21,24,65$, 78,154

inclusive fitness theory: aunts and uncles and 135, 141-142; biased investments and 21 ; biological versus non-biological grandparents and 64; description of $17-18,36-37$; fertility and 87,90 , 92; fertility decisions and 94; genetic relatedness and 23, 138, 139, 140; kinship premium hypothesis and 38; parental investment theory and 20; reproductive value and 72 indirect ambivalence 32-33 injuries 109

in-laws: family structures and 56-57, 56; fertility and $24,88,91-92$; inclusive fitness theory and 18 ; inverse genetic relatedness and 20,74-75; kin versus 66-67, 73; parent-grandparent relationship quality and 155 ; reproductive conflict and 27; see also parent-grandparent relationship quality instrumental support 72

interdisciplinarity 4-5

intergenerational ambivalence 27, 31-33, 39,76

intergenerational relations: concept of 50-51; factors related to $63-80$; meaning of 2 ; structure of 49-60; theories on $12-40$

intergenerational solidarity $27,30-31,39$

intergenerational stake hypothesis $30-31,71-72$

intradisciplinarity 4-7

inverse genetic relatedness $66,73,74$

investment, rejection of 72-73

Isler, K. 1, 2

It Takes a Village and Other Lessons Children Teach Us (Clinton) 1

Jæger, M. M. 112, 114

Jamison, C. S. 68

Janhunen, K. 23

Jankowiak, W. 137

Jappens, M. 78, 79

Jennions, M. 1

Jetz, W. 1

Johnstone, R. A. 27, 89

Johow, J. 67

Jones, K. 79

Kachel, F. A. 17

Kalil, A. 108

Kalmijn, M. 57, 76

Kalwij, A. 90

Kaplan, H. 1, 2, 16, 17, 53

Kaptijn, R. 37, 71, 94, 148

Kaufman, G. 73

Kautz, T. 104 
Keene, J. R. 126

Kenny, D. A. 64

key life course events 33

Kiecolt, K. J. 76

Kim, P. S. 17

kin affection 38

kin altruism 38,73

kin detection 25-26

King, V. 29, 38, 51, 71, 73, 77, 78

kin investments: by aunts and uncles 138-141; fertility and 90, 93-95; as unconscious behavior 15; use of term 87; see also grandparental investment/involvement kin keepers 29-30, 38, 66, 68, 74

kin presence: child survival and 100-103; fertility rates and 91-93

kin relations 64

kin selection theory 18

kinship premium hypothesis 38

Kirkpatrick Johnson, M. 33

Knigge, A. 113

Knudsen, K. 77, 78

Koblewski, P. J. 71

Kohler, H. P. 89

Kohli, M. 8, 71

Koivumaa-Honkanen, H. 121

Kokko, H. 23

Korchmaros, J. D. 64

Kramer, P. 25

Kreidl, M. 107, 108

Kreyenfeld, M. 90, 91

Krueger, P. M. 108

Kruk, E. 153

Krupp, D. B. 25

$\mathrm{Ku}$, L.-J. E. 125, 126, 129

Künemund, H. 31, 78

Kuypers, J. A. 30, 71

Laham, S. M. 22, 24, 69-70, 140

Lahdenperä, M. 16-17, 27, 89, 101-102

Lappegård, T. 53

Lee, J. Z. 102

Lee, P. C. 16

Lee, S. 125

Lehti, H. 143

Leitner, S. 33

Lendon, J. P. 32, 33, 76

Leonetti, D. L. 37, 70, 88, 148

Leopold, T. 50, 53

Lesthaeghe, R. 57

Levetan, J. L. 110

Lieberman, D. 25

Liefbroer, A. C. 35, 94 life course approach 27, 33-34

life expectancy $2,49,51-53,52,54,120$

life history theory $16-17,34,39$, 53-54, 95-96

life satisfaction 122-123, 127-128

Lindahl, M. 112

lineage, sex and 68-71, 139-140, 151

linked lives perspective 38-39, 74

Linn, R. 67

Litwin, H. 27

Liu, B. 121

Liu, G. 36, 125, 127

Loichinger, E. 52

logical coherence 12

Loury, L. D. 112, 143

Low, B. S. 16, 54, 95

Lummaa, V. 34, 123

Lumsdaine, R. L. 120

Lundberg, S. 104

Lüscher, K. 32, 39

Lussier, G. 105

Lyubomirsky, S. 122

Macdonald, D. 1

Mace, R. 16, 23, 24, 68, 88, 100, 101, 102

Mackenbach, J. P. 52

Madoff, R. D. 112

Mahne, K. 124, 128

Majamaa, K. 76

male investment in descendants 2

Marcinkowska, U. M. 25

Mare, R. D. 7, 14, 111, 113

Marelich, W. D. 141

Margolis, R. 52, 53, 122

marital status 77-78

Marlowe, F. 17

Martinson, M. L. 107

Marx, J. 111

Mathews, P. 93

mating effort 65

matrilateral effect 68

matrilinial bias 74

matrilocal cultures 37, 70, 101, 148

Matthews, S. H. 28, 29, 68

Mayer, K. U. 33

McBurney, D. H. 24, 139

McDonald, P. 90

McLain, D. K. 25

McLanahan, S. 108

mental health problems 110

Merton, R. K. 13

Michalski, R. L. 15

Milardo, R. M. 136, 144

Miller, G. E. 17 
Minkler, M. 124, 125

Millennium Cohort Study 94, 106

mixed-sex grandparent-grandchild dyads 71

MMM (Mothers Matter Most) principle 68

MMMM (Mother's Mothers Matter Most) principle 68

Modin, B. 112

Moffit, T. E. 104

Moisio, P. 112

Møllegaard, S. 112

mortality: active grandparenting and 129-130; childhood 51-52, 89, 109; of older people 121, 123

Mortimer, J. T. 33

mothers, importance of 68

motives, unconscious 15

Mueller, M. M. 55, 71

Mueller, Z. 27

multigenerational relations, definition of 51

Murphy, M. 49

Musil, C. M. 125, 126

Mutchler, J. E. 127

Myrskylä, M. 122

Nakamichi, M. 16

naturalistic fallacy 6

natural selection, theory of 14-15

need structures 75-76, 152-153

nephews 135-144

Nettle, D. 53, 95

Neugarten, B. L. 123

Newson, L. 92

Neyer, F. J. 64, 138

nieces 135-144

non-biological grandparenthood 64-65

non-biological kin relations 64,151

non-cognitive outcomes 104-105

non-coresiding grandparents $127-130$

nuclear family 3

nutritional status 102, 106

obesity 106

Odgers, C. L. 104

opportunity, need, family, and cultural-

contextual (ONFC) model 31, 39

opportunity structures $75-76,152-153$

Paley, B. 33

parental ambivalence 76

parental and grandparental generations,

relations between $71-75$

parental detection 25-26 parental investment theory $17-18,20$, 29-30, 36-37

parental presence, fertility and $88-89$, 91-93

parental separation 105,153

parent-grandparent relationship

quality $154-155$

parenthood, impact of 74-75

Park, H. 108

parsimony 12

Pashos, A. 21, 37, 57, 65, 70, 148

paternity uncertainty $24,26,38,68,69$, $101,139,140$

patrilocal cultures 37, 70-71, 101, 102, 148

Patterson, C. J. 66

Paul, A. 16

Peccei, J. S. 17

Penman-Aguilar, A. 95

Perry, G. 1, 3, 37, 68, 70, 110

personality traits 104

Pettay, J. E. 27, 89

Pfeffer, F. T. 35, 109

Piketty, T. 112

Pilkauskas, N. V. 107, 124

Pillemer, K. 32, 39, 76

Pittman, L. D. 108, 110

Pittsburgh 139

Platek, S. M. 25, 26

playing favourites 63

Plug, E. 113

Pollet, T. V. 24, 37-38, 64, 68-69, 77, 137-138, 141-142, 152

Pong, S. L. 110

postponement 95-96

Post, S. G. 35

Powdthavee, N. 120, 122

preferential investment hypothesis 24-25, 69-70, 140

productivity 12

pro-natal messages 92

Pronin, E. 5

proximate mechanisms 13-14, 121, 143,150

psychological ambivalence 32

public support 78-79, 90

Puur, A. 49

Rantala, M. J. 25

rational choice theory 34

rational grandparents 34

receivers' reproductive value 31

reciprocity 121

Reczek, C. 65

Reilly, J. J. 106 
Rein, M. 31, 78

Reinkowski, J. 129

rejection of investment 72-73

relative explanatory power 12

remarriage 77-78, 153-154

replacement level, fertility rates and 90

reproduction, support of 2

reproductive competition 89

reproductive conflict 26-27, 95

reproductive value/reproductive value

hypothesis $31,71,72$

resemblance 67-68

Resnick, R. P.

resource allocation, life history theory and 16

resource competition 26, 108, 127

restriction of interaction $72-73$

retirement 120-121

Rice, W. R.

Richardson, D. S.

risk situations 34-35, 149-150

Roberts, R. E. 4, 30

Robertson, J. F. 29, 38

Rocco, L. 128

Romero, L. 95

Roser, M. 51, 52

Ross, M. E. T. 125

Rossi, A. S. 29, 64, 73

Rotkirch, A. 3, 5, 20, 21, 23, 38, 53, 64, $73,95,106,151$

Rubenstein, D. R. 1

Rubin, D. M. 111

Ruggles, S. 126

Salmon, C. A. 3, 71, 148, 151

same-sex couples 65-66

same-sex grandparent-grandchild dyads 71

Sandefur, G. 108

Sanderson, S. K. 6, 12, 14

Saraceno, C. 76

SAT test 104

Schaffnit, S. B. 92,94

Scheeren, L. 113

Schwarz, B. 73

Sear, R. 7, 14, 15, 16, 23, 24, 37, 68, 70, 87-88, 91, 92, 93-94, 100-102, 103, $105,121,149$

Segal, N. L. 64, 138, 141

Segerstråle, U. 6

selection effect 96, 123, 126

Sénéchal, M. 108

selective grandparenting 121

Settersten, R. A. 33

Settles, B. H. 34, 121

sex and lineage 68-71, 139-140, 151 sex chromosome prediction 102-103

sex-chromosome relatedness 67

sex effect hypothesis $68,137,140$

sex-specific reproductive strategies 23-24, $29,38,68,75,88,139$

Shackelford, T. K. 3, 148, 151

Shanahan, M. J. 33

shared reproductive interest 74-75

shared years: increase in 53; statistics on 49-50

Sheng, X. 34, 121

Sheppard, P. 101

siblings: adult 136-138; competition among 20; fertility decisions and 94-95

Silverstein, M. 30, 36, 73, 121, 124, 125 , 127,130

Simmons, T. 124

simultaneous reproduction 89

single-parent families 105, 108, 110, 111

skipped-generation households see custodial grandparent families

Skopek, J. 50, 53

Smith, M. S. 22, 24

Smorti, M. 71

Snopkowski, K. 91, 93

social generations, definition of 50

socialisation 29

social mobility $111-113$

social norms 29

social science approaches 4-5

social science theories on intergenerational relations $27-36,38-40$

social stratification 111-113, 142-144

socio-demographic factors $75-78$

socioeconomic status $53-54,76,95,96$, $104,111-113,123,142-144$

socio-emotional outcomes 104

sociological ambivalence 32

Solomon, J. 111

Somary, K. 123

Speare, A. 127

Sprey, J. 28, 29, 68

Stanca, L. 122

Stearns, S. C. 16, 17, 53

stepgrandparents/stepgrandchildren 21,57 , $60,64-65,153-154$

Stock, J. T. 100

Stone, A. 126

Strassmann, B. I. 17, 26, 101, 108

stratification sociologists 7

Strawbridge, W. J. 125

Stricker, G. 123

Strom, P. S. 124 


\section{Index}

structure of intergenerational families, basic $54-60$

Survey of Health, Ageing and Retirement in Europe 79, 129

Szydlik, M. 27, 28, 31, 33, 37, 39, 75, 78, 79,152

Tanskanen, A. O. 21, 22, 23, 26, 36, 38, $57,65,67,71,75,77,92,94,95,105$, $106,108,109,122,123,137,138,140$, $141,142,149,153,154$

Tarkiainen, L. 52

Taylor, M. F. 124

teenage mothers 95-96

Thang, L. L. 125

theory: definition of 12 ; purposes of 13 ; usefulness criteria for 12

Thiele, D. M. 123

Thomas, D. 104

Thomas, J. L. 123

Thomese, F. 35, 94

Thompson, L. 29, 38

three-generational households 107-110, $126-127$

three-generational studies 76-78

time transfers 71

Timonen, V. 27

Tinbergen, N. 150

Tomes, N. 111

trade-offs, life history theory and 17

traditional and historical populations 87-88, 100-103, 106

Triadó, C. 71

Trivers, R. L. 15, 17-18, 20, 22, 23, 29-30, 36

Trivers-Willard hypothesis 20

Tsai, F.-J. 124

Turner, J. H. 5

twins $135,137-138,141$ two-generational studies $64,72,76$

Tymicki, K. 88

Uhlenberg, P. 68-69, 73, 76-78

ultimate reasons $13,14,150$

uncles 135-144

unconscious favouring 15

unconscious motives 15

Van Bavel, J. 78, 79

Van Schaik, C. P. 1, 2

Villar, F. 51

Voland, E. 88, 101, 102

Walker, A. J. 29, 38

Warren, J. R. 111, 112

Washbrook, E. 104

Waynforth, D. 66, 94

Weber, D. 52

Weinstein, K. K. 123

weight issues 106-107

Weitzel, B. 22, 24, 68-69, 71

welfare states/services 78-79, 148, 152

Wells, J. C. K. 100

Westermarck, E. 16, 25

Westermarck effect 25

Westphal, S. H. 57

Wheelock, J. 79

Whelan, T. A. 123

Wild, L. 106

Wild, L. G. 110

Willard, D. E. 20

Willson, A. E. 29, 32, 64, 66, 73, 76

Wilson, M. 25, 64

within-child models 106

Wright, L. 52

Wroblewski, E. E. 16

Xie, Y. 112 